\title{
Satiety and body weight regulation
}

Citation for published version (APA):

Kovacs, E. M. R. (2002). Satiety and body weight regulation. [Doctoral Thesis, Maastricht University]. Maastricht University. https://doi.org/10.26481/dis.20021004ek

Document status and date:

Published: 01/01/2002

DOI:

10.26481/dis.20021004ek

Document Version:

Publisher's PDF, also known as Version of record

\section{Please check the document version of this publication:}

- A submitted manuscript is the version of the article upon submission and before peer-review. There can be important differences between the submitted version and the official published version of record.

People interested in the research are advised to contact the author for the final version of the publication, or visit the DOI to the publisher's website.

- The final author version and the galley proof are versions of the publication after peer review.

- The final published version features the final layout of the paper including the volume, issue and page numbers.

Link to publication

\footnotetext{
General rights rights.

- You may freely distribute the URL identifying the publication in the public portal. please follow below link for the End User Agreement:

www.umlib.nl/taverne-license

Take down policy

If you believe that this document breaches copyright please contact us at:

repository@maastrichtuniversity.nl

providing details and we will investigate your claim.
}

Copyright and moral rights for the publications made accessible in the public portal are retained by the authors and/or other copyright owners and it is a condition of accessing publications that users recognise and abide by the legal requirements associated with these

- Users may download and print one copy of any publication from the public portal for the purpose of private study or research.

- You may not further distribute the material or use it for any profit-making activity or commercial gain

If the publication is distributed under the terms of Article $25 \mathrm{fa}$ of the Dutch Copyright Act, indicated by the "Taverne" license above, 


\section{SATIETY AND BODY WEIGHT REGULATION}




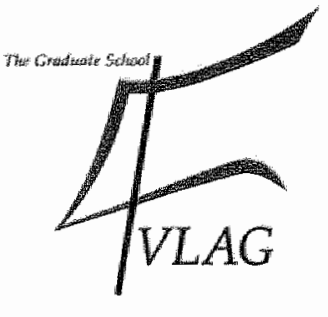

nutim
The studies presented in this thesis were periormed at the Nutrition and Toxicology Research Insitule Maastricht (NUTRIM), which participates in the Graduate School VLAG (Food Technology, Agrobiotechnology, Nutrition and Health Sciences) accredited by the Royal Netheriands Academy of Aris and Sciences.

The research described in this thesis was supported by grants from Novartis Consumer Health Ltd.

Printing of this thesis was financially supported by Novartis Consumer Health Ltd, Unilever Health Institute, Danone Vitapole, Nutricia Nederland BV and Nederlandse Associatie voor de Studie van Obesitas.

Cover design: Martina Brouns

Lay-out: Eva Kovacs

Printed by: $\quad$ Datawyse, Universitaire Pers Maastricht

(C) Eva Margit Rita Kovacs, Maastricht 2002

ISBN 905278.3543 


\title{
SATIETY AND BODY WEIGHT REGULATION
}

\author{
PROEFSCHRIFT
}

ter verkrijging van de graad van doctor

aan de Universiteit Maastricht,

op gezag van de Rector Magnificus,

Prof. dr. A.C. Nieuwenhuizen Kruseman, volgens het besluit van het College van Decanen,

in het openbaar te verdedigen

op vrijdag 4 oktober 2002 om 14.00 uur

door

Eva Margit Rita Kovacs

geboren te Locarno (Zwitserland) op 24 januari 1969

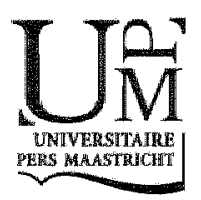




\section{Promotor:}

Prof. dir. ir. W.H.M. Saris

\section{Co-promotor:}

Dr. M.S. Westerterp-Plantenga

\section{Beoordelingscommissie:}

Prof. dr. ir. P.A. van den Brandt (voorzitter)

Dr. R.-J.M. Brummer

Prof. dr. W. Langhans (ETH Zürich, Zwitserland)

Prof. dr. ir. R.P. Mensink

Prof. dr. A.B. Steffens (Rijksuniversiteit Groningen) 


\section{CONTENTS}

Page

1 General introduction

2 The effect of addition of modified guar gum to a low-energy semisolid meal on appetite and body weight loss.

3 The effect of guar gum addition to a semisolid meal on appetite related to blood glucose, in dieting men

4 The effect of different dosages of guar gum on gastric emptying and small intestinal transit of a consumed semisolid meal.

5 Associations between spontaneous meal initiations and blood glucose dynamics in overweight men in negative energy balance

6 Effects of 2-week ingestion of (-)-hydroxycitrate and (-)hydroxycitrate combined with medium-chain triglycerides on satiety and food intake.

7 The effects of 2-week ingestion of (-)-hydroxycitrate and (-)hydroxycitrate combined with medium-chain triglycerides on satiety, fat oxidation, energy expenditure and body weight.

8 Does (-)-hydroxycitrate reduce de novo lipogenesis in humans?

9 The effects of enterostatin intake on food intake and energy expenditure

10 General Discussion

Summary

Samenvatting

Riassunto

Dankwoord

Publications

Curriculum vitae 



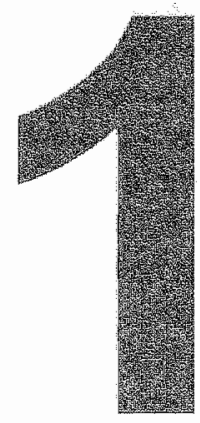

GENERAL INTRODUCTION 


\section{PREVALENCE OF OBESITY}

Obesity is defined as an excess accumulation of body fat. Body mass index (BM) = body weight $\left.(\mathrm{kg}) / \mathrm{height}(\mathrm{m})^{2}\right)$ is commonly used to classify overweight and obesity. $\mathrm{BMI}$, however, is not a perfect measure of body fatness. Although correlation of BMI with percentage body fat is relatively good (16), BMI is less accurate for estimating body fatness in very muscular individuals who may have a high BMI but normal or low body fat percentage or in very short individuals. A recent classification of adults by BMI has been published by the World Health Organisation (WHO) in 1998 (Table 1) $(44,60)$.

During the past few decades, the prevalence of obesity has increased worldwide to epidemic proportions. In the United States, initial results from the 1999 National Health and Nutrition Examinations Survey (NHANES 1999) indicate that an estimated $61 \%$ of the adults ( $>20$ years) are either overweight or obese (BMI $\geq 25.0$ $\left.\mathrm{kg} / \mathrm{m}^{2}\right) .35 \%$ have a BMI between 25.0 and $29.9 \mathrm{~kg} / \mathrm{m}^{2}$ and $26 \%$ have a BMI $\geq 30.0$ $\mathrm{kg} / \mathrm{m}^{2}$. This represents approximately a $5 \%$ higher prevalence compared to the estimates obtained from NHANES (1988-1994). In the Netherlands, the prevalence of obesity (BMI $\geq 30.0 \mathrm{~kg} / \mathrm{m}^{2}$ ) increased approximately $2-3 \%$ over the years 1987 1996, and amounted $9 \%$ in men and $10 \%$ in women in 1996 (44). The prevalence of obesity shows a wide variation between countries (Figure 1) as well within countries (44).

The increasing incidence of obesity is a recognized medical problem in developed countries (43). Obesity is associated with an increased risk of developing serious disorders, including hypertension, dyslipidemia, cardiovascular disease, noninsulin dependent diabetes mellitus, gallbladder disease, respiratory dysfunction, gout, and asteoarthritis (34). Health risks associated with obesity are not only

a)

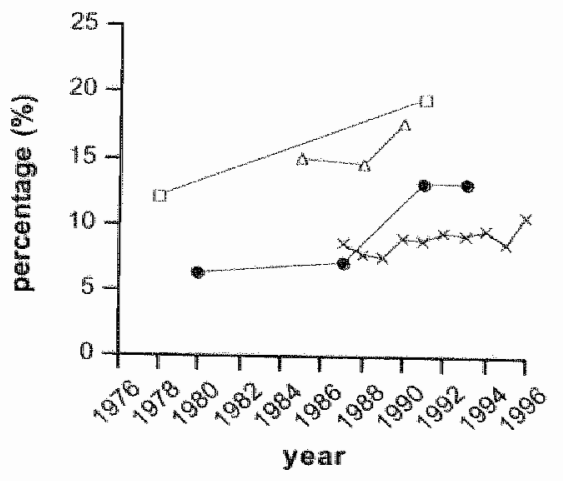

- United States A United Kingdom b)

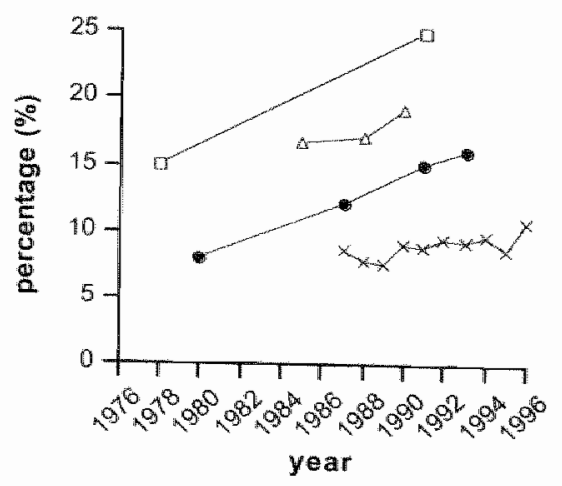

- Germany $x$ Netherlands

Figure 1 Time trends in obesity, defined as body mass index $\geq 30 \mathrm{~kg} / \mathrm{m}^{2}$, in men (a) and women (b) in various countries. 
Table 1 The WHO classification in adults by BMI

\begin{tabular}{lll}
\hline BMil $\left(\mathrm{kg} / \mathrm{m}^{2}\right)$ & Classification & Associated health risks \\
\hline$<18.5$ & Underweight & Low (but risk of other clinical problems increased) \\
$18.5-24.9$ & Normal range & Average \\
$\geq 25.0$ & Overweight & \\
$25.0-29.9$ & Pre-obese & Increased \\
$30.0-34.9$ & Obese class I & Moderately increased \\
$35.0-39.9$ & Obese class II & Severely increased \\
$\geq 40$ & Obese class III & Very sewerely increased \\
\hline
\end{tabular}

related to the total amount of fat but also to the distribution of fat in the body. Abdominal fat is most related to health risks. In this regard, the waist circumference alone is widely used to determine abdominal obesity, and is now considered superior to the traditionally used waist to hip ratio (26).

There is evidence that modest weight loss, $5-10 \%$ of the initial body weight, is associated with marked clinical improvement (18).

\section{ETIOLOGY OF OBESITY}

Energy balance is relatively stable on the long-term and this is mirrored by a constant body weight over time. A stable body weight is maintained when energy intake (EI) and energy expenditure (EE) are in equilibrium, according to the classical energy balance equation (51):

$$
E l=E E+\Delta E
$$

when $E I>E E$ than $\triangle E=$ energy storage

when $E I<E E$ than $\Delta E=$ energy mobilization

Obesity develops when the equilibrium between energy intake and energy expenditure shifts towards a positive balance, the excess energy being stored in the adipose tissue. Factors suggested to be related to the development of obesity are increased energy intake, especially from increased energy density through increased fat intake (58), and decreased energy expenditure, particularly from reduced physical activity (52). Therefore, much of the research in the obesity field has focussed on the possible deviations in the components of the energy balance equation to reach weight loss or to prevent weight (re)gain. Recently "evidence has accumulated that energy balance can only be achieved when macronutrients are in balance too $(13,15,55)$. Macronutrients balance requires that oxidation of a type of substrate matches its intake (12). Body weight loss and prevention of weight (re)gain can thus be achieved by reducing energy intake, manipulating the macronutrients, increasing energy expenditure, and/or reducing energy storage. Because changes in energy expenditure only slightly attenuate imbalances 
between energy intake and energy balance, adjustment of food intake to energy expenditure is therefore the critical factor for the maintenance of energy balance under conditions of ad libitum food intake (12). This can be realized by interaction of a variety of factors, such as hunger, satiety and sensory signals that control the actual food intake and meal pattern (55).

The studies presented in this thesis mainly focussed on different ways to reduce energy intake, particularly by stimulating satiety, to increase energy expenditure and to reduce energy stores in order to achieve moderate body weight loss or prevention of weight (re)gain.

\section{SATIETY}

To understand the problem of human obesity and to develop strategies to treat or prevent this condition it is necessary to understand the mechanisms of body weight regulation, h.e. energy balance regulation and as a part of it energy intake regulation, i.e. food intake regulation and appetite control.

A variety of satiety signals are involved in the short-term and long-term regulation of food intake. When food consumption suppresses hunger and inhibits further eating, two processes are involved: satiation and satiety (3). Satiation is the process that develops during the course of eating and that brings a period of eating to an end. The process of satiation therefore influences the size of the eating episode. Satiety is defined as inhibition of hunger and further eating that arises as a consequence of food consumption. Satiety therefore influences the duration of time elapsing until the next eating episode and/or the amount consumed during the next eating episode. These two processes therefore control events going on withinmeals or between-meals. Consequently, satiation and satiety act together to determine the pattern of eating behaviour $(30,59)$.

For complete understanding of satiety, it is useful to distinguish the different phases of satiety and the different mechanisms that characterize them. Four satiety mediating processes have been identified and can be roughly classified as sensory, cognitive, postingestive and postabsorptive (4). These processes are operated by the impact of food on physiological and biochemical mechanisms and have collectively been referred to as the satiety cascade (Figure 2) (22). Sensory processes are generated through smell, taste, temperature and texture of food. Cognitive processes are characterized by the beliefs held about the properties of foods. Postingestive (preabsorptive) processes include gastric distension, the rate of gastric emptying, the release of hormones (e.g. cholecystokinin, insulin) and the stimulation of gastrointestinal receptors. Postabsorptive processes represent the effects that result from the metabolism of absorbed nutrients (profile of metabolites, thermogenic effect, hepatic fatty acid oxidation). The concept of the satiety cascade implies that foods varying in nutrient composition will engage differently with the satiety mediating processes and will therefore exert different effects on satiation and satiety. 


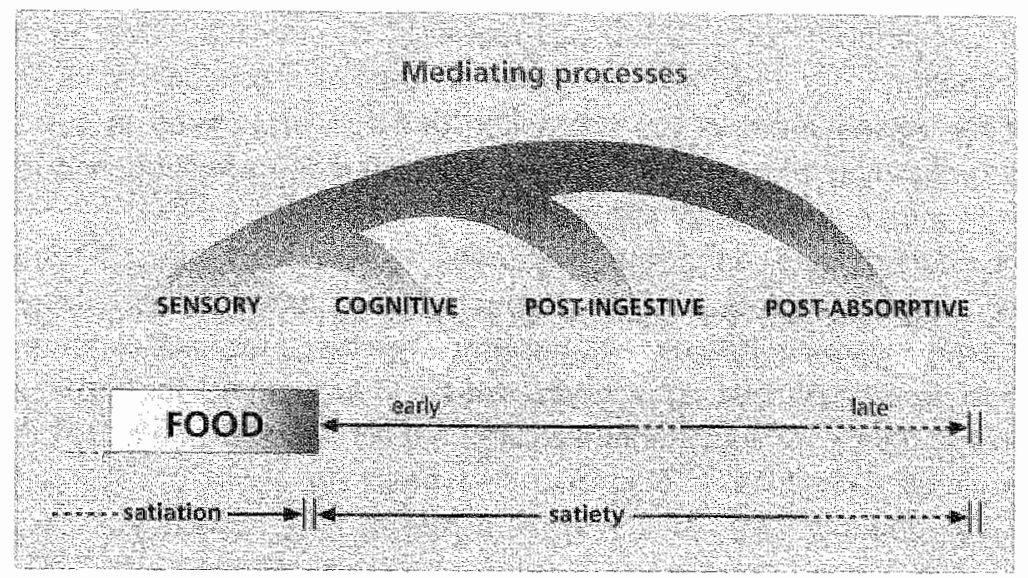

Figure 2 The satiety cascade (22)

The psychobiological system involved in the expression of appetite is present at three levels: the level of psychological events and behavioural operations, the level of peripheral physiology and metabolic events, and the level of neurotransmitter and metabolic interactions in the brain (5). The expression of appetite reflects the synchronous operation of events and processes in these three levels (Figure 3 ) (22).

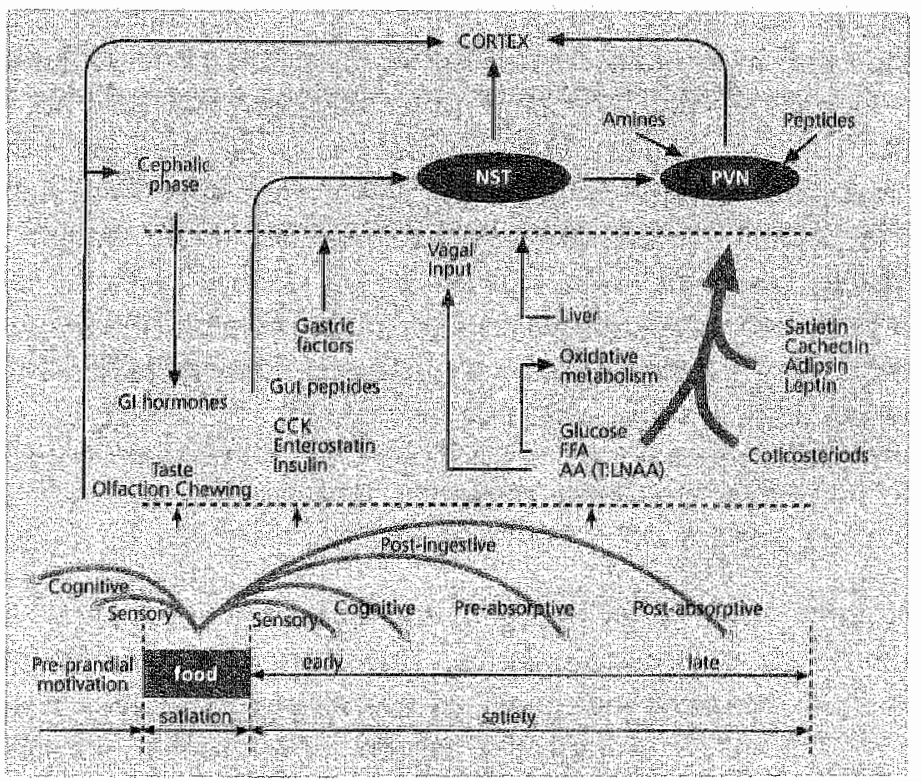

Figure 3 The satiety cascade retated to three levels of operation of the psychobiological system: the behavioural pattern, peripheral physiology and metabolism, and brain activity (22) PVN = paraventricular nucleus, $\mathbb{N S T}=$ nucleus of the tractus solitarius, $C \mathrm{CK}=$ cholecystokinin, $A A=$ amino acids, $T=$ tryptophan, $L N A A=$ large neutral amino acids. 
Nutritional substances or pharmacological agents administered to induce or intensify satiation (57) may act on some of the four processes of the satiety cascade (30). Assessment of the interaction of these processes is a prerequisite for the understanding of how interventions may influence satiation and satiety and possibly food intake and energy intake.

Energy expenditure and substrate metabolism may also affect satiely. Energy expenditure may stimulate satiety through diet-induced thermogenesis (55). Increased energy expenditure at rest, implying increased oxygen consumption and increased body temperature, has been shown to be related to increased satiety (53). An explanation for this might be that satiety is increased under reduced oxygen avallability conditions. This also has been observed at high altitude (56) and in COPD patients (40). Evidence for a role of hepatic fatty acid oxidation on stimulating satiety has been shown in animals (25). Satiety can also be stimulated by increasing the rate of hepatic glycogen synthesis (20).

\section{ENERGY EXPENDITURE}

Energy expenditure is required to maintain basic physiologic functions (resting metabolic rate), to digest, metabolise, and store ingested food (diet-induced thermogenesis) and for physical activity (activity-induced energy expenditure). Reduced daily energy expenditure that is not matched by an equivalent reduction in energy intake contributes over the long-term to the development of obesity. There is some evidence that individuals characterized by a low resting metabolic rate are more prone to gain weight over time (35), although this has not been always confirmed $(42,49)$. A reduced thermogenic response to food has also been reported in subjects prone to obesity $(17,41)$, but this has not been found consistently (8). Resting metabolic rate declines with body weight loss (2). The decline in resting metabolic rate caused by an energy-restricted diet has been shown to be positively correlated with unsuccessful weight maintenance (33). It is possible that body weight loss creates a metabolic state favouring weight regain to return to some aptimal or regulated level (61).

\section{ENERGY STORAGE}

Over the long-term, most adult humans are able to maintain body energy stores through the process of energy balance. Howewer, when energy intake exceeds energy expenditure, the body increases its overall energy stores. There is a clearly defined hierarchy of energy storage that shows a prefferential storage of energy as fat (19). This process occurs at low metabolic cost and is an extremely efficient process. For carbohydrate there is a limited storage capacity in the form of glycogen. Excess carbohydrate can also be converted to fat through de novo lipogenesis (21), but this mechanism is limited in humans. Protein metabolism is 
in general well regulated and the storage capacity for protein is limited. For alcohol, there is no storage capacily in the body and alcohol is immediately oxidized.

\section{STRATEGIES FOR THE TREATMENT OF OBESITY}

Long-term treatment of obesity is often unsuccessful. Because the efficacy of methods to improve weight loss has improved over the last decades, short-term reduction of body weight is no longer a major problem. However intervention strategies for promoting long-term weight loss are less successful (24). In the long term, decreased compliance and habituation to an energy-restricted diet accompanied by increased appetite (9) may result in unsuccessful weight loss. Furthermore, it has often been observed that weight loss is not maintained on the long term $(7,14,33,54)$. Therefore, identification of strategies to improve body weight loss during an energy-restricted diet or to prevent weight regain after body weight loss is needed for the treatment of obesity.

Finding ways to stimulate satiety may be one of these strategies. Stimulation of satiety may result in both energy intake reduction and hunger suppression during energy restriction. In this respect, reduced hunger and sustained satiety may improve compliance to an energy-restricted diet (1). Satiety can be stimulated at four different levels: sensory, cognitive, postingestive and postabsorptive. Affecting postingestive and postabsorptive processes may be effective in hunger suppression and subsequently helpful in maintaining energy intake restriction. Therefore, identification of ingredients that stimulate satiety in the postingestive and postabsorptive phase may be useful in the treatment of obesity.

Stimulation of energy expenditure may be another strategy to improve body weight loss and prevention of weight (re)gain by inducing a negative energy balance and by stimulating satiety. The most effective way to increase energy expenditure is by improving physical activity (50). In addition, identification of ingredients that increase energy expenditure may contribute to keep energy balance and thus body weight within acceptable limits.

Inhibition of energy storage or stimulation of energy mobilization may be another strategy in the treatment of obesity. Identification of ingredients that inhibit storage of energy, especially as fat, or that stimulate energy mobilization for example through increased fat oxidation may be useful for preventing changes in body weight and body composition.

\section{OUTLINE OF THE THESIS}

The studies described in the thesis investigated ingredients, which aim at inducing a slightly negative energy balance, to induce moderate body weight loss or to prevent weight (re)gain. We particularly focussed on ingredients that might affect satiety in the postingestive and postabsorptive phase, or ingredients that might 
affect energy expenditure of storage. In addition to assessing the effects of food ingredients, attention was paid to one peptide that might affect food intake.

In general, dietary fibres have been found to effectively increase satiety resulting in reduced energy intake $(11,32)$. However, controversial findings have been shown on the effects of dietary fibers along with an energy restricted diet $(1,23,37,38$, $39.45)$. Therefore, the first step of the present research was to investigate whether addition of a particular dietary fibre (modified guar gum) to a ready-lo-eat lowenergy semisolid meal was effective in sustaining satiety while reducing food intake in overweight subjects (chapter 2). We investigated whether the satiating effect of guar gum was related to the blood glucose response (chapter 3) and/or to gastric emptying and intestinal transit (chapter 4). Because changes in blood glucose have been suggested to play a role in short-term food intake regulation, we investigated whether an association between meal initiations and blood glucose dynamics was present in dieting subjects (chapter 5).

(-)-Hydroxycitrate, an inhibitor of ATP-citrate-lyase, has been proposed to be effective in body weight regulation by three mechanisms: by increasing hepatic fatty acid oxidation $(28,29)$, by increasing the rate of hepatic glycogen synthesis (20) or by limiting the capacity for de novo lipogenesis (48). Medium-chain triglycerides have been proposed to increase satiety and decrease food intake $(36,47,62)$ by involving both pre- and postabsorptive mechanisms. Therefore, the second step of the present project was to investigate the effects of 2 -week ingestion of $(-)$ hydroxycittate and (-)-hydroxycitrate combined with medium-chain triglycerides on satiety, food intake, fat oxidation, energy expenditure, and body weight in overweight subjects (chapter 6-7). We further investigated whether (-)-hydroxycitrate had the potential to reduce de novo lipogenesis during carbohydrate overfeeding in normal weight subjects (chapter 8).

Several peptides have been shown to inhibit food intake (6). One of these peptides, enterostatin, has been found to inhibit food intake and selectively inhibit fat intake in rats $(10,27,31,46)$. Therefore, the aim of the last study described in the thesis was to investigate the effects of oral administration of enterostatin during ingestion of a high-fat diet on food and fat intake and energy expenditure in subjects with a preference for a high-fat diet (chapter 9). Finally, the results of the above described studies are discussed to come to a general conclusion on the role of ingredients for body weight regulation (chapter 10).

\section{REFERENCES}

4. Astrup $A$, Vrist $E$, Quaade $F$. Dietary fiber added to very low calorie diet reduces hunger and alleviates constipation. Int I Obes 1990; 14: 105-112.

2. Astrup A, Gotzsche PC, Werken $K$ van de, Ranneries $C$, Toubro $S$, Raben A, Buemann $B$. Meta-analysis of resting metabolic rate in formerly obese subjecls. Am J Clin Nutr 1999; 69 : $1117-1122$.

3. Blundell JE. Hunger, appetite, and satiety - construcks in search of identities. In: Turner M (ed). Nutrition and lifestyle. Applied Sci: London, 1979 $\mathrm{pp} 21-42$. 
4. Blundell JE, Hill AJ, Rogers PJ. Hunger and the saliety cascade - their importance for food acceptance in the late $20^{\text {hit }}$ century. Im: Thompson DMH (ed). Food Acceptability. Elsevier: London, 1988, pp 233-250.

5. Blundell JE, Halford JCG. Regulation of nutrient supply: the brain and appelite control. Proc Nutr Soc 1994; $53: 407-418$.

6. Bray GA. Afferent signals regulating food intake. Proc Nutr Soc 2000; 59: $373,384$.

7. Dale D van, Saris WHM, ten Hoor F. Weight maintenance and resting metabolic rate 18-40 months after a dietexercise treatment. Int $f$ Obes 1990; $14: 347-359$.

8. D'Alessio DA, Kavle EC, Mozzoli MA, Smalley KJ, Poiansky M, Kendrick ZV, Owen LR, Bushman MC. Boden $G$, Owen OE. Themic effect of food in lean and obese men. $J$ Chn Invest 1988; 81:1781-1789.

9. Doucet E, Imbeaul $P$. St-Pierre $S$, Ameras N, Mauriege P. Richard D. Tremblay A. Appetite atter weight loss by energy restriction and a low-fat diet-exercise follow-up. Int $J$ obes 2000 ; 24: $906-914$.

10. Erlanson-Abertsson C, Mei J, Okada S, York D, Bray GA. Pancreatic procolipase propeptide, enterostatin, specifically inhibits fat intake. Physiol Behav 1991; 49: 1191-4194.

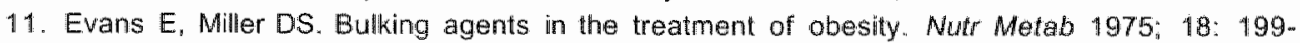
203 .

12. Flatt IP. McCollum Award Lecture, 1995: Diet, lifestyle, and weight maintenance. Am J Chn Nutr 1995; 62: $820-836$.

13. Flatt JP. Glycogen levels and obesity. Int $/$ Obes 1996; 20 (Suppl): S1-511.

14. Fogelholm M, Kukkonen-Harjula K, Oja P. Eating control and physïcal activity as determinants of short-term weight maintenance after a very-low-calorie diet among obese women. Int $J$ Obes $1999 ; 23: 203-210$.

15. Frayn KN. Physiological regulation of macronutrient balance. Int J Obes 1995; 19 (Suppl): S4. s10.

16. Gallagher D, Visser M, Sepulvedla D, Pierson RN, Harris T. Heymsfield SB. Body mass index as an estimate of fatness across gender, age, sex, and ethmic groups. Am J Epidemiol 1996 ; 143: $228-239$.

17. Golay A. Blunted glucose-induced thermogenesis: a factor contributing to relapse of obesity. Int J Obes 1993; 17 (Suppl): S23 527 .

18. Goldstein DJ. Beneficial health effects of madest weight loss. Ir J Obes 1992: 16:397-415.

19. Goran Mil. Energy metabolism and obesity. Med Clin North Am 2000; 84: 347-362.

20. Helierstein MK, Xie $Y$. The indirect pathway of hepatic glycogen synthesis and reduction of food intake by metabolic inhibitors. Life Sal 1993; 53 : 1833-1845.

21. Hellerstein MK. De novo lipogenesis in humans: metabolic and regulatory aspects. Eur $J$ Chin Nutr 1999; 53 (Suppl): $\$ 53-\$ 65$.

22. Hetherington MM, Blundell JE. Eating disorders. In: Westerterp-Plantenga MS. Steffens AB. Tremblay A (eds). Regulation of Food Intake and Energy Exponditure. EDRA: Milano. 1999: $185-199$

23. Hylander B, Rössner $S$. Effects of dietary fiber intake before meals on weight loss and hunger in a weightreducing club. Acta Med Scand 1983; 213:217-220.

24. Jeftery RW, Drewnowski A, Epstein LH, Stunkard A., Wison GT, Wing RR, Hill DR. Long-term maintenance of weight loss: current status. Health Psychol 2000; 19 (Suppl): $5-16$.

25. Lamghans $W$. Metabolic control of food intake. Role of the liver. In: Westerterp-Planterga MS. Steffen AB. Tremblay A (eds). Regulation of food intake and energy expenditure. EDRA: Milano, 1999, 185-199.

26. Lemieux 3 , Prudhomme D, Bouchard $C$, Tremblay $A$, Despres I. A single threshold walue of wailst girth identifies nomal-weight and overweight subjects with excess visceral adipose tissue. Am J Colm Nutr 1996; 64: 685-693.

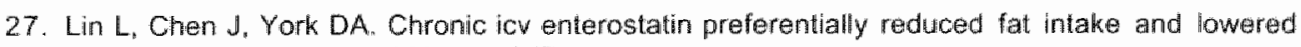
body weight. Peptides 1997; 18: 657 -661.

28. McCarty MF. Promotion of hepatic lipid oxidation and gluconoogenesis as a strategy for appetite contral. Med Hypotheses $1994 ; 42 ; 215-225$. 
29. MCGarry JD. Foster DW. In support of the roles of malonyl-CoA and carnitine acyltransferase I in the regulation of hepatic fatty acid oxidation and ketogenesis. I Biol Cherm 1979: 254: $8163-8168$.

30. Melanson $K J$, Westerterp-Plantenga MS, Saris WHM, Smith FJ, Camplield LA. Blood glucose patterns and appetile in time blinded humans: carbohydrate versus fat. Am J Physiof 1999; 277: R337-R345.

31. Okada S, York DA, Bray GA, Erlanson-Albertssion C. Enterostatin (Val-Pro-Asp-Pro-Arg) the activation peptide of procolipase selectively reduces lat intake. Physiol Behav 1991; 49: $1185-1129$.

32. Pasman WJ, Wauters M. Westerterp-Plantenga MS, Saris WHM. Effect of one week of fibre supplementation on hunger and satiety or energy intake. Appetite 1997: 29: 77-87.

33. Pasman WJ, Saris WHM, Westerterp-Plantenga MS. Predictors of weight maintenance. Obes Ress 1999: 7: 43-50.

34. Pi-Sunyer FX. Medical hazards of obesity. Ann tntern Med 1993; 119: 655-660.

35. Ravussin E, Lillioja S, Knowler WC, Christin L, Freymond D, Abbott WG, Boyce W, Howard BV, Bogardus $C$. Reduced rate of energy expenditure as a risk factor for body-weight gain. $N$ Engl I Med' 1988: 318: 467-472.

36. Rolls BJ, Gnizak N. Summerfeld A, Laster LJ. Food intake in dieters and mondieters after a liquid meal containing medium-chain triglycerides. Am J Chin Nutr 1988; 48: 66-71.

37. Rössner $S$, Zweigbergk $D$ won, Öhlin $A$, Ryttig $K$. Weight reduction with dietary fibre supplements. Results of two double-blind randomized studies. Acta Med Scand 1987; 222: 83-88.

38. Rössner, Andersson H-L, Ryttig K. Effects of a dietary fibre supplement to a weight reduction programme on blood pressure. A randomized, double-blind, placebo-controlled study. Acta Med Scand 1988; 223: 353-357.

39. Ryytig $K R$, Tellnes $G$, Hæegh $L$, Bwe $\mathbb{E}$, Fagerthun $H$. A dietary fibre supplement and weight maintenance after weight reduction: a randomized, double-bilind, placebo-controlled long-term trial. Int $J$ Obes 1989: 13: 165-171.

40. Schols AM. Nutrition and outcome in chronic respiratory disease. Nutrition 1997; 13: 161-163.

41. Segal KR, Edano A, Tomas MB. Themic effect of a meal over 3 and 6 hours in lean and obese men. Metabolism 1990; 39: 985-992.

42. Seidell JC. Muller DC, Sorkin JD, Andres R. Fasting respiratory exchange ratio and resting metabolic rate as predictors of weight gaim: the Baltimore Longitudinal Study on Aging. Int $J$ Obes 1992: 16: 667-674

43. Seidell JC. Obesity in Europe. Obes Res 1995; 3 (Suppl): 249s-259s.

44. Seldell JC. Obesily: a growing problem. Acta Paediatr 1999; 428 (Suppl): 46-50.

45. Solum TT, Ryttig KR, Solum E, Larsen $S$. The influence of high-fibre diet on body weight, serum fipids and blood pressure in slightly overweight persons. A randomized, double-blind, placebo-controlled investigation with diet and fibre tablets (Dumovital). Int I Obes 1987; 11 (Suppl): 67-71.

46. Sörhede M, Mei J.Erlanson-Albertsson C. Enterostatin -- a gut-brain peptide - regulating fat intake in rat. J Physiof Paris 1993; 87: 273-275.

47. Slubbs, RJ. Harbron CG. Covert manipulation of the ratio of medium- to long-chain triglycerides in iscenergetically dense diels: effect on food intake in ad libitum feeding men. Int J Obes 1996; $20: 435-444$.

48. Sullivan AC. Hamilton JG, Miller ON. Wheatley VR. Imhibition of lipogenesis in rat liver by ( - hydroxycitrate. Arch Brochem Piophys 1972; 150: 183-190.

49. Weinsier RL, Nelson KM, Hensrud DD, Damell BE, Hunter GR, Schutz Y. Metabolic predictors of obesity. Contribution of resting energy expenditure, thermic effect of food, and fuel 95: $980-985$.

50. Westerterp KR, Saris WH, Es M van, ten Hoor F. Use of the doubly labeled water technique in humans during heavy sustained exercise. $J$ Apol Physiol 1986; 61: 2162-2167. 
51. Westerterp KR. Body composition. In: Westerterp-Plantenga MS. Fredrix EWHM, Steffens AB (eds). Food intake and Energy Expenditure. CRC Press: Boca Raton, 1994, pp 259-277.

52. Westerterp KR. Pattern and intensity of physical activity. Nature 2001: 410:539.

53. Westerterp-Plantenga MS. Wouters $L_{\text {, }}$ ten Hoor $F$. Deceleration in cumulative food intake curves, changes in body temperature and diet-induced thermogenesis. Physiol Behgu 1990; 48: $831-836$.

54. Westerterp-Plantenga MS, Kempen KPG, Saris WHM. Determinants of weight maintenance in women after diet-induced weight reduction. Int $J$ Obes 1998; 22: 1-5.

55. Westerterp-Plantenga MS, Rolland $V$, Wilson SAJ, Westerterp KR. Satiety related to 24h dietinduced thermogenesis during high protein/carbohydrate ws high fat diets measured in a respiration chamber. Eur J Clin Nutr 1999; 53: 495-502.

56. Westerterp-Plantenga MS, Westerterp KR, Rubbens M, Verwegen CRT, Richallet JP, Gardette B. Appetite at "high altitude" [Operation Everest 111 (Comex-97)]: a simulated ascent of Mount Everest. J Appl Physiol 1999: 87: 391-399.

57. Westerterp-Plantenga MS. Eating behavior in humans, characterized by cumulative food intake curves - a review. Neurosci Biobehav Rev 2000; 24: 239-248.

58. Westerterp-Plantenga MS. Analysis of energy density of food in relation to energy intake regulation in human subjects. Br \& Nutr 2001; 85: 351-361.

59. Westerterp-Plantenga MS, Kovacs EMR, Melanson KJ. Habitual meal frequency and energy intake regulation in partially temporally isolated men. Int $J$ Obes 2002; 26: 102-110.

60. WHO. Obesity: preventing and managing the global epidemic. WHO: Geneva, 1998: WHO/NUT/NCD/98.1.

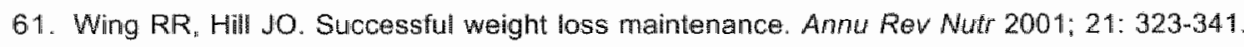

62. Wymelbeke $V$ van, Himaya $A$, Louis-Sylvestre J, Fantino $M$. Influence of medium-chain and long-chain triacylglycerols on the control of food intake in men. Am J Clin Nutr 1998; 68: 226234. 


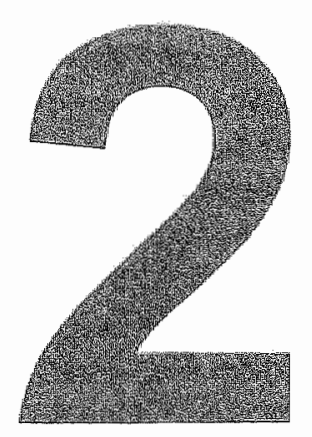

\section{The effect of addition of modified guar gum to a low-energy semisolid meal on appetite and body weight loss}

Kovacs EMR, Westerterp-Plantenga MS, Saris WHM, Goossens I, Geurten P, Brouns F

International Journal of Obesity $2001 ; 25: 307-315$ 


\section{ABSTRACT}

Objective: To investigate the effect of addition of modified guar gum (GG) to a lowenergy semisolid meal on appetite and body weight (BW) loss.

Subjects: Twenty eight mainly overweight male volunteers (age, $19-56 \mathrm{y}$, body mass index, $29 \pm 2 \mathrm{~kg} / \mathrm{m}^{2}$, BW, $89.4 \pm 9.2 \mathrm{~kg}$ ).

Design: Baseline of one week with self-selected diet. Three treatments of 2 weeks with a low-energy diet divided over three times a day, consisting of a semisolid meal with (SSM+) or without GG (SSM) or a solid meal (SM) with the same energy content $(947 \mathrm{~kJ})$ and macronutrient composition, and a dinner of the subject's own choice. Washout periods lasted 4 weeks.

Results: Compared to baseline values, reduction in energy intake and BW loss were similar for SSM+, SSM and SM. Appetite (hunger, desire to eat, or estimation of how much one could eat) was increased in SSM and in SM compared to baseline, but not in SSM+. Satiety and fullness in SSM+, SSM and SM were similar to baseline. Any intervention was more effective on BW loss when it took place the first time compared to the second and third times $(2.6 \pm 0.2 \mathrm{~kg}, 1.7 \pm 0.2 \mathrm{~kg}$ and 1.1 $\pm 0.2 \mathrm{~kg}$, respectively; $P<0.001$ ). The SM - SSM+ - SSM sequence was more effective on BW loss compared to the SSM+ - SSM - SM sequence $(5.6 \pm 1.0 \mathrm{~kg}$ and $2.5 \pm 0.6 \mathrm{~kg}$, respectively; $P<0.05$ ).

Conclusion: All the three treatments were equally effective with respect to BW loss. GG addition to a semisolid meal prevented an increase in appetite, hunger and desire to eat, which increase was present in the other treatments. However, differences between treatments were not statistically significant. The order effect shows that repeated 2 -week bouts of dieting become increasingly ineffective. The sequence SM - SSM+ - SSM was more effective than the sequence SSM+ - SSM SM, probably because compliance was relatively higher with the SSM+ or SSM diet, and compliance decreased towards the end of the complete experiment.

Keywords: guar gum, energy intake, body weight loss, appetite, obesity treatment 


\section{INTRODUCTION}

The increasing incidence of obesity is a recognized medical problem in developed countries (38). Obesity is known to be related to increased risks of coronary heart diseases, hypertension, non-insulin dependent diabetes mellitus and certain types of cancer $(19,22,29)$. Factors suggested to be related to the development of obesity are decreased physical activity and increased energy intake, especially fat intake. Weight loss and loss of body fat can thus be achieved by reducing energy intake and/or increasing energy expenditure.

Low-energy diets have been shown to be successful in the reduction of body weight on the short-term. However, during long-term treatment, decreased compliance and increased habituation to an energy-restricted diet accompanied by increased appetite (7) may result in unsuccessful weight loss or prevention of weight regain. Reduced hunger and increased satiety feelings may improve compliance to an energy-restricted diet (2). Therefore, identification of substances that improve or sustain satiety during energy restriction is needed for the treatment of obesity. The effects of dietary fiber on appetite, energy intake and/or body weight have been extensively investigated and reported in a number of reviews $(5,6,41)$. Dietary fiber such as guar gum (GG) was found to effectively increase fullness and satiety resulting in reduced energy intake $(8,30)$. It has been proposed that soluble viscous fiber, such as $G G$, may decrease the rate of gastric emptying and small intestinal transit $(3,17,50)$, resulting in a delayed glucose absorption (4) and a prolonged feeling of satiety (25). The lowered energy intake and increased satiety feeling may be beneficial for short-term weight loss (8) and long-term weight maintenance $(23,44)$. Controversial findings have been shown on the effects of different types of dietary fiber along with an energy-restricted diet on food intake and/or body weight loss $(2,20,33,34,36,40)$. To our knowledge, only one study investigated the effects of $G G$ supplementation during energy restriction on energy intake, hunger and satiety (30). The hunger-reducing effect of GG during the energy-restricted condition suggested that GG may be useful in the treatment of obesity, by increasing the compliance to a low-energy diet. Moreover, we assessed a new type of $G G$, namely a highly purified dietary galactornannan fiber that forms a gel in 5-7 min after adding water. Furthermore we combined the energy-providing meal directly with the GG.

The aim of the present study was to test the hypothesis whether the addition of modified GG to a ready-to-eat low-energy semisolid meal was effective in sustaining satiety while reducing food intake. It was hypothesized that GG addition to a low-energy semisolid meal would lead to gel forming in the stomach resulting in sustained feeling of satiety or prevention of increase of appetite or hunger. Moreover, this was expected to result in a more effective body weight (BW) loss. Furthermore, since the possible effect of a treatment with the ready-to-eat low-

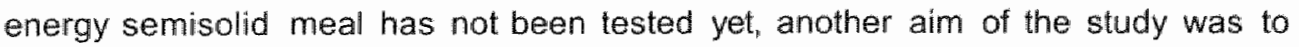
compare the effects of the semisolid meal itself with a self-prepared low-energy solid diet on appetite and BW loss. 


\section{METHODS}

\section{Subjects}

The study was started with 36 male mainly overweight subjects who were recruited by advertisements in local newspapers. Eight subjects dropped out of the study: six subjects stopped participation before (baseline) or during the first intervention because they were not able to follow our prescriptions, mostly because of a lack of time, and two subjects stopped during the third intervention because they moved far away. Statistical analysis revealed no difference in the number of dropouts between treatment sequences. Therefore the data presented in this study are based upon 28 subjects. Baseline subjects characteristics are presented in Table 1. The nature and risks of the experimental procedure were explained to the subjects, and all subjects gave their written informed consent. The study protocol was approved by the Ethical Committee of the Maastricht University.

\section{Experimental design}

The experimental design consisted of a baseline period of 1 week and then three intervention periods of 2 weeks in a randomized cross-over design. The intervention periods were separated by washout periods of 4 weeks (Figure 1).

During baseline and the washout periods, the subjects consumed a self-selected diet. During the intervention periods, the subjects consumed for breakfast, lunch and as a four o'clock snack a low-energy meal. In addition, for lunch, subjects were allowed to eat a piece of fruit (e.g. apple "pear or orange). For dinner, the subjects ingested what they liked, but they were instructed to drink not more than one glass

Table 1 Subjects characteristics $(n=28)$ at baseline

\begin{tabular}{lcc}
\hline & mean \pm SO & range \\
\hline Age $(\mathrm{y})$ & $42.5 \pm 10.5$ & $19-56$ \\
Height $(\mathrm{m})$ & $1.77 \pm 0.05$ & $1.65-1.89$ \\
Weight $(\mathrm{kg})$ & $89.4 \pm 9.2$ & $74.1-112.7$ \\
Body mass index $\left(\mathrm{kg} / \mathrm{m}^{2}\right)$ & $28.6 \pm 2.1$ & $24.1-33.7$ \\
Waist circumference $(\mathrm{cm})$ & $98 \pm 7$ & $85-108$ \\
Hip circumference $(\mathrm{cm})$ & $104 \pm 6$ & $89-119$ \\
Waist-hip ratio & $0.95 \pm 0.05$ & $0.85-1.06$ \\
Bodly fat (\%) $(n=15)$ & $30.9 \pm 1.1$ & $23.3-38.5$ \\
Systolic blood pressure (mmHg) & $151 \pm 22$ & $116-206$ \\
Diastolic blood pressure (mmHg) & $92 \pm 10$ & $77-115$ \\
Blood glucose (mmol/ $)$ & $5.4 \pm 0.3$ & $4.4-6.0$ \\
F1 (cognitive restraint) & $5 \pm 3$ & $0-9$ \\
F2 (disinhibition) & $4 \pm 2$ & $1-12$ \\
F3 (hunger) & $4 \pm 3$ & $0-11$ \\
Herman-Polivy restraint & $14 \pm 5$ & $6-22$ \\
\hline
\end{tabular}


of alcoholic beverage or soft drink. Subjects were instructed to refrain from snacks between meals. During the day, the subjects were allowed to drink ad hibitum water, coffee and tea (without sugar and milk).

The low-energy meal consisted of a semisolid meal (Milicall Creme, Laboratoires Diététique et Santé, Revel, France) with (SSM+) or without (SSM) supplementation of $2.5 \mathrm{~g}$ of a new type of modified GG (Meyprofin ${ }^{3}$ M-175, Meyhall AG, Kreuzlingen, Switzertand), a highly purified dietary galactomannan fiber which forms a gell in about 5-7 min after adding water, or a solid meal (SM) with the same energy content and macronutrient composition (energy, $947 \mathrm{~kJ}$; protein, $17.9 \mathrm{~g}$; carbohydrate, $21.0 \mathrm{~g}$; fat, $7.9 \mathrm{~g}$ ), which was prepared by the subjects themselves using our instructions. Acceptability of these meals was tested in the subjects as well.

Subjects, matched for BMI, age, weight and blood glucose, were included in three intervention sequences, that is SSM+ - SSM - SM $(n=10)$, SSM - SM - SSM+ $(n=9)$, and SM - SSM+ - SSM $(n=9)$.

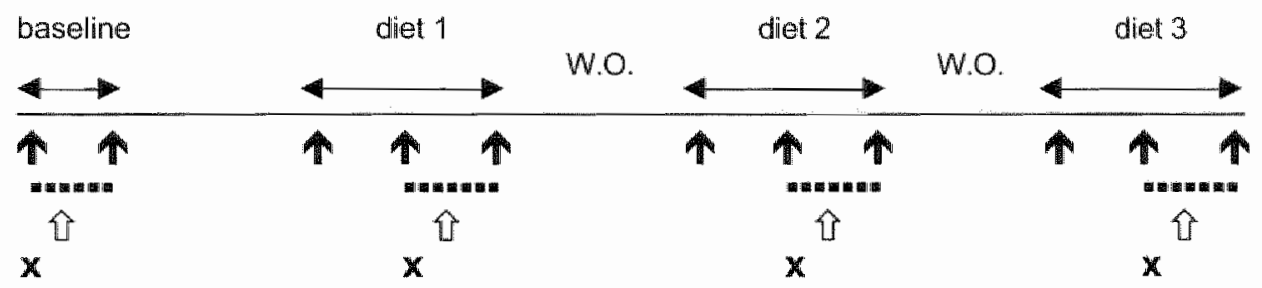

Figure 1 Experimental design

diet 1 , diet 2 , diet $3=$ intervention periods; $W . O$. = washout periods; $1=$ measurement of body weight; "... " = recording of food intake; $\hat{t}=$ questionnaires on hunger and satiety and eating behavior; $\mathbf{X}=$ measurement of body fat

\section{Anthropometry}

Body weight (BW) was measured during screening, at the beginning and at the end of baseline as well as at the beginning, after 1 week and at the end of each intervention period on a digital balance (Seca, model 707. Hamburg, Germany; weighing accuracy of $0.1 \mathrm{~kg}$ ) with subjects in underwear, in a fasted state and after voiding their bladder. Height was measured using a wall-mounted stadiometer (Seca, model 220. Hamburg. Germany). The body mass index was calculated by BWheight ${ }^{2}\left(\mathrm{~kg} / \mathrm{m}^{2}\right)$.

The distribution of fat was investigated during screening and at the end of the experiment by measuring the waist and hip circumferences and calculation of the waist-hip ratio (WHR). The waist circumference was measured at the site of the smallest circumference between the rib cage and the ileac crest, with the subjects in standing position. The hip circumference was measured at the site of the largest 
circumference between the waist and the thighs. The WHR was calculated by dividing the waist circumference by the hip circumference.

Total body water (TBW) was measured before baseline and during each intervention period in a random subsample of 15 subjects using the deuterium $\left({ }^{2} \mathrm{H}_{2} \mathrm{O}\right)$ dilution technique (37). The dilution of the deuterium isotope is a measure for total body water (TBW) (26). Subjects were asked to collect a urine sample in the evening just before drinking a weighed amount of deuterium-enriched water solution. After ingestion of the deuterium solution no further fluid or food consumption was permitted. Ten hours after ingestion of the deuterium solution a second urine sample (second voiding) was collected. Deuterium concentration in the urine samples was measured using an isotope ratio mass spectrometer (Micromass Optima, Manchester, UK). TBW was obtained by dividing the measured deuterium dilution space by 1.04 (37). Fat free mass (FFM) was calculated by dividing the TBW by the hydration factor 0.73 . By subtracting FFM from $B W$, fat mass (FM) was obtained. FN expressed as a percentage of BW revealed body fat percentage.

\section{Blood parameters}

Systolic and diastolic blood pressure was measured during screening by an automatic blood pressure monitor (Omron $705 \mathrm{CP}$. Omron Healthcare $\mathrm{GmbH}$, Hamburg, Germany).

A fasted blood sample $(2 \mathrm{ml})$ was obtained and mixed with EDTA to prevent clotting. Plasma was obtained by centrifugation and then stored at $-20^{\circ} \mathrm{C}$ until analysis of glucose by a hexokinase method (Cobas Bio, Roche Diagnostics, Hoffmann-La Roche, Basel, Switzerland).

\section{Eating behavior}

Eating behavior was analyzed during screening as well as at the beginning and at the end of baseline and of each intervention period using a validated Dutch translation of the Three-Factor Eating Questionnaire (TFEQ) (43,49). Cognitive restrained and unrestrained eating behavior (factor 4), emotional eating and disinhibition (factor 2) and the subjective feeling of hunger (factor 3) were scored. Body weight fluctuation was investigated with the Herman Polivy questionnaire (HP) (18).

\section{Food intake}

Food intake and meal frequency were recorded during the last 7 days of each intervention period using a food intake diary. Personal instruction was given in adwance. The food intake diaries were analyzed using the Dutch food composition table (42) and the accessory computer program (Becel Nutrition. Program 1988). Compliance of the subjects to the dietary instructions was checked using the food intake diaries. For each incorrect food intake action (e.g. consumption of only two low-energy meals during a day, extra alcoholic beverage during dinner, sugar in 
coffee) they scored a noncompliance point. Compliance to dietary instructions was analyzed using these points.

Accuracy of food intake recording was determined in a random subsample of 15 subjects by comparing water intake and water loss (13). Water intake was measured using a food intake diary. Water intake was determined from reported food intake using a computer program (Becel Nutrition Program 1988) based on food tables (42). Water loss was measured with the deuterium elimination method 19). The evening before the start of the recording week, the subjects drank a weighed amount of deuterium solution $\left({ }^{2} \mathrm{H}_{2} \mathrm{O}\right)$ after collecting a baseline urine sample. Water loss was callculated from ${ }^{2} \mathrm{H}$ elimination in urine samples, collected on day 1 . (in the morning and in the evening), day 7 (in the evening) and day 8 (in the morning) $(9,46)$. Deuterium content in the urine samples was measured with an isotope ratio mass spectrometer (Micromass Optima, Manchester, UK). Under normal conditions, water balance is preserved and water intake matches water loss. When water intake, corrected for metabolic water, is less than water loss. underrecording is present (13). The deuterium dilution method was validated with the doubly labelled water method, showing that the recording precision of water intake was representative for total food recording $(13,14)$. To ensure that food recording in these 15 subjects was not influenced by the fact that they were aware that water intake and water loss were measured, also the other subjects followed the same protocol, but using tap water.

\section{Satiety}

Perception of satiety (hunger, satiety, fullness, desire to eat, appetite, estimation of how much one could eat, and thirst) was scored on anchored $100 \mathrm{~mm}$ visual analogue scales at day 4 during baseline and day 11 during each intervention period. Questionnaires were completed at 10 fixed time points, respectively just before and after breakfast, in the morning between 10:00 $\mathrm{h}$ and 11:00 $\mathrm{h}$, before and after lunch, before and after a four $0^{\prime}$ clock snack, before and after dinner and in the evening between 22:00 h and 23:00 h (49).

To characterize the development of satiation during a meal questions on hunger, satiety and pleasantness of taste were answered on $100 \mathrm{~mm}$ visual analogue scales every 2 min during dinner consumed on the same day.

\section{Tolerance}

Tolerance of the intervention diets was determined at the end of each diet period using a questionnaire on occurrence of gastrointestinal and other complaints and scored on a 5 points scale $(0=$ never, $1=$ rarely, $2=$ sometimes, $3=$ often, $4=$ very often).

\section{Hedonic value and user-friendliness}

Hedonic value and user-friendliness of the treatments were determined using a questionnaire which the subjects were asked to complete at the end of the 
experiment. The hedonic value of the semisolid meal was scored on a $0-5$ scale (0 $=$ not tasty at all, $1=$ not tasty, 2 = less tasty, $3=$ rather tasty, $4=$ tasty, $5=$ very tasty). User-friendiness of the diets was scored on a $0-2$ scale $10=$ not user-friendly at all, 4 = rather user-friendly, 2 = user-friendly) and subjects were asked to say which diet they would prefer to use in the future.

\section{Statistical anallysis}

Data are presented as mean \pm standard error (SE). Differences between baseline and the treatments as well as differences between the treatments were determined by analysis of variance for repeated measures (ANOVA) and Sheffe- $F$ post-hoc test (Statview SE Graphics ${ }^{\mathrm{TM}}$ ). The measurements at baseline and at the end of the experiment were compared using paired $t$-tests. Pearson correlation coefficients were calculated to determine the relationship between selected variables. Level of significance was set at $P<0.05$.

\section{RESULTS}

During the entire experiment BW decreased by $4.4 \pm 0.7 \mathrm{~kg}$ and $\mathrm{BM} 1$ by $1.4 \mathrm{~kg} / \mathrm{m}^{2}(P$ $<0.001)$ in the whole group. Wailst and hip circumferences were reduced both by 4 $\mathrm{cm}(P<0.001)$. The WHR did not change during the experiment. Body fat percentage determined in 15 subjects decreased by $3.8 \%(P<0.01)$.

Blood pressure also decreased during the experiment (diastolic, $-17 \mathrm{mmHg}$; systolic, $-10 \mathrm{mmHg} ; P<0.001)$. No change was found in blood glucose concentration.

Scores on the Herman Polivy questionnaire (frequency of dieting) and scores for factor 2 (disinhibition) and 3 (hunger) of the TFEQ were similar for all treatments. For factor 1 (restrained eating) significantly increased scores were found during each of the intervention periods compared to baseline $(P<0.01)$.

BW loss during 2 weeks treatment, irrespective of the order of treatment, was $2.1 \pm$ $0.3 \mathrm{~kg}, 1.6 \pm 0.2 \mathrm{~kg}$ and $1.7 \pm 0.3 \mathrm{~kg}$ during SSM+, SSM and SM, respectively, with no significant differences between treatments. During the first intervention period BW loss was greater than during to the second and third intervention periods (2.6 $\pm 0.2 \mathrm{~kg}, 1.7 \pm 0.2 \mathrm{~kg}$ and $1.1 \pm 0.2 \mathrm{~kg}$, respectively; $P<0.001)$. SSM+ and SSM treatments resulted in an acute effect on BW. In SSM+ and SSM, BW loss was greater during the first compared to the third intervention period (SSM+, $P<0.01$; SSM, $P<0.05$ ). Treatment SM showed no difference in BW loss with respect to the different sequences.

The SM - SSM+ - SSM intervention sequence was more effective in reducing BW than SSM+ - SSM - SM $(P<0.05)$. From the start to the end of intervention, the subjects lost $5.6 \pm 1.0 \mathrm{~kg}$ in the SM - SSM+ - SSM sequence, $4.6 \pm 1.0 \mathrm{~kg}$ in the SSM - SM - SSM+ sequence and $2.5 \pm 0.6 \mathrm{~kg}$ in the SSM+ - SSM - SM sequence.

Reported energy intake was significantly lower during the intervention periods compared to baseline (baseline, $10.2 \pm 0.4 \mathrm{MJ} / \mathrm{d}$; SSM $+6.7 \pm 0.3 \mathrm{MJ} / \mathrm{d}$; SSM, $6.9 \pm$ 
$0.2 \mathrm{MJ} / \mathrm{d} ; \mathrm{SM}, 6.9 \pm 0.2 \mathrm{MJ} / \mathrm{d} ; P<0.001)$ and not different between treatments. The level of underrecording determined in 15 subjects was similar for all trials (baseline, $21 \%$, range: $-7-58 \%$; SSM $+22 \%$, range: $-27-60 \%$; SSM, $18 \%$, range: $35 \%-55 \%$; SM, $24 \%$, range: $-26-75 \%$ ). The reported energy intake was corrected for the level of underreporting (baseline, $12.3 \mathrm{MJ} / \mathrm{d} ; \mathrm{SSM}+, 8.2 \mathrm{MJ} / \mathrm{d} ; \mathrm{SSM}, 8.1 \mathrm{MJ} / \mathrm{d}$; SM; $8.6 \mathrm{MJ} / \mathrm{d}$ ). Energy deficil was therefore 4.2, 4.2 and $3.8 \mathrm{MJ} / \mathrm{d}$ for SSM+, SSM and SM. respectively. With an energy cost of weight loss of $30 \mathrm{MJ} / \mathrm{d}$, this would result in a total expected body weight loss of $5.9 \mathrm{~kg}$ during the three treatments combined. This is in line with the body weight loss found in this study $(5.4 \mathrm{~kg})$. Reduced energy intake resulted from reduction in fat, carbohydrate and alcohol intake (Figure 2).

The following results on food intake are derived from the records in the food intake diaries. Fat, carbohydrate and alcohol intake was similar between the intervention periods. Dietary fiber intake was reduced in the SSM treatment $(P<0.001)$. Energy intake from the low-energy meals was higher during SSM+ and SSM compared to $\mathrm{SM}(2.5 \pm 0.1 \mathrm{MJ}, 2.5 \pm 0.1 \mathrm{MJ}$ and $2.1 \pm 0.1 \mathrm{MJ}$, respectively; $P<0.001)$. Energy intake from the free dinner was $3.4 \pm 0.2 \mathrm{MJ}, 3.3 \pm 0.2 \mathrm{MJ}$ and $3.1 \pm 0.2 \mathrm{MJ}$ during SSM+, SSM and SM, respectively (NS). Energy intake from the snacks was lower in the SSM+treatment $(0.8 \pm 0.2 \mathrm{MJ})$ compared to SM $\left(1.6 \pm 0.3 \mathrm{MJ} ; P^{\circ}<0.01\right)$ and was $1.0 \pm 0.2 \mathrm{MJ}$ during SSM. Food intake during each intervention was decreased during breakfast, in the morning, during lunch, and in the evening compared to baseline $(P<0.001)$, but was similar during dinner $(P=0.61)$ (Figure 3 ).

Energy intake during the dinner, during which the questionnaires on hunger, satiety and pleasantness of taste were completed, was similar for all situations (baseline,

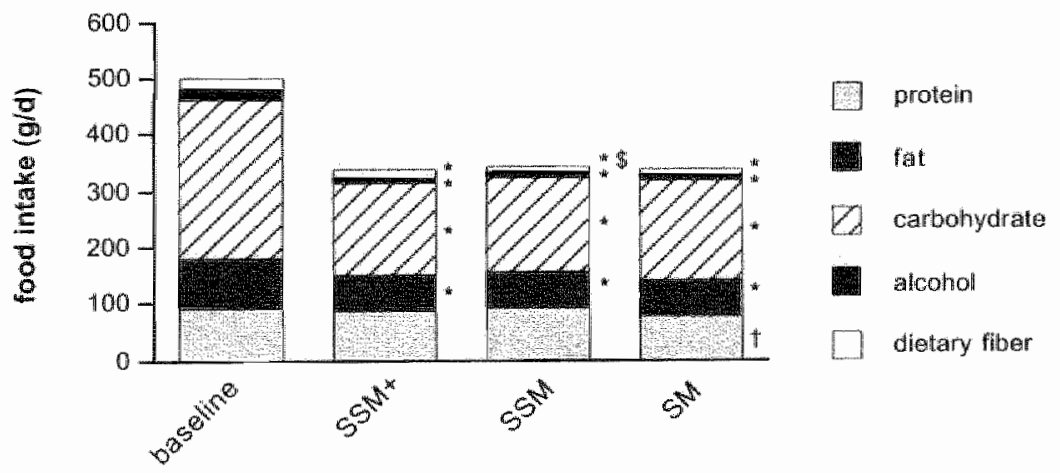

Figure 2 Daily food intake ( $g / d$ ) as recorded using a food intake diary

Values are mean. SSM+ = semisolid meal with guar gum; SSM = semisolid meal: $S M=$ solid meal. Statistical sigmificance was determined by an analysis of variance for repeated measures (ANOVA). " SSMH, SSM and SM significantly different from baseline $(P<0.001) ;$ SSM significantly different from SSM+ and SM $(P<0.001) ;{ }^{\dagger} \mathrm{SM}$ significantly different from baseline and SSM $(P<0.01)$. 


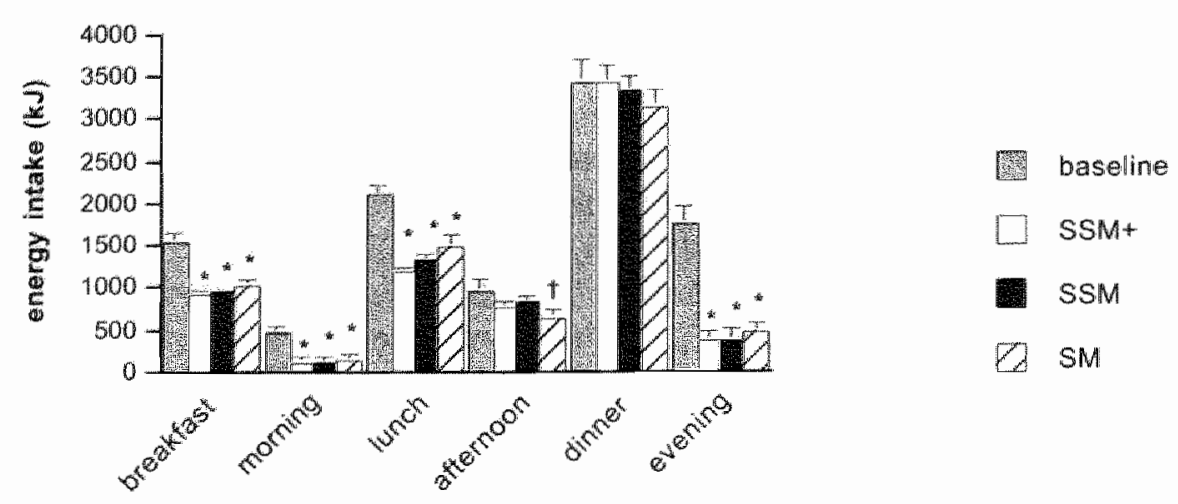

Figure 3 Food intake ( $k J)$ at different time points during the day

Values are mean \pm SE. SSM+ = semisolid meal with guar gum; SSM = semisolid meal; $S M=$ solid meal. Statistical significance was determined by an analysis of variance for repeated measures (ANOVA). "SSM+, SSM and SM significantly different from baseline $(P<0.01)$. ${ }^{\top} \mathrm{SM}$ significantly different from baseline

$3.1 \pm 0.2 \mathrm{MJ} ; \mathrm{SSM}+3.4 \pm 0.3 \mathrm{MJ} ; \mathrm{SSM}_{\|} 4.0 \pm 0.5 \mathrm{MJ} ; \mathrm{SM}, 3.1 \pm 0.3 \mathrm{M}$ ). The rate of change in satiety over the meal was smaller during SM compared to baseline $(P<$ 0.05 ). The rate of change in hunger and pleasantness of taste was similar for all situations (Table 2).

As they were instructed, the subjects consumed more meals and fewer snacks during the intervention periods compared to baseline $(P<0.001)$. When considering the total number of meals plus snacks (eating moments), subjects ate more frequently during baseline compared to the intervention $(P<0.001)$. In treatment SM, the subjects consumed fewer meals compared to SSM+ and SSM ( $P$ $<0.001$ ), but in total they had the same number of eating moments as in the treatments SSM+ and SSM because they compensated with snacks.

The number of reported meals, snacks and eating moments during baseline, but not during the intervention, was positively correlated with BMI at baseline $(r=0.39, r$ $=0.47$ and $r=0.51$, respectively; $P<0.05$ ).

Compliance to the dietary instructions during treatment SM was less good compared to SSM+ and SSM $(P<0.001)$, but compliance was not related to body weight changes (SSM+, $r=0.32 ; S S M, r=0.33 ; S M, r=0.22 ; P>0.05$ ).

The ratings on the questions throughout the day, expressed as area under the curve (AUC), corrected for the subject's minimum score, are shown in Table 3. The AUC of hunger was higher during treatments SSM and SM compared to baseline. but not during treatment SSM+. Appetite, the estimation of how much one could eat and desire to eat (also expressed as AUC) during SSM treatment were higher compared to baseline; this was not the case during treatments SSM\# and SM. However, the differences from baseline in AUC of the appetite-related parameters. 
Table 2 Changes of the following $100 \mathrm{~mm}$ visual analogue scale ratings over the self-selected dinner $(\mathrm{mm} / \mathrm{min})$

\begin{tabular}{lccccc}
\hline & baseline & SSM & \multicolumn{1}{c}{ SSM } & \multicolumn{1}{c}{ SM } & P \\
\hline Change in satiety & $4.7 \pm 0.3$ & $3.9 \pm 0.4$ & $3.6 \pm 0.4$ & $3.6 \pm 0.4^{*}$ & $<0.05$ \\
Change in hunger & $-3.3 \pm 0.4$ & $-3.5 \pm 0.4$ & $-3.2 \pm 0.3$ & $-2.5 \pm 0.3$ & NS \\
Change in pleasantmess of taste & $-1.7 \pm 0.5$ & $-1.2 \pm 0.5$ & $-1.3 \pm 0.3$ & $-1.1 \pm 0.5$ & $\mathrm{NS}$ \\
\hline
\end{tabular}

Values are mearn \pm SE SSM+ = semisolid meal with guar gum; SSM = semisolid meal: SM = sollid meal. Slatistical significance was determined by an analysis of variance for repeated measures (ANOVA): : Significantly different from baseline; NS = no significance.

with the SSM+ treatment were not different from the differences from baseline following SSM or SM. The AUC of fullness, satiety and thirst was not different between the four situations.

Diets were well tolerated. Intervention SSM+ resulted in a slightly higher incidence of nausea compared to SSM and SM (SSM $4,0.3 \pm 0.1 ; \mathrm{SSM}_{1} 0.0 \pm 0.0 ; \mathrm{SM}_{1} 0.0 \pm$ $0.0 ; P<0.05)$ and flatulence compared to SM (SSM+, $1.1 \pm 0.2 ; S S M, 0.7 \pm 0.2 ;$ SM; $0.3 \pm 0.1 ; P<0.05)$. However, values for complaints remained low.

The hedonic value of the semisolid meal was $3.8 \pm 0.1$ on a $0-5$ scale. Userfriendliness of the semisolid meal was $1.9 \pm 0.1$ on a $0-2$ scale, while userfriendliness of the solid meal was $1.2 \pm 0.1(P<0.001)$. SSM+ was rated as the most preferred treatment (by 18 out of 28 subjects) over SSM and SM (by 10 and 6 out of 28 subjects, respectively).

Table 3 Area under the curve from the following $100 \mathrm{~mm}$ visual analogue scale ratings over 16 $h$, that is before and after breakfast, lunch, four $0^{\circ}$ clock snack and dinner, in the morning between 10 en $11 \mathrm{~h}$ and in the evening belween 22 and $23 \mathrm{~h}(\mathrm{~mm} \cdot \mathrm{h}$ )

\begin{tabular}{lccccc}
\hline & baseline & SSM+ & SSM & SM & $P$ \\
\hline Hunger & $470 \pm 30$ & $579 \pm 34$ & $663 \pm 43^{*}$ & $603 \pm 36^{*}$ & $<0.001$ \\
Appetite & $512 \pm 32$ & $588 \pm 35$ & $672 \pm 42^{*}$ & $615 \pm 37$ & $<0.01$ \\
Desire to eat & $517 \pm 31$ & $584 \pm 38$ & $707 \pm 41^{*}$ & $627 \pm 37$ & $<0.01$ \\
Fullness & $520 \pm 38$ & $595 \pm 36$ & $537 \pm 42$ & $553 \pm 38$ & NS \\
Saltiety & $588 \pm 32$ & $606 \pm 34$ & $518 \pm 35$ & $591 \pm 30$ & NS \\
Thirst & $492 \pm 31$ & $576 \pm 41$ & $579 \pm 44$ & $564 \pm 40$ & NS \\
Estimation of how much one & $540 \pm 41$ & $590 \pm 43$ & $682 \pm 48^{*}$ & $599 \pm 44$ & $<0.05$ \\
Could eat & & & & & \\
\hline
\end{tabular}

Values are mean $\pm S E$. SSM+ = semisolid meal with gual gum; SSM = semisolid meal; $S M=$ solid meal. Statistical significance was determined by an analysis of variance for repeated measures (ANOVA). "Significantly different from baseline; NS = no significance. 


\section{DISCUSSION}

All the three treatments were effective with respect to BW loss and $E \|$ reduction compared to baseline. Despite a reduced El during the treatments compared to baseline, satiety, fullness and thirst had not changed. Nevertheless appetiterelated parameters (hunger, appetite, desire to eat and estimation of how much one could eat) were increased with the semisolid meal alone and hunger with the solid meal. In contrast, addition of $\mathrm{GG}$ to the semisolid meal prevented an increase in appetite, hunger and desire to eat, although the differences between treatments were not statistically significant. Also, with the SSM+ treatment snacking was significantly lower than with the SM treatment, indicating a better sustained satiety in between meals. Therefore addition of $G G$ to the semisolid meal showed a rather modest effect on sustaining satiety or prevention of increase of hunger.

Modest weight loss of $5-10 \%$, which has been shown to contribute to reduction of mortality and morbidity in obese people, has been considered a realistic goal in dietary treatments $(41,12)$. With supplementation of $\mathrm{GG}(8,30)$ or other dietary fiber (32), some positive results have been found in short-term studies. It has been proposed that soluble viscous fiber, such GG may influence satiety by decreasing the rate of gastric emptying and the small intestinal transit time $(3,17,50)$. However, some recent studies also found opposite results $(24,27,28,35)$. A decreased rate of gastric emplying and/or intestinal transit may delay glucose absorption (4). It might be argued that the potential effect of $G G$ on glucose absorption and on the insulinaemic response may be less pronounced when a low-energy diet is consumed. However, it was even more interesting to assess whether such a mechanism would be effective with a low-energy diet. In this respect, in a separate study we found that addition of the same modified $G G$ to a low-energy semisolid meal resulted in a more moderate change in blood glucose and insulin after meal ingestion (21). This may result in a prolonged feeling of satiety (25).

Evidence for long-term weight maintenance with dietary fiber has been presented by a study of Hamilton and Anderson (16). In some studies lasting less than a year, GG supplementation was shown to be beneficial with respect to BW $(23,44)$. However, in studies lasting more than one year, onlly Uusitupa ef al, (45) found a slight reduction in BW after GG supplementation, while other studies did not find a beneficial effect of GG supplementation on weight control $(31,39)$.

The El reduction observed in different short-term studies may be an acute effect and may disappear when fiber is supplemented for a longer period. This may be due to habituation to the fiber $(10,31)$. Several studies examined the effect of fiber supplementation next to an energy restricted diet on weight loss. Additional fiber intake next to a low-energy diet has been shown to be effective in several studies $(33,40)$ even during long-term treatment (36), but not in all $(34)$. The prevention of increased hunger ratings when fiber is supplemented may improve compliance to an energy-restricted diet $(2,36,40)$ and subsequently increase the chances for successful weight loss or prevention of weight gain. 
In the present study, no significant difference in BW loss and El was found between treatments. However, irrespective of the type of diet, the first treatment was more effective on BW loss compared to the second and third treatments. This could be associated with the fact that, at the beginning of the experiment, the subjects were more motivated. A second possible reason would be that subjects already lost some weight during the first intervention and therefore further weight loss during the following treatments was more difficult to achieve. The SM - SSMt - SSM sequence, that is the sequence that started with the solid meal, was more effective on BW loss compared to the SSM+ - SSM - SM sequence, that is the sequence that ended with the solid meal. Compliance to the treatment with the solid meal was less good compared to compliance to the treatments with the semisolid meals. Subjects had much more difficulty to follow the treatment with the solid meal as it was prescribed compared to the semisolid meal treatments. Furthermore, at the end of the experiment, the subjects indicated that the ready-to-eat semisolid meal was much more easily to use compared to the solid meals that they had to prepare themselves. Therefore, a low-energy self-prepared solid meal will probably only be effective when used at the beginning of a treatment. Thus, for longer-term treatments with a low-energy meal, an alternating use of a ready-to eat semisolid meal with a self-prepared solid meal might be more effective.

Daily mean recorded El as well as fat, carbohydrate and alcohol intake were not different between treatments, but they were reduced compared to baseline. Dietary fiber intake was reduced below the recommended level of $10 \mathrm{~g} / 1000 \mathrm{kcal}$ when the semisolid meal was used allone. This was not the case for the semisolid meal with GG and the solid meal. During dinner when the subjects were allowed to eat what they liked, El was similar for all four situations. This indicates that the lowenergy diets were sufficient, because the subjects did not compensate for the lower El during the day by eating more during dinner. The number of meals increased, which was a treatment condition, but the number of snacks decreased during intervention. Using solid meals, the subjects consumed fewer meals than using semisolid meals. This indicated a poorer compliance to the prescribed regimen. However, eating more snacks compensated for the reduced meal frequency.

A higher degree of underrecording was expected at baseline because, compared to the treatments when the subjects consumed three prescribed meals and only one meal was free, the subjects were free to eat whatever they liked. Because underrecording of food intake was similar in all situations, it was possible to use the data from the food intake diary in order to compare energy and macronutrient intake between treatments. Results from food intake diaries have been shown to be unreliable because of underrecording, especially in overweight/obese subjects. Underrecording in the present study (18-24\%) was higher compared to the results of Goris et al. (15) who found a $12 \%$ underrecording in obese men (BMI, 34.1 $\mathrm{kg} / \mathrm{m}^{2}$ ) and no underrecording in highly motivated female dieticians with normal weight (BMI, $\left.22.1 \mathrm{~kg} / \mathrm{m}^{2}\right)(13)$. 
Scores on cognitive restrained eating increased during the intervention periods, indicating that dieting had an effect on this aspect of eating behavior (48). Because the subjects became more restrained, they were able to complete the treatment. However, the subjects were still classified as unrestrained (score $<9$ ).

With respect to the effect of GG addition to a low-energy semisolid meal we conclude that the semisolid meal with or without GG and the solid meal were well tolerated and were effective on BW loss without affecting satiety negatively. However, in the case of the semisolid meal without $G G$ and the solid meal, appetite-related parameters were increased, which was not the case for the semisolid meal with GG treatment, when these parameters remained at baseline level. Still, there was no significant difference between the appetite parameters of SSM+ and SSM or SM. The semisolid meal with GG was found to be relatively more advantageous because it allowed a reduced El together with the usual level of appetite scores and this treatment showed the higher preference, which observations contribute to possible compliance to such a diet on the longer term.

This type of treatment with three intervention periods of 2 weeks and washout periods in between has been shown to be relatively effective with respect to $\mathrm{El}$ reduction and BW loss. During the treatments, El was 3.3-3.5 MJ lower compared to baseline, that is $142.8 \mathrm{MJ}$ over $3 \times 14$ days. For the whole group, Ell reduction during treatments resulted in a BW loss of $4.4 \mathrm{~kg}$ for the entire intervention period. This BW loss was mainly attributed to a loss in body fat. Allison et al. (1) observed that decreased mortality rate is likelly to be dependent on the degree to which weight is lost as fat and not on the degree of weight loss per se. Assuming that an El deficit of $30 \mathrm{MJ}$ results in a BW loss of $1 \mathrm{~kg}(47)$, an energy deficit of $132 \mathrm{MJ}$ is needed to lose $4.4 \mathrm{~kg}$. In other words, the observed energy deficit over $3 \times 1.4$ days $(142.8 \mathrm{MJ})$ was in line with the expected energy intake reduction $(132 \mathrm{MJ})$ and related to BW loss. Given the relatively short periods of effort during treatments and the washout periods, in which the subjects were not undergoing any restriction, this indicates that an intermittent treatment might be successful, although the success changes from an emphasis on body weight loss into prevention of body weight gain.

With respect to the type of treatment we conclude that the used intermittent treatment may be advantageous for a weight reduction or weight maintenance program. The main reason for this is prevention of habituation by means of the washout periods (31) and a more likely compliance because of the shorter periods of time.

\section{ACKNOWLEDGEMENTS}

This work was supported by Novartis Consumer Health Ltd, Nyon, Switzerland. 


\section{REFERENCES}

1. Alison DB, Zannolli $R$, Faith MS, Heo M, Pietrobelli A, Van Itallie TB, Pi-Sunyer FX, Heymsfield SB. Weight loss increases and fat loss decreases all-cause mortality rate: results from two independent cohort studies. Int J Obes 1999; 23: 603-611.

2. Astrup A, Wrist $E$, Quaade $F$. Dietary fiber added to very low calorie diet reduces hunger and alleviates consipation. Int $J$ Obes $1990 ; 14$ : 105-112.

3. Blackburn NA, Holgate AM, Read NN. Does guar gum improve post-prandial hyperglycernia in humans by reducing small intestinal contact area? Br J Nutr 1984; 52: 197-204.

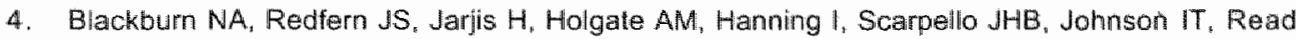
NW. The mechanism of action of guar gum in improving glucose tolerance in man. Clin Sci 1984: $66: 329-336$.

5. Blundell JE, Burley $V J$. Satiation, satiety and the action of fibre on food intake. wit $J$ Obes 1987: 11 (Suppl): 9-25.

6. Burley $V J$, Blundell JE. Action of dietary fiber on the satiety cascade. In: Kritchevsky $D$, Bonfield C. Anderson JW (eds). Dietary fiber: chemistry, physiology, and health offects. Plenum Press: New York, 1990, pp 227-246.

7. Doucet $E$, Imbeault $P$, St-Pierre $S$, Alméras N, Mauriège P, Richard D, Tremblay A. Appetite after weight loss by energy restriction and a low-fat diet-exercise follow-up. Int $J$ Obes 2000; 24: $906-914$.

8. Evans E, Miller DS. Bulking agents in the treatment of obesity. Nutr Metab 1975; 18:199-203.

9. Fjeld $\mathrm{CR}$, Brown $\mathrm{KH}$, Schoeller DA. Validation of the deuterium oxide method for measuring average daily milk intake. Am J Chin Nutr 1988; 48: 671-679.

10. Fllorent C, Flourie B, Leblond A, Rautureau M, Bernier J-J, Rambaud J-C. Influence of chronic lactulose ingestion on the colonic metabolism of lactulose in man (and in vivo study). $J$ Clin Invest $1985 ; 75: 608-613$.

11. Gaal LF van, Wauters MA, Leeuw IH de. The beneficial effects of modtest weight loss on cardiovascular risk factors. Int J Obes 1997; 21 (Suppl): $\$ 5-\$ 9$.

12. Goldstein DJ. Beneficial effects of modest weight loss. Int J Obes 1992; 16: 397-415.

13. Goris AHC. Westerterp KR. Underreporting of habitual food intake is explained by undereating in highly motivated lean women. J'Nutr 1999; 129: 878-882.

14. Goris AHC. Westerterp KR. Improved reporting of habitual food intake after confrontation with earlier results on food reporting. Br J Nutr 2000; 83: 363-369.

15. Goris AHC. Westerterp-Plantenga MS, Westerterp KR. Undereating and underrecording of habitual food intake in obese men: selective underreporting of fat intake. Am I Clin Nutr $2000: 71: 130-134$

16. Hamilton CC, Anderson JW. Fiber and weight maintenence. I Fla Med Assoc 1992; 79: 379381.

17. Harju $E$. Increases in meal viscosity caused by addition of guar gum decrease postprandial activity and rate of emptying of gastric contents in healthy subjects. Panminerva Mad 1985; 27: $125-128$.

18. Herman CP. Polivy J. Restrained eating. In: Stunkard AJ (ed). Obesily. W.B. Saunders: Philadelphia, 1980, pp 208-225.

19. Hubert $H B$, Feinleib M, McNamara PM, Castelli WP. Obesity as an independent risk factor for cardiovascular disease: a 26-year follow-up of participants in the Framingham Heart Sludy. Circulation 1983; 67: 968-977.

20. Hylander $B$, Rössner $S$. Effects of dietary fiber intake before meals on weight loss and hunger in a weight-reducing club. Acta Med Scand 1983; 213: 217-220.

21. Kovacs EMR, Westerterp-Plantenga MS, Saris WHM, Melanson KJ, Goossens II, Geurten P. Brouns $F$. The effect of guar gum addition to a semisolid meal on appetite related to blood glucose, in dieting men. Eur I Clin Nutr 2002; 56: 771-778.

22. Kromhout D. Body weight, diet, and serum cholesterol in 871 middle-aged men during 10 years of follow-up (the Zutphen Study). Am I Clin Nutr 1983; 38: 591-598. 
23. Krokiewski M. Effect of guar gum on body weigh, hunger ratings and metabolism in abese subiects. Brit it Mutr 1984; $52: 97-105$.

24. Lavin JH, Read NW. The effect on hunger and satiety of slowing the absorption of glucose: relationship with gastric emptying and postprandial blood glucose and insulin responses. Appotite 1995: 25 : 89.95 .

25. Leeds AR. Dielary fiber: mechanism of action. Int J Obes 1987; 11 (Suppl): 3-7.

26. Marken Lichtenbelt WD van, Westerterp KR, Wouters L. Deuterium dilution as a method for determining total body water effect of test protocol and sampling time. Br J Mutr 1994; 72 : 491497 .

27. Meier R, Beglinger $C$, Schneider $H$, Rowedder $A$, Gyr K. Efect of a liquid dief with and without soluble fiber supplemertation on intestinal transit and cholecystokinin release in volunteers. $J$ Parent Ent Nutr 1993: 17:231-235.

28. Niedwenhoven MA van, Kovacs EMR, Marin A-M, Brummer R-JM, Westerterp-Plantenga MS, Brouns $F$. The effect of different dosages of guar gum on the rate of gastric emptying and intestinal transit of a consumed semisolid meal. J Am Colf Nutr 2001: 20: 87-91.

29. Noppa $\mathrm{H}$. Body weight change in relation to incidence of ischemic heart disease and change in risk factors for ischemic heart disease. Am J Epidemio 1980; 11: 693-704.

30. Pasman WJ. Wauters $M$. Westerterp-Plantenga MS, Saris WHM. Effect of ane week of ribre supplementition on hunger and satiety or energy intake. Appetite 1997; 29:77-87.

3*1. Pasman WJ, Westerterp-Plantenga MS, Muls E. Vansant G, Ree J van. Saris WHM. The effectiveness of long-term fitber supplementation on weight maintenance in weight-reduced women. Int $J$ Obes 1997; 21: $548-555$.

32. Porikos K, Hagamen $S$. Is fiber satiating? Effects of a high fuber preload on subsequent foad intake of normal-weight and obese young men. Appetite 1986; 7: $153-162$.

33. Rössner S, Zweigbergk D von, Ohlin A, Ryttig K. Weighth reduction with dietary fibre supplemenis. Results of two double-blind randomized studies. Acta Med Scand 1987; 222: 83-88.

34. Rössner, Andersson I-L. Ryttig K. Effects of a dietary fibre supplement to a weight reduction programme on blood pressure. A randomized, double-blind, placebo-controlled study. Acta Med Scand 1988; 223: 353-357.

35. Rydning A, Berstad A, Berstad T, Hertzenberg L. The effect of guar gum and fibermenriched wheiat bran on gastric emplying of a semisolid meal in healthy subjects. Sicand I Gastroenterol 1985; 20:330-334.

36. Rytlig KR, Tellines G Hagh L, Bøe E, Fagerthun H. A dietary fibre supplement and weight maintenance after weight reduction: a randomized, double-blind, placebo-controlled longterin trial. Iot J Obes 1989; 13: 165-171.

37. Schoeller DA, Santen E v, Peterson DW, Diez W, Jaspan J, Klein PD. Total body water measurement in thumans with $\mathrm{O}$ and "H labelled water. Am J Clin Nutr 1980; 33: 2686-2693.

38. Seldell $1 \mathrm{C}$. Obesity in Europe. Obes Res 1995; 3 (Suppl): $2495-259 \mathrm{~s}$.

39. Simons LA, Gayst $S$, Balasubramanian $S$ ii Ruys J. Long-tem treatment of hypercholesterolaemia with a new palatable formulation of guar gum. Atherosclerosis 1982: 45: $101-108$.

40. Solum TT, Rytig KR, Solum E, Larsen S. The influence of high-fibre dilet on body weight, serum lipids and blood pressure in slightly overweight persons. A randomized double-blind, placebo-controlled investigation with diet and fibre tablets (Dumovital). Int J Obes 1987; 11 (Suppl): $67-71$.

41. Stevens J. Does dietary fiber affect food intake and body weight? A Am Dief Assoc 1988; 88: $939-942,945$.

42. Stichting Nederlands Voedingsstoffenbestand. Nevo Tabel. Den Haag. Voorlichtingsbureau voor da voeding, 1996.

43. Stunkard $A J$. Messick $S$. The three-factor eating questionnaire to measure dietairy restraint, disinhibition, and hunger. J Psychosom Res 1985; 29:71.83.

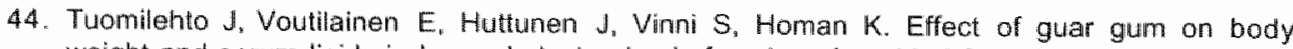
weight and serum lipids in hypercholesterolemic females. Acta Med Scand 1980; 208; 45-48. 
45. Uusitupa $M$, Siitonen $O$, Savolainen $K$, Silvas $M$, Penttilä 1 , Parviainen M. Metabolic and nutritional effects of long-term use of guar gum in the treatment of non-insulin dependent diabetes of poor metabolic control. I Clin Nutr 1989; 49: 345m351.

46. Westerterp KR, Kayser $B$, Brouns F, Herry JP, Saris WHM. Energy expenditure climbing Mit. Everest. J Appl Physiol 1992; 73: 1815-1819.

47. Westerterp, KR, Donkers JHHLM, Fredrix EWHM. Bioekhoudt P. Energy intake, physical activity and body weight: a simulation model. J Nutr 1995, 73: 337-347.

48. Westerterp-Plantenga MS, Kempen KPG, Saris WHM. Determinants of weight maintenance in women after diet-induced weight reduction. Int $J$ Obes 1998; 22: 1-6.

49. Westerterp-Plantenga MS, Rolland V. Wilson SAJ, Westerterp, KR. Satiely related to $24 \mathrm{~h}$ diet-induced thermogenesis during high protein/carbohydrate ws high fat diets measured in a respiration chamber. Eur J Clin Nutr 1999; 53: 1-8.

50. Wilmshurst $P$, Crawley JCW. The measurement of gastric transit time in obese subjects using ${ }^{24} \mathrm{Na}$ and the effects of energy content and guar gum on gastric emplying and satiety. $\mathrm{Br} J$ Nutr 1980; $44: 1-6$. 


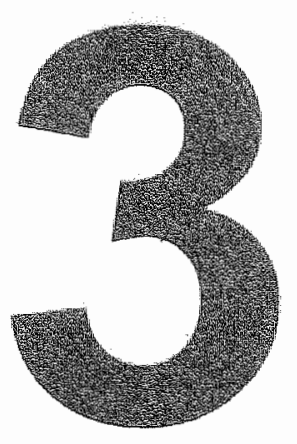

\section{The effect of guar gum addition to a semisolid meal on appetite related to blood glucose, in dieting men}

Kovacs EMR, Westerterp-Plantenga MS, Saris WHM, Melanson KJ, Goossens I, Geurten P. Brouns F 


\section{ABSTRACT}

Objective: To investigate whether addition of modified guar gum (GG) to a lowenergy semisolid meal might be effective on appetite by modifying the response of blood glucose and other blood parameters.

Design: Three intervention periods of 2 weeks each "separated by washoul periods of 4 weeks. Randomized and cross-over design.

Subjects: Fifteen overweight male subjects (mean \pm SD; age, $44 \pm 9$ y; body mass index, $28.6 \pm 1.8 \mathrm{~kg} / \mathrm{m}^{2}$ ).

Intervention: Subjects consumed a low-energy diet divided over three times a day, consisting of a semisolid meall with (SSM+) or without (SSM) addition of $2.5 \mathrm{~g} \mathrm{GG}$, or a solid meal (SM) with the same energy content $(947 \mathrm{~kJ})$ and macionutrient composition, plus a dinner of the subject's own choice. At the end of each intervention, time and number of meal initiations, dynamics of blood glucose and other blood parameters, and appetite ratings such as hunger and satiety were determined in a time-blinded situation.

Results: The changes in blood glucose from meal initiation to blood glucose peak and from peak to nadir were smaller with SSM+ and SM compared to SSM. Satiety before the third meal was higher with SSM+ and SM Compared to SSM $(P<0.01)$. Meal pattern, general appetite and total energy intake were similar for all treatments.

Conclusions: We conclude that, similar to SM, SSM+ resulted in a more moderate change in blood glucose compared to SSM and positively affected satiety before the third meal, while general appetite, total energy intake and meal pattern did not differ.

Keywords: guar gum, blood glucose, intermeal interval, appetite, satiety, food intake regulation, meal pattern 


\section{INTRODUCTION}

In the treatment of obesity, long-term reduction of energy intake is one of the cornerstones of therapy. Low-energy diets have been shown to be successful in the reduction of body weight in the short term, but in the long term decreased compliance and habituation result in unsuccessful weight loss or in weight regain (6). Reduced hunger and increased satiety feelings may improve compliance to an energy-restricted diet (1). Therefore, identification of substances that improve or sustain satiety during energy restriction is needed for the treatment of obesity. The effects of dietary fibers on satiety, energly intake and/or body weight have been extensively investigated $(4,5,31)$. Dietary fibers such as gual gum (GG) were found to effectively increase fullness and satiety resulting in reduced energy intake $(7,24)$, e.g. by decreasing the rate of gastric emptying and small intestinal transit $(2,8,35)$. However, other more recent studies found no effects of GG supplementation on gastric emptying and/or intestinal transit rate $(14,18,27)$. It has also been observed that GG ingestion may modify glucose absorption (3) resulting in a prolonged feeling of satiety (15). Controversial findings have been shown on the effects of different types of dietary fibers along with an energy-restricted diet on energy intake and/or body weight loss $(1,11,25,26,28,30)$. To our knowledge, only a few studies have investigated the effects of GG supplementation during energy restriction on energy intake, hunger and satiety $(9,24)$. Pasman et al. (24) found a hungerreducing effect of GG during the energy-restricted condition suggesting that GG might be useful in the treatment of obesity, by increasing the compliance to a lowenergy diet. However, Heini et al. (9) did not confirm this effect of GG.

In a larger study, we investigated the effects of $G G$ addition to a low-energy semisolid meal on appetite and body weight loss during a 2 -week intervention. It was shown that GG addition to a low-energy semisolid meal prevented an

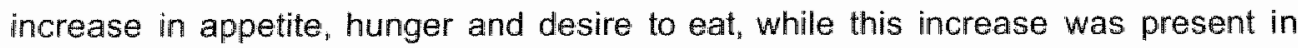
the unsupplemented semisolid meal and in a low-energy solid meal (13).

The aim of the present study was to investigate whether this satiating effect of $G G$ addition to a low-energy semisolid meal is mediated by modifying the response of blood glucose and/or other blood parameters, also in comparison to the effects of a similar but solid meal. We hypothesized that addition of $G G$ to the semisolid meal would result in a more moderate change in blood glucose and insulin, similar to the solid meal, and that this would affect appetite parameters.

\section{METHODS}

\section{Subjects}

Fifteen overweight malle subjects participated in this study. The subjects were recruited by advertisements in local newspapers, in which we asked for moderately obese male subjects who wanted to participate in a study on the effects of different 
low-energy diets on appetite, food intake, and body weight. The subjects were a subsample of the study mentioned before that is described in Kovacs et al. (13). Selection for this study with a more intensive protocol took place according to health criteria (fasting blood glucose $<6.2 \mathrm{mmol} / /$; blood pressure $<95 \mathrm{mmHg}$ (diastolic) and $<160 \mathrm{mmHg}$ (systolic), no diabetes, no cardiovascular diseases, and no medical treatment) and body weight criteria (body mass index: 25-30 $\mathrm{kg} / \mathrm{m}^{2}$ ). Baseline characteristics of the subjects are presented in Table 1 . The subjects did not use fiber supplements regularly before the study. The nature and risks of the experimental procedure were explained to the subjects, and all subjects gave their written informed consent. The study was approved by the Ethicall Committee of Maastricht University.

\section{Experimental design}

The experiment had a randomized and cross-over design. The experimental design consisted of three treatments, each consisting of a 2-week low-energy diet and a subsequent time-blinded test, separated by a 4-week washout period (Filgure 1) (13).

Daily during the intervention periods, the subjects consumed a low-energy meal for breakfast, lunch and as a four o'clock snack. In addition, for lunch, subjects were allowed to eat a fruit (e.g. apple, pear, orange). For dinner, the subjects ingested what they liked, but they were instructed to drink no more than one glass of alcoholic beverage or soft drink. Subjects were instructed to refrain from snacks in

Table 1 Subjects characteristics $(n=15)$ at baseline

\begin{tabular}{|c|c|c|}
\hline & mean $\pm \mathrm{SD}$ & range \\
\hline Age $(y)$ & $43.7 \pm 9.3$ & $29-56$ \\
\hline Height (m) & $1.77 \pm 0.06$ & $1.65-1.88$ \\
\hline Weight $(\mathrm{kg})$ & $89.2 \pm 7.7$ & $79.6-102.7$ \\
\hline Body mass index $\left(\mathrm{kg} / \mathrm{m}^{2}\right)$ & $28.6 \pm 1.8$ & $25.9-32.4$ \\
\hline Waist circumference (cm) & $98 \pm 6$ & $91-108$ \\
\hline Hip circumference (cm) & $104 \pm 5$ & $96-112$ \\
\hline Waist hip ratio & $0.94 \pm 0.04$ & $0.85-1.01$ \\
\hline Body fat $(\%)$ & $30.9 \pm 1.1$ & $23.3=38.5$ \\
\hline Systolic blood pressure $(\mathrm{mm} \mathrm{Hg})$ & $149 \pm 23$ & $116-206$ \\
\hline Diastolic blood pressure $(\mathrm{mm} \mathrm{Hg})$ & $91 \pm 11$ & $77-106$ \\
\hline Blood glucose (mmolli) & $5.4 \pm 0.2$ & $4.86-5.65$ \\
\hline F1 (cognintive restraint) & $4.0 \pm 2.8$ & $0-9$ \\
\hline F2 (disinhibition) & $3.9 \pm 1.4$ & $1-5$ \\
\hline F3 (hunger) & $3.5 \pm 2.1$ & 0.8 \\
\hline Herman Polivy restraint & $13.7 \pm 4.5$ & $6-20$ \\
\hline
\end{tabular}

F1-F3, factors 1-3 of the Three-Factor Eating Questionnaine. For Herman Polivy restraint (normal < 15) and $F+-F 3$ scores (nomal < 9 ) a higher value indicates more restraint, disinhibition, hunger. 


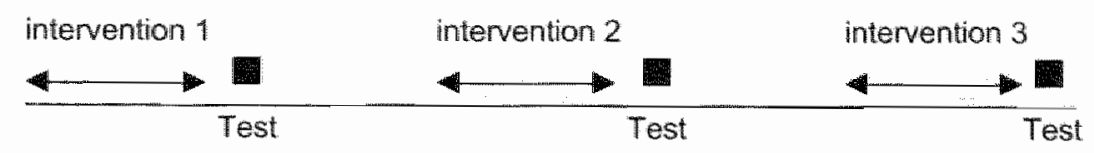

BW BW BW BW BW BW BW BW BW

Figure 1: Experimental design

$\mathrm{BW}=$ measurement of body weight.

between meals. During the day, the subjects were allowed to drink ad libitum water, coffee and tea (without sugar and milk). The low-energy meal consisted of a semisolid meal with (SSM+) or without (SSM) addition of $2.5 \mathrm{~g}$ of modified GG (Meyprofin ${ }^{(3)}$ M-175, Meyhall AG, Kreuzlingen. Switzerland, a highly purified dietary galactomannan fiber which forms a gel in approximately 5-7 min after adding water) or a solid meal (SM). A relatively low dosage of $2.5 \mathrm{~g}$ of $\mathrm{GG}$ was chosen because a higher dosage appeared not to affect gastrointestinal transit rate but to increase the viscosity of the semisolid meal, thus reducing palatability (23). The semisolid meal was a pudding (Milical Crème, Laboratoires Diététique et Santé, Revel, France, $47 \mathrm{~g}$ dissolved in $200 \mathrm{ml}$ water; energy, $947 \mathrm{~kJ}$; proteim, $17.9 \mathrm{~g}$; carbohydrate, $21.0 \mathrm{~g}$; fat, $7.9 \mathrm{~g}$ ). It was offered in three flavors (vanilla, chocolate, caramel) and the subjects were allowed to chose the meals in the flavors they preferred. The solid meal consisted of bread with cheese, meat or fish, salad or vegetables with dressing, and had the same energy content and macronutrient composition as the semisolid meal. The subjects prepared the solid meal themselves using our specific instructions. These instructions indicated the type of food and the amount that the subjects were allowed to consume. Compliance to the dietary instructions was controlled using food intake diaries (13).

At the end of each intervention, the subjects reported to the laboratory between 8:00 $h$ and 9:00 $h$, following a $10 \mathrm{~h}$ overnight fast, for a testing day (Figure 2). Testing started at different times between 8:00 h and $9: 30$ h that were randomly chosen for the purpose of time blinding. During the test, subjects were housed in a room and isolated from time and food cues to eliminate habitual (time-determined) meal patterns, enabling the investigators to observe meal responses to mainly physiological cues. Television, video, radio, watches and clocks were not in the room, and research staff refrained from making time-related statements. With exception of the investigators and the subject, no other people were allowed in the room. Subjects sat on a bed and were allowed to read or write during the test. They were not allowed to sleep. Subjects could verbally request a meal ( $=$ meal initiation) at any time. According to the randomly assigned treatment, subjects consumed, upon the first, second and third meal request (breakfast, lunch and snack, respectively), the same low-energy meal (SSM+, SSM or SM) they received during the preceding 2 weeks. The semisolid meal consisted of a portion of pudding and the solid meal consisted of white bread $(50 \mathrm{~g})$. low-fat margarine (7 g), ham $(50 \mathrm{~g})$, and tomato $(50 \mathrm{~g})$. 


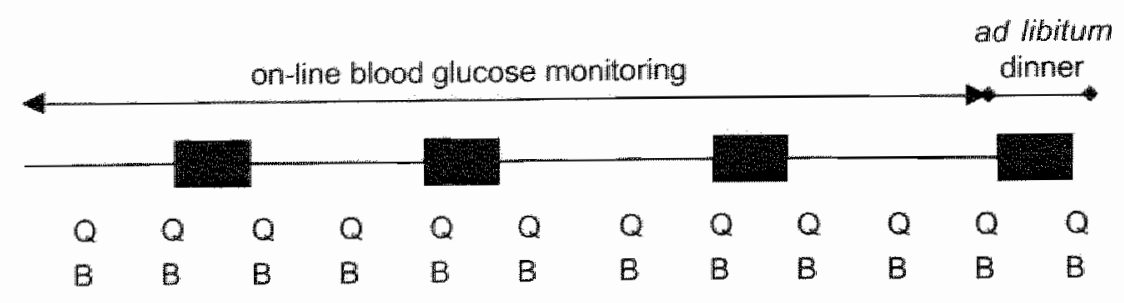

Figure 2: Design during testing

= meal initiation; $\mathrm{Q}=$ questionnaires on appetife ratings: $\mathrm{B}=$ blood sampling

During the day, water, coffee and tea (without sugar or milk) were offered ad libitum. Then, upon their fourth meal request (dinner), they ingested ad libitum a standardized meal (950 g pasta with tomato sauce; per $100 \mathrm{~g}$ : energy, $553 \mathrm{~kJ}$; protein, $5 \mathrm{~g}$; carbohydrate, $19.2 \mathrm{~g}$; fat, $3.9 \mathrm{~g}$ ). The dinner was offered in another room from the universal eating monitor $(12,23)$. The subjects were allowed to drink water during the meal. Testing was stopped at the subject's fourth meal request or at 18:00 $\mathrm{h}$ if the subject had not requested a third or fourth meal yet. If the subject requested the third meal after $17: 00 \mathrm{~h}$, testing was stopped at that time point. Upon completion of the testing, subjects were asked to estimate the clock time in order to verify that they were blinded to the time of the day.

\section{Anthropometry}

Body weight (BW) was measured during screening, at the beginning, after 1 week and at the end of each intervention period on a digital balance (Seca, model 707 , Hamburg, Germany; weighing accuracy of $0.1 \mathrm{~kg}$ ) with subjects in underwear, in a fasted state, and after voiding their bladder. Height was measured during screening using a wall-mounted stadiometer (Seca, model 220, Hamburg, Germany). The body mass index was calculated by $B W / h^{2} \mathrm{hht}^{2}\left(\mathrm{~kg} / \mathrm{m}^{2}\right)$.

The distribution of fat was determined during screening by measuring the waist and hip circumferences and calculation of the waist-hip ratio (WHR). The waist circumference was measured at the site of the smallest circumference between the rib cage and the ileac crest, with the subjects in standing position. The hip circumference was measured at the side of the largest circumference between the waist and the thighs. The WHR was calculated by dividing the waist circumference by the hip circumference.

Body composition was measured at baseline by using the deuterium $\left({ }^{2} \mathrm{H}_{2} \mathrm{O}\right)$ dilution technique (29). The dilution of the deuterium isotope is a measure for total body water (TBW) (17). Subjects were asked to collect a urine sample in the evening just before drinking a weighed amount of deuterium-enriched water. After ingestion of the deuterium-enriched water, no further fluid or food consumption was permitted. Ten hours later a second urine sample (second voiding) was collected. Deuterium concentration in the urine samples was measured using an isotope ratio mass spectrometer (Micromass Optima, Manchester, UK). TBW was 
obtained by dividing the measured deuterium dilution space by 1.04 (29). Fat free mass (FFM) was calculated by dividing the TBW by the hydration factor 0.73 . By subtracting FFM from BW, fat mass (FM) was obtained. FM expressed as a percentage of BW revealed body fat percentage.

\section{Attitude towards eating}

Attitude towards eating with respect to dietary restraint was determined during screening using a validated Dutch translation of the Three Factor Eating Questionnaire (TFEQ) $(32,34)$. Cognitive restrained and unrestrained eating behavior (factor 1), emotional eating and disinhibition (factor 2) and the subjective feelings of hunger (factor 3) were scored. Body weight concern and chronic dieting behavior were investigated with the Herman Polivy questionnaire (HP) (10).

\section{Blood parameters}

Systolic and diastolic blood pressures were measured during screening by an automatic blood pressure monitor (Omron $705 \mathrm{CP}$, Omron Healthcare $\mathrm{GmbH}$, Hamburg, Germany). A fasted blood sample $(2 \mathrm{ml})$ was obtained and mixed with EDTA to prevent clotting. Plasma was obtained by centrifugation and then stored at $-20^{\circ} \mathrm{C}$ until analysis of glucose by a hexokinase method (Cobas Bio, Roche Diagnostics, Hoffmann-La Roche, Basel, Switzerland).

\section{Testing day}

\section{On-line blood glucose monitoring}

After the subject was comfortably settled, an 18-gauge, $5 \mathrm{~cm}$ angiocath was placed in the antecubital vein of the non-dominant arm. The blood withdrawal end of a specially modified, $2.5 \mathrm{~m}$ long double-lumen catheter (MTB Medizintechnik, Amstetten, Germany) was fit into the angiocath. The catheter was continuously heparinized by pumping a sterile heparin-saline solution $(500-5000 \mathrm{U} / \mathrm{ml})$ at a rate of approximately $25 \mu \mathrm{l} / \mathrm{min}$ through the distal lumen of the catheter to the tip of the cannula. The blood and heparin-saline solution mixture was continuously withdrawn through the proximall lumen of the cannula at a rate of approximately 50 $\mu / / \mathrm{min}$ (blood withdrawal rate $=25 \mu / / \mathrm{min}$ ). The blood and heparin-saline solution mixture was mixed with a heparinized phosphate buffer, at a $1: 10$ ratio, and continuously infused into a sample chamber of a glucose analyzer (Model 23A, Yellow Springs Instrument Ca., Yellow Springs, Ohia, USA). Approximately $15 \mathrm{ml}$ of blood were withdrawn on the testing day. The transit lime of this continuous sampling was approximately $4 \mathrm{~min}$, which was timed for each catheter, and accounted for in the data analysis. Sampling occurred at a rate of 10 times per min. and analogue data were amplified, digitized "interfaced (Data Translation Interface Board, model 1028), and displayed continuously on a computer monitor. This monitor was not visible to the subjects. One-minute averages of blood glucose levels over time were plotted for each subject's testing day. For $30 \mathrm{~min}$ prior to the 
insertion of the catheter into the subjects, and following the completion of testing, the system was calibrated using a bag of sterile saline with a known concentration of glucose added. This calibration was done using the same blood-withdrawal cannula that was used in the subject that day $(19,20,21)$.

\section{Blood parameters}

An additional 20-gauge, $3.2 \mathrm{~cm}$ angiocath was placed in the antecubital vein of the other arm for occasional blood sampling. At baseline, just before and $35 \mathrm{~min}$ after breakfast, lunch and snack and just before dinner, a $9 \mathrm{ml}$ blood sample was collected into an EDTA-containing tube to prevent clotting. Plasma was obtained by centrifugation $\left(4^{\circ} \mathrm{C}, 3000 \mathrm{rpm}, 10 \mathrm{~min}\right)$ and stored at $-80^{\circ} \mathrm{C}$ until analysis of glucose by the hexokinase method (Roche Diagnostics, Hoffmann-La Roche, Basel, Switzerland), free fatty acids by the ACS-ACOD method (Wako chemicals, Neuss, Germany), glycerol by the glycerolkinase-lipase method (Boehringer, Mannheim), B-hydroxybutyrate by the method of Moore et al. (22) using a semiautomated centrifugal spectrophotometer (Cobas Fara, Roche Diagnostics), and insulin with the 1235 AutoDELFIA automatic immunoassay system (AutoDELFIA Insulin kit B080-101, WallacOy, Turku, Finland).

\section{Appetite ratings}

Appetite ratings (i.e. ratings of hunger, satiety, fullness, desire to eat, appetite, anticipated food intake and thirst) were scored on $100 \mathrm{~mm}$ visual analogue scales (VAS) anchored with "not at all" and "extremely". Questionnaires were completed at nine fixed time points, respectively at baseline, before and immediately after breakfast, lunch, snack, as well as before and immediately after dinner. Appetite ratings, corrected for the subject's minimum score, were expressed as area under the curve (AUC) over $10 \mathrm{~h}$. Questionnaires were completed at three further time points (35 min after breakfast, lunch, and snacks) for comparison with blood parameters.

\section{Statistics}

Data are presented as mean \pm standard error (SE). Differences between the treatments were determined by analysis of variance for repeated measures (ANOVA) and Sheffe-F post-hoc test (Statview SE Graphics ${ }^{\top M}$ ). Pearson correlation coefficients, $r$, were calculated to determine the relationship between results from blood sampling and outcomes such as appetite ratings and intermeal interval. This was performed for the three treatments separately, as well as for all the test days combined. The level of significance was set at $P<0.05$. 


\section{RESULTS}

BW loss during 2 weeks of intervention was $2.5 \pm 0.4 \mathrm{~kg}, 1.8 \pm 0.3 \mathrm{~kg}$ and $1.8 \pm 0.4$ $\mathrm{kg}$ during SSM+, SSM and SM, respectively, with no significant differences between treatments. The subjects were in negative energy balance on the testing day.

The subject's estimation of clock time at the end of the testing day ranged from -96 to +198 min, verifying that the subjects were blinded to the time of the day. During each test two to four meal initiations occurred, but there was no difference in the number of meal initiations between treatments (SSM+, 3.1 $\pm 0.2 ; S S M, 3.2 \pm 0.2$; $\left.S M_{1} 3.0 \pm 0.2\right)$.

Figure 3 depicts parameters calculated from the on-line blood glucose monitoring curves. Average baseline blood glucose was higher in treatment SM compared to SSM $(P<0.05)$, with values from treatment SSM+ intermediate. The time at which meal initiation, glucose peak or subsequent glucose nadir occurred in relation to breakfast, lunch or snack was similar for all treatments. However, time from meal initiation to glucose peak was longer in treatment SM compared to SSM and SSM+ $(P<0.01)$. Glucose at meal initiation was higher during treatment $S M$ compared to $\operatorname{SSM}(P<0.05)$. Glucose at peak was similar for all treatments, but glucose at the subsequent nadir was higher in treatment SM compared to SSM and SSM+ $P<$ 0.001). The 28 declines in blood glucose observed during treatment SSMconstituted a $34.5 \pm 3.2 \mathrm{mg} / \mathrm{dl}$ decrease (30\%), which followed a rise in blood glucose induced by meal ingestion $\left(29.2 \pm 2.3 \mathrm{mg} / \mathrm{dl}_{*} 34.2 \%\right)$. The 32 declines in blood glucose observed during treatment SSM constituted a $48.5 \pm 5.5 \mathrm{mg} / \mathrm{dl}$ decrease $(39 \%)$, which followed a rise in blood glucose induced by meal ingestion $(41.4 \pm 4.9 \mathrm{mg} / \mathrm{dl}, 49 \%)$. The 26 declines in blood glucose observed during treatment SM constituted a $31.6 \pm 3.0 \mathrm{mg} / \mathrm{dl}$ decrease $(26 \%)$, which followed a rise in blood glucose induced by meal ingestion ( $31.5 \pm 2.5 \mathrm{mg} / \mathrm{dl}, 35 \%$ ).

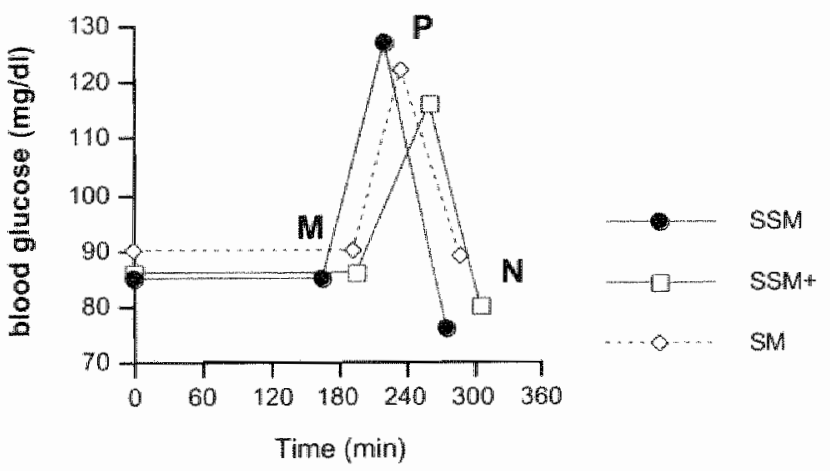

Figure 3 Data obtained from the on-line glucose monitoring curves Values are mean. SSM* = semisolid meal with guar gum; $S S M=$ semisolid meal; $S M=$ solid meal; $M=$ meal hnitiation; $P=$ blood glucose peak" $N=$ blood glucose nadir. 
Increase in blood glucose from meal initiation to peak was smaller in treatment SSM + compared to SSM ( $P<0.05$ ). Decrease in blood glucose from peak to nadir was significantly smaller in SSM+ and SM compared to SSM $(P<0.05)$.

Plasma fasting levels of glucose, insulin, free fatty acids, glycerol and $B$ hydroxybutyrate during the testing day were not different between treatments (Table 2). Plasma glucose concentration increased as a result of meal consumption and then decreased until next meal consumption. Plasma glucose concentration before lunch was higher during SM treatment compared to SSM $(P<0.05)$. However, mean plasma glucose concentration over time was similar for all treatments. Plasma insulin concentration increased after ingestion of a meal and decreased thereafter (Figure 4). Plasma insulin concentration during treatment SSM was lower compared to SM before lunch $(P<0.01)$, and higher $35 \mathrm{~min}$ after both lunch and snack $(P<0.05)$. However, mean plasma insulin concentration over time was similar for all treatments. There were no significant differences in plasma free fatty acids, glycerol and B-hydroxybutyrate concentrations between treatments at any time points and over time (data not shown). Plasma glucose and insulin concentrations were negatively correlated with hunger $(r=-0.50$ and $r=-0.44$, respectively; $P<0.004)$ and positively correlated with satiety $(r=0.35$ and $r=0.43$, respectively; $P<0.001$ ), measured at the same time points. Plasma glycerol concentrations were positively correlated with hunger $(r=0.21 ; P<0.001)$ and negatively correlated with satiety $(r=-0.23 ; P<0.001)$. Plasma free fatty acid concentrations were positively correlated with hunger $(r=0.12 ; P<0.05)$ but not with satiety, and plasma B-hydroxybutyrate concentrations were correlated with satiety $(r=0.14 ; P<0.05)$ but not with hunger.

Meall frequency was similar for all treatments (SSM+, 3.5 \pm 0.1 ; SSM, $3.5 \pm 0.1 ;$ SM, $3.3 \pm 0.1$ ). No significant difference in intermeal intervals between treatments was found from the first to the second meal (SSM+, $190 \pm 15 \mathrm{~min}$; SSM, $187 \pm 12 \mathrm{~min}$; SM, $202 \pm 15 \mathrm{~min}$ ), from the second to the third meal (SSM+, $197 \pm 15 \mathrm{~min}$; SSM, $180 \pm 10 \mathrm{~min} ; \mathrm{SM}, 180 \pm 11 \mathrm{~min})$, and from the third to the fourth meal (SSM+, $110 \pm$ $10 \mathrm{~min}, n=7 ; \mathrm{SSM}, 106 \pm 8 \mathrm{~min}, n=8 ; \mathrm{SM}, 138 \pm 11 \min _{n} n=5$ ). There was no order effect for the number of meals or for the intermeal intervals.

Table 2 Fasting pllasma parameters

\begin{tabular}{|c|c|c|c|c|}
\hline & SSNH+ & SSM & SM & $P$ \\
\hline Glucose (mmolin) & $5.3 \pm 0.1$ & $5.2 \pm 0.1$ & $5.3 \pm 0.1$ & NS \\
\hline Imsullin (U/A) & $8.3 \pm 0.6$ & $8.0 \pm 0.7$ & $9.3 \pm 0.7$ & NS \\
\hline Free fatty acids ( $\mu$ molili) & $430 \pm 38$ & $377 \pm 34$ & $417 \pm 51$ & NS \\
\hline Glyceral (umolin) & $70 \pm 7$ & $67 \pm 7$ & $80 \pm 11$ & NS \\
\hline B-Hydroxybulyrate (mmol/l) & $271 \pm 34$ & $219 \pm 27$ & $284 \pm 62$ & NS \\
\hline
\end{tabular}

Values are mean \pm SE SSM+ = semisolid meal with guar gum; SSM = semisolid meal "SM = solid meal. Statistical significance was determined by an analysis of variance for repeated measures (ANOVA). NS = no significance. 


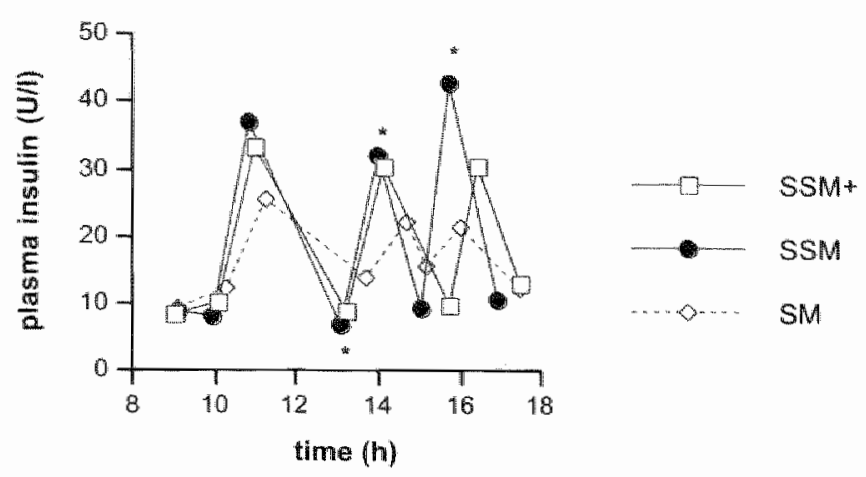

Figure 4 Plasma insulin concentration (U/i)

Values are mean. SSM+ = semisolid meal with guar gum: $\mathrm{SSM}=$ semisolid meal: $\mathrm{SM}=$ solid meal. Statistical significance was determined by an analysis of wariance for repeated measures (ANOVA). "SSM significantly different from SM $(P<0.01, P<0.05$ and $P<0.05$, respectively).

The appetite ratings throughout the testing day, expressed as AUC, are shown in Table 3. The AUC of these parameters showed a similar trend and were not different between any of the three treatments. Satiety scores before the third meal (snack) were lower during SSM treatment compared to SSM+ and SM $(P<0.01)$.

Energy intake during the ad libitum dinner did not differ between the treatments $(S S M+, 2.9 \pm 0.3 \mathrm{MJ} ; \mathrm{SSM}, 2.9 \pm 0.3 \mathrm{MJ} ; \mathrm{SM}, 2.9 \pm 0.3 \mathrm{MJ})$. Tatal energy intake during the testing day amounted to $5.7 \pm 0.3 \mathrm{MJ}$ for SSM, $5.6 \pm 0.3 \mathrm{MJ}$ for SSM and $5.5 \pm 0.4 \mathrm{MJ}$ for SM (NS) and was significantly lower compared to baseline (10.2 \pm $0.6 \mathrm{MJ}, \mathrm{P}<0.001)(13)$.

Table 3 Area under the curve (AUC) ( $\mathrm{mm} / \mathrm{h}$ ) from the following $100 \mathrm{~mm}$ VAS ratings over $16 \mathrm{~h}$ (baseline, before and after breakfast, lunch, snack and dinner)

\begin{tabular}{lcccc}
\hline & SSM & SSM & SM & P \\
\hline Hunger & $364 \pm 28$ & $381 \pm 28$ & $336 \pm 28$ & NS \\
Appetite & $368 \pm 30$ & $414 \pm 28$ & $345 \pm 30$ & NS \\
Anticipated food intake & $427 \pm 32$ & $439 \pm 28$ & $370 \pm 36$ & NS \\
Desire to eat & $361 \pm 25$ & $402 \pm 28$ & $338 \pm 30$ & NS \\
Fullness & $306 \pm 24$ & $256 \pm 20$ & $292 \pm 19$ & NS \\
Saltiety & $341 \pm 24$ & $294 \pm 25$ & $321 \pm 19$ & NS \\
Thirst & $330 \pm 29$ & $313 \pm 30$ & $308 \pm 23$ & NS \\
\hline
\end{tabular}

Values are mean $\pm S E$. SSM+ = semisolid meal with guar gum; $S S M M=$ semisolid meal; $S M=$ solid meal. Statistical significance was determined by an analysis of variance for repeated measures (ANOVA). NS = no significance. 


\section{DISCUSSION}

The present study investigated the effect of guar gum addition to a low-energy semisolid meal on appetite related to blood glucose in overweight men consuming a low-energy diet. Effects were shown on satiety and blood glucose parameters. but not on total energy intake, meal pattern, or general appetite.

Satiety before the third meal was higher with SSM+ and SM Compared to SSM.

From continuous on-line glucose monitoring, it was observed that the increase in blood glucose from meal initiation to blood glucose peak and the decrease from blood glucose peak to nadir were more depressed with SSM+ and SM compared to SSM. A first explanation for the less marked changes in blood glucose and insulin with SSM+ compared to SSM could be that addition of GG decreases gastric emptying or intestinal transit time. However, in a previous study we observed that the addition of 2.5 to $4.5 \mathrm{~g} \mathrm{GG}$ to the same low-energy semisolid meal had no effect on the gastric emptying rate and the rate of intestinal transit (23). Thus other physiological processes are likely to be involwed in reported satiating effects of $G G$ supplementation $\{13,24)$. GG may exert an action on glucose absorption by an impaired diffusion rate through the intestinal unstirred layer (16). This would lead to a prolonged period of glucose uptake in the intestine and consequently a prolonged influence on bload glucose and possibly on insulin levels. This, along with the fact that other nutrients may be absorbed at a lower rate, may affect satiety. Melanson ef al. (21) suggested that subjects who rapidly absorb carbohydrate into the blood stream feel satiated more rapidly, but the higher blood glucose peaks are, the more hungry the subjects are prior the subsequent meal. Therefore, it would be expected that the satiating effect of the SSM would disappear faster and that hunger would reappear sooner. Evidence for this was shown in that despite $^{2}$ the lack of difference in the number of meal requests or intermeal intervals between the treatments, the subjects felt more satiated with SSM+ (not different from the SM results) compared to SSM (different from the SM results) before ingestion of the third meal in the afternoon. This may indicate that the decreased satiety feeling with the unsupplemented semisolid meal will occur later during the day. Although there was no difference in general appetite ratings and energy intake during the testing day in these subjects, determination of appetite in a larger group of subjects at home indicated that GG added to the same semisolid meal allowed a reduced energy intake but prevented an increase in appetite; this increase was present in the unsupplemented semisolid meal and in the sollid meal (13). These results are in line with previous findings that one-week of GG supplementation effectively reduces hunger and increases satiety at a low energy intake level (24). The prevention of increased appetite may improve compliance to an energyrestricted diet (1) and subsequently increase the chances of successful weight loss or prevention of weight gain. On the contrary, Heini et al. (9) did not find any effect of one-week of GG supplementation during energy restriction on appetite and other measured parameters (blood concentrations of glucose, insulin, leptin, and respiratory quotient), with the exception of CCK. In contrast to the form of GG used 
in our study, the GG they used has no viscosity effect. However, this does not explain the discrepancy with the results of Pasman et al. (24), as they used the same type of fiber and the same dosage, for a similar duration.

Significant differences were found in bload glucose and insulin, as determined by occasional blood sampling, between the unsupplemented semisolid meal and the solid meal at certain time points. In contrast, no difference was found in blood glucose and insulin profile or in appetite ratings between the supplemented semisolid meal and the solid meal, although the solid meal is expected to have a slower gastric emptying and intestinal transit. In this respect, the supplemented semisolid meal was found as efficacious as the solid meal in order to prevent rapid changes in the blood glucose profile, which may be responsible for a quicker appearance for hunger and/or a shorter interval between meals. However, the semisolid meal was found to be much more convenient compared with the solid meal that the subjects had to prepare themselves. The use of a ready-to-eat semisolid meal would therefore result in better compliance to an energy-restricted diet in the long term compared to a self-prepared solid meal (13).

The inability of the subjects to reliably estimate clock time at the end of the testing day implies that hunger ratings and meal requests were the results of internal, physiological signals and not of external time cues.

It is concluded that SSM+ and SM showed a more moderate change in blood glucose, as determined by continuous on-line glucose monitoring and that this may have caused the relative increase in satiety in the afternoon before ingestion of the third meal. However, all three treatments had similar effects on general appetite, energy intake and meal patterns. Therefore, we conclude that the addition of guar gum to a low-energy semisolid meal prevented reduction of satiety and moderated changes in blood glucose, while maintaining the advantage of a readyto-eat meal.

\section{ACKNOWLEDGEMENTS}

Supported by Novartis Consumer Health Ltd, Nyon, Switzeriand.

\section{REFERENCES}

1. Astrup $A_{0}$ Visist $E$, Quaade $F$. Dietary fiber added to very low calorie diet reduces hunger and alleviates constipation. Int $J$ Obes 1990; 14: 105-112.

2. Blackburn $N \mathrm{~A}_{\text {, Holgate }}$ AM, Read NW. Does guar gurm improve post-prandial hyperglycemial in humars by reducing small intestinal contact area? Br I Nurr 1984; 52: 197-204.

3. Blackburn NA, Redfern JS, Jariis $H_{2}$, Holgate AM, Hanning I, Scarpello JHB, Johnson IT, Read NW. The mechanism of action of guar gum in improving glucose tolerance in man. Clin Sci 1984; 66: $329-336$.

4. Blundell JE. Burley VJ. Satiation, satiety and the action of fibre on food intake. Int I Obes 1987; 11 (Suppl): $9-25$. 
5. Burtey VJ. Blundell JE. Action of dietary fiber on the satiety cascade. In: Krichersky $D$ Bonfield $C_{\text {: }}$ Anderson JW (eds). Dietary fiber: chemistry, physiology, and health effects. Plenum Press: New York, 1990, pp 227-246.

6. Doucet E. Imbeaul P. StPlerre S. Almeras N, Mauriege P. Richard D, Tremblay A. Appeite after weight loss by energy restriction and a low-fat diet-exercise follow-up. Int $J$ Obes 2000 ; 24: $906-914$.

7. Evans E, Miller DS. Bulking agents in the treatment of obesity. Nutr Metab 1975: 18:199-203.

8. Harju $E$. Increases in meal visicosity caused by addition of guar gum decrease postprandial activify and rate of emptying of gastric contents in healthy subjects. Panminerva Med 1985; 27: $125-128$.

9. Heini AF. Lara-Castro $C_{n}$ Schneider H, Kirk KA, Considine RV, Weinsier RL. Effect of hydrolyzed guar fiber on fasting and postprandial satiety and satiely hormones: A doublem bilind, placebo-controlled trial during controlled weight loss. Int J Obes 1998; 22: 906-909.

10. Herman CP, Polivy J. Restrained eating. In: Stunkard A.J (ed). Obesity. W.B. Saunders: Philadelphia, 1980, pp 208-225.

11. Hylander $B$, Rössner $S$. Effects of dietary fiber intake before meals on weight loss and hunger in a weight-reducing club. Acla Med Scand 1983; 213: 217-220.

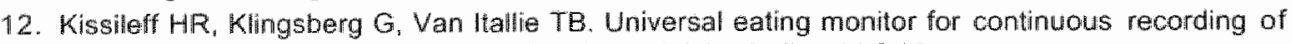
solld or liquid consumption in mari. Am J Physiol 1980: 7: R14-R22.

13. Kovacs EMR, Westerterp.Plantenga MS, Saris WHM, Melanson KJ. Goossens I, Geurten P, Brouns $F$. The fffect of addition of modified guar gum to a lowenergy semisolid meal on appetite and body weight loss. Int I Obes 2001: 25: 307-315.

14. Lavin $\mathrm{JH}$, Read NW. The effect on hunger and satiety of slowing the absorption of glucose: relationship with gastric emptying and postprandial blood glucose and insulin responses. Appetite 1995; 25: 89-96.

15. Leeds AR. Dietary fiber: mechanism of action. Int J Obes 1987; 11 (Suppl): 3-7.

16. Lembcke $B$, Ebert $R$, Ptok $M$, Caspary $W F$, Creutzfeldt $W$, Schicha $H$. Emrich $D$. Role of gastrointestinal transit in the delay of absorption by viscous fibre (guar). Hepatogastroenterology 1984; 31: 183-186.

17. Marken Lichtenbelt WD van, Westerterp $K R$, Wouters $L$. Deuterium dilution as a method for determining total body water: effect of test protocol and sampling time. $\mathrm{Br} J \mathrm{Nutr}$ 1994; 72: $491-497$.

18. Meier R, Beglinger C, Schneider H, Rowedder A. Gyr K. Effect of a liquid diet with and withoust soluble fiber supplementation on intestinal transit and cholecystokinin release in volunteers. $J$ Parent Ent Nutr 1993: 17: 231-235.

19. Melanson KJ, Westerterp-Planteriga MS, Smith FJ, Camptield LA, Saris WHM. Blood glucase patterns and appetite in time-blinded humans: carbohydrate versus fat. Am J Physio 1999; 277: R337-R345.

20. Melanson KJ, Westerterp-Plantenga MS, Campfield LA, Saris WHM. Appetite and blood glucose profiles in humans following glycogen-depleting exercise. J Appl Physiol 1999; 87 : $947-954$

21. Melanson $\mathrm{KJ}$, Westerterp-Plantenga MS, Campfield $L A$, Saris WHM. Blood glucose and meal palterns in time-blinded males, after aspartame, carbohydrate, and fat consumption, in relation to sweetness perception. Br J Nutr 1999; $82 ; 437 \times 446$.

22. Moore $J J$, Marcus M, Sax SM. Kinetic assay of B-hydroxybutyrate in plasma with cobas bio centrifugal analyzer. Clin Chem 1982; 73: 1334-1339.

23. Nieuwenhoven MA van, Kovacs EMR, Martin A-M, Brummer R-JM, Westerterp-Plantenga MS, Biouns $F$. The effect of different dosages of guar gum on the rate of gastric emptying and intestinal transit of an ingested semisolid meal. J Am Coll Nutr 2001; 20: 87-91.

24. Pasman WJ, Wauters M, Westerterp-Plantenga MS, Saris WHM. Effect of one week of fibre supplementation on thunger and satiety or energy intake. Appetite 1997; 29: 77-87.

25. Rössner $S$. Zweigbergk $D$ von. Ohlin $A$, Ryttig $K$. Weight reduction with dietary fibre supplements. Results of two double-balind randomized studies. Acta Med Scand 1987; 222: $83-88$. 
26. Rössner "Andersson $1-L$. Ryttig K. Effects of a dietary fibre supplement to a weight reduction programme on blood pressure. A randomized, double-blind, placebo-controlled study. Acta Med Sicand 1988; 223: 353-357.

27. Rydning $A$, Berstad $A$, Berstad $T$. Hertzenberg $L$. The effect of guar gum and fiberwantiched wheat bran on gastric emptying of a semisolid meal in healthy subjects. Scand $J$ Gastroenterol 1985; 20: 330-334.

28. Ryttig KR, Tellnes $G$ Hægh $L$, Bide $E$, Fagerthun $H$. A dietary fibre supplement and weight maintenance after weight reduction: a randomized, double-blind, placebo-controlled longterm trial. int $J$ Obes 1989; 13: 165-171.

29. Schoeller DA, Santen E V, Peterson DW, Diez W, Jaspan J, Klein PD. Total body water measurement in humans with ${ }^{18} \mathrm{O}$ and ${ }^{2} \mathrm{H}$ labeled water. Am $J$ Clin Nutr 1980; 33: 2686-2693.

30. Solum TT, Ryttig KR, Solum $E$, Larsen $S$. The infuence of high-fibre diet on body weight, serum lipids and blood pressure in slightly owenweight persons. A randomized, double-blind, placebo-controlled investigation with diet and fibre tablets (Dumovital). Int J Obes 1987 ; 11 (Suppl): $67-71$.

31. Stevens $\rfloor$. Does dietary fiber affect food intake and body weight? J Am Diet Assoc 1988; 88: $939-942,945$.

32. Stunkard AJ, Messick S. The three-factor eating questionnaire to measure dietary restraint, disinhibition, and hunger. J Psychosom Res 1985; 29: 71-83.

33. Westerterp-Plantenga MS, Westerterp KR, Nicolson NA, Mordant $A$, Schoffelen PFM, ten Hoor $F$. The shape of the cumulative food intake curve in humans, during basic and manipulated meals. Physiol Behav 1990; 47: 569-576.

34. Westerterp-Plantenga MS, Rolland V, Wilson SAJ, Westerterp. KR. Satiety related to $24 \mathrm{~h}$ diet-induced thermogenesis during high protein/carbohydrate vs high fat diets measured in a respiration chamber. Eur J Clin Nutr 1999; 53: 1-8.

35. Wilmshurst $P$, Crawley JCW. The measurement of gastric transitt time in obese subjects using ${ }^{24} \mathrm{Na}$ and the effects of energy content and guar gum on gastric emptying and satiety. $\mathrm{Br} J$ Nutr $1980 ; 44: 1-6$. 


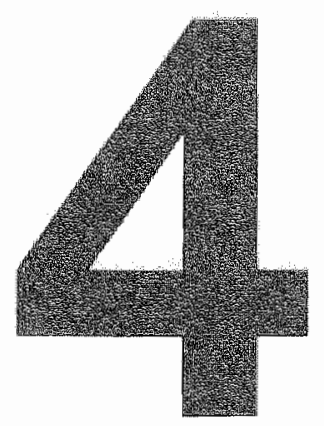

The effect of different dosages of guar gum on gastric emptying and small intestinal transit of a consumed semisolid meal

van Nieuwenhoven MA, Kovacs EMR, Brummer R-JM, Westerterp-Plantenga MS, Brouns F

Journal of the American College of Nutrition 2001; 20:87-91 


\section{ABSTRACT}

Background: There is no consensus about the effect of guar gum supplementation on gastrointestinal transit. It has been suggested that guar gum slows gastric emptying and intestinal transit, thus inducing an increased feeling of satiety.

Objective: To investigate whether addition of guar gum to a semisolid meal affects gastrointestinal transit.

Design: Eight male subjects were randomly studied four times. They consumed a standard semisolid test meal containing either $0 \mathrm{~g}, 2.5 \mathrm{~g}, 3.5 \mathrm{~g}$ or $4.5 \mathrm{~g}$ of guar gum. The test meals contained $1 \mathrm{mCi}{ }^{99 m} \mathrm{Tc}$-hepatate for scintigraphy, and $5 \mathrm{~g}$ lactulose for the $\mathrm{H}_{2}$-breath test. Scintigraphic scanning was performed for at least 2 $\mathrm{h}$, and gastric half-emptying time (T1/2) was calculated. Breath samples were collected at $45 \mathrm{~min}$ intervals and analyzed for $\mathrm{H}_{2}$-enrichment. The orocecal transit time (OCTT) was then determined. A parameter of intestinal transit (PIT) was obtained by subtracting the T1/2 from the OCTT.

Results: There were no significant differences between the different tests in both $T 1 / 2(0 \mathrm{~g}, \mathrm{t}=88.2 \pm 11 \mathrm{~min} ; 2.5 \mathrm{~g}, \mathrm{t}=83.3 \pm 11.9 \mathrm{~min} ; 3.5 \mathrm{~g}, \mathrm{t}=83.3 \pm 13.6 \mathrm{~min} ; 4.5$ $\left.\mathrm{g}_{\mathrm{r}} \mathrm{t}=72.4 \pm 7.2 \mathrm{~min} ; \mathrm{P}=0.86\right)$ and PIT $(0 \mathrm{~g}, \mathrm{t}=149.9 \pm 26.6 \mathrm{~min} ; 2.5 \mathrm{~g}, \mathrm{t}=145.5 \pm$ $25.6 \mathrm{~min} ; 3.5 \mathrm{~g}, t=175.3 \pm 17.6 \mathrm{~min} ; 4.5 \mathrm{~g}, \mathrm{t}=152.6 \pm 22.4 \mathrm{~min}, P=0.52)$.

Conclusion: Addition of guar gum to a semisolid meal up to a dosage of $4.5 \mathrm{~g}$ does not affect gastrointestinal transit. Other mechanisms than gastrointestinal motility are involved in a possible satiating effect of guar gum supplementation.

Keywords: guar gum, gastric emptying, intestinal transit, satiety, scintigraphy, $\mathrm{H}_{2}-$ breath test 


\section{INTRODUCTION}

Dietary fiber is an important component of the diet. However, controversy and confusion still exists about the physiological effects of dietary fibers on serum lipids, blood glucose and induction of satiety. It has been suggested that guar gum may play an important role in weight maintenance in obese subjects. It has been established that guar gum can induce an increased feeling of satiety, thus reducing food intake (17). A possible mechanism for this increased feeling of satiety is a delayed gastrointestinal transit.

The aim of the study was to determine the effect of different dosages of a highly purified guar gum type (Meyprofin® $\mathrm{M}-175$ ) on the gastric emptying rate and small intestinal transit time of a standardized homogeneous low-caloric semisolid meal, using scintigraphy to measure gastric emptying, and the hydrogen breath test to measure the intestinal transit rate. These techniques are regarded as the gold standard.

It is hypothesized that guar gum addition to a semisolid meal will lead to gel forming in the stomach, resulting in a substantial delay of gastric emptying. It is also hypothesized that guar gum will delay the intestinal transit. The data from the current dosage-response study may possibly lead to the establishment of the most optimal guar gum dosage, which can be ingested shortly before a meal or can be added to a meal, with the aim to increase the delay of gastric emptying and a possible subsequent effect on appetite. The establishment of this dosage then could be used in subsequent short- and long-term studies on food intake and weight maintenance.

\section{METHODS}

\section{Viscosity measurements}

Viscosity of the test meals containing $0 \mathrm{~g}$ guar gum and $4.5 \mathrm{~g}$ guar gum was measured at $37^{\circ} \mathrm{C}$, at different shear rates $(0.12,0.30,0.74,1.85,4.65,11.7,29.4$, $73.5,185$ and $465 / \mathrm{s}$ ) using a $3 \mathrm{~cm}$ plate diameter rheometer (Bohlin Vor. Rheometer, Bohlin Rheology $\mathrm{AB}$, Sweden). The guar gum was added to the semisolid meal and homogenization took place by a 5 min shaking, followed by a $10 \mathrm{~min}$ stabilization period. Samples were sheared for at least $2 \mathrm{~min}$ before the first reading was taken to ensure stable viscosity readings and temperature equilibration of the sample. The viscosity was measured in upward and subsequent backward order of shear rates. No precautions were taken to avoid sample evaporation.

\section{Study design}

Four different dosages (control $=0 \mathrm{~g}$, low $=2.5 \mathrm{~g}$, medium $=3.5 \mathrm{~g}$, high $=4.5 \mathrm{~g}$ ) of modified guar gum (Meyprofin ${ }^{\circledR}$ M-175, Meyhall AG, Kreuzlingen, Switzerland), a 
highly purified dietary galactomannan fiber, which forms a viscous liquid in approximately 5-7 $\mathrm{min}$ after addition to water, were administered to a semisolid meal in a double blind randomized crossover study design.

\section{Subjects}

Eight healthy, sedentary, non-obese male subjects (age $19.1 \pm 0.8$ y), recruited from the university, were included in the study. Informed consents were obtained. The study was approwed by the Medical Ethics Committee of the Maastricht University. The subjects were studied on four different occasions. All tests were separated at least $72 \mathrm{~h}$. The subjects were asked to abstain from alcohol, medication and fiber-rich food the day before the study. Additionally the subjects were asked to register dietary intake the evening before the test and to consume exactly the same diet before the other tests. After an overnight fast, at 8:00 h the subjects consumed $200 \mathrm{ml}$ of a standardized semisolid breakfast (Milical Crème, Laboratoires Diététique et Santé, Revel, France). The subjects arrived at the laboratory at noon for the experiment.

\section{Test substances}

The different dosages of guar gum were mixed with a standard $203 \mathrm{kcal}$ semisolid meal (1 sachet of Milical Crème dissolved in $200 \mathrm{ml}$ water) and labeled with $1 \mathrm{mCl}$ (37 MBq) $99 \mathrm{mT}$ c-hepatate, as a marker of the semisolid phase. The meal consisted of $19 \mathrm{~g}$ carbohydrates (maltodextrin), $16 \mathrm{~g}$ protein, $7.1 \mathrm{~g}$ fat and $1 \mathrm{~g}$ electrolytes. The meal itself did not contain a viscous non-digestible fiber. Subsequently $5 \mathrm{~g}$ of lactulose (syrup $670 \mathrm{mg} / \mathrm{ml}$, Centrafarm, Etten-Leur, The Netherlands) were mixed with the test meal. The different guar gum dosages resulted in meals with different consistencies. The consistency of the semisolid meal without guar gum was comparable with custard, while the consistency of the semisolid meal with added $4.5 \mathrm{~g}$ guar gum was comparable with soft dough, in which a spoon was supported in an upright position. We considered a higher dose of guar gum not suitable for consumption. Immediately after preparation, the meals were consumed within 3 min. A scintigraphic pillot experiment, which we performed, demonstrated that these semisolid meals empty according to a linear function.

\section{Scintigraphic technique}

The subjects sat in a semi-reclined position with a single-headed rectangular gamma camera equipped with energy collimators positioned in front of the stomach area. Subsequently the test meal was consumed. The images were recordled with a $10 \%$ window around a 140 Kev $99 \mathrm{~m}$ Tc-peak during a dynamic scanning (180 s per image) of at least $2 \mathrm{~h}$. If the remaining radioactivity had not been reduced to $50 \%$ of the maximum activity, the procedure was continued.

Data were stored on an on-line computer network. The gastric counts were determined for each image in the marked region of interest and corrected for tissue attenuation using a lateral image, down scatter and radioactive decay. Values for 
relative residual radioactivity (\% RRA) for the solid component of the meal, using the activity at time zero (end of meal consumption) as $100 \%$, were calculated at each time point. A linear regression fit was applied in order to calculate the gastric half-emptying time $(T 1 / 2)$ and lag time of the solid component.

\section{Hydrogen breath technique}

The consumed meal contained a non-digestible soluble carbohydrate (5 g lactulose) allowing the measurement of orocecal transit time (OCTT) via $\mathrm{H}_{2}$ measurement in breath. This method is the gold standard for determining the presence of bacterial overgrowth and for measurement of the OCTT. Lactulose itself has an accelerating effect on intestinal transit, which might hypothetically outstrip the effect of guar gum on intestinal transit. To avoid this, we used a small amount of lactulose, which has little effect on intestinal transit. Caride et al. (3) observed that if scintigraphy and the hydrogen breath test using lactulose were used simultaneously, similar results were obtained. As soon as the lactulose enters the colon, bacterial fermentation will take place, and $\mathrm{H}_{2}$-gas will be produced (12). At 15 min intervals after ingestion of the test meal, the subjects breathed for $2 \mathrm{~min}$ via a mouthpiece in a mixing chamber. A breath sample was drawn from the mixing chamber using a $140 \mathrm{ml}$ syringe. The $\mathrm{H}_{2}$-enrichment of the breath samples (in ppm), due to the colonic fermentation of the added lactulose, was determined by injecting the breath sample into an exhaled $\mathrm{H}_{2}$-monitor (GMI Medical Ltd., Renfrew, Scotland). The OCTT was determined using the time of onset of a sustained increase in breath $\mathrm{H}_{2}$, which is the first breath sample that shows a higher breath $\mathrm{H}_{2}$ than the preceding one, followed by two or more breath samples that show a further increase. Since the OCTT is determined by the processes of both gastric emptying, and the rate of intestinal transit, a parameter of intestinal transit (PIT) could be obtained by subtracting the $T 1 / 2$ obtained from the gastric emptying measurements from the OCTT.

\section{Statistics}

Data of the gastrointestinal transit measurements are presented as mean \pm standard deviation (SD). The differences in T1/2 and PIT between the trials were evaluated using Friedman's nonparametric test. All analyses were performed using the SPSS 7.5 for Windows statistical package. Values of $P<0.05$ were accepted as statistically significant. The data of the viscosity measurements are presented as a graph with logarithmic axes. 


\section{RESULTS}

\section{Viscosity measurements}

The results of the viscosity measurements are displayed in Figure 1. The figure demonstrates that addition of $4.5 \mathrm{~g}$ guar gum resulted in approximately a 10-fold increase in the viscosity of the test meal. At the highest shear rate $(465 / \mathrm{s})$ the viscosity of the meal without guar gum was $0.08 \mathrm{~Pa} \cdot \mathrm{s}$ and with $4.5 \mathrm{~g}$ guar gum it was 0.22 Pa.s.

\section{Gastrointestinal transit measurements}

All the subjects showed full compliance to the study. All the gastric emptying measurements showed a linear relationship in time. Friedman's non-parametric analyses showed no significant differences between the different dosages of guar gum in the $T 1 / 2(0 \mathrm{~g}, \mathrm{t}=88.2 \pm 11 \mathrm{~min} ; 2.5 \mathrm{~g}, \mathrm{t}=83.3 \pm 11.9 \mathrm{~min} ; 3.5 \mathrm{~g}, \mathrm{t}=83.3 \pm$ $13.6 \mathrm{~min} ; 4.5 \mathrm{~g}, t=72.4 \pm 7.2 \mathrm{~min} ; P=0.86$ ), as displayed in Figure 2. The PIT also failed to demonstrate differences between the different guar gum dosages $\left(0 \mathrm{~g}_{\mathrm{t}} \mathrm{t}=\right.$ $149.9 \pm 26.6 \min ; 2.5 \mathrm{~g}, \mathrm{t}=145.5 \pm 25.6 \min ; 3.5 \mathrm{~g}, \mathrm{t}=175.3 \pm 17.6 \min ; 4.5 \mathrm{~g}, \mathrm{t}=$ $152.6 \pm 22.4 \mathrm{~min} ; P=0.52$ ), as displayed in Figure 3 .

\section{DISCUSSION}

Gastric distension is assumed to be an important signal of satiety (19). Guar gum is assumed to be able to induce a delayed gastric emptying by forming a gel in the stomach, leading to a prolonged gastric distension, which results in prolonged satiety signals from the stomach. However, the relationship between guar gum and gastric emptying is not clear yet. Various gastric emptying studies, in which guar gum was added to test meals, have been carried out, and show different results $(1,4,6,7,8,9,10,11,13,14,15,16,18,20,21,22)$.

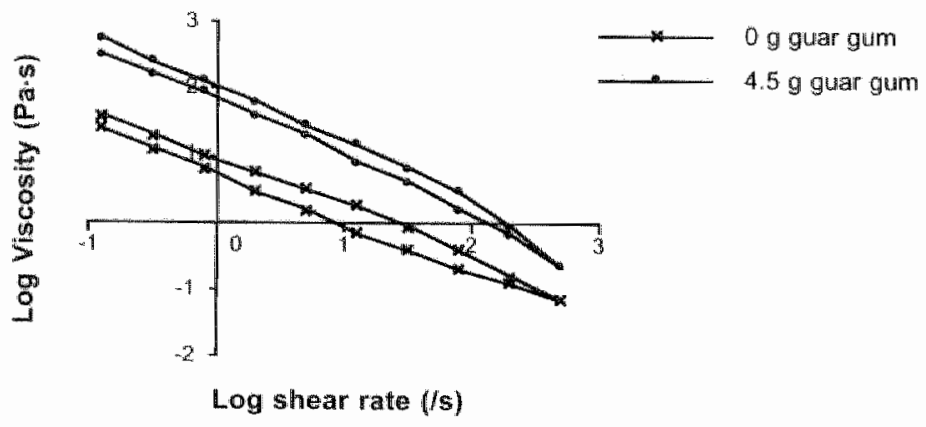

Figure 1 Viscosity plots of the semisolid meal and the semisolid meal with added $4.5 \mathrm{~g}$ guar gum. 


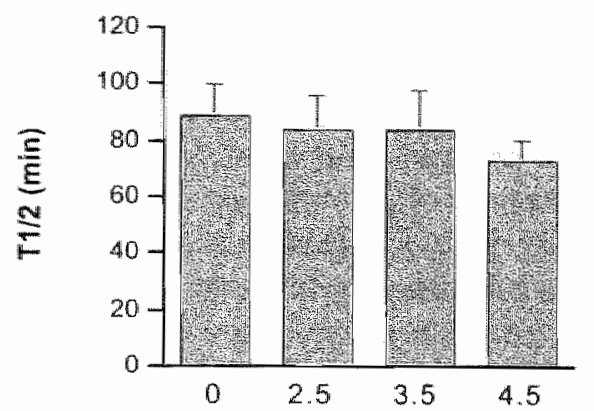

Figure 2 The effect of different dosages of guar gum on the gastric emptying rate (mean $\pm \mathrm{SD}_{n} n$ $=8, P=0,86$ ).

These discrepancies may be explained by the different methods that are used to measure gastric emptying. In some studies only the gastric emptying of the liquid phase was measured, using the paracetamol absorption method $(14,15,16)$. This was sometimes done after consumption of a solid/liquid meal, which means that no information about the gastric emptying of the solid phase is available. It is well known that liquids, solids and fats show different gastric emptying kinetics; liquids empty according to an exponential function, and solids and fats empty according to a linear function. Moreover, the gastric emptying rate is dependent on the volume, temperature and caloric contents of both the liquid and solid phase. Unusual methods such as ${ }^{24} \mathrm{Na}$-absorption or sampling of gastric contents using a nasogastric tube have also been used to measure gastric emptying (22). In other studies the common scintigraphy technique was used $(1,4,9,10,11,16,20,21,22)$. In addition, different types (purified vs. non-purified) and dosages of guar gum have been used, leading to different viscosities and textures of the meals. Finally, there were differences in the type of meal (liquid $(7,8,9,10,11,13,22)$, liquid/solid $(6,14,15,18,20)$ or semisolid $(21)$, high fat $(4,16))$ and the quantity of the meals, which were consumed.

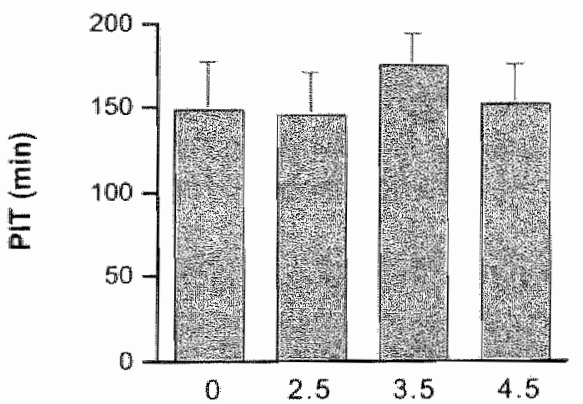

Figure 3 The effect of different dosages of guar gum on the parameter of intestinal transit (PIT) $\left(\right.$ mean $\left.\pm \mathrm{SD}_{n} n=8, P=0.52\right)$. 
The results of the present study clearly indicated that addition of guar gum in dosages ranging from 0 to $4.5 \mathrm{~g} / 200 \mathrm{~m}$ semisolid low-caloric meal led to a large increase in meal viscosity, but has no effect on either the gastric emptying rate or the rate of small intestinal transit. These results suggest that other physiological processes are involved in a possible satiating effect of guar gum. it is useful to distinguish different processes involved in satiety (5): 1) sensory processes, 2) cognitive processes (these processes will not be discussed in this paper), 3) postinglestive processes these include a number of possible actions, including gastric distension, the rate of gastric emptying. small bowel transit, the colonic transit, the release of gastrointestinal peptides and hormones and the stimulation of specific nutrient receptors along the gastrointestinal tract), 4) post-absorptive mechanisms (these include mechanisms arising from the effect of metabolism of glucose, fatty acids and amino acids after small intestinal absorption).

Since addition of guar gum does not result in a change of post-ingestive processes, such as a prolongation of gastric distension due to a decreased gastric emptying rate, or a delay in the rate of intestinal transit, a possible satiating effect of guar gum is not the result of a delayed gastrointestinal transit. However, it might be possible that guar gum addition to a meal induces a prolonged feeling of satiety resulting from the increased viscosity of the meal, leading to a lower intestinal uptake rate of nutrients, which leads to a prolonged exposure of intestinal chemo-receptors to mutrients. The postprandial plasma glucose peak is lower after a meal with guar gum, compared to a meal without guar gum. This is most probably due to a decreased rate of glucose absorption because of an impaired transport of glucose in the lumen. It is likely, however "that thils impaired diffusion rate will lead to a prolonged period of intestinal glucose uptake and consequently a prolonged influence on blood glucose and insulin levels. In this respect, it is logical to assume that the monitoring of blood glucose levels by receptors in the brain or in the liver plays a role in controlling appetite.

The combination of gastric emptying measurements with OCTT measurement provides a complete insight in the effect of guar gum on the process of gastrointestinal transit. The hydrogen breath test is a commonly used method to measure small intestinal transit in gastroenterological practice. The method is rellable since every individual has a colonic flora. There are situations in which false-negative or false-pasitive results can be obtained such as after an antibiotic therapy which eradicates the colonic flora, or if subjects are suffering from bacterial overgrowth. However, this was not the case in this study since we only included healthy volunteers.

Measurement of the OCTT alone does not provide information about the rate of intestinal transit, since the influence of the glastric emptying component is unknown. Therefore we propose the calculation of a parameter of intestinal transit (PIT), by subtracting the TH/2 from the OCT. This parameter gives information about the intestinal transit itself, because a correction is made for the gastric emptying component. 
In summary, it is concluded that addition of guar gum to a semisolid, low energetic meal, up to a dosage of $4.5 \mathrm{~g} / 200 \mathrm{ml}$, has no effect on either the gastric emptying rate or the rate of intestinal transit. These results indicate that mechanisms other than gastrointestinal motility and transit might be involved in the satiating effect of guar gum supplementation, as has been observed in other studies. Therefore, it is proposed that further research on the effects of the modified guar gum used in the present study should focus on a combination of postprandial satiety ratings with continuous blood glucose measurements, plasma insulin and gastrointestinal peptide and hormone measurements.

\section{REFERENCES}

1. Blackburn NA, Redfern JS, Jariis $H$, Holgate AM, Hanning I, Scarpello JH, Johnson IT, Read NW. The mechanism of action of guar gum in improving glucose tolerance in man. Clin Sci 1984; 66 : 329-336.

2. Blundell JE, Halford JC. Regulation of mutrient supply: the brain and appetite control. ProG Nutr Soc 1994; 53 : 407-418.

3. Caride VJ. Prokop EK Trancale FJ, Buddoura W. Winchenbach K. McCallum RW. Scintigraphic determination of small intestinal transit time: comparison with the hydrogen breath technique. Gastroenterology 1984; 86: 714-720.

4. French $S . J$, Read NW. Effect of guar gum on lhunger and satiety after meals of differing fat content: relationship with gastric emptying. Am J Clin Nutr 1995; 59; 87-91.

5. Groop $\mathrm{PH}$, Aro $\mathrm{A}$, Stenman S, Groop L. Long-term effects of guar gum in subjects with noninsulin dependent diabetes mellitus. Am J Clin Nutr 1993; 58: 513-518.

6. Harju $E$. Increases in meal viscosity caused by addition of guar gum decrease postprandial acidity and rate of emptying of gastric contents in healthy subjects. Panminerva Med 1985; 27: $125-128$.

7. Holt $S$, Heading RC, Carter DC, Prescott LF, Tothill P. Effect of gel fibre on gastric emptying and absorption of glucose and paracetamol. Lancet 1979; 1: 636-639.

8. Jenkins DJA, Wolever TMS, Leeds AR, Gassull MA, Dilawari JB, Goff DV, Metz GL, Aiberti GM. Dietary fibres, fibre analogues, and glucose tolerance: importance of viscosity. Br Med J 1978: 1: 1392-1394.

9. Kasper $H_{0}$ Ellles $C$. Reiners $C$. Schrezemeir J. The influence of dietary fiber an gastric transit time. Hepatogastroenterol 1985; $32 ; 69-7 \%$.

10. Lavin $\mathrm{JH}$, Read NW. The effect on hunger and satiety of slowing the absorption of glucose: relationship with gastric emptying and postprandial blood glucose and insulin responses. Appatite 1995; 25: 89-96.

11. Lembcke $B$, Ebert $R$, Ptok M, Caspary WF, Creutzfeldt W. Schicha $H$, Emrich D. Role of gastrointestinal transit in the delay of absorption by viscous fibre (guar). Hepatogastroenteror 1984: 31: 183-186.

12. Levitt MD. Production and excretion of hydrogen gas in man. New Engl \& Med 1969: 281: 122-127.

13. Meier $R$, Beglinger $C$. Schneider $H$, Rowedder $A$. Gyr $K$. Effect of a liquid diet with and without soluble fiber supplementation on intestinal transit and cholecystokinin release in volunteers. J Parent Enteral Nutr 1993; 17: 231-235.

14. Morgan LM, Tredger JA, Madden A, Kwasowski P, Marks $W$. The effect of guar gum on carbohydrate-, fat- and protein-stimulated gut hormone secretion: modification of postprandial gastric inhibitory polypeptide and gastrin responses. Br J Nutr 1985: $53: 467-475$.

15. Morgan LM, Tredger JA, Wright J, Marks $V$. The effect of soluble- and insoluble-fibre supplementation on post-prandiall glucose tolerance, insulin and gastric inhibitory polypeptide secretion in healthy subjects. Br J Nutr 1990; 64: $103-110$. 
16. Morgan LM, Tredger JA, Shavita $Y$, Travis US, Wright J. The effect of non-starch polysaccharide supplementation on circulating bile acids, hormone and metabiolite levels following a fat meal in human subjects. Br J Nutr 1993; $70: 491-501$.

17. Pasman WJ, Wauters MAl, Westerterp-Plantenga MS, Saris WHM. Effect of one week of fibre supplamentation on hunger and satiety or energy intake. Appetite 1997: 29:77-87'.

18. Penagini $R$, Velio $P$, Vigorelli $R$, Bozzani $A$, Castagnone $D$. Ranzi $T$. Bianchi $P A$. The effect of distary guar on serum cholesterol, intesthal transilt, and fecal output in man. Am J Gastroenterol 1986; $81: 123-125$.

19. Plata-Salaman CR. Regulation of hunger and satiety in man. Dig Dis Sci 1991; 9:253-268.

20. Pay TK. Long-term effects of dietary fiber on glucose tolerance and gastric emptying in nonirsulindependent diabetic patients. Am $/$ Clin Nutr 1983; 37:376-381.

21. Fydning A, Berstad A, Berstad $T$. Hertzenberg $L$. The effect of guar gum and fiberwentiched wheat bran on gastric emptying of a semisolid meal in heathy subjects. Scand J Gastroonteral 1985:20:330-334.

22. Wimshurst P, Crawley JCW. The measurement of gastric transit time in obese subjects using 24 $\mathrm{Na}$ and the effects of energy content and guar gum on gastric emptying and satiety. Br $J$ Nutr 1980; 44: 1-6. 


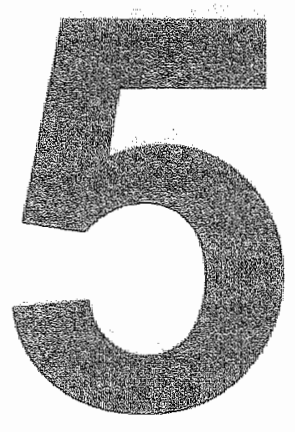

\section{Associations between spontaneous meal initiations and blood glucose dynamics in overweight men in negative energy balance}

Kovacs EMR, Westerterp-Plantenga MS, Saris WHM, Melanson KJ, Goossens I, Geurten P, Brouns F 


\section{ABSTRACT}

The aim of the present study was to investigate associations between spontaneous meal initiations and blood glucose dynamics in overweight male subjects in negative energy balance. In a randomized cross-over design, 15 overweight male subjects (body mass index, $28.6 \pm 1.8 \mathrm{~kg} / \mathrm{m}^{2}$ ) participated in three treatments, each of which consisted of 2 weeks consuming a low-energy diet followed by a test of voluntary food ingestion in the absence of time-related cues. The low-energy diet consisted of three daily meals (947 kJ) which were either semisolid with or without $2.5 \mathrm{~g}$ guar gum or solid and a dinner of subject"s own choice. During the time-blinded test, on the first, second, and third meal initiation subjects ingested a low-energy meal corresponding to that used during the preceding weeks. Changes in blood glucose were monitored on-line. Associations between spontaneous meal initiations and blood glucose dynamics were determined using the $\chi^{2}$-test. No difference was found between treatments in the occurrence of postabsorptive and postprandial declines in blood glucose or in associations between meal initiations and blood glucose dynamics. Postprandial dynamic blood glucose declines were associated with meal initiation $\left(X^{2}=26.8, P\right.$ $<0.001$ ), but postabsorptive and postprandial transient declines were not. In overweight subjects, the usual association between transient declines and spontaneous meall initiation was completely absent in negative energy balance.

Keywords: glucostatic theory; food intake regulation; low-energy diet; blood glucose pattern 


\section{INTRODUCTION}

Carbohydrate metabolism has been proposed to be fundamental in the regulation of food intake, due to its limited storage, high turnover rate, immediate and tight regulation, and its critical role as fuel source for the central nervous system $(7,15)$. The glucostatic hypothesis postulates that reduced glucose utilization in critical brain regions leads to perception and expression of hunger in animals $(2,8,13,15,23)$ and human subjects $(6,16,18)$. As a consequence, changes reflected by declines in blood glucose have been suggested to play a role in shortterm food intake regulation and may depend on carbohydrate availability. Transient blood glucose declines have been shown to coincide with increased hunger and to precede and signal meal initiation in free-feeding lean, obese and diabetic rats $(2,3,4,5,13,22)$ and in fasting human subjects $(6,16,18)$. In the postprandial state, transient and dynamic blood glucose declines have been shown to predict spontaneous meal initiation in time-blinded human subjects $(16,18)$. Previously, a major limitation in the investigation of the role of blood glucose in hunger has been the use of discrete blood sampling $(3,4,5,13,15,20,22,25)$. The application of contemporary technology for continuous monitoring of blood glucose concentration $(2,6,16,17,18)$ allows testing of the hypothesis that hunger and meal initiations in humans can be related to patterns in blood glucose concentration. Continuous blood glucose monitoring has been applied in humans to study meal initiation during the morning after an overnight fast (6), as well as during a full day in lean males, in energy balance $(16,17,18)$.

In a larger study we investigated the effects of guar gum addition to a low-energy sernisolid meal on appetite in relation to blood glucose and other blood variables, in overweight male subjects who were on a low-energy diet $(10,11)$. We found that guar gum addition to a semisolid meal prevented an increase in appetite, hunger and desire to eat, while this increase was present in the unsupplemented semisolid meal and in a low-energy solid meal. In addition, similarly to the solid meal, the semisolid meal with guar gum resulted in a more moderate change in blood glucose compared to the unsupplemented semisolid meal. Because of these different effects of meal type on appetite and blood glucose variables, we wondered whether in these subjects in a negative energy balance food intake would still be related to the same physiological variables, eg blood glucose patterns, as in lean males in energy balance. Therefore, the aim of the present study was to investigate associations between spontaneous meal initiations and blood glucose dynamics in overweight male subjects, after a 2-week low-energy diet consisting of three meals per day, which were either semisolid (with or without 2.5 g guar gum) or solid, and a dinner of subject's own choice. 


\section{METHODS}

\section{Subjects}

Fifteen overweight male subjects participated in this study. The subjects were a subsample of a larger study that is described in Kovacs et al. $(10,11)$. Selection for this study took place following health criteria (fasting blood glucose $<6.2 \mathrm{mmol} / 1$, no diabetes, no cardiovascular diseases, and no medical treatment) and body weight criteria (body mass index: $25-30 \mathrm{~kg} / \mathrm{m}^{2}$ ). Baseline characteristics of the subjects are presented in Table 1. The nature and risks of the experimental procedure were explained to the subjects, and all subjects gave their written informed consent. The study was approved by the Ethical Committee of Maastricht University.

\section{Experimental design}

The experiment had a randomized and cross-over design. The experimental design consisted of three treatments, each consisting of a 2-week low-energy diet and a subsequent time-blinded test, separated by a 4-week washout period $(10,11)$.

Daily during the treatments, the subjects consumed a low-energy meal for breakfast, lunch and as a four o'clock snack. In addition, for lunch, subjects were allowed to eat a fruit (eg apple, pear, orange). For dinner, the subjects ingested a meal of their own choice, but they were instructed to drink no more than one glass

Table 1 Subjects characteristics $(n=15)$ at baseline

\begin{tabular}{lcc}
\hline & mean $\pm \mathrm{SD}$ & range \\
\hline Age $(\mathrm{y})$ & $43.7 \pm 9.3$ & $29-56$ \\
Height $(\mathrm{m})$ & $1.77 \pm 0.06$ & $1.65-1.88$ \\
Weight $(\mathrm{kg})$ & $89.2 \pm 7.7$ & $79.6-102.7$ \\
Body mass index $\left(\mathrm{kg} / \mathrm{m}^{2}\right)$ & $28.6 \pm 1.8$ & $25.9-32.4$ \\
Waist circumferience $(\mathrm{cm})$ & $98 \pm 6$ & $91-108$ \\
Hip circumference $(\mathrm{cm})$ & $104 \pm 5$ & $96-112$ \\
Waist-hip ratio & $0.94 \pm 0.04$ & $0.85-1.01$ \\
Body fat (\%) & $30.9 \pm 1.1$ & $23.3-38.5$ \\
Syslolic blood pressure $(\mathrm{mmHg})$ & $149 \pm 23$ & $116-206$ \\
Diastolic blood pressure $(\mathrm{mmHg})$ & $91 \pm 11$ & $77-106$ \\
Blood glucose (mmol/l) & $5.4 \pm 0.2$ & $4.86-5.65$ \\
F1 (cognitive restraint) & $4.0 \pm 2.8$ & $0-9$ \\
F2 (disinhibition) & $3.9 \pm 1.4$ & $1-5$ \\
F3 (hunger) & $3.5 \pm 2.1$ & $0-8$ \\
Herman Polivy restraint & $13.7 \pm 4.5$ & $6-20$ \\
\hline
\end{tabular}

F1-F3, factors $1-3$ of the Three Factor Eating Questionnaire. 
of an alcoholic beverage or soft drink. Subjects were instructed to refrain from snacks between meals. During the day, the subjects were allowed to drink water, coffee and tea (without sugar and milk) ad libitum. The low-energy meal consisted of a semisolid meal (Milical Crème, Laboratoires Diẻtétique et Santé "Revel France, $47 \mathrm{~g}$ dissolved in $200 \mathrm{ml}$ water) with (SSM+) or without (SSM) addition of $2.5 \mathrm{~g}$ of modified guar gum (Meyprofin ${ }^{2}$-175, Meyhall AG, Kreuzlingen, Switzerland, a highly purified dietary galactomannan fiber which forms a gel in approximately 5-7 min after adding water) or a solid meal (SM) with the same energy density and macronutrient composition (energy, $947 \mathrm{~kJ}$; protein, $17.9 \mathrm{~g}$; carbohydrate, $21.0 \mathrm{~g}$; fat, $7.9 \mathrm{~g}$ ). The semisolid meal was offered in three flavours (vanilla, chocolate, caramel) and the subjects were allowed to choose the meals in the flavours they preferred. The solid meal was prepared by the subjects themselves using our specific instructions. Compliance to the dietary instructions was controlled using food intake diaries (10).

At the end of each intervention, the subjects reported to the laboratory between 8:00 $\mathrm{h}$ and $9: 00 \mathrm{~h}$, following a $10 \mathrm{~h}$ overnight fast, for a time-blinded test (11). Testing started at different times that were randomly chosen for the purpose of time blinding. During the test, subjects were housed in a room and isolated from time and food cues to eliminate habitual (time-determined) meal patterns, enabling the investigators to observe meal responses to mainly physiological cues. Television, video, radio, watches and clocks were not in the room, and research staff refrained from making time-related statements. With exception of the investigators and the subject, no other people were allowed in the room. Subjects siat on a bed and were allowed to read or write during the test. They were not allowed to slleep. Subjects could verbally request a meal (= meal initiation) at any time. According to the randomly assigned treatment, subjects consumed, upon the first, second and third meal request (breakfast, lunch and snack, respectively), the low-energy meal (SSM+, SSM or SM) corresponding to that used during the preceding 2 weeks. During the day, water, coffee and tea (without sugar or milk) were offered ad libitum. Then, upon their fourth meal request (dinner), they ingested a standardized meal ad libitum (pasta with tomato sauce). Testing was stopped at the subject"s fourth meal request or at 18:00 $\mathrm{h}$ if the subject had not yet requested a third or fourth meal. If the subject requested the third meal after 17:00 $\mathrm{h}$, testing was stopped at that time point. Upon completion of the testing, subjects were asked to estimate the clock time in order to verify that they were blinded to the time of the day.

\section{Anthropometry}

Body weight (BW) was measured during screening, at the beginning and at the end of each treatment on a digital balance (Seca, model 707, Hamburg, Germany; weighing accuracy of $0.1 \mathrm{~kg}$ ) with subjects in underwear, in the fasting state, after voiding their bladder. Height was measured during screening using a wallmounted stadiometer (Seca, model 220, Hamburg. Germany). The body mass 
index was calculated by BW/height ${ }^{2}\left(\mathrm{~kg} / \mathrm{m}^{2}\right)$. The fat distribution was determined during screening by measuring the waist and hip circumferences and calculation of the waist-hip ratio (WHR). The waist circumference was measured at the site of the smallest circumference between the rib cage and the ileac crest, with the subjects in standing position. The hip circumference was measured at the side of the largest circumference between the waist and the thighs. The WHR was calculated by dividing the waist circumference by the hip circumference. Body composition was measured at baseline by using the deuterium $\left({ }^{2} \mathrm{H}_{2} \mathrm{O}\right)$ dilution technique (21). The dilution of the deuterium isotope is a measure for total body water (TBW) (14). Subjects were asked to collect a urine sample in the evening just before drinking a weighed amount of deuterium-enriched water. After ingestion of the deuterium-enriched water, no further fluid or food consumption was permitted. Ten hours later a second urine sample (second voiding) was collected. Deuterium concentration in the urine samples was measured using an isotope ratio mass spectrometer (Micromass Optima, Manchester, UK). TBW was obtained by dividing the measured deuterium dilution space by 1.04 (21). Fat-free mass (FFM) was calculated by dividing the TBW by the hydration factor 0.73 . By subtracting FFM from $B W$, fat mass (FM) was obtained. FM expressed as a percentage of BW revealed body fat percentage.

\section{Attitude towards eating}

Attitude towards eating with respect to dietary restraint was determined using a validated Dutch translation of the Three Factor Eating Questionnaire (TFEQ) $(24,27)$. Cognitive restrained and unrestrained eating behavior (factor 1), emotional eating and disinhibition (factor 2) and the subjective feeling of hunger (factor 3 ) were scored. Body weight concern and chronic dieting behavior were investigated with the Herman Polivy questionnaire (HP) (9).

\section{Blood variables}

Systolic and diastolic blood pressures were measured during screening by an automatic blood pressure monitor (Omron $705 \mathrm{CP}$, Omron Healthcare $\mathrm{GmbH}$, Hamburg, Germany). A fasting blood sample $(2 \mathrm{ml})$ was obtained and mixed with EDTA to prevent clotting. Plasma was obtained by centrifugation and then stored at $-20^{\circ} \mathrm{C}$ until analysis of glucose by a hexokinase method (Cobas Bio, Roche Diagnostics, Hoffmann-La Roche, Basel, Switzerland).

\section{On-line blood glucose monitoring}

After the subject was comfortably settled, an 18-gauge, $5 \mathrm{~cm}$ angiocath was placed in the antecubital vein of the non-dominant arm. The blood withdrawal end of a specially modified, $2.5 \mathrm{~m}$ long double-lumen catheter (MTB Medizintechnik, Amstetten, Germany) was fit into the angiocath. The catheter was continuously heparinized by pumping a sterile heparin-saline solution $(500-5000 \mathrm{U} / \mathrm{ml})$ at a rate of approximatelly $25 \mu \mathrm{l} / \mathrm{min}$ through the distal lumen of the catheter to the tip of the 
cannula. The blood and heparin-saline solution mixture was continuously withdrawn through the proximal lumen of the cannula at a rate of approximately 50 $\mu / /$ min (blood withdrawal rate $=25 \mu / \mathrm{min}$ ). The blood and heparin-saline solution mixture was mixed with a heparinized phosphate buffer, at a 1:10 ratio, and continuously infused into a sample chamber of a glucose analyzer (Model 23A, Yellow Springs Instrument Co., Yellow Springs, Ohio, USA). Approximately $15 \mathrm{mI}$ blood were withdrawn on the testing day. The transit time of this continuous sampling was approximately $4 \mathrm{~min}$, which was timed for each catheter, and accounted for in the data analysis. Sampling occurred at a rate of ten times per min, and analogue data were amplified, digitized, interfaced (Data Translation Interface Board, model 1028), and displayed continuously on a computer monitor. This monitor was not visible to the subjects. For 30 min prior to the insertion of the catheter into the subjects, and following the completion of testing, the system was calibrated using a bag of sterile saline with added a known concentration of glucose. This calibration was done using the same blood-withdrawal cannula that was used in the subject that day $(16,17,18)$.

\section{Statistics}

Data are presented as mean \pm standard error (SE). Differences between treatments were determined by analysis of variance for repeated measures (ANOVA) and Sheffe-F post-hoc test (Statview SE Graphics ${ }^{\text {TM }}$ ). The level of significance was set at $P<0.05$.

One-minute averages of blood glucose concentrations over time were plotted for each subject's test day. The data set was corrected by the exact transit time of the catheter used for sampling. An analysis program was written to determine whenever there was a period of stable baseline glucose (standard deviation < $0.055 \mathrm{mmol} / \mathrm{l}$ ) that lasted $5 \mathrm{~min}$ of longer. Transient declines in blood glucose have been defined as a decrease of at least $5 \%$ below a stable baseline glucose level (standard deviation $>0.114 \mathrm{mmol} / \mathrm{l}$ ) for at least $5 \mathrm{~min}(2,5,6)$. Dynamic declines in blood glucose were defined as rapid declines which did not originate from a stable baseline, but rather from a peak induced by nutrient ingestion (16). Transient and dynamic declines were tallied for each test day, and the number of times that meal initiation occurred in the presence or absence of a blood glucose decline was quantified. Postabsorptive refers to the state when all the previously inglested food has been absorbed from the digestive tract, whereas postprandial refers to the state when the digestive tract contains ingested food. Since, in the present study, testing started at least $10 \mathrm{~h}$ after the last nutrient ingestion, the postabsorptive state was defined as the period from the beginning of testing until the first meal consumption. The postprandial state was defined as the period from the first meal consumption until the end of testing. Associations between meal initiations and changes in blood glucose were tested using the $x^{2}$-test for $2 \times 2$ contingency tables. with correction for continuity (19). 


\section{RESULTS}

The subjects were in negative energy balance during the time-blinded test. BW loss during 2 -week treatment was $2.5 \pm 0.4 \mathrm{~kg}, 1.8 \pm 0.3 \mathrm{~kg}$ and $1.8 \pm 0.4 \mathrm{~kg}$ during $\mathrm{SSM}^{+}, \mathrm{SSM}$ and $\mathrm{SM}$, respectively and not significantly different between treatments. During the first trial, BW loss was greater than during the second and the third trial $(2.9 \pm 0.3 \mathrm{~kg}, 1.9 \pm 0.3 \mathrm{~kg}$ and $1.3 \pm 0.3 \mathrm{~kg}$, respectively; $P<0.001)$. There was no difference in $\mathrm{BW}$ loss between treatments during the first, the second or the third trial. Mean body weight regain amounted $0.6 \pm 0.4 \mathrm{~kg}$ during washout from the first to the second trial and $0.6 \pm 0.3 \mathrm{~kg}$ during washout from the second to the third trial. This is $20 \%$ and $32 \%$ of body weight lost during the previous trial, respectively.

During each test two to four spontaneous meal initiations occurred, but there was no difference in the number of meal initiations between treatments $(S S M+, 3.1 \pm$ $0.2 ; S_{S M}, 3.2 \pm 0.2 ; S M, 3.0 \pm 0.2$ ).

(a)

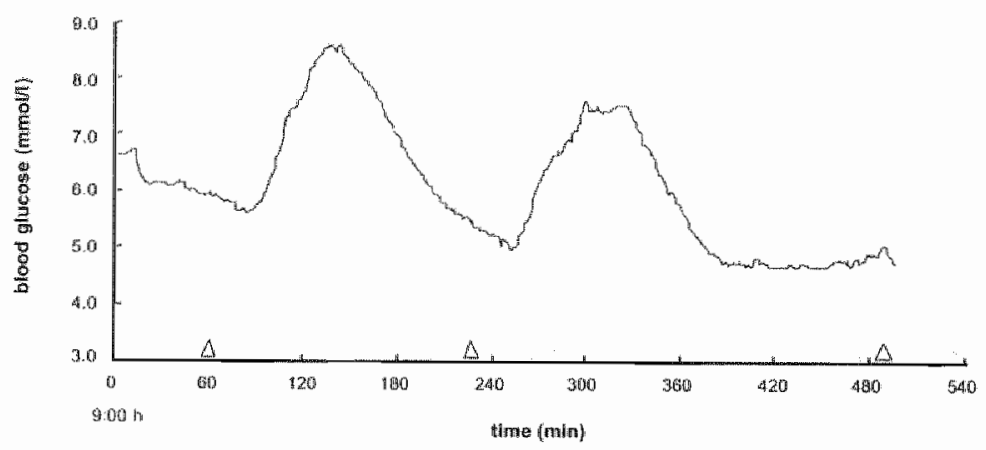

(b)

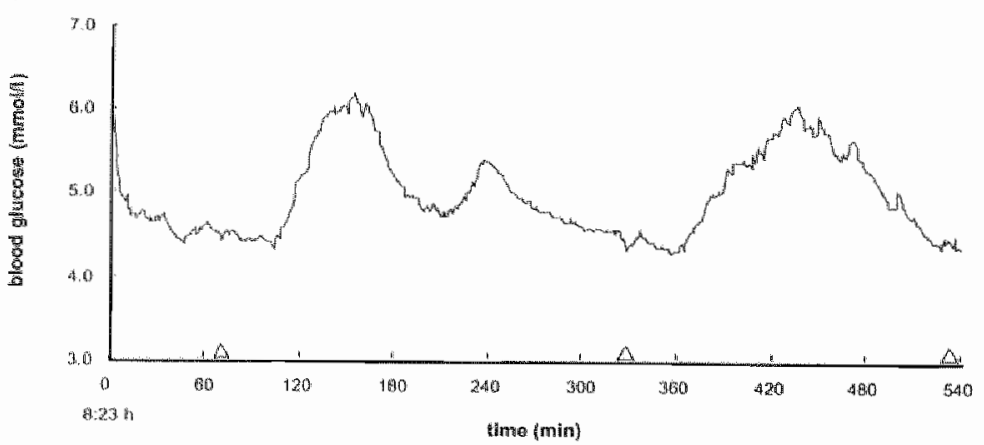

Figure 1 Blood glucose profiles of wo subjects during testing with solid meals. $\Delta_{\text {, Initiation of }}$ meal. In both cases, the first meal was initiated in absence of a transient decline. (a) The second meal was initiated at the nadir of a dynamic decline and the third meal occurred during a period of relative stable blood glucose after a dymamic decline. (b) The second meal occurred in association with a postprandial transient decline and the third meal was initiated at the nadir of a dynamic decline. 
Table 2 Responses observed in relationship between blood glucose patterns and spontaneous meal initiations for each treatment

\begin{tabular}{|c|c|c|c|c|c|c|}
\hline & \multicolumn{3}{|c|}{$\begin{array}{c}\text { Declines in blood glucose } \\
\text { associated with meal } \\
\text { iniliations }\end{array}$} & \multicolumn{3}{|c|}{$\begin{array}{c}\text { Neal initiations associated } \\
\text { wilh declines in blood } \\
\text { glucose }\end{array}$} \\
\hline & yes & no & tolal & yes & no & tolal \\
\hline \multicolumn{7}{|l|}{ Semisolid meal with guar gum } \\
\hline postabsorptive transient & 0 & 0 & 0 & 0 & 13 & 13 \\
\hline postprandial transient & 2 & 0 & 2 & 2 & 11 & 13 \\
\hline postprandial dynamic & 13 & 15 & 28 & 13 & 0 & 13 \\
\hline \multicolumn{7}{|c|}{ Semisolid meal without guar gum } \\
\hline postlabsorplive transient & 0 & 0 & 0 & 0 & 14 & 14 \\
\hline postprandial transient & 1 & 0 & 1 & 1 & 12 & 13 \\
\hline postprandial dynamic & 15 & 17 & 32 & 15 & 0 & 15 \\
\hline \multicolumn{7}{|l|}{ Solid meal } \\
\hline postabsorptive transient & 0 & 0 & 0 & 0 & 13 & 13 \\
\hline postprandial transient & 1 & 0 & 1 & 1 & 10 & 11 \\
\hline postprandial dynamic & 13 & 13 & 26 & 13 & 0 & 13 \\
\hline
\end{tabular}

The subject's estimation of clock time at the end of the testing day ranged from -96 to $+198 \mathrm{~min}$, verifying that the subjects were blinded to the time of the day.

From the total of 45 testing days, 40 blood glucose curves were complete to be used for calculations. The other 5 blood glucose curves were stopped early because of occlusion of the catheter by clotting and were therefore not used for calculation. Examples of glucose curves are depicted in Figure 1. There were no significant differences among the three treatments in the number of postabsorptive and postprandial declines in blood glucose of in associations between meal initiations and blood glucose dynamics (Table 2). Moreover there were no significant treatment differences in baseline blood glucose measured by on-line blood glucose monitoring, plasma glucose, insulin, free fatty acids, glycerol, Bhydroxybutyrate (11) and respiratory quotient (unpublished data). Therefore the results for SSM+. SSM and SM were pooled for further analysis. In the postabsorptive state, no transient declines occurred. The 40 meal initiations in the postabsorptive state were not associated with changes in blood glucose patterns (Table 3). In the postprandial state, 86 dynamic declines occurred and spontaneous meal initiation occurred during $41(48 \%)$ of these declines (Table 3). Moreover, in the postprandial state, 4 transient declines occurred, all associated with spontaneous meal initiation (Table 3). Finally, in the postprandial state, 33 more meals occurred in the absence of blood glucose declines (Table 3). Thus, blood glucose declines only occurred in the postprandial state and were associated with meal initiations in $50 \%$ of the total number of cases. In the 
Table 3 Responses observed in relationship between blood glucose patterns and spontaneous meal initiations for all treatments combined

\begin{tabular}{|c|c|c|c|c|c|c|}
\hline & \multicolumn{3}{|c|}{$\begin{array}{c}\text { Declines in blood glucose } \\
\text { associated with meal } \\
\text { initiations }\end{array}$} & \multicolumn{3}{|c|}{$\begin{array}{c}\text { Meal initiations associated } \\
\text { with declines in blood } \\
\text { glucose }\end{array}$} \\
\hline & yes & no & total & yes & mo & total \\
\hline postabsorptive transient" & $\begin{array}{l}0 \\
(-)\end{array}$ & $\begin{array}{l}0 \\
(-)\end{array}$ & 0 & $\begin{array}{c}0 \\
(0 \%)\end{array}$ & $\begin{array}{c}40 \\
(100 \%)\end{array}$ & 40 \\
\hline postprandial transient ${ }^{2}$ & $\begin{array}{c}4 \\
(100 \%)\end{array}$ & $\begin{array}{c}0 \\
(0 \%)\end{array}$ & 4 & $\begin{array}{c}4 \\
(11 \%)\end{array}$ & $\begin{array}{c}33 \\
(89 \%)\end{array}$ & 3.7 \\
\hline postprandial dynamic & $\begin{array}{c}41 \\
(48 \%)\end{array}$ & $\begin{array}{c}44 \\
(52 \%)\end{array}$ & 86 & $\begin{array}{c}4 i \\
(100 \%) \\
\end{array}$ & $\begin{array}{c}0 \\
(0 \%)\end{array}$ & 41 \\
\hline
\end{tabular}

$n=40$ testing days. Association between meal initiations and blood glucose declines was determined using the $X^{2}$-test. " $X^{2}=$ error; $^{2} X^{2}=2.63, P>0.1 ;{ }^{3} X^{2}=26.8, P<0.001$.

postabsorptive state, meal initiations occurred always in the absence of blood glucose declines. In the postprandial state, $58 \%$ of the meal initiations occurred in the presence of blood glucose declines. Only the association between meal initiations and postprandial dynamic declines was statistically significant $(P<$ 0.001 ; Table 3).

\section{DISCUSSION}

In the present study, transient declines in blood glucose were completely absent in the postabsorptive state in overweight men who were in a negative energy balance. This is in contrast to earlier studies with similar experimental conditions in which postabsorptive transient declines in blood glucose were highly associated with sponteneous meal initiations in humans who were in energy balance $(6,16,18)$ and in rats $(2,13)$. Campfield and Smith (5) have proposed that it is the pattern of blood glucose over time, ie the transient decline in blood glucose, rather than glucose concentration per se that signals meal initiation, indicating a need for fuel ingestion to the organism. However, the findings of the present study are more in line with the results of a recent study in which it was observed that postabsorptive transient declines in blood glucose are infrequent in glycogenmdepleted lean subjects (17). In that study, spontaneous meal initiation occurred in the absence of such declines, and it was thus suggested to be associated with deprivationinduced feeding. In the present study, a first explanation for the absence of transient declines in the postabsorptive state may be that subjects were in a negative energy balance. During the 2 weeks prior to testing they consumed 3.6$4.0 \mathrm{MJ} /$ day lless than during a normal situation (10). Carbohydrate intake was also diminished and subjects were in a negative carbohydrate balance. The absence of postabsorptive transient declines in blood glucose may therefore be explained by 
decreased substrate awailability. In this respect, decreased substrate availability after 2 weeks of low-energy diet was evidenced by a relatively high concentration of free fatty acids (mean for the three treatments: $408 \mu$ moll $(11)$ ) and a relatively low respiratory quotient (approximately 0.79; unpublished data) in the fasting state. similar to the findings of Melanson et al. (17) in glycogen-depleted lean subjects. Moreover, increased hepatic fatty acid oxidation was indicated by a relatively high concentration of fasting plasma $\mathbb{B}$-hydroxybutyrate (mean for the three treatments: $258 \mathrm{mmol} / \mathrm{l}(11) \mathrm{)}$. In this regard, fatty acid oxidation is associated with decreased hunger and reduced food intake (12). Baseline blood glucose levels measured by on-line blood glucose monitoring $(4.8 \mathrm{mmol} /)$ were similar to the levels measured in lean subjects in stable energy balance $(4.5 \mathrm{mmol} / 1(16,18))$, indicating that mechanism are activated in order to maintain glycemia to a normal level during negative energy balance. Hepatic fatty acid oxidation fuels gluconeogenesis, and a constantly high level of gluconeogenesis in negative energy balance may be a reason for the absence of postabsorptive transient declines in blood glucose. A second explanation for the absence of transient declines in the postabsorptive state may be that subjects were overweight, therefore having a less pronounced food intake regulation and blood glucose response compared to young lean male subjects (1). Further research is needed to assess whether the absence of postabsorptive transient declines is due to the energy balance state (negative ws positive energy balance) or to subject's characteristics (overweight vs lean) (7). If the absence of transient declines is related to a negative energy balance, the relationship between spontaneous meal initiations and transient declines in blood glucose is only present within a normal physiological range of energy (carbohydrate) status.

Postprandially, dynamic declines were associated with spontaneous meal initiations, which has been previously reported $(16,17,18)$. However, Melanson et al. $(16,17,18)$ observed a higher association between meal initiations and postprandial dynamic declines $(71-78 \%)$ compared to the association found in the present study (48\%). The fact that postprandial dynamic declines initiate only $48 \%$ of meals may indicate that food intake regulation in these subjects is less conditioned by blood glucose response. Postprandially, all transient declines initiated a meal. However, because only few transient declines occurred and because most of the meals were initiated in absence of a transient decline, no association between meal initiation and transient declines was found. This is in contrast to other studies in which spontaneous meal initiations in the postprandial state was associated with transient declines in blood glucose $(16,17,18)$. Melanson et al. (17) observed that transient declines in the postprandial state became apparent and were significantly associated with spontaneous meal initiations, even in glycogen-depleted lean subjects after refeeding with highcarbohydrate or high-fat food and beverages. In the present study, however, the subjects were not only in negative energy balance prior to testing but they also consumed low-energy meals throughout the day. The resulting low substrate 
availability and increased hepatic fatty acid oxidation during testing might explain the absence of a relationship between meal initiations and postprandial transient declines. The association between spontaneous meal initiations and transient declines is therefore likely dependent on glycogen stores or postprandially avalable carbohydrates. Thus, in negative energy balance, the usual relationship between tramsient declines and spontaneous meal initiations was completely absent also postprandially. indicating a loss of physiological food intake regulation in the overweight while dieting. This might have implications for weight maintenance, in that this can only be achieved by increasing cognitive restraint (26). Food intake regulation that still was associated with blood glucose patterns consisted of the postprandial association of meal initiations with very rare transient declines and with $48 \%$ of the dynamic declines.

In summary, postprandial dynamic blood glucose declines were significantly associated with meal initiations, but postabsorptive and postprandial transient declines were not. Therefore, we conclude that in overweight subjects, the usual association between transient declines and spontaneous meal initiations was completely absent in negative energy balance.

\section{ACKNOWLEDGEMENT}

Supported by Novartis Consumer Health Ltd, Nyon, Switzerland.

\section{REFERENCES}

1. Björntorp P. Disturbances in the regulation of food intake. Obesity: anatomic and physiologicbiochemical observations. Adv Psychosom Med 1972; 7: 116-127.

2. Campfield LA Brandon P. Smith FJ. On-line continuous measurement of blood glucose and meal paltern in free-feeding rats: the role of glucose in meal initiation. Brain Res Bulf 1985* 14. $605-616$.

3. Campfield LA, Smith FJ. Functional coupling between transient declines in blood glucose and feeding behavior: temporal relationships. Brain Res Bull 1986; 17: 427-433.

4. Campfield LA. Smith FJ. Transient decines in blood glucose signal meal initiation. Int $J$ Obes $1990 ; 14: 15-33$.

5. Campfield LA, Smith FJ. Systemic factors in the control of food intake: evidence for patterns as signals. In: Stricker EM (ed). Handbook of Behavioral Neurobiology: Neurobiology of Food and Fluid htake. Plenum Press: New York, 1990, pp 183-206.

6. Campfield LA, Smith FJ, Rosenbaum M, Hirsch J. Human eating: evidence for a physiological basis using a modified paradigm. Neurosei Biobehav Rev 1996; 20: 133-137.

7. Flatt JP. Is rood intake regulation based on signals arising in carbohydrate metabolism inherently inadequate for accurate regulation of energy balance on high-fat diets? Behav Brain Sci 1981; 4: $581-583$.

8. Flatt JP. Carbohydrate balance and body weight regulation. Proc Nutr Soc 1996: 55: 449465.

9. Herman CP. Polivy J. Restrained eating. In: Stunkard AJ (ed). Obesity. W.B. Saunders: Philadelphia, 1980, pp 208-225. 
10. Kovacs EMR, Wastenterp-Plantenga MS. Saris WHW, Melanson K. Goossens 1, Geurten p. Brouns $F$. The effect of addition of modified guar gum to a low-energy semisolid meal on appetite and body weight loss. In $J$ Obes 2001: 25: 307-315.

11. Kovacs EMR, Mesteterp-Plantenga MS. Saris WHM, Melanson KJ, Goossens 1, Geurten P. Brouns $F$. The effect of guar gum addition to senisolid meal on appetite related lo blood glucose, in dieting men. Eur $J$ Chin Nutr 2002; 56: 771-778.

12. Lamghans W. Metabolic control of food intake. Role of the liver. In: Westerterp-Plantenga MS. Steffens AB. Tremblay A (eds). Regulation of food intake and energy expendikre. Edra: Mlano, 1999. pp. 185-199.

13. Loulis-Sylvestre ", Le Magnen $\rfloor$. A fall in blood glucose level precedes mes onset in free feeding rats. Neurosci Biobehav Rev 1980; 4: 13-15.

14. Marken Lichtenbelt WD van, Westerterp KR, Wouters L. Deulerium dilution as a melhod for determining lotal body water: effect of test protocol and sampling time. Br J Nutr 1994; 72 : $491-497$.

15. Mayer J. Glucostatic mechanisms in the regulation of food intake. N Engl J Med 1953: 249 : 13-16.

16. Melanson KJ, Westerterp-Plantenga MS, Smith FJ, Campfield LA, Saris WHMt. Blood glucose patterns and appetite in time-blinded humans: carbohydrate wersus fat. Am physiol $1999 ;$ 277: R337 $\mathbb{R} 345$.

17. Melanson KJ. Westerterp Plantenga MS, Campfield LA, Saris WHM. Appetite and blood glucose profiles in humans following glycogen-depleting exercise. I Appl Physiol 1999; 87 : $947-954$.

18. Melanson KJ, Westerterp Plantenga MS, Campfielid LA, Saris WHM. Blood glucose and meal patterns in imemblinded males, after aspartame, carbohydrate and fat consumption, in relation to sweetness perception. Br J Nutr 1999; $82: 437-446$.

19. Parker RE. In: Arnold E (ed). Introductory Statistics for Biology. The Camelot Press: Southampton, 1986, pp. 43-54.

20. Pollack C.P. Green J, Smith GP. Blood glucose prior to meal request in humans isolated from all temporal cues. Physiol Bahav 1989; 49; 529-534.

21. Schoeller DA, Santen EV. Peterson DW, Diez W. Jaspan J, Klein PD. Total body water measurement in humans with ${ }^{18} \mathrm{O}$ and ${ }^{2} \mathrm{H}$ labeled water. Am I Chn Nutr 1980; 33: 2686-2693.

22. Smith FJ, Campfield LA. Meal initiation occurs after experimental induction of transilent declimes in blood glucose. Am f Physial 1993; 265: R1423-R1429.

23. Steffens AB. Plasma insulin content in relation to blood glucose level and meal pattern in the normal and hypothalamic hyperphagic rat. Physiol Behav $1970 ;$ 5: 147-151.

24. Stunkard AJ, Messick S. The three-factor eating questionnaire to meastre dietary restraint. disintibition, and hunger. A Psychosom Res 1985; 29: 71-83.

25. Van Italie TB. The gucostatic theory 1953-1988: roots and turanches. int I Obes $1990 ; 14$ $(5$ ipplipi: $1-10$.

26. Westerterp-Plantenga MS, Kempen KPG, Saris WHM. Deteminants of weight maintenance In women after diet-induced weight reduction. Int J Obes 1998; 22: 1-6.

27. Westerterp-Plantenga MS, Rolland W. Wison SAj, Westerterp KR. Satlety related to 24 h diet-induced thermogenesis during high proteindcarbohydrate ws high fat diets measured in a respiration chamber. Eur J Clin Nutr 1999; 53: 1-8. 


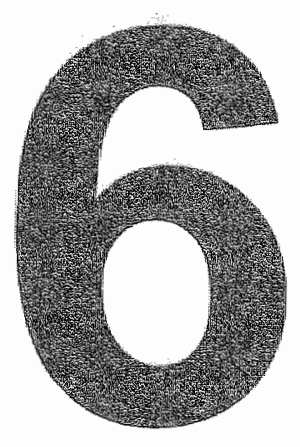

\section{Effects of 2-week ingestion of (-)-} hydroxycitrate and (-)-hydroxycitrate combined with medium-chain

\section{triglycerides on satiety and food intake}

Kovacs EMR, Westerterp-Plantenga MS, de Vries M, Brouns F, Saris WHM 


\section{ABSTRACT}

The aim of this study was to assess the effects of 2 weeks supplementation with (-hydroxycitrate (HCA) and HCA combined with medium-chain triglycerides (MCT) on satiety and energy intake. The experimental design consisted of three intervention periods of 2 weeks separated by washout periods of 2 or 6 weeks in a double-blind, placebo-controlled, randomized, and cross-over design. Seven male and 14 female normal to moderately obese subjects (mean $\pm S D$; age, $43 \pm 10 \mathrm{y}$; body mass index, $27.6 \pm 2.0 \mathrm{~kg} / \mathrm{m}^{2}$ ) participated in this study. Subjects consumed three self-selected meals and four isoenergetic snacks daily with either no supplementation (PLA), with $500 \mathrm{mg} \mathrm{HCA}$ (HCA) or $500 \mathrm{mg} \mathrm{HCA}$ and $3 \mathrm{~g} \mathrm{MCT}$ (HCA+MCT). Each intervention period ended with a test day, consisting of a standardized breakfast and ad libitum a lunch and a dinner. There was a significant body weight loss during the 2 weeks of intervention ( $P L A,-0.5 \pm 0.3 \mathrm{~kg}, P$ $<0.05 ; \mathrm{HCA},-0.4 \pm 0.2 \mathrm{~kg}, P<0.05 ; \mathrm{HCA}+\mathrm{MCT},-0.7 \pm 0.2 \mathrm{~kg}, P<0.01)$, but this reduction was not different between treatments. 24-h energy intake (PLA, $8.1 \pm 0.3$ $\mathrm{MJ} ; \mathrm{HCA}, 8.3 \pm 0.3 \mathrm{MJ} ; \mathrm{HCA}+\mathrm{MCT}, 8.4 \pm 0.3 \mathrm{MJ})$ and the area under the curve of the appetite-related parameters during the test day were similar for all treatments. Two weeks of supplementation with HCA and HCA combined with MCT did not result in increased satiety or decreased energy intake compared to placebo in subjects losing body weight.

Key words: (-)-hydroxycitrate, medium-chain triglycerides, appetite, satiety, energy intake, body weight loss 


\section{INTRODUCTION}

The increasing incidence of obesity is a recognized medical problem in developed countries (34). However, treatment of obesity is often unsuccessful. Weight loss can be achieved, but long-term weight maintenance after weight loss is rarely shown $(8,28,43)$. Therefore, identification of substances that increase satiety or at least sustain satiety during energy restriction is needed. One possible way to improve satiety is by increasing hepatic fatty acid oxidation (33). Therefore, finding ways to stimulate hepatic fatty acid oxidation should be promising for appetite and weight control. In this experiment we propose to interfere in post-ingestive modullation of fat-induced satiety by stimulating hepatic fatty acid oxidation. We therefore investigated the potential of (-)-hydroxycitrate (HCA), which is believed to induce hepatic fatty acid oxidation $(25,39,42)$, and medium-chain triglycerides (MCT), which are more readily oxidized $(9,29,31,36)$, to increase satiety. HCA is an active ingredient that is extracted from the rind of the fruit Garcinia cambogia, a native species to India, and is promoted as a weight loss agent. HCA is an inhibitor of ATP-citrate-lyase, a cytosolic (extramitochondrial) enzyme that catalyzes the cleavage of citrate to oxaloacetate and acetyl-CoA $(38,40,42)$. The effect of HCA would therefore be to reduce the acetyl-COA pool, limiting the availability of 2carbon groups required for the synthesis of fats and cholesterol. In this respect, HCA might promote weight maintenance by inhibiting or limiting the capacity for de novo lipogenesis (38). Furthermore, HCA might induce weight loss through increased satiety by increasing fatty acid oxidation $(24,26)$, probably by inhibition of acetyl-CoA and subsequently of malonyl-CoA formation that in turn, would stimulate carnitine transferase activity, or by increasing the rate of glycogen synthesis in the liver (13). Up to now, however, the results on the effects of HCA on appetite, body weight (BW) and energy expenditure and its possible contribution as a weight loss agent in humans are controversial $(4,7,16,32)$. Several studies found a positive effect of HCA administration alone or in combination with other ingredients on appetite, energy intake. BW loss or energy expenditure $(3,6,10,23,41,45)$, but others did not $(15,19,20,21,30)$. MCT have been repeatedly suggested to contribute to the control of body weight. MCT are known to be rapidly hydrolyzed and absorbed $(1,5)$. It has been shown that fatty acids delivered by MCT are preferentially oxidized and poorly stored within tissues, and that MCT have a marked thermic effect (17). In addition to that, MCT have been shown to have satiating properties and to decrease food intake $(29,36,46)$ by involving a cascade of pre-absorptive and post-absorptive mechanisms. However, the exact mechanism underlying the reduction in food intake after MCT ingestion is not fully understood $(1,2)$. In another study, we concentrated on the effects of HCA and HCA combined with MCT on energy expenditure while feeding subjects in energy balance (19). In the present study, we concentrated on the effects of HCA and HCA combined with MCT on satiety and energy intake during ad libitum feeding. Therefore, the aim of the present study was to investigate the effects of 2 -week ingestion of HCA and MCT on satiety and energy intake. We hypothesized that HCA 
supplementation might affect BW regulation by inducing satiety and reducing food intlake. We further hypothesized that the combination of HCA and MCT may have a stronger effect on satiety compared to HCA alone.

\section{METHODS}

\section{Subjects}

Seven male and 14 female normal to moderately obese subjects participated in this study. The subjects were recruited by advertisements in locall newspapers, in which we asked for moderately obese male and female subjects who wanted to participate in a study on the effects of natural food supplements on appetite, food intake, and body weight. Selection took place following health criteria (no diabetes. no cardiovascular diseases, no medical treatment) and BW criteria (body mass index: $\left.24-32 \mathrm{~kg} / \mathrm{m}^{2}\right)$. Baseline characteristics are presented in Table 1 . The nature and risks of the experimental procedure were explained to the subjects, and all subjects gave their written informed consent. The study was approved by the Ethics Committee of Maastricht University.

\section{Experimental design}

The experiment had a double-blind, placebo-controlled, randomized, cross-over design. The experimental design consisted of three intervention periods of 2 weeks separated by washout periods of 2 or 6 weeks (Figure 1), to ensure that the women were always in the same phase of the menstrual cycle. Statistical analysis (t-test) of the results revealed that there were no differences between the washout periods of 2 or 6 weeks, with respect to the energy intake on the test day.

Tablo 1 Subjects characteristics $(n=21 ; 7$ men and 14 women) at baseline

\begin{tabular}{lcc}
\hline & mean $\pm \mathrm{SD}$ & range \\
\hline Age $(\mathrm{y})$ & $43 \pm 10$ & $29-57$ \\
Height $(\mathrm{m})$ & $170 \pm 8$ & $155-180$ \\
Weight $(\mathrm{kg})$ & $79.3 \pm 9.0$ & $61.2-93.0$ \\
Body maiss index $\left(\mathrm{kg} / \mathrm{m}^{2}\right)$ & $27.6 \pm 2.0$ & $24.0-31.5$ \\
Waist circumiference $(\mathrm{cm})$ & $88 \pm 8$ & $74-104$ \\
Hip circumference $(\mathrm{cm})$ & $104 \pm 6$ & $95-116$ \\
Waist-hip ratio & $0.85 \pm 0.08$ & $0.74-1.01$ \\
F1 (cognitive restraint) & $8 \pm 3$ & $1-14$ \\
F2 (disinhibition) & $6 \pm 3$ & $1-11$ \\
F3 (hunger) & $5 \pm 3$ & $0-10$ \\
Herman-Palivy restraint & $16 \pm 5$ & $6-30$ \\
\hline
\end{tabular}

F1-F3, factors $1-3$ of the Three Factor Eating Questionnaire. 
During the washout periods, the subjects consumed a self-selected and selfprepared diet. During the intervention periods, the subjects consumed at home three self-selected and self-prepared meals daily (breakfast, lunch, and dinner) with no restriction regarding type and amount of food. They were instructed to drink maximally one glass of alcoholic beverage per day. Between the mealls, the subjects consumed an isoenergetic snack (cereal bar) of $22 \mathrm{~g}$ (energy, $420 \mathrm{~kJ}$; protein, $0.7 \mathrm{~g}$; fat, $4 \mathrm{~g}$; carbohydrate, $14 \mathrm{~g}$; dietary fibre, $0.5 \mathrm{~g}$ ) with no supplementation (PLA), with supplementation of $500 \mathrm{mg}(-$ )-hydroxycitrate (HCA; $850 \mathrm{mg}$ SuperCitrimax HCA 600 SXG, HCA content: 58,81\%, EuroChem Feinchemie GmbH, München, Germany) or $500 \mathrm{mg}$ HCA and $3 \mathrm{~g}$ MCT (HCA+MCT). The dosage of HCA used was similar or even higher to that used in several studies in which an effect of HCA on BW loss was found $(500 \mathrm{mg}, 3$ times/d $(3,6) ; 55-110$ mg, 2 times/d (10)). The snacks were consumed at four fixed time points: 1 h before lunch, $2 \mathrm{~h}$ after lunch, $1 \mathrm{~h}$ before dinner and $2 \mathrm{~h}$ after dinner. The snack was used for practical comfort, because HCA (powder) and MCT (oil) could be easily incorporated into the product. Between the meals, the subjects were not allowed to eat with exception of the prescribed snacks. They were allowed to drink ad libitum water, coffee and tea (without sugar and milk).

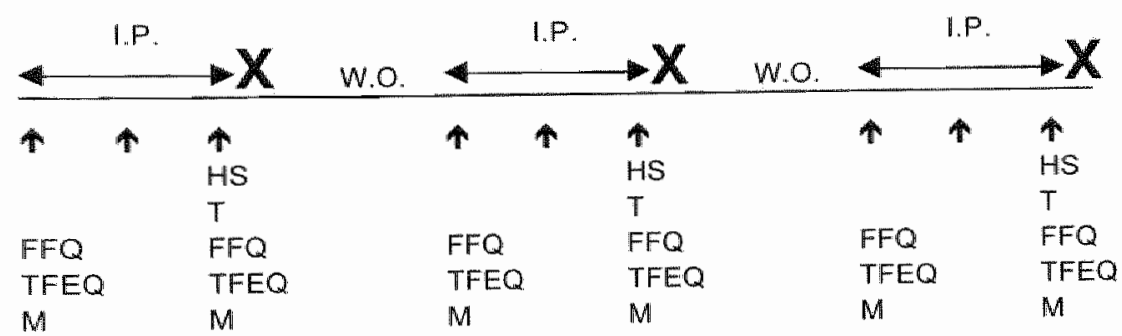

Figure 1 Experimental design.

L.P. $=$ imtervention periods; $W . O .=$ washout periods; $\mathbf{X}=$ test day; $\boldsymbol{\uparrow}=$ measurement of body weight; $H S=$ questiannaires on hunger and satiety; $T=$ questionnaire on tolerance; $F F Q=$ food frequency questionnaire; $T F E Q=$ questionnaire on eating behavior; $M=$ questionnaire on mood.

\section{Anthropometry}

BW was measured during screening, at the beginning, after 1 week and all the end of each intervention period on a digital balance accurate to $0.02 \mathrm{~kg}$ (Chyo MW. $150 \mathrm{~K}$, Japan) with subjects in underwear, in the fasted state and after woiding their bladder. Height was measured to the nearest $0.1 \mathrm{~cm}$ during screening using a wall-mounted stadiometer (Seca, model 220, Hamburg, Germany). The body mass index was calculated by BW/height ${ }^{2}\left(\mathrm{~kg}^{\mathrm{m}} \mathrm{m}^{2}\right)$.

The distribution of fat was investigated during screening by measuring the waist and hip circumferences and calculation of the waist-hip ratio (WHR). The waist circumference was measured at the site of the smallest circumference between 
the rib cage and the lleac crest, with the subjects in standing position. The hip circumference was measured at the site of the largest circumference between the waist and the thighs. The WHR was calculated by dividing the waist circumference by the hip circumference.

\section{Eating behavior}

Eating behavior was analyzed during screening, at the beginning and at the end of each intervention period using a validated Dutch translation of the Three-Factor Eating Questionnaire (TFEQ) $(37,44)$. Cognitive restrained and unrestrained eating behavior (factor 1), emotional eating and disinhibition (factor 2) and the subjective feeling of hunger (factor 3) were scored. Body weight concern and chronic dieting behavior were investigated with the Herman Polivy questionnaire (HP) during screening, at the beginning and at the end of each intervention period (14).

\section{Daily energy intake}

Energy intake over the previous week was recorded at the beginning and at the end of each intervention period using a food frequency questionnaire. Personal instruction was given in advance. The questionnaires were analyzed using the Dutch food composition table (35) and the accessory computer program (Becel Nutrition Program 1988). Daily energy intake before and during intervention was compared with predicted 24-h energy expenditure (12) that amounted on average $10.6 \pm 0.3 \mathrm{MJ} / \mathrm{d}$ in all treatments. Since this was significantly higher compared to the reported energy intakes (before intervention: $\mathrm{PLA}, 7.4 \pm 0.5 \mathrm{MJ} / \mathrm{d}$; $\mathrm{HCA}, 6.9 \pm 0.5$ $\mathrm{MJ} / \mathrm{d}$; HCA $+\mathrm{MCT}, 7.3 \pm 0.6 \mathrm{MJ} / \mathrm{d}$; during the second week of intervention: PLA, $8.0 \pm$ $0.5 \mathrm{MJ} / \mathrm{d} ; \mathrm{HCA}, 7.7 \pm 0.4 \mathrm{MJ} / \mathrm{d} ; \mathrm{HCA}+\mathrm{MCT}, 7.8 \pm 0.4 \mathrm{MJ} / \mathrm{d}$ ), these data were not further used to express daily energy intake.

\section{Mood}

Mood questionnaires were completed at the beginning and at the end of each intervention period (22). The subjects indicated on anchored $100 \mathrm{~mm}$ visual analogue scales ranging from "not at all" to "extremely" how relaxed, gloomy, fine, angry, scared, and sad they felt.

\section{Tolerance}

Tolerance questionnaires were completed at the end of each intervention period. The subjects indicated on a 5-point scale questionnaire $(0=$ not al all, $1=$ less, $2=$ sometimes. 3 = rellatively much, 4 = very much) how intensively they experienced unwell feeling, headache, weakness, tiredness, nausea, vomit, eructation, abdominal pain, bloating, flatulence, constipation, diarrhea, dryness in the mouth, changes in taste, increased sweat production, and increased thirst. 


\section{Test day}

At the end of each interwention period, the subjects were invited for an experiment in the laboratory assessing 24-h energy intake and appetite profile.

The subjects arrived between 7:30 and 9:00 $\mathrm{h}$, always at the same day of the week and at the same time of the day. They received a standardized breakfast. consisting of bread, butter, cheese, coffee or tea. After breakfast they left and returned between $12: 00$ and 13:00 h for lunch. Lunch, consisting of bread (brown, white), a choice of sweet and savory bread filling (jam, chocolate vermicelli, cheese, and ham) and different kinds of drinks (milk, tea, and coffee) was consumed ad libitum. The subjects refurned again between 17:00 and 18:30 $\mathrm{h}$ for dinner. Dinner. which consisted of a cooked meal (pasta or nasi for vegetarians) and a dessert, was also consumed ad libitum. The foods offered during the test day were typical Dutch items, according to food consumption surveys (27). Between the meals, the subjects were not allowed to eat with exception of the prescribed snacks, water. coffee and tea (without sugar and milk). Energy intake and food selection were determined.

Appetite profile during the day was scored on anchored $100 \mathrm{~mm}$ visual analogue scales and completed at ten fixed time points, respectively immediately before and after breakfast, in the morning between 10:00 and 11:00 h, immediately before and after lunch, in the afternoon between $14: 30$ and $15: 30 \mathrm{~h}$, immediately before and after dinner, in the evening between $21: 00$ and 22:00 $\mathrm{h}$, and before sleeping (44).

\section{Statistical analysis}

Data are presented as mean \pm standard error (SE). Differences between the treatments were determined by analysis of variance for repeated measures (ANOVA) and Sheffe-F post-hoc test (Statview SE Graphics ${ }^{\text {TM }}$ ). The measurements at the beginning and at the end of the experiment were compared using paired $t$ tests. Pearson correlation coefficients, $r$, were calculated to determine the relationship between selected variables. The level of significance was set at $P<$ 0.05 .

\section{RESULTS}

There was a significant BW loss during the 2 weeks treatment for the whole group (PLA, $-0.5 \pm 0.3 \mathrm{~kg}, P<0.05$; HCA, $-0.4 \pm 0.2 \mathrm{~kg}, P<0.05 ; \mathrm{HCA}+\mathrm{MCT},-0.7 \pm 0.2 \mathrm{~kg}$; $P<0.01$ ). However, BW reduction was not different between treatments for the whole group as well as for the men and women apart. BW loss was greater during the first compared to the second and third intervention periods $(-1.2 \pm 0.5 \mathrm{~kg} \mathrm{Vs}-0.2$ $\pm 0.2 \mathrm{~kg}$ and $-0.3 \pm 0.2 \mathrm{~kg}$. respectively; $P<0.001$ )

Scores on the HP and the TFEQ questionnaires were similar for all treatments and did not change during treatment.

There was no difference in mood before and after intervention between treatments. The snacks were well tolerated and values for complaints remained low. The smacks were similarly tollerated in all treatments. 


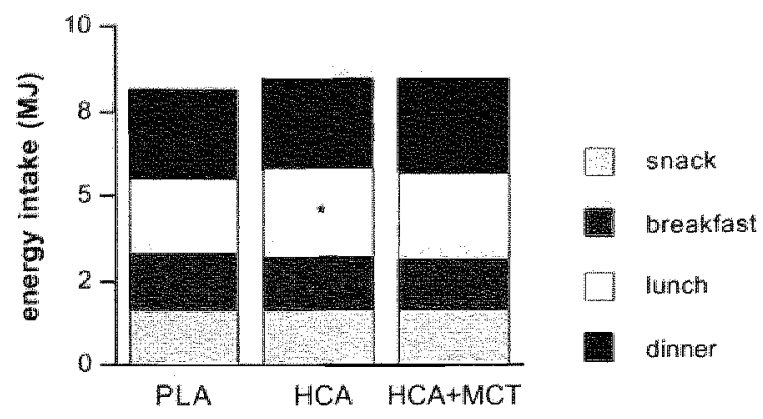

Figure 2 Energy intake during the test day

Values are mean. PLA = placebo; HCA $=(-)$-hydroxycitrate; $M C T=$ medium-chain triglycerides. Statisticall significance was determined by an analysis of variance for repeated measures (ANONA) * HCA significantly different from PLA $(P<0.05)$ during lunch.

24-h energy intake during the test day for the whole group was similar in all reatments (PLA, 8.1 $40.3 \mathrm{MJ} ; \mathrm{HCA}, 8.4 \pm 0.2 \mathrm{M}$; HCA+MCT, $8.4 \pm 0.3 \mathrm{MJ}$ ). 24-h energy intake was similar in all treatments for both men (PLA, 9.4 $\pm 0.3 \mathrm{MJ} ; \mathrm{HCA}$, $9.2 \pm 0.2 \mathrm{MJ} ; \mathrm{HCA}+\mathrm{MCT}, 9.3 \pm 0.3 \mathrm{MJ}$ ) and women (PLA, $7.4 \pm 0.2 \mathrm{MJ} ; \mathrm{HCA}, 7.9 \pm$ $0.2 \mathrm{M} ; \mathrm{HCA}+\mathrm{MCT}, 7.9 \pm 0.3 \mathrm{MJ})$. 24-h energy intake was lower compared to predicted 24-h energy expenditure (10.6 $\pm 0.3 \mathrm{MJ})(12)$ in all treatments, confirming that the subjects were in a negative energy balance during the test day. Energy intake was similar for all treatments during breakfast and dinner, but was higher with HCA compared to PLA during lunch (PLA, $2.2 \pm 0.2 \mathrm{MJ} ; \mathrm{HCA}, 2.6 \pm 0.1 \mathrm{MJ} ; \mathrm{P}<$ 0.05 ; Figure 2). Energy intake during lunch was different between HCA and PLA in women (PLA, $2.0 \pm 0.1 \mathrm{MJ} ; \mathrm{HCA}, 2.5 \pm 0.2 \mathrm{MJ} ; P<0.01$ ), but not in men.

Table 2 Area under the curve from the following $100 \mathrm{~mm}$ visual analogue scale ratings completed at ten fixed time points over $16 \mathrm{~h}(\mathrm{~mm}-\mathrm{h})$

\begin{tabular}{lcccc}
\hline & PLA & HCA & HCA+MCT & $P$ \\
\hline Hunger & $436 \pm 37$ & $463 \pm 30$ & $462 \pm 33$ & NS \\
Appetite & $540 \pm 39$ & $504 \pm 35$ & $527 \pm 32$ & NS \\
Anticipated food intake & $540 \pm 39$ & $534 \pm 42$ & $558 \pm 54$ & NS \\
Desire to eat & $494 \pm 35$ & $497 \pm 31$ & $471 \pm 30$ & NS \\
Fulmess & $636 \pm 42$ & $705 \pm 37$ & $668 \pm 26$ & NS \\
Satiety & $691 \pm 30$ & $733 \pm 32$ & $714 \pm 25$ & NS \\
Thirst & $575 \pm 30$ & $643 \pm 38$ & $616 \pm 40$ & NS \\
\hline
\end{tabular}

Values are mean \pm SE. PLA $=$ placebo; HCA $=(-)$-hydroxycitrate; MCT $=$ medium - chain triglycerides. Statistical significance was determined by an analysis of variance for repeated measures (ANOVA). NS = no significance. 
No relationship was found between Factor 1 of the TFEQ (cognitive restrained/ unrestrained eating behavior) and the difference in energy intake during lunch between the HCA and the PLA treatments $(r=0.05)$.

The ratings on the appetite-related questions throughout the day, expressed as area under the curve (AUC) over $16 \mathrm{~h}$, corrected for the subject's minimum score, are shown in Table 2. The AUC of these parameters were not different between the three treatments. Hunger scores at $20: 30 \mathrm{~h}$ and thirst scores after lunch were higher with HCA compared to PLA $(P<0.05$ and $P<0.01$, respectively).

Compliance to the snacks was determined by asking the subjects how many snacks were left. A mean of $98 \%$ of the snacks was consumed, indicating a very high compliance to the snacks.

\section{DISCUSSION}

In the present study we investigated the potential of HCA and MCT on satiety, energy intake and body weight control. The results did not support the hypothesis that HCA induces satiety and reduces energy intake, in these subjects losing body weight.

Results on the effectiveness of HCA ingestion in human studies are controversial. Our findings are in contrast with several studies that observed decreased appetite $(6,41)$, reduced 24-h energy intake (45) or increased body weight and/or fat loss $(3,6,10,41)$ after ingestion of HCA alone or in combination with other ingredients. However, other studies also failed to find significant effects of HCA on body weight loss $(15,30)$ or energy expenditure $(19,20,21)$.

One possible reason why HCA did not reduce appetite and food intake in the present study is the state of negative energy balance of the subjects as shown by the mean body weight loss of $0.5 \mathrm{~kg}$ during the two weeks of intervention. Body weight loss probably resulted from a diet regimen that prescribed to refrain from food ingestion in between the meals with exception of the given snacks and noncaloric beverages and to minimize alcohol consumption. Because of this weight loss in all subjects, the possible effect of HCA, i.e. increase of satiety reduction of food intake and inhibition of fat synthesis, would have had to occur in a negative energy balance. This is unlikely, since the conversion of citrate into acetyl-CoA by ATP-citrate-lyase only occurs when energy intake exceeds the energy requirements of the body. When the energy requirements of the body are not met, carbohydrate will be used in the citric acid cycle to produce ATP for energy rather than to form citrate, the substrate for de nowo fatty acid synthesis. It is therefore likely that the ATP-citrate-lyase is relatively inactive when the subjects are in a negative energy balance. Consequently. HCA would be ineffective in inhibiting fat synthesis (32). The ineffectiveness of HCA when the subjects are in a negative energy balance has also been observed in other studies $(15,30)$. In addition, Westerterp-Plantenga and Kovacs (45) found a reduced 24-h energy intake in weight stable subjects as a result of HCA ingestion using a similar experimental design, and Mattes and 
Bormann (23) found a greater food intake reduction and body weight loss using HCA during 12 weeks compared to placebo.

Negative energy balance was much greater during the first intervention $(-1.2 \mathrm{~kg})$ compared to the second and third intervention $(-0.2 \mathrm{~kg}$ and $-0.3 \mathrm{~kg}$, respectively). Therefore HCA and HCA combined with MCT would have had a greater opportunity to show effectiveness during these two latter interventions. We also examined the results after having removed the data from the first intervention. We did not find any effect of HCA on energy intake or appetite-related parameters during the test day. However, when the subjects started with the second and third intervention, they were already in a situation of negative energy balance compared to baseline $(-0.7$ $\mathrm{kg}$ and $-0.2 \mathrm{~kg}$, respectively), as they did not completely regain the weight lost during the first intervention.

Although 24 h energy intake was similar for all treatments, energy intake during lunch was higher with HCA compared to PLA, in the women, this in contradiction to the originall hypothesis. We do not have a direct explanation for this, as energy intake for breakfast and with snacks was standardized and no difference in energy intake during dinner was found between treatments. Dietary restraint is unlikely to have played a role in the higher energy intake during lunch with HCA compared to PLA.

The negative result on the effectiveness of HCA could potentially be affected by ils bioavailability. Water solubility and $\mathrm{pH}$ level are two major components of bioavailability that may differ between HCA compounds available on the market. $\mathrm{A}$ compound complexed with calcium and potassium, like the one used in the present study, is nearly $100 \%$ soluble and creates a pH level that is favorable for maximal gastrointestinal absorption (7). In our laboratory, bioavailability of HCA supplemented in humans has been assessed by van Loon et al. (21). It was. shown that ingestion of a single dose of HCA $(4.4 \mathrm{~g})$ resulted in maximal plasma HCA concentration after $60-90 \mathrm{~min}(0.12 \mathrm{mmol} / \mathrm{l}=1.4 \%$ of the administered $\mathrm{HCA}$, assuming $4.5 \mathrm{~L}$ blood and a hematocrit of $45 \%$ ) and that HCA remained present at least for $3 \mathrm{~h}$. Therefore, we assume that in our study with sustained administration of HCA, low concentrations of HCA were continuously present in plasma.

Whereas MCT have been repeatedly shown to have satiating properties and to reduce food intake in humans $(29,36,46)$, we found no additional effect of MCT on satiety, food intake or body weight loss. However, these studies used a different study prolocol and/or a higher dosage MCT. Stubbs and Harbron (36) observed that substitution of LCT with MCT (65\% fat) in high-fat, high-energy diets for 14 days decreased energy intake. Van Wymelbeke et al. (46) found that a breakfast supplemented with MCT $(43 \mathrm{~g})$ decreased energy intake during a free-choice lunch. Rolls et al. (29) found that a small preload of MCT (ca. $18 \mathrm{~g}, 36 \mathrm{~g}$, or $54 \mathrm{~g}$ ) incorporated into a liquid meal was more effective at suppressing energy intake of a subsequent meal presented $30 \mathrm{~min}$ later, compared to LCT, already with the lowest dosage. In the present study, a lower dosage of MCT (12 g/d) was used. The maximal amount of oral MCT that can be tolerated in the gastrointestinal tract 
is small. Ivy et al. (18) reported that administration of $30 \mathrm{~g} \mathrm{MCT}$, in combination with cereal, caused some minor distress in $10 \%$ of the subjects. This was a reason why we kept the MCT dosage low, as supplementation lasted 2 weeks. Although the supplementation occurred for a 2-week period, this low dosage might explain why no effect of MCT was found on energy intake. Furthermore, in the present study, MCT were not investigated alone. Therefore, we cannot make statements about the efficacy of MCT themselves. Since HCA was not effective in the present study, it is possible that a possible additional effect of MCT was inhibited.

The supposed effectiveness of HCA through inhibition of de novo lipogenesis, increased hepatic fatty acid oxidation, and promotion of glycogen stores preservation did not appear under these circumstances. Under negative energy ballance conditions, de novo lipogenesis and preservation of gllycogen reserves are highly unlikely to appear. The only possible remaining mechanism is an increased hepatic fatty acid oxidation. Since we did not measure hepatic fatty acid oxidation in the present study, we cannot draw a firm conclusion on that aspect. It might be argued that a 2-week intervention is too short to demonstrate significant effects of HCA or HCA combined with MCT on appetite or body weight. However, Westerterp-Plantenga and Kovacs (45) did observe a reduced 24 -h energy intake with HCA using a similar 2-week intervention protocol in weight stable subjects, although this effect was not reflected in body weight changes. In addition. Goris and Westerterp showed that 2 weeks are sufficient for body weight effects (11).

In summary, we showed that HCA and HCA combined with MCT were not effective with respect to satiety and energy intake under a negative energy balance condition.

\section{ACKNOWLEDGEMENTS}

The work was supported by Novartis Consumer Health Ltd, Nyon, Switzerland.

\section{REFERENCES}

1. Bach AC, Babayan VK. Medium-chain triglycerides: an update. Am J Clin Nutr 1982; 36: 950962.

2. Bach AC, Ingenbleek $Y$. Frey $A$. The usefulness of dietary medium-chain triglycerides in body weight control: fact or fancy? I Lipid Res 1996; 37:708-726.

3. Badmaev $\mathrm{V}$. Majeed $M$. Open field, physician controlled, clinical evaluation of botanical weight loss formula citrin. Presented at: Nutracon 1995: Nutraceuticals, Dietary Supplements and Functional Foods; July 11-13; Las Vegas, Nev.

4. Badmaev $V$. Majeed $M$, Conte AA. Garcinia cambogia for weight loss (letter). J/AMA 1999: 282: 233-234.

5. Beckers EJ, Jeukendrup AE, Brouns F, Wagenmakers AJM, Saris WHM. Gastric emptying of carbohydrate - medium chain triglyceride solutions in rest. Int J Sports Med 1992; 13: 581 584.

6. Conte AA. A non-prescription alternative in weight reduction therapy. Am I Bariatr Med 1993; Summer: 17-19. 
7. Firenzuolf F, Gori L. Garcinia cambogia for werght loss (letter). JAMA 1999; 282: 234.

8. Fogeholm $\mathbb{M}$, Kukkonen-Harjula $K$, Oja $P$. Eating control and physical activity as determinanis of short-term weight maintenance after a very-low-calorie diet among obese women. Int $J$ Obes 1999; 23: 203-210.

9. Furuse M, Choi YH, Mabayo RT, Okumura JI. Feeding behavior in rats fed diets containing medium chain triglyceride. Physiol Behav 1992; 52: 815-8:7.

10. Girola, $M$, de Bemardi $M$, Contos $S$, Tripodi $S$, Ventura $P$, Guarino $C_{2}$ Marletta M. Dose effect in lipid-lowering activity of a new dietary integrator (chitosan. Garcinia cambogia extract and chrome). Acta Toxicot ther 1996; 17: 25-40.

11. Coris $A M C$, Westerterp KR. Improved reparting of habitual food intake after confrontation with earlier results on food reporting. Br J Nutr 2000; 83: 363-369.

12. Harris $J A$, Benedict FG. A biametric study of basial metabolism in man. Washington, Carnegie Institution, 1919.

13. Hellerstein MK, Xie $Y$. The indirect pathway of hepatic glycogen synthesis and reduction of food intake by metabolic inhibitors. Life Sci 1993; 53 : 1833-1845.

14. Herman CP, Polivy J. Restrained eating. In: Stunkard AJ (ed). Obesity. W.B. Saunders: Philadelphia, 1980, pp 208-225.

15. Heymsfield SB, Allison DB, Vasselli JR, Pietrobelli A, Greenfield D, Nunez C. Garcinia cambogia (hydroxycitric acid) as a potent antiobesity agent. JAMA 1998; 280: 1596-1600.

16. Heymsfield SB, Allison DB, Vasselli JR, Pietrobelli A, Greenfield $D$, Nunez $C$. Garcinia cambogia for weight loss (letter). JAMA 1999; 282: 234-235.

17. Hill JO, Pelers $J C_{\text {, }}$ Yang $D$, Shart $T$, Kaler $M$, Abumrad NN, Greene $H L$. Thermogenesis in humans during overfeeding with medium-chain and long-chain triglycerides. Am J Clin Nutr 1991; $53: 1130-1133$.

48. Wy JL, Costill DL. Fink WJ, Maglischo E. Contribution of medium and long chain intake to energy metabolism during prolonged exercise. Int I Sports Med 1980; 1: 15-20.

19. Kovacs EMR, Westerterp-Plantenga MS, Saris WHM. The effects of 2-week ingestion off (-)hydroxycitrate and $(-)$-hydroxycitrate combined with medium-chain triglycerides on satiety fat oxidation, energy expenditure and body weight. Int $J$ Obes: 2001; 25: 1087-1094.

20. Kriketos $A D$, Thompson $H R$, Greene $H$, Hill JO. (-)-Hydroxycilric acid does not affect energy expenditure and substrate oxidation in adult males in a posi-absorptive state. Int $J$ Obes 1999; 23: $867-873$.

21. Loon LJC van, Rooijen JJM van, Niesen B, Verhagen H. Saris WHM, Wagenmakers AJM. Effects of (-)-hydroxycitrate supplementation on substrate metabolism at rest and during exercise in humans. Am I Clin Nutr 2000; 72: 1445-1450.

22. Lorr M. MoNair DM. Manual. Profile of Mlood States. Bi-Polar Form (POMS-BI). Educational and industrial testing service (EDITS). San Diego, California 1984.

23. Mattes RD. Bormann L. Effects of $(-)$-hydroxycitric acid on appetitive variables. Physiol Behav $2000: 71: 87-94$.

24. McCarty MF. Promotion of hepatic lipid oxidation and gluconeogenesis as a strategy for appetite control. Med Hypotheses 1994; 42; 215-225.

25. McCarthy MF. Reduction of free fatty acids may ameliorate risk factors associated with abdominal obesity. Med Hypotheses 1995; 44: 278-286.

26. McGarry JD, Foster DW. In support of the roles of malonyl-CoA and carnitine acyltransferase 1 in the regulation of hepatic fatty acid oxidation and ketogenesis. J Biol Chem 1979; 254: 8163-8168.

27. Ministerie van Welzijn, Volksgezondheid en Cultuur, en het Ministerie van Landbouw en Visserij. Wat eet Nederland. Resultaten van de voedselconsumptiepeiling 1987-1988. Rijswijk: Ministerie van Welzijn, Volksgezondheid en Cultuur, en het Ministerie van Landbouw en Visserij, 1988.

28. Pasman WJ, Saris WHM. Westerterp-Plantenga MS. Predictors of weight maintenance, Obes Res 1999; 7: 43-50.

29. Rolls $B . J_{*}$ Gnizak $N$, Summerfeld A, Laster LJ. Food intake in dieters and nondieters after a liquid meal containing medium-chain triglycerides. Am J Clin Nutr 1988; 48: 66-71. 
30. Rothacker DQ. Waitmann BE. Effeciveness of Garcinia cambogia and natural caffeine combination in weight loss - a double-blind placebo-controlled pilot study (abstract). Int $J$ Obes 1997; 21 (Suppl): S53.

31. Satabin $P_{0}$ Auclair $E$. Servan $E$, Achagiatis $C L$. Guezennec $C Y$. Influence of glucose, medium-chain and long-chain triglyceride gastric loads and forced exercise on food intake and body weight in rats. Physiol Behav 1991; $50: 147-150$.

32. Schaller JL. Garcinia cambogia for weight loss (letter). JAMA 1999;282:234.

33. Scharrer $E$, Langhans W. Control of food intake by fatty acid oxidation. Am I Physiol 1986: 250: R1003-R1006.

34. Seidell JC. Obesity in Europe. Obes Res 1995; 3 (Supp): 249-259.

35. Stichting Nederlands Voedingsstoffenbestand. Nevo Tabel. Den Haag, Voorlichtingsbureau voor de voeding. 1996.

36. Stubbs RJ, Harbron CG. Covert manipulation of the ratio of medium- to long-chain triglycerides in isoenergetically dense diets: effect on food intake in ad libitum feeding men. Int $J$ Obes 1996; 20 : 435-444.

37. Stunkard A.l, Messick $S$. The three-factor eating questionnaire to measure dietary restraint, disinmibition, and hunger. J Psychosom Res 1985; 29:71-83.

38. Sullivan AC. Hamilton JG, Miller ON. Wheatley VR. Inhibition of lipogenesis in rat liver by (-) hydroxycitrate. Arch Biochem Piophys 1972; 150; 183-190.

39. Sullivan AC, Triscari J. Metabolic regulators as a control for lipid disorders. I. influence of $(-)$. hydroxycitrate on experimentally induced obesity in the rodent. Am J Chin Nutr 1977; 30:767776.

40. Szutowicz A, Stepien M, Lysiak W. Angielski $S$. Effect of $(-y$-hydroxycitrate on the activities of ATP citrate lyase and the enzymes of acetyl-CoA metabolism in rat brain. Acta Biochim Pol 1976; $23: 227-234$

41. Thom $E$, Andrews $B$. Short- and long-term efficacy and folerability of (-)-hydroxycitrate in the treatment of obesity (abstract). Int J Obes 1997; 21 (Suppl): S53.

42. Watson JA, Fang M. Lowenstein JM. Tricaballylate and hydroxycitrate: substrate and inhibitor of ATP: citrate oxaloacetate lyase. Arch Biochem Biophys 1969; 135: 209-217.

43. Westerterp-Plantenga MS, Kempen KP. Saris WHM. Determinants of weight maintenance in women after diet-induced weight reduction. Int J Obes 1998; 22: 1-6.

44. Westerterp-Plantenga MS, Rolland $V$, Wilson SAJ, Westerterp KR. Satiety reliated to 24 th diet-induced thermogenesis during high protein/carbohydrate vs high fat diets measured in a respiration chamber. Eur J Clin Nutr 1999; 53: 1-8.

45. Westerterp-Plantenga MS, Kovacs EMR. The effect of (-)-tydraxycitrate on energy intake and satiety in overweight humans. Int $J$ Obes 2002; 26: 870-872.

46. Wymalbeke $V$ van, Himaya $A$ Louis-Sylvestre J, Fantino M. Influence of medium-chain and long-chain triacylglycerols on the control of food intake in men. Am J Clin Nutr 1998; 68: 226234. 


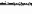




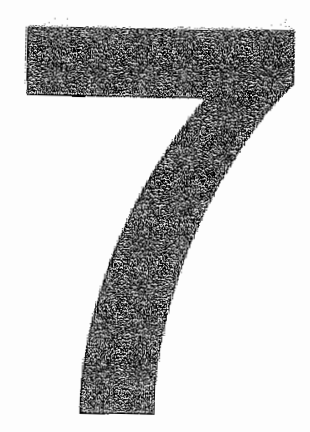

The effects of 2-week ingestion of (-)hydroxycitrate and (-)-hydroxycitrate combined with medium-chain triglycerides on satiety, fat oxidation, energy expenditure and body weight

Kovacs EMR, Westerterp-Plantenga MS, Saris WHM Intemational Journal of Obesity 2001: 25: 1087-1094 


\section{ABSTRACT}

Objective: Assessment of the effect of 2-week supplementation with $(-)$ hydroxycitrate (HCA) and HCA combined with medium-chain triglycerides (MCT) on satiety, fat oxidation, energy expenditure (EE) and body weight (BW) loss.

Design: Three intervention periods of 2 weeks separated by washout periods of 4 weeks. Double-blind, placebo-controlled, randomized, and cross-over design.

Subjects: Eleven overweight male subjects (mean $\pm \mathrm{SD}$; age, $47 \pm 16 \mathrm{y}$; body mass index, $27.4 \pm 8.2 \mathrm{~kg} / \mathrm{m}^{2}$ ).

Intervention: Subjects consumed three self-selected meals and four isa-energetic $(420 \mathrm{~kJ})$ snacks daily with either no supplementation (PLA), with $500 \mathrm{mg}$ HCA

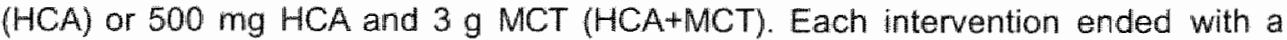
36 -h stay in the respiration chamber.

Results: There was a significant BW loss during the 2 weeks of intervention (PLA, $1.0 \pm 0.4 \mathrm{~kg}, P<0.05 ; \mathrm{HCA},-1.5 \pm 0.5 \mathrm{~kg}, P<0.01 ; \mathrm{HCA}+\mathrm{MCT},-1.3 \pm 0.2 \mathrm{~kg}, P<$ $0.001)$, but this reduction was not different between treatments. 24-h EE (PLA, 11.8 $\pm 0.2 \mathrm{MJ} ; \mathrm{HCA}, 11.7 \pm 0.1 \mathrm{MJ} ; \mathrm{HCA}+\mathrm{MCT}, 11.5 \pm 0.1 \mathrm{MJ}), 24$-h $\mathrm{RQ}(0.85 \pm 0.00$ in all treatments) and the area under the curve of the appetite-related parameters were not different between treatments.

Conclusion: Two-week supplementation with HCA and HCA combined with MCT did not result in increased satiety, fat oxidation, 24-h EE or BW loss compared to PLA, in subjects losing BW.

Keywords: (-)-hydroxycitrate, medium-chain triglycerides, satiety, energy expenditure, body weight loss 


\section{INTRODUCTION}

The increasing incidence of obesity is a recognised medical problem in developed countries (44). Obesity is the net result of disrupted balance between energy intake and energy output (12), the excess being stored in the adipose tissue. It is a major factor for a number of diseases, including coronary heart diseases, hypertension, type 2 diabetes mellitus, putmonary dysfunction, osteoarthritis and certain types of cancer $(22,26,35)$. Treatment of obesity is often unsuccessful. Weight loss can be achieved, but long-term weight maintenance after weight loss is rarely shown $(11,36,57)$. Therefore, identification of substances that improve or at least sustain satiety during energy restriction is needed. One possible way to improve satiety is to increase hepatic fatty acid oxidation. Evidence for a role of hepatic fatty acid oxidation in the control of eating has been shown in animals (27). Therefore, finding ways to stimulate fatty acid oxidation in the liver should be promising for appetite and weight control. We hypothesise that a stimulation of the post-ingestive fatty acid oxidation could modulate fat-induced satiety. We therefore investigated the potential of ( - )-hydroxycitrate (HCA) and medium-chain triglycerides (MCT), which are believed to induce fatty acid oxidation $(13,23,32,37,39,47,51,54)$, to increase satiety and decrease body weight.

HCA is an active ingredient that is extracted from the rind of the fruit Garcinia cambogia, a native species to India, and is promoted as a weight loss agent. HCA is an inhibitor of ATP-citrate-lyase, a cytosolic (extramitochondrial) enzyme that catalyses the cleavage of citrate to oxaloacetate and acetyl-CoA $(49,52,54)$. HCA might induce satiety by inhibiting malonylCOA formation, which in turn would stimulate carnitine transferase activity, resulting in decreased fat synthesis and increased fat oxidation $(31,33)$ or by increasing the rate of hepatic glycogen synthesis $(\$ 7)$. Furthermore HCA might promote weight maintenance by inhibiting or limiting de capacity for de novo lipogenesis (49), especially along with a high carbohydrate diet. Up to now, however, the results on the effects of HCA on appetite, body weight and energy expenditure and its possible contribution as a weight loss agent in humans are controversial $(4,10,20,40)$. Several studies found a positive effect of HCA administration alone or in combination with other ingredients on appetite, energy intake, body weight loss, fat oxidation or energy expenditure $(3,8,14,53,59)$, but others did not $(19,25,28,38)$. To distinguish the satiety effect of HCA from the fatty acid oxidation effect, we conducted two separate studies. In our previous study we found no effect of HCA on satiety in subjects losing body weight (24). In the present study, we concentrate on the possible effects of chronic HCA administration on fatty acid oxidation.

Medium-chain triglycerides (MCT) have been repeatedly suggested as a food ingredient that may contribute to the control of body weight. MCT are known to be rapidly hydrolysed and absorbed comparably to glucose $(1,5)$. Unlike long-chain triglycerides (LCT) that are transported in chylomicrons through the lymphatic system, MCT are converted into medium-chain fatty acids (MCFA) that directly enter the blood through the portal system. MCFA can cross the inner mitochondrial 
membrane in the liver and muscle independently of the acylcarnitine transferase system (6). Studies showed that fatty acids delivered by MCT are preferentially oxidised and poorly stored within tissues, and that MCT have a marked thermic effect (21). In addition to that, MCT have been shown to have satiating properties and to decrease food intake compared to LCT $(37,47,60)$ by involving a cascade of pre-absorptive and post-absorptive mechanisms. However, the exact mechanism underlying the reduction in food intake after MCT ingestion is not fully understood $(1,2)$.

The aim of the present study was to investigate the effects of 2-week administration of HCA and HCA combined with MCT on satiety, fal oxidation, energy expenditure and body weight. We hypothesised that HCA supplementation might affect appetite and body weight regulation by increasing fat oxidation and metabolic rate, reflected by an increase in energy expenditure. We further hypothesised that the combination of HCA and MCT may have a stronger effect on fatty acid oxidation and consequently on satiety compared to HCA alone. In addition MCT could have a thermogenic effect.

\section{METHODS}

\section{Subjects}

Eleven normal to moderately obese male subjects participated in this study. The subjects were recruited by advertisements in local newspapers. Selection took place following health criteria (no diabetes, no cardiovascular diseases, and no medical treatment) and body weight (BW) criteria (body mass index: $25-31 \mathrm{~kg} / \mathrm{m}^{2}$ ). Baseline characteristics of the subjects are presented in Table 1. The subjects were not HCA or MCT users. The nature and risks of the experimental procedure were explained to the subjects, and all subjects gave their written informed consent. The study was approved by the Ethical Committee of Maastricht University.

\section{Experimental design}

The experiment had a double-blind, placebo-controlled, randomized, cross-over design. The experimental design consisted of three intervention periods of 2 weeks separated by washout periods of 4 weeks. Each intervention period ended with a $36-\mathrm{h}$ stay in the respiration chamber.

During the washout periods, the subjects consumed a self-selected and selfprepared diet. During the intervention periods, the subjects consumed at home three self-selected and self-prepared meals daily (breakfast, lunch, and dinner) with no restriction regarding type and amount of food. They were instructed to drink maximally one glass of alcoholic beverage per day. Between the meals, the subjects consumed an iso-energetic smack (cereal bar) of $22 \mathrm{~g}$ (energy, $420 \mathrm{~kJ}$; protein, $0.7 \mathrm{~g}$; fat, $4 \mathrm{~g}$; carbohydrate, $14 \mathrm{~g}$; dietary fibre, $0.5 \mathrm{~g}$ ) with no 
Table 1 Subjects characteristics $(n=11)$ at baseline

\begin{tabular}{lcc}
\hline & mean \pm SD & range \\
\hline Age $(\mathrm{y})$ & $47 \pm 16$ & $27-56$ \\
Height $(\mathrm{m})$ & $1.77 \pm 0.51$ & $1.71-1.85$ \\
Weight $(\mathrm{kg})$ & $85.4 \pm 25.8$ & $73.4-98.6$ \\
Body mass index $\left(\mathrm{kg} / \mathrm{m}^{2}\right)$ & $27.4 \pm 8.2$ & $24.5-31.4$ \\
Waist circumference $(\mathrm{cm})$ & $94 \pm 28$ & $86-109$ \\
Hip circumference $(\mathrm{crm})$ & $102 \pm 30$ & $90-111$ \\
Waist-hip ratio & $0.93 \pm 0.27$ & $0.83-1.04$ \\
Blood glucose (mmol/l) & $5.21 \pm 1.59$ & $4.81-5.62$ \\
Blood lriglycerides (mmol/l) & $4.32 \pm 0.70$ & $0.44-2.05$ \\
F1 (cognitive restraint) & $7 \pm 4$ & $2-15$ \\
F2 (disinhibition) & $4 \pm 3$ & $1-8$ \\
F3 (hunger) & $3 \pm 2$ & $0-6$ \\
Herman-Polivy restraint & $16 \pm 6$ & $10-21$ \\
\hline
\end{tabular}

F1-F3, factors 1-3 of the Three Factor Eating Questionnaire.

supplementation (PLA), with supplementation of $500 \mathrm{mg}$ (-)-hydroxycitrate (HCA; $850 \mathrm{mg}$ SuperCitrimax HCA 600 SXG, HCA content: $58,81 \%$, EuroChem Feinchemie $\mathrm{GmbH}$, München, Germany) or $500 \mathrm{mg} \mathrm{HCA}$ and $3 \mathrm{~g} \mathrm{MCT} \mathrm{(HCA+MCT).}$ The dosage used was similar or higher to that used in other studies in which an effect of HCA on BW reduction was found (3x500 mg/d $(3,8) ; 2 \times 55-110 \mathrm{mg} / \mathrm{d}(14))$. The snacks were consumed at four fixed time points: $1 \mathrm{~h}$ before lunch, $2 \mathrm{~h}$ after lunch, $1 \mathrm{~h}$ before dinner and $2 \mathrm{~h}$ after dinner. Between the meals, the subjects were not allowed to eat with exception of the prescribed snacks. They were allowed to drink ad libitum water, coffee and tea (without sugar and milk). During the last 3 days of each intervention, the subjects were instructed to consume no alcohol and to eat ad libitum food that was supplied from our laboratory for breakfast, lumch and dinner. The food had a food quotient (FQ) of 0.85 .

\section{Anthropometry}

BW was measured during screening, at the beginning, after 1 week and at the end of each intervention period on a digital balance accurate to $0.02 \mathrm{~kg}$ (Chyo-MW$150 \mathrm{~K}$, Japan) with subjects in underwear, in the fasted state and after voiding their bladder. Height was measured to the nearest $0.1 \mathrm{~cm}$ during screening using a wall-mounted stadiometer (Seca, model 220, Hamburg, Germany). The body mass index was calculated by BW/height ${ }^{2}\left(\mathrm{~kg} / \mathrm{m}^{2}\right)$.

The distribution of fat was investigated during screening by measuring the waist and hip circumferences and calculation of the waist-hip ratio (WHR). The waist circumference was measured at the site of the smallest circumference between the rib cage and the ileac crest, with the subjects in standing position. The hip circumference was measured at the site of the largest circumference between the 
waist and the thighs. The WHR was calculated by dividing the waist circumference by the hip circumference.

Body composition was measured at the beginning and at the end of each intervention period by hydrodensitometry and deuterium $\left({ }^{2} \mathrm{H}_{2} \mathrm{O}\right)$ dilution technique (41) and was calculated using the combined equation of Siri (45). Body weight was measured in the fasted state with a digital balance accurate to $0.01 \mathrm{~kg}$ (Sauter Typ E1200, Ebingen, Germany). Whole body density was determined by underwater weighing with simultaneous assessment of long volume residual with the helium dilution technique using a spirometer (Volugraph 2000, Mijnhardt, The Netherlands). Measurements were performed in triplicate and the average was used to calculate body density. The dilution of the deuterium isotope is a measure for total body water (TBW) (30). Subjects were asked to collect an urine sample in the evening just before drinking a weighed amount of deuterium-enriched water solution. After ingestion of the deuterium-enriched no further fluid or food consumption was permitted. Ten hours after ingestion of the deuterium solution a second urine sample (second voiding) was collected. Deuterium concentration in the urine samples was measured using an isotope ratio mass spectrometer (Micromass Optima, Manchester, UK). TBW was obtained by dividing the measured deuterium dilution space by 1.04 (41). Fat-free mass (FFM) was calculated by dividing the TBW by the hydration factor 0.73 . By subtracting FFM from $B W$, fat mass was obtained. Fat mass expressed as a percentage of $B W$ revealed body fat percentage.

\section{Eating behavior}

Eating behavior was analyzed during screening, during the first and the last day of each intervention period using a validated Dutch translation of the Three Factor Eating Questionnaire (TFEQ) $(48,58)$. Cognitive restrained and unrestrained eating behavior (Factor 1), emotional eating and disinhibition (Factor 2) and the subjective feeling of hunger (Factor 3) were scored. Body weight concern and chronic dieting behavior were investigated with the Herman Poliwy questionnaire (HP) (18).

\section{Blood parameters}

At the beginning and at the end of each intervention period, a fasting blood sample of $10 \mathrm{ml}$ was obtained and mixed with EDTA to prevent clotting. Plasma was obtained by centrifugation $\left(4^{\circ} \mathrm{C}, 3000 \mathrm{rpm}, 10 \mathrm{~min}\right)$ and stored at $-80^{\circ} \mathrm{C}$ until analysis of glucose by a hexokinase method (Roche Diagnostics, Hoffmann-La Roche, Basel, Switzerland), triglycerides (GPO-trinder 337, Sigma), free fatty acids by an ACS-ACOD method (Wako chemicals, Neuss, Germany). glycerol by a glycerolkinase-lipase method (Boehringer, Mannheim, Germany): Bhydroxybutyrate (BHB) by the method of Moore et al. (34) using a semi-automated centrifugall spectrophotometer (Cobas Fara, Roche Diagnostics), and insulin with ELISA (Mercodia 10-1113-01). 


\section{Daily energy intake}

Energy intake over the previous week was recorded at the beginning and at the end of each intervention period using a food frequency questionnaire. Personal instruction was given in advance. The food frequency questionnaires were analyzed by using the Dutch food composition table (46) and the accessory computer program (Becel Nutrition Program 1988).

Daily energy intake before and during the second week of intervention was compared with predicted 24 -h energy expenditure (16) that amounted on average $12.0 \pm 1.1 \mathrm{MJ} / \mathrm{d}$. Since predicted 24 -h energy expenditure was significantly higher compared to the reported energy intakes (before intervention: PLA, $6.9 \pm 0.4 \mathrm{MJ} / \mathrm{d}$; HCA, $6.5 \pm 0.4 \mathrm{MJ} / \mathrm{d}$; HCA+MCT, $7.1 \pm 0.5 \mathrm{MJ} / \mathrm{d}$; during the second week of intervention: PLA, $7.5 \pm 0.5 \mathrm{MJ} / \mathrm{d} ; \mathrm{HCA}, 7.9 \pm 0.3 \mathrm{MJ} / \mathrm{d} ; \mathrm{HCA}+\mathrm{MCT}, 8.6 \pm 0.5 \mathrm{MJ} / \mathrm{d}$ ) and mean changes in reported energy intake were not related to mean changes in body weight $(r=0.04 ; P>0.05)$, these data were not used for further analysis.

\section{Mood}

Changes in mood during intervention were scored on anchored $100 \mathrm{~mm}$ visual analogue scales at the beginning and at the end of each intervention period (29).

\section{Tolerance}

Tolerance of the snacks was determined at the end of each intervention period using a questionnaire on occurrence of gastrointestinal and other complaints and scored on a 5 -point scale $(0=$ not at all, $1=$ less, $2=$ sometimes, $3=$ relatively much, 4 = very much).

\section{Indirect calorimetry}

Oxygen consumption and carbon dioxide production were measured in a whole room calorimeter (42). The respiration chamber was a $14 \mathrm{~m}^{3}$ room, furnished with a bed, chair, computer, television, radio-cassette player, telephone, intercom, sink and toilet. The room was ventilated with fresh air at a rate of $70-80 \mathrm{l} / \mathrm{min}$. The ventilation rate was measured with a dry gas meter (Schlumberger, type 4 , the Netherlands). The concentration of oxygen and carbon dioxide was measured using a paramagnetic $\mathrm{O}_{2}$ analyser (Hartmann \& Braun, type Magnos 6G, Germany; Servomex, type OA184A, England) and an infrared $\mathrm{CO}_{2}$ analyser (Hartmann and Braun, type Uras $3 G$, Germany). During each $15 \mathrm{~min}$ period, six samples of outgoing air for each chamber, one sample each of fresh air, zero gas, and calibration gas were measured. The gas samples to be measured were selected by a computer that also stored and processed the data (42).

\section{Physical activity}

In the respiration chamber subjects followed a protocal consisting of fixed times for breakfast, lunch and dinner, sedentary activities and bench stepping exercise. The bench stepping exercise was performed three times a day $(10: 30 \mathrm{~h}, 14: 30 \mathrm{~h}$, and 
$20: 30 \mathrm{~h})$ for $30 \mathrm{~min}$ at intervals of 5 min exercise alternated with 5 min rest, at a rate of one step per second with a bench height of $25 \mathrm{~cm}$. Apart from the exercise protocols, subjects were not restricted in their activities, only sleeping and strenuous physical activity were not allowed. Physical activity was monitored using a radar system working on the Doppler principle.

\section{Energy intake}

Before entering the respiration chamber, the subjects consumed ad libitum a standardised dinner (pasta meal; energy, $393 \mathrm{~kJ} / 100 \mathrm{~g}$; protein, $3.8 \mathrm{~g} / 100 \mathrm{~g}$; carbohydrate, $11.1 \mathrm{~g} / 100 \mathrm{~g}$; $1 \mathrm{at}, 3.8 \mathrm{~g} / 100 \mathrm{~g}$ ) and food intake was determined.

Energy intake (El), adapted to reach energy balance, was determined from 24-h sleeping metabolic rate (SMR) measured during the first night and multiplied by an activity index of 1.6 (43). The subjects received a diet divided over three meals (breakfast at $8: 30 \mathrm{~h}$, lunch at $12: 00 \mathrm{~h}$, and dinner at 18:00 $\mathrm{h}$ ) and four snacks $(1 \mathrm{~h}$ before and $2 \mathrm{~h}$ after lunch, $1 \mathrm{~h}$ before and $2 \mathrm{~h}$ after dinner). The food had a FQ of 0.85 .

\section{Energy expenditure and substrate oxidation}

24-h energy expenditure (24-h EE) consisted of sleeping metabolic rate (SMR) dietinduced thermogenesis (DIT) and activity-induced energy expenditure (AEE). 24-h EE and 24-h respiratory quotient (RQ) were calculated from 7:00 to $7: 00 \mathrm{~h}$, from oxygen consumption and carbon dioxide production according to the method of Weir (55).

SMR was measured on both nights and was defined as the lowest mean $E E$ measured over three consecutive hours between 0:00 and 7:00 h. The average SMR of the two nights was used in further calculations. DIT was calculated by plotting EE against radar output, both averaged over $30 \mathrm{~min}$ periods. The intercept of the regression line at the lowest radar output represented the energy expenditure in the inactive state (resting metabolic rate, RMR), consisting of SMR and DIT (56). DIT was determined by subtracting SMR from RMR. AEE was determined by subtracting RMR from 24-h EE.

Carbohydrate, fat, and protein oxidation was calculated using oxygen consumption and carbon dioxide production and urinary nitrogen excretion (7):

Protein oxidation $(\mathrm{g} / \mathrm{d})=6.25$ * $\mathrm{N}$

Fat oxidation $(\mathrm{g} / \mathrm{d})=1.718 * \mathrm{VO}_{2}-1.718 * \mathrm{VCO}_{2}-0.315 * \mathrm{P}$

Carbohydrate oxidation $(\mathrm{g} / \mathrm{d})=4.17 * \mathrm{VCO}_{2}-2.965 * \mathrm{VO}_{2}-0.390 * \mathrm{P}$

where: $\quad N$ is total nitrogen excreted in urine $(\mathrm{g} / \mathrm{d})$

$\mathrm{VO}_{2}$ is oxygen consumption (l/d)

$\mathrm{VCO}_{2}$ is carbon dioxide production (I/d)

$P$ is protein oxidation ( $g / d)$

24-h urine was collected from the second voiding on the day of the experiment until the first voiding of the following day. Samples were collected in containers with 10 $\mathrm{ml} \mathrm{H}_{2} \mathrm{SO}_{4}$ to prevent nitrogen loss through evaporation. Volume and nitrogen 
concentration were measured, the latter using a nitrogen analyser (Elemental Analyzer, CHN-O-Rapid, Heraeus).

\section{Satiety}

During the stay in the respiration chamber, appetite ratings (hunger, satiety, fullness, desire to eat, appetite, anticipated food intake and thirst) were scored on anchored $100 \mathrm{~mm}$ visual analogue scales (58). Questionnaires were completed at 10 fixed time points, respectively immediately before and after breakfast, in the morning at 10:30 h, immediately before and after lunch, in the afternoon at 15:00 $\mathrm{h}$, immediately before and after dinner, in the evening at 20:30 $\mathrm{h}$, and before sleeping at 23:30 h. Appetite ratings during 24-h stay in the respiration chamber were expressed as area under the curve $(24-h$ AUC), corrected for the subject's minimum score.

\section{Statistical analysis}

Data are presented as mean \pm standard error (SE). Differences between the treatments were determined by analysis of variance for repeated measures (ANOVA) and Sheffe-F post-hoc test (Statview SE Graphics ${ }^{\text {TM }}$ ). The measurements at the beginning and at the end of the experiment were compared using paired ttests. Pearson correlation coefficients, $r$, were calculated to determine the relationship between selected variables. The level of significance was set at $P<$ 0.05

\section{RESULTS}

There was a significant $B W$ reduction during two weeks of intervention (PLA, $-1.0 \pm$ $0.4 \mathrm{~kg}, P<0.05 ; \mathrm{HCA},-1.5 \pm 0.5 \mathrm{~kg}, P<0.01 ; H \mathrm{HA}+\mathrm{MCT},-1.3 \pm 0.2 \mathrm{~kg}, P<0.001)$, However, BW reduction was not different between treatments. BW loss was greater during the first compared to the third intervention periad $(-2.0 \pm 0.5 \mathrm{~kg}$ vs. $-0.5 \pm 0.2$ $\mathrm{kg}$; $P<0.05)$ with values for the second intervention intermediate $(-1.3 \pm 0.3 \mathrm{~kg})$. Body fat decreased with HCA+MCT $(-0.9 \pm 0.4 \%, P<0.05)$, but not with PLA and HCA $(-0.6 \pm 0.8 \%$ and $-0.3 \pm 0.3 \%$, respectively). However, no difference in body fat loss was found between treatments.

Scores on the HP and the TFEQ questionnaires were similar for all treatments and did not change during intervention.

Fasting plasma glucose concentration before and after intervention was similar for each treatment. Plasma glucose concentration was reduced as a result of intervention with PLA $(-0.17 \pm 0.07 \mathrm{mmol} / \mathrm{l} ; P<0.05)$, but not with HCA and HCA + MCT $(-0.09 \pm 0.09 \mathrm{mmol} / \mathrm{l}$ and $-0.08 \pm 0.09 \mathrm{mmol} / \mathrm{l}$, respectively). However, reduction in plasma glucose was not different between treatments. Fasting plasma FFA, glycerol, triglycerides and insulin concentrations before and after intervention as well as changes during intervention were similar between treatments. Fasting plasma $\mathrm{BHB}$ before intervention was higher with HCA+MCT compared to PLA $(P<$ 
0.05). There was no difference in plasma $B H B$ after intervention or in plasma $B H B$ change during intervention between treatments.

There was no change in mood (relaxed, gloomy, pleasant, angry, afraid, sad) during intervention, and no differences were found between treatments. The snacks were similarly tolerated in all treatments and walues for complaints remained low. Compliance to the snacks was determined by asking the subjects. how many snacks were left. A mean of $96 \%$ of the snacks was consumed, indicating a high compliance to the snacks.

Food intake during ad libitum meal before entering the respiration chamber was similar for all treatments (PLA, $2153 \pm 102 \mathrm{~kJ}$; HCA, $2076 \pm 161 \mathrm{~kJ}$; HCA+MCT. $2234 \pm 140 \mathrm{~kJ})$.

Mean 24-h El and 24-h EE during the stay in the respiration chamber are presented in figure 1. El was chosen to reach energy balance. However, the subjects tended to be in negative energy balance (PLA, $-0.6 \pm 0.3 \mathrm{MJ} ; \mathrm{HCA},-0.5 \pm 0.2 \mathrm{MJ}$; HCA+MCT, $-0.5 \pm 0.3 \mathrm{MJ}$; all $P<0.1$ ), but the level of negative energy balance was not different between treatments. There was no difference in SMR, RMR, DIT and AEE between treatments (figure 1). DIT was $7.7 \pm 1.3 \%, 8.9 \pm 3.2 \%$ and $7.7 \pm 1.3 \%$ of El with PLA, HCA and HCA+MCT, respectively (NS). Calculated physical activity index, defined as EE divided by SMR, was not different between treatments (PLA $1.65 \pm$ $0.03 ; \mathrm{HCA}, 1.62 \pm 0.02 ; \mathrm{HCA}+\mathrm{MCT}, 1.61 \pm 0.02)$. SMR was related to FFM with HCA $+M C T(r=0.67, P<0.05)$, and tended to be related to FFM with PLA and HCA $(r$ $=0.57$ and $r=0.62$, respectively: $P<0.1$; figure 2). 24-h $E E$ was not related to FFM in any of the treatments (PLA, $r=0.34 ; \mathrm{HCA}, r=0.52 ; \mathrm{HCA}+\mathrm{MCT}, r=0.45 ; P>0.05)$.

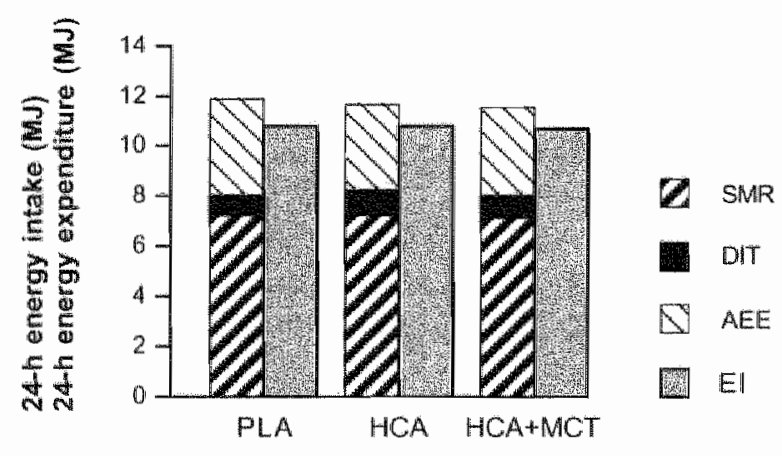

Figure 1 24-h energy intake and 24-th emergy expenditure

Values are mean. PLA = placebo; HCA $=(-)$-hydroxycitrate: $M C T=$ medium - chain triglycerides; $S M R$ = sleeping metabolic rate; $D I T$ = diet-induced thermogenesis; $A E E=$ activity-induced energy expenditure; $\mathrm{EI}=$ energy intake. Statistical significance was determined by an analysis of variance for repeated measures (ANOVA). 


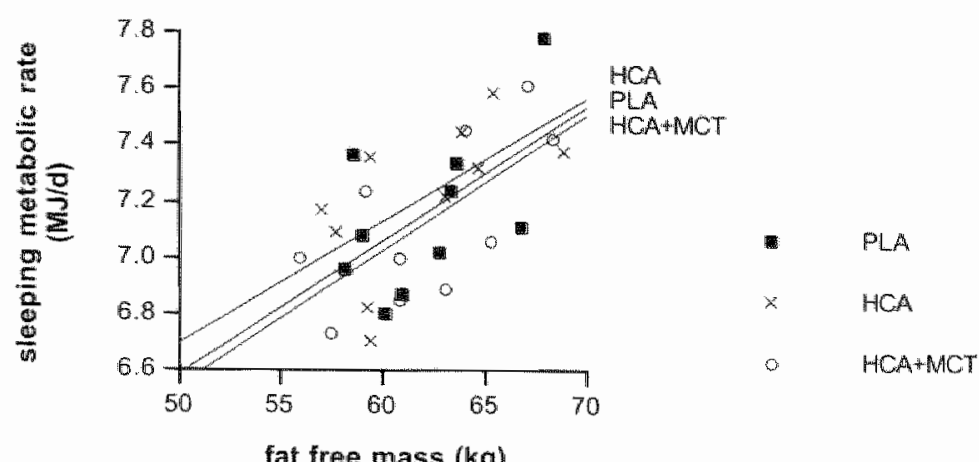

Figure 2 Relation between sleeping metabolic rate and fat free mass

PLA = placebo; HCA $=(-)$-hydroxycitrate; $M C T=$ medium-chain triglycerides. Relation between variables was determined by calculating Pearson correlation coefficients. PLA. $r=0.57, P<0.1 ;$ HCA, $r=0.62, P<0.1 ;$ HCA+MCT, $r=0.67, P<0.05$.

There was no difference in protein (PLA, $82 \pm 4 \mathrm{~g} / \mathrm{d} ; \mathrm{HCA}, 81 \pm 3 \mathrm{~g} / \mathrm{d} ; \mathrm{HCA}+\mathrm{MCT}, 74$ $\pm 4 \mathrm{~g} / \mathrm{d}$ ), fat (PLA, $80 \pm 4 \mathrm{~g} / \mathrm{d} ; \mathrm{HCA}, 81 \pm 6 \mathrm{~g} / \mathrm{d} ; \mathrm{HCA}+\mathrm{MCT}, 77 \pm 3 \mathrm{~g} / \mathrm{d}$ ) and carbohydrate oxidation (PLA, $201 \pm 7 \mathrm{~g} / \mathrm{d}$; HCA, $192 \pm 9 \mathrm{~g} / \mathrm{d}$; HCA+MCT, $202 \pm 7 \mathrm{~g} / \mathrm{d}$ ) between trials. 24-h RQ and non-protein RQ were similar in all trials (PLA, $0.85 \pm$ 0.00 and $0.85 \pm 0.00 ; \mathrm{HCA}, 0.85 \pm 0.00$ and $0.84 \pm 0.01 ; \mathrm{HCA}+\mathrm{MCT}, 0.85 \pm 0.00$ and $0.85 \pm 0.00$, respectively).

The 24-h AUC of hunger, satiety, fullness, desire to eat, appetite, anticipated food intake and thirst were similar in all treatments. Satiety was higher with HCA compared to HCA+MCT before dinner and fullness was higher with PLA compared to HCA before sleeping $(P<0.05)$. The subjects felt thirstier with PLA compared to HCA after dinner $(P<0.05)$. There was no difference at any time point in hunger, desire to eat, appetite, and anticipated food intake between treatments.

\section{DISCUSSION}

In the present study, the potential of HCA and HCA combined with MCT on satiety, fat oxidation, energy expenditure and body weight was investigated in overweight men. The results did not support the hypothesis that HCA supplementation may be effective on appetite and weight control by increasing fat oxidation, and that MCT may have an additional effect.

Results on the effect of HCA supplementation in humans are controversial. Several studies found a positive effect of HCA alone or in combination with other ingredients, (e.g. chromium, caffeine, chitosan) on appetite $(8,53), 24-\mathrm{h}$ energy intake (59) and body weight loss $(3,8,14,53)$. However, other studies did not find a significant effect of HCA on body weight $(19,38)$. HCA has been suggested to contribute to body weight loss by increasing fat oxidation and inducing satiety. Until 
now, few studies have investigated the effects of HCA ingestion on fat oxidation and energy expenditure in humans. Kriketos et al. (25) found no effect of 3 days. HCA supplementation $(3.0 \mathrm{~g} / \mathrm{d})$ on fat oxidation and energy expenditure during rest or moderate exercise in sedentary humans. Similarly, van Loon et al. (29) found no acute effect of HCA on energy expenditure and fat oxidation during rest and exercise in trained subjects, even following ingestion of large quantities of HCA $(18.3 \mathrm{~g})$. From these results, it may be argued that treatment with HCA was not sufficiently long and that HCA might have an effect on fat oxidation or other parameters such as appetite only over a longer investigation period. In the present study, supplementation with HCA and HCA combined with MCT lasted two weeks. However, no effect of HCA on fat oxidation or 24-h energy expenditure was found, and $M C T$ did not result in an additional effect.

HCA administration has been shown to inhibit the rate of lipogenesis in rodents $(15,49,50)$ and to increase the rate of hepatic glycogen synthesis $(17)$, but this has not been confirmed in humans. An excess energy intake as carbohydrate is needed to promote de novo lipogenesis and to increase glycogen synthesis. However, the subjects who participated in the present study were in a state of negative energy balance. This is confirmed by a body weight loss $>1 \mathrm{~kg}$ during the two weeks of intervention. Body weight loss resulted from a food intake regimen that prescribed to refrain from food consumption in between meals, with exception of the four snacks and non-caloric beverages, and to minimize alcohol intake. This negative energy balance may explain why HCA was not effective in reducing appetite and inhibiting fat synthesis as the conversion of citrate into acetylCoA by ATP-citrate-lyase only occurs when energy intake exceeds the energy requirements of the body. In other words, when a low-energy diet did not meet the energy requirements of the body, carbohydrate will be used in the citric acid cycle to produce ATP for energy rather than to form citrate, the substrate for de novo fatty acid synthesis. The results suggest that HCA is not effective in inhibiting fat synthesis or stimulating hepatic glycogen formation in a condition of a moderate negative energy balance. The ineffectiveness of HCA in dieting humans in fact has also been observed in other studies $(19,38)$. Moreover, in a condition of energy balance, Westerterp-Plantenga and Kovacs (59) found that administration of HCA for two weeks resulted in reduced 24-h energy intake on a subsequent test day.

in conclusion, it has been shown that, in circumstances when two mechanisms which may play a role in the effectiveness of HCA (i.e. de novo lipogenesis, hepatic glycogen synthesis) are very likely excluded, the other mechanism (i.e. fatty acid oxidation), which also might induce satiety, was not present. If HCA is an effective food supplement in relation to body weight regulation, it would likely be effective by inhibiting de novo lipogenesis or by stimulating hepatic glycogen synthesis. HCA may not be effective in inhibiting do novo lipogenesis and stimulating hepatic glycogen formation in a condition of negative energy balance and body weight loss. HCA might therefore be effective in prevention of weight (re)gain, and thus in prevention of obesity, rather than in supporting body weight loss. Further 
confirmation needs to be obtained from experiments an possible effects of HCA on de novo lipogenesis and glycogen synthesis during weight (re)gain in humans. Supplementation with MCT did not result in an additional effect on satiety, 24-h energy expenditure, fat oxidation or body weight. Studies showed that MCT have satiating properties and decrease food intake compared to LCT $(37,47,60)$. Van Wymelbeke et al. (60) found that a breakfast supplemented with MCT (40 g) decreased energy intake during a free-choice lunch. Rolls of al. (37) found that a small prelcad of MCT (ca. $18 \mathrm{~g}, 36 \mathrm{~g}$, or $54 \mathrm{~g}$ ) incorporated into a liquid meal was more effective at suppressing energy intake of a subsequent meal presented 30 min later, compared to LCT, already with the lowest dosage. In the present study, a lower dosage of MCT $(12 \mathrm{~g} / \mathrm{d})$ was used. This might explain why no effect of MCT was found on energy intake. Studies also showed that MCT increase thermogenesis and fat oxidation (21). The stimulating effect of MCT on energy expenditure was shown with low dosages of MCT (15 and $30 \mathrm{~g} / \mathrm{d}$ ) but disappeared at a dosage below $15 \mathrm{~g} / \mathrm{d}(9)$. This may indicate that the dosage of MCT used in the present study was to low in order to find an effect on energy expenditure. Finally, we are not able to make statements about the efficacy of MCT themselves, as they were not investigated alone. Since HCA was not effective in this study, it is possible that the possible effect of MCT was inhibited.

\section{ACKNOWLEDGEMENTS}

We gratefully acknowledge Miranda de Vries, Joan Senden, and Paul Schoffelen for their assistance. This study was supported by Novartis Consumer Health, Ltd., Nyon, Switzerland.

\section{REFERENCES}

1. Bach $\mathrm{AC}_{1}$ Babayan VK. Medium-chain triglycerides: an update. Am J Clin Nutr 1982; 36: 950962.

2. Bach $A C$, ingenbleek $Y$, Frey $A$. The usefulness of dietary medium-chain triglycerides in body weight control: fact or fancy? J Lipid Ries 1996; 37: 708-726.

3. Badmaev V. Majeed M. Open field, physician controlled, clinical evaluation of botanical weight loss formula citrin. Presented at: Nutracon 1995: Nutraceuticals, Dietary Supplements and Functional Foods; July 11-13, 1995; Las Vegas, Nev.

4. Badmaev $V$, Majeed $M$, Conte AA. Garcinia cambogia hor weight loss [letter]. JAMA 1999: 282: $233-234$.

5. Beckers EJ, Jeukendrup AE, Brouns F, Wagenmakers AJM, Saris WHM. Gastric emptying of carbohydrate - medium chain triglyceride solutions in rest. Int J Sports Med 1992, 13: 581. 584.

6. Bremer J. Carnitine - melabolism and functions. Physiol Rev 1983; 63: 1420-1479.

7. Brouwer $E$. On simple formulae for calculating the heat expenditure and the quantities of carbohydrate and fat oxidised in metabolism of men and animals, from gaseous exchange (oxygen intake and carbonic output) and urine-n. Acta Physiol Pharmacol Neerlandica 1957: 6: $795-802$ 
8. Conte AA. A non-prescription alternative in weight reduction therapy. Am I Bariatr Med 1993; Summer: $17-19$.

9. Dulloo AG, Fathi M, Mensi N, Girardier L. Twenty-four-hour energy expenditure and urinary catecholamines of humans consuming low-tomoderate amounls of medium-chain triglycerides: a dosemesponse study in a human respiratory chamber. Eur I Clin Nutr 1996; 50: $152-158$.

10. Firenzuoli $F$, Gori L. Garcinia cambogia for weight loss [letter]. JAMA 1999; 282: 234.

11. Fogeholm M, Kukkonen-Harjula $K$, Oja P. Eating control and physical activity as determinants of short-term weight maintenance after a very-low-calorie diet among obese women. Int $J$ Obes Relat Metab Disond 1999; 23: 203-210.

12. Flatt JP, Ravussin E. Acheson KJ, Jéquier $E$. Effects of dietary fat on postprandial substrate oxidation and on carbohydrate and fat balances. I Clin Invest 1985; 76; 1019-1024.

13. Furuse $M_{s}$ Chó $Y H$, Mabayo RT, Okumura Jl. Feeding behavior in rats fed diets containing medium chain triglyceride. Physiol Bethav 1992; 52 : 815-817.

14. Girola M, de Bernardi M, Contos S. Tripodi S, Ventura P. Guarino C. Marletta M. Dose effect in lipid-lowering activity of a new dielary integrator (chitosan, Garcinia cambagia extract and chrome). Acta Toxical Ther 1996; 17: 25-40.

15. Greenwood MRC, Cleary MP, Gruen R, Blasě D, Stern „S, Triscari J, Sullivan AC. Effect of ( $y$ hydroxycitrate on development of obesity in the Zucker obese rat. Am J Physiol 1981:240: E72-E78.

16. Harris JA, Benedict $F G$. A biometric sfudy of basal metabolism in man. Washington: Camegie Institution, 1919.

17. Hellerstein MK, Xie $Y$. The indirect pathway of hepatic glycogen synthesis and reduction of food intake by metabolic inhibilors. Life Sci 1993; 53 : 1833-1845.

18. Herman CP. Polityy J. Restrained eating. In: Stunkard AJ (ed). Obesity. W.B. Saunders: Philadelphia, 1980, pp 208-225.

19. Heymsfield SB, Allison DB, Vasselli, JR, Pietrobelli A, Greenfield D. Nunez C. Garcinia cambogia (hydraxycitric acid) as a potent antiobesity agent. JAMA 1998; 280: 1596-1600.

20. Heymsfield SB, Alison DB, Vasselli JR, Pietrobelli A, Greenfield D, Nunez C. Garcinia cambogia for weight loss [letter]. JAMA 1999; 282: 234-235.

21. Mill JO, Peters JC, Yang D, Shart $T$, Kaler $M$, Abumrad NN, Greene HL. Thermogenesis in humans during overfeeding with medium-chain and long-chain triglycerides. Am J Clin Nutr 1991; $53: 1130-1133$.

22. Hubert HB, Fenleib M, McNamara PM, Castelli WP. Obesity as an independent risk factor for cardiovatscular disease: a 26-year follow-up of participants in the Framingham Heart Study. Circulation 1983; $67: 968-977$.

23. Jeukendrup AE, Saris WHM, Wagenmakers A.JM. Fat metabolism during exercise: a review. Part III: The effects of nutritional interventions. Int J Sports Med 1998; 19: 371.379 .

24. Kovacs EMP, Westerterp-Plantenga MS, de Vies M, Brouns F, Saris WHM. Effects of 2-week ingestion of (-)-hydroxyclitrate and (-)-hydroxycitrate combined with medium-chain triglycerides on satiety and food intake. Phys Behew 2001; 74: 543-549.

25. Kriketos $A D$, Thompson $H R$, Greene $H$, Hill JO. (-)-hydroxycitric acid does not affect energy expenditure and substrate oxidation in adult males in a post-absorptive state. Int $\mathrm{J} O \mathrm{Obes}$ $1999 ; 23: 867-873$.

26. Kromhout D. Body weight, diet, and serum cholesterol in 871 middle-aged men during 10 years of follow-up (the Zutphen Study). Am J Clin Nutr 1983; 38: 591-598.

27. Langhans $W$. Metabolic control of food intake. Role of the liver. In Westerterp-Plantenga MS. Steffen $A B$. Tremblay A (eds). Regulation of food intake and energy expenditure. EDRA: Milano (1). 1999: 185-199.

28. Loon LJC van, Rooijen JJM wan, Niesen B, Verhagen $H$. Saris WHM, Wagenmakers A.JM. Effects of (-) -hydroxycitrate supplementation on substrate metabolism at rest and during exercise in humans. Am I Chin Nutr 2000; 72 : 1445-1450.

29. Lorr M. MCNair DM. Manual. Profile of Mood States. Bi-Polar Form (POMS-BI). Educational and industrial festing service (EDITS). San Diego: California, 1984. 
30. Marken Lichtenbelt WD van, Westerterp $K R$, Wouters $L$. Deuterium dilution as a method for determining total body water: effect of test protocol and sampling time. Br J Nutr 1994: 72 : $491-497$.

31. McCarty MF. Promotion of hepatic lipid oxidation and gluconeogenesis as a strallegy for appetite control. Med Hypotheses 1994; 42: $215-225$.

32. MeCarty MF. Reduction of free fatty acids may ameliorate risk factors associated with abdominal obesity. Med Hypotheses $1995 ; 44: 278-286$.

33. MoGarry JD. Foster DW. In support of the roles of malonyl-CoA and carnitine acyltransferase I in the regulation of hepatic fatty acid oxidation and ketogenesis. J Biol Chem 1979;254: 8163-8168.

34. Moore JJ, Marcus M. Sax SM. Kinetic assay of B-hydroxybutyrate in plasma with cobas bio centrifugal analyzer. Clin Chem 1982; 73: 1334-1339.

35. Noppa H. Body weight change in relation to incidence of ischemic heart disease and change in risk factors for ischemic heart disease. Am J Epidemiol 1980; 111: 693-704.

36. Pasman WJ, Saris WHM, Westerterp-Plantenga MS. Predictors of weight maintenance. Obes Res 1999; $7: 43-50$.

37. Rolls BJ, Gnizak N. Summerfeld A, Laster LJ. Food intake in dieters and nondieters after a liquid meal containing medium-chain triglycerides. Am J Clin Nutr 1988; 48: 66-71.

38. Rothacker DQ, Waitmann BE. Effectiveness of Garcinia cambogia and natural caffeine combination in weight loss - a double-blind placebo-controlled pilot study [abstract]. Int J Obes 1997; 21(Suppl 2): $\$ 53$.

39. Satabin P, Auclair $E$, Servan $E$. Achagiotis $C L$, Guezenned $C r$. Influence of glucose, medium-chain and long-chain triglyceride gastric loads and forced exercise on food intake and body weight in rats. Physiol Behav 1991; 50: 147-150.

40. Schaller Jt. Garcinia cambogia for weight loss [letter]. JAMA 1999; 282: 234.

41. Schoeller DA, Santen E V. Peterson DW, Diez W, Jaspan J, Klein PD. Total body water measurement in humans with "B $O$ and ${ }^{2} H$ labeled water. Am J Clin Nutr 1980; 33: 2686-2693.

42. Schoffelen PFM, Westerterp $K R$, Saris WHM ten Hoor $F$. A dual respiration chamber with automated calibration. J Appl Physiol 1997; 83: $2064-2072$.

43. Schrauwen P, Marken Lichtenbelt van WD, Saris WHM, Westerterp KR. Changes in nutrient oxidation in response to a high-fat diet. Am J Clin Nutr 1997; 66: 276-262.

44. Seidell JC. Obesity in Europe. Obes Res 1995; 3(Suppl 2): 249s-259s.

45. Siri, WE. Body composition from fluid spaces and density: analysis of methods. In: Brozek $J_{\text {: }}$ Henschel A, (eds). Techniques for measuring body composition. National Acaderny of Science: Washington DC, 1964, 223-244.

46. Stichting Nederlands Voedingsstoffenbestand. Nevo Tabel. Den Haag, Voorlichtingsbureau voor de voeding, 1996.

47. Stubbs Rd, Harbron CG. Covert manipulation of the ratio of medium triglycerides in isoenergetically dense diets: effect on food intake in ad libilum feeding men. int $J$ Obesity 1996: 20: 435-444

48. Stunkard AJ, Messick S. The three-factor eating questionnaire to measure dietary restraint. disinhibition, and hunger. J PSychosom Res 1985; 29: 71.83.

49. Sullivan $A C$, Hamilton JG, Miller $O N$, Wheatiey VR. Inhibition of lipogenesis in rat liver by (t) hydroxycitrate. Arch Biochem Piophys 1972; 150: 183-190.

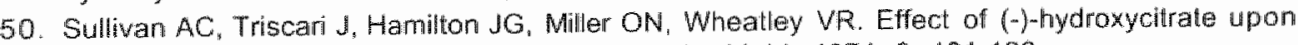
the accumullation of lipid in the rat. I Lipogenesis. Lipios 1974; 9: $121-129$.

51. Sullivan AC, Triscari J. Metabolic regulators as a control for lipid disorders. I. Influence of (n)inydroxycitrate on experimentally induced obesity in the rodent. Am J Clin Nutr 1977; 30: 76.7776.

52. Szutowicz A, Stepien M. Lysiak W. Angielski S. Effect of (-) -hydroxycitrate on the activilies of ATP citrate lyase and the enzymes of acetyl-CoA metabolism in rat brain. Acta Biochim Pol $1976 ; 23: 227-234$.

53. Thom $E$, Andrews $B$. Short- and long-term efficacy and tolerability of ( $\rightarrow$-hydroxycitrate in the treatment of obesity [abstract]. Int J Obes 1997; 21(Suppl 2): $\$ 53$. 
54. Watson $J A_{,}$Fang $M$, Lowenstein $M M$. Tricabalylate and hydroxycitrate: substrate and inhibitor of ATP: citrate oxaloacetate lyase. Arch Biochem Biophys 1969; 135: 209-217.

55. Weir JBDV. New methodis for calculating metabolic rate with special references to protein metabolism. I Physiof 1949; 109: 1-9.

56. Westerterp KR, Wilson SAd, Rolland $V$. Diet induced thermogenesis measured over $24 \mathrm{~h}$ in arespiration chamber effect of diet composition. Int $J$ Obes $1998 ; 22: 1-6$.

57. Westerterpm Plantenga MS, Kempen KP, Saris WHM. Determinants of weight maintenance in women after diet-induced weight reduction. Int J Obes Relat Metab Disord 1998; 22: 1-6.

58. Westerterpw Plantenga MS, Rolland V, Milson SAJ, Westerterp, KR. Satiety related to $24 \mathrm{~h}$ diet-induced thermogenesis during high protein/carbohydrate vs high fat diets measured in a respiration chamber. Eur I Clin Nutr 1999; 53: 1-8.

59. Westerterp-Plantenga MS, Kovacs EMR. The effect of (-)-hydroxycitrate on energy intake and satiety in overweight humans. Int $J$ Obes 2002; 26: 870.872.

60. Wymelbeke $V$ van, Himaya $A$, Louis-Sylvestre $J$, Fantino $M$. Influence of medium-chain and long-chain trilacylglycerols on the control of food intake in men. Am I Clin Nutr 1998; 68: 226234. 


\section{Does (-)-hydroxycitrate reduce de novo lipogenesis in humans?}

Kovacs EMR, Westerterp-Plantenga MS

Submitted for publication 


\section{ABSTRACT}

Background: (-)-Hydroxycitrate (HCA) might promote weight maintenance by limiting the capacity for de novo lipogenesis (DNL). In humans DNL is not of quantitative significance, but a persistent excess of energy intake as carbohydrate will promote DNL.

Objective: This study investigated whether HCA may reduce DNL in humans.

Design: In a double-blind, placebo-controlled, randomized, and cross-over design, 10 sedentary lean male subjects (mean $\pm \mathrm{SD}$; age, $24 \pm 5 \mathrm{y}$; BMI, $21.8 \pm 2.1 \mathrm{~kg} / \mathrm{m}^{2}$ ) performed a glycogen depletion exercise test followed by a 3-day high-lat diet (F/CHO/P, 60/25/15\%en; $100 \%$ of energy expenditure (EE)) and a 7 -day high-CHO diet (F/CHO/P, $<5 />85 / 10 \%$ en; $130-175 \%$ of EE; overfeeding). During overfeeding, they ingested $3 \times 500 \mathrm{mg} / \mathrm{d} \mathrm{HCA}$ or placebo (PLA). Each intervention ended with a 60-h stay in the respiration chamber (day 9 and 10).

Results: Body weight increased during overfeeding (HCA, $2.9 \pm 0.2 \mathrm{~kg}$; PLA, $2.8 \pm$ $0.2 \mathrm{~kg}$; NS). Respiratory quotient (RQ) was $>1.00$ in all subjects, indicating that DNL was present. On day 9, 24-h EE was lower with HCA compared to PLA $(P<$ $0.05)$. On day 10 , resting metabolic rate and $R Q$ during night were lower $(P<0.01$ and $P<0.05$, respectively) and non-protein $R Q$, fat balance, and fat synthesis as DNL tended to be lower $(P<0.1)$ with $H C A$, indicating lower DNL; activity-induced EE was higher with HCA $(P<0.05)$, indicating the urge to eliminate the excess of energy ingested.

Conclusion: An experimental condition that results in DNL in humans was created. Treatment with HCA resulted in lower DNL.

Keywords: (-)-hydroxycitrate, overfeeding, de novo lipogenesis, energy metabolism, substrate oxidation 


\section{INTRODUCTION}

During the past few decades, the prevalence of obesity has increased worldwide to epidemic proportions (36). Because long-term treatment of obesity is often unsuccessful $(10,33,45)$, more attention should be drawn to the prevention of obesity. Therefore, identification of strategies to prevent body weight gain may be useful in the treatment of obesity. In the present study we focussed on the treatment of a group of vulnerable subjects, i.e. young males with a normal body mass index, with a sedentary and comfortable lifestyle, who like food and have no problem with excess eating. We accelerated the process of weight gain through overfeeding, resulting in de novo lipogenesis, to simulate the dynamics of obesity. During overfeeding we tested the hypothesis whether (-)-hydroxycitrate (HCA) reduces de novo lipogenesis.

$\mathrm{HCA}$ is an active ingredient that is extracted from the rind of the fruit Garcinia cambogia, a native species to India, and is promoted as a weight loss agent. HCA is an inhibitor of ATP-citrate-lyase, a cytosolic (extramitochondrial) enzyme that catalyses the cleavage of citrate to oxaloacetate and acetyl-CoA $(38,39,42)$. The action of HCA would thus reduce the acetyl-CoA and subsequently the malonyl-CoA pool, limiting the availability of 2-carbon groups required for the synthesis of fats and cholesterol. In this respect, it has been found that mice lacking malonyl-CoA show decreased fat accumulation in adipose tissue and liver (2). From animal studies, it has been suggested that HCA may affect food intake and body weight through inhibition of ATP-citrate-lyase by three mechanisms: 1) by inhibiting or limiting the capacity for de novo lipogenesis $(38), 2)$ by inhibiting malonylCoA formation, which in turn would stimulate carnitine transferase activity, resulting in decreased fat synthesis and increased fat oxidation (29) or 3) by increasing the rate of hepatic glycogen synthesis (14). However, the results on the effects of HCA supplementation on food intake and body weight in humans are controversial, and the mechanisms by which HCA might possibly exert an effect are poorly investigated. No evidence was found for the suggestion that HCA may contribute to body weight regulation in humans by increased fat oxidation $(18,19,27)$. Therefore we investigated whether HCA might be effective through another mechanism, i.e. inhibiting de novo lipogenesis. Although it has been suggested that the conversion of carbohydrate to fat through de novo lipogenesis is negligible in humans $(3,13)$, several studies clearly demonstrated de novo lipogenesis during carbohydrate overfeeding $(1,4,22)$. An excess energy intake as carbohydrate will initially suppress fat oxidation and promote direct storage of ingested dietary fat without de novo lipogenesis. Persistent excess energy intake as carbohydrate will ultimately promote de novo lipogenesis, with storage of carbohydrate as fat.

The aim of the present study was to create an experimental condition that results in de novo lipogenesis and to investigate whether HCA may limit the capacity for de novo lipogenesis in humans. We hypothesized that HCA will reduce de novo lipogenesis, as reflected by a lower respiratory quotient and energy expenditure, a less positive fat balance and a lower fat synthesis as de novo lipogenesis. 


\section{METHODS}

\section{Subjects}

Ten sedentary male subjects participated in this study. The subjects were recruited by advertisements in local newspapers. Selection took place according to health criteria (no diabetes, no gastrointestinal and cardiovascular diseases, and no medical treatment) and body weight (BW) criteria (body mass index: $18-25 \mathrm{~kg} / \mathrm{m}^{2}$ ). The subjects had to be unrestrained eaters, as indicated by the Three Factor Eating Questionnaire (37) and the Herman Polivy questionnaire (16). Baseline characteristics of the subjects are presented in Table 1. The nature and risks of the experimental procedure were explained to the subjects, and all subjects gave their written informed consent. The study was approved by the Ethical Committee of Maastricht University.

\section{Experimental design}

The experiment had a double-blind, placebo-controlled, randomized, and crossover design. The experimental design consisted of two 10-day intervention periods separated by washout periods of at least 4 weeks.

Table 1 Subjects characteristics $(n=10)$ at baseline

\begin{tabular}{lc}
\hline & mean $\pm \mathrm{SD}$ \\
\hline Age $(\mathrm{y})$ & $24 \pm 5$ \\
Height $(\mathrm{m})$ & $1.81 \pm 0.06$ \\
Weight $(\mathrm{kg})$ & $71.1 \pm 6.5$ \\
Body mass index $\left(\mathrm{kg} / \mathrm{m}^{2}\right)$ & $21.8 \pm 2.1$ \\
Waist circumference $(\mathrm{cm})$ & $77 \pm 4$ \\
Hip circumference (cm) & $91 \pm 4$ \\
Waist-hip ratio & $0.85 \pm 0.03$ \\
Maximal power output (wait) & $266 \pm 30$ \\
Maximal power output (watt/kg) & $3.8 \pm 0.4$ \\
Maximal heart rate (beats/min) & $194 \pm 14$ \\
F1 (cognitive restraint) & $3 \pm 3$ \\
F2 (disinhibition) & $4 \pm 2$ \\
F3 (hunger) & $4 \pm 2$ \\
Herman-Polivy restraint & $8 \pm 4$ \\
\hline
\end{tabular}

F1-F3, factors 1.3 of the Three Factor Eating Questionnaire. For Herman Polwy restraint (normal $<$ 15 ) and $F \|-F 3$ scores (normal $<9$ ) a higher value indicales more restraint, disinhibition, hunger. 
In order to promote maximal glycogen storage capacity, the following protocol was used (Figure 1). The subjects performed a glycogen depletion exercise test to exhaustion on the evening of day 0 , followed by a 3-day high-fat low-carbohydrate diet (depletion period; day 1-3) and a 7-day high-carbohydrate low-fat diet (overfeeding period; day 4-11). During the depletion period energy intake was $100 \%$ of the subject specific predicted energy expenditure (12) and was increased from $130 \%$ to $175 \%$ during the overfeeding period. During the overfeeding period, the subjects ingested (-)-hydroxycitrate (HCA) or placebo (PLA). From the evening of day 8 until the morning of day 11, the subjects stayed in a respiration chamber for $60 \mathrm{~h}$. Measurements of energy expenditure and substrate oxidation were performed on day 9 and day 10 (Figure 1).

\section{Maximal power output}

In a pretest, each subject performed an incremental exhaustive exercise test on an electromagnetically braked cycle ergometer (Lode Excalibur, Groningen, the Netherlands) to determine the actual maximal power output ( $\left.W_{\text {max }}\right)(20)$.

\section{Glycogen depletion exercise}

The subjects came to the laboratory at about 18:00 h to perform a glycogen depletion exercise test (21) on an electromagnelically braked cycle ergometer (Lode Excalibur, Groningen, the Netherlands) (day 0). This exercise protocol has been validated to deplete muscle glycogen stores $(21,41)$.

\begin{tabular}{|c|c|c|c|c|c|c|c|c|c|c|c|}
\hline & \multicolumn{3}{|c|}{$\begin{array}{l}\text { DEPLETION } \\
\text { high-fat diet }\end{array}$} & \multicolumn{7}{|c|}{$\begin{array}{c}\text { OVERFEEDING } \\
\text { high-CHO diet }\end{array}$} & \\
\hline (u) & $100 \%$ & $100 \%$ & $100 \%$ & $130 \%$ & $130 \%$ & $130 \%$ & $145 \%$ & $145 \%$ & $160 \%$ & $175 \%$ & \\
\hline D & 1 & 2 & 3 & 4 & 5 & 6 & 7 & 8 & 9 & 10 & 11 \\
\hline & & & & & & & & & $\begin{array}{l}\text { respir } \\
\text { chan }\end{array}$ & $\begin{array}{l}\text { attion } \\
\text { beer }\end{array}$ & \\
\hline
\end{tabular}

\begin{tabular}{|c|c|c|c|c|c|c|c|}
\hline $\mathrm{BW}$ & $B W$ & BW & BW & $B W$ & BW & BW & $\begin{array}{l}\mathrm{BW} \\
\% \mathrm{BF}\end{array}$ \\
\hline$M$ & M & $\mathbb{M}$ & $M$ & $M$ & $M$ & $M$ & $M$ \\
\hline$T$ & $T$ & $T$ & $\mathrm{~T}$ & $T$ & $\mathrm{~T}$ & $\mathrm{~T}$ & $T$ \\
\hline $\mathrm{B}$ & $B$ & $\mathbb{B}$ & B & $B$ & B & B & $\mathrm{B}$ \\
\hline
\end{tabular}

Figure 1 Experimental design

$\mathrm{BW}=$ measurement of bady weight; $\% \mathrm{BF}=$ measurement of body fat: $\mathrm{M}=$ questionnaire on mood; $T=$ questioninaire on tolerance; $B=$ blood sample; $H \& S=$ questionnaire on hunger and satiety; $E E / R Q=$ measurement of $24-\mathrm{h}$ energy expenditure, respiratory quotient, and substrate oxidation. 


\section{Energy intake}

After the glycogen depletion exercise test, the subjects received a high-fat lowcarbohydrate meal (energy, $3.97 \mathrm{MJ}$; protein, $65 \mathrm{~g}$; fat, $64 \mathrm{~g}$; carbohydrate $28 \mathrm{~g}$ ).

During the depletion period (day 1-3) the subjects consumed a high-fat lowcarbohydrate diet. The diet was composed of $60 \%$ en fat, $25 \%$ en carbohydrate, and $15 \%$ en protein. Energy intake was calculated as $100 \%$ of predicted energy expenditure (with physical activity level $(P A L)=1.6(12)$ ).

During the overfeeding period (day 4-10), the subjects consumed a highcarbohydrate low-fat diet. The diet was composed of $<5 \%$ en fat, $>85 \%$ en carbohydrate, and $10 \%$ en protein. Energy intake was $130 \%$ of predicted energy expenditure (with PAL $=1.6(12)$ ) on day $4-6,145 \%$ on day $7-8,160 \%$ on day 9 and $175 \%$ on day 10 . Carbohydrate intake consisted predominantly of simple sugars ( $>50 \%$ of carbohydrates) and less of complex carbohydrates.

During day 1-6, food was supplied to the subjects. During day 7-10, the subjects came to eat at the University Eating Laboratory. They received the diet divided over three meals (breakfast at $8: 30 \mathrm{~h}$, lunch at $12: 00 \mathrm{~h}$ and dinner at 18:00) and snacks.

\section{Food supplements}

During the overfeeding period, three times daily, the subjects ingested a capsule containing $500 \mathrm{mg}$ Regulator ${ }^{1} \mathrm{HCA}$ (HOB Ireland Ltd., Dublin, Ireland; content HCA: $96,5 \%$ ) (HCA treatment) or $500 \mathrm{mg}$ placebo (lactose) (PLA treatment).

This resulted in a daily intake of $1447,5 \mathrm{mg}$ or $0 \mathrm{mg}$ HCA. The capsules were ingested $60 \mathrm{~min}$ before breakfast, lunch and dinner along with a glass of water.

\section{Measurements}

\section{Anthropometry}

Body weight was measured during screening and on day $0,1,4,7,8,9,10,11$ on a digital balance accurate to $0.02 \mathrm{~kg}$ (Chyo-MW-150K, Japan) with subjects in underwear, in the fasted state and after voiding their bladder.

Height was measured to the nearest $0.1 \mathrm{~cm}$ during screening using a wallmounted stadiometer (Seca, model 220, Hamburg, Germany). The body mass index was calculated as $B W /$ height ${ }^{2}\left(\mathrm{~kg} / \mathrm{m}^{2}\right)$.

The distribution of fat was investigated during screening by measuring the waist and hip circumferences and calculation of the waist-hip ratio (WHR). The waist circumference was measured at the site of the smallest circumference between the rib cage and the ileac crest, with the subjects in standing position. The hip circumference was measured at the site of the largest circumference between the waist and the thighs. The WHR was calculated by dividing the waist circumference by the hip circumference.

Whole body composition was determined on day 11 by underwater weighing with simultaneous assessment of long volume residual with the helium dilution technique using a spirometer (Volugraph 2000, Mijnhardt, the Netherlands). 
Measurements were performed in triplicate and the average was used to calculate body density.

\section{Attitude towards eating}

The subject's attitude towards eating was analyzed during screening using a walidated Dutch translation of the Three Factor Eating Questionnaire $(37,46)$. Body weight concern and chronic dieting behavior were investigated with the Herman Polvy questionnaire (16).

\section{Mood}

Parameters of mood (28) were scored on day $0,1,4,7,8,9,10,11$ on anchored $100-\mathrm{mm}$ visual analogue scales.

\section{Tolerance}

Tolerance of the diet was determined on day $0,1,4,7,8,9,10,11$ using a questionnaire on the occurrence of gastrointestinal and other complaints and scored on a 5 -point scale $(0=$ not at all, $1=$ less, $2=$ sometimes, $3=$ relatively much, 4 = extremely).

\section{Appetite ratings}

Appetite ratings (hunger, satiety, fullness, desire to eat, appetite, anticipated food intake and thirst) were scored on anchored $100 \mathrm{~mm}$ visual analogue scales (46) on day 9 and 10. Questionnaires were completed at 10 fixed time points, respectively immediately before and after breakfast, in the morning at $10: 30 \mathrm{~h}$, immediately before and after lunch, in the afternoon at 15:00 $\mathrm{h}$, immediately before and after dinner, in the evening at $20: 30 \mathrm{~h}$ and at 23:30 $\mathrm{h}$ before sleeping. The appetite ratings were corrected for the subject's minimum score and expressed as area under the curve (AUC).

\section{Blood parameters}

A fasting blood sample of $10 \mathrm{ml}$ was obtained on day $0,1,4,11$ and mixed with EDTA to prevent clotting. Plasma was obtained by centrifugation $\left(4^{\circ} \mathrm{C}, 3000 \mathrm{rpm}\right.$, $10 \mathrm{~min}$ ) and stored at $-80^{\circ} \mathrm{C}$ until analysis. Glucose (hexokinase method; GLUC HK kit, Hoffmann-La Roche, Basel, Switzerland), triacylglycerol (GPO-trinder 337. Sigma Diagnostics, St. Louis, MO, USA), free fatty acids (ACS-ACOD method: Wako chemicals, Neuss, Germany), glycerol (glyceralkinase-lipase method; Boehringer Mannheim, Mannheim, Germany), B-hydroxybutyrate (method of Moore et al (30)), total cholesterol (CHOD-PAP method; Monotest cholesterol, Boehringer Mannheim, Mannheim, Germany), HDL cholesterol (precipitation method; Monotest cholesterol Boehringer Mannheim, Mannheim, Germany) were analyzed using a semiautomated centrifugal spectrophotometer (Cobas Fara, Roche Diagnostics, Basel, Switzerland). LDL and VLDL cholesterol were calculated by the Friedwald equation (11). Insulin was analyzed with ELISA (Mercodia 10-1113-01) and leptin by radioimmunoassay (Human Leptin RIA kit, Linco Research, lnc. St.Charles, MO, USA) 


\section{Indirect calorimetry}

Oxygen consumption and carbon dioxide production was measured in a respiration chamber (35). The respiration chamber is a $14-\mathrm{m}^{3}$ room, furnished with a bed, chair, computer, television, radio-cassette player, telephone, intercom, sink and a toilet. The room was ventilated with fresh air at a rate of $70-80 \mathrm{l} / \mathrm{min}$. The ventilation rate was measured with a dry gas meter (Schlumberger, type 4, the Netherlands). The concentration of oxygen and carbon dioxide was measured using a paramagnetic $\mathrm{O}_{2}$ analyzer (Hartmann \& Braun, type Magnos 6G, Germany; Servomex, type OA184A, England) and an infrared $\mathrm{CO}_{2}$ analyzer (Hartmann and Braun, type Uras 3G, Germany). During each 15-min period six samples of outgoing air for each chamber, and one sample of fresh air, zero gas, and calibration gas was measured. The gas samples to be measured were selected by a computer that also stored and processed the data (35).

In the respiration chamber subjects followed a protocol consisting of fixed times for breakfast $(8: 30 \mathrm{~h})$, lunch $(12: 00 \mathrm{~h})$ and dinner $(18: 00 \mathrm{~h})$, snacks and sedentary activities. Subjects were expected to sleep from 23:00 $\mathrm{h}$ to 8:00 $\mathrm{h}$.

\section{Energy expenditure}

Energy expenditure was measured on both day 9 and day 10 of the protocol. $24-h$ energy expenditure (24-h EE) consisted of sleeping metabolic rate (SMR), dietinduced thermogenesis (DIT) and activity-induced energy expenditure (AEE). 24-h EE was calculated from 7:00 $\mathrm{h}$ to $7: 00 \mathrm{~h}$, from oxygen consumption and carbon dioxide production according to the formulas of Weir (43). SMR was defined as the lowest mean EE measured over three consecutive hours between 0:00 $\mathrm{h}$ and 7:00 h. DIT was calculated by plotting EE against radar output, both averaged over $30-$ min periods. The intercept of the regression line at the lowest radar output represented the EE in the inactive state (resting metabolic rate, RMR), consisting of SMR and DIT (44). DIT was determined by subtracting SMR from RMR. AEE waS determined by subtracting RMR from 24-h EE. PAL was calculated by dividing 24-h EE by SMR.

\section{Substrate oxidation}

Substrate oxidation was determined for both day 9 and day 10. 24-h respiratory quotient $(R Q)$ was calculated from $7: 00 \mathrm{~h}$ to $7: 00 \mathrm{~h}$, from oxygen consumption and carbon dioxide production. $\mathrm{RQ}$ during the night was calculated from $0: 00 \mathrm{~h}$ to $7: 00 \mathrm{~h}$ and $R Q$ during the day was calculated from 7:00 $\mathrm{h}$ to $0: 00 \mathrm{~h}$. Urinary nitrogen excretion was deternined from $7: 00 \mathrm{~h}$ to $7: 00 \mathrm{~h}$, to allow calculation of $24-\mathrm{h}$ nonprotein $R Q$ (NPRQ = RQ corrected for protein oxidation). 24-h urine was collected from the second voiding on the day of the experiment until the first voiding of the following day. Samples were collected in containers with $10 \mathrm{ml} \mathrm{H}_{2} \mathrm{SO}_{4}$ to prevent nitrogen loss through evaporation. Volume and nitrogen concentration were measured, the latter using a nitrogen analyzer (Elemental Analyzer, CHN-O-Rapid, Heraeus). NPRQ was calculated to determine the proportion of oxygen consumption used for fat and carbohydrate oxidation using the formula: 
$\mathrm{NPRQ}=\left(\mathrm{VCO}_{2}-4.8 \mathrm{~N}\right) /\left(\mathrm{VO}_{2}-6.0 \mathrm{~N}\right)$

where $\mathrm{VCO}_{2}$ is the measured carbon dioxide production (Vd)

$\mathrm{VO}_{2}$ is the measured oxygen consumption (V/d)

$N$ is the total nitrogen excreted in urine $(\mathrm{g} / \mathrm{d})$

4.8 is the volume of carbon dioxide equivalent $1 \mathrm{~g} N(/ / \mathrm{d})$

6.0 is the volume of oxygen equivalent to $1 \mathrm{~g} \mathrm{~N}(1 / \mathrm{d})$

Protein oxidation was calculated using the formula:

Protein oxidation $(\mathrm{g} / \mathrm{d})=6.25 * \mathrm{~N}$

where $N$ is the total nitrogen excreted in urine $(g / d)$

Carbohydrate and fat utilization, carbohydrate balance, percentage of carbohydrate utilized for heat production or stored as fat "and fat balance were calculated using the formula of Elia and Livesey (8) (see appendix).

Fat synthesized from the de novo lipogenesis was calculated using the formula:

Fat from de novo lipogenesis $(\mathrm{g} / \mathrm{d})=$ (fat balance - fat intake)

\section{Urinary glucose}

Glucose concentration (hexokinase method; GLUC HK kit, Hoffmann-La Roche, Basel, Switzerland) was analyzed from 24-h urine collected on day 10 using a semi-automated centrifugal spectrophotometer (Cobas Fara, Roche Diagnostics. Basel, Switzerland), and 24-h urinary glucose excretion was calculated.

\section{Data analysis}

Data are presented as mean \pm standard error (SE). Differences between treatments and changes during time were determined by analysis of variance for one-factor repeated measures (ANOVA) and Sheffe-F post-hoc test (Statview SE Graphics ${ }^{T M}$ ). When appropriate, a paired one-tailed t-test was applied. Time $x$ treatment interaction for plasma parameters was determined by analysis of variance for two-factor repeated measures (ANOVA). Pearson correlation coefficients, $r$, were calculated to determine the relationship between selected variables. The level of significance was set at $P<0.05$.

\section{RESULTS}

\section{Glycogen depletion exercise}

The average duration of the glycogen depletion exercise was $64 \mathrm{~min}$, ranging from 35 to 99 min, with no differences between the HCA and the PLA treatment (63 min and $65 \mathrm{~min}$ respectively).

\section{Body weight}

Body weight remained stable during the depletion period in both treatments (HCA, $0.4 \pm 0.2 \mathrm{~kg} ;$ PLA, $-0.0 \pm 0.1 \mathrm{~kg})$. During the overfeeding period there was an 
increase in body weight in both treatments (HCA, $2.9 \pm 0.2 \mathrm{~kg}$; PLA, $2.8 \pm 0.2 \mathrm{~kg} ; P<$ $0.001)$. However, body weight changes were not different between treatments. No intraindividual relationship was found between body weight change with HCA and body weight change with PLA $(r=0.53 ; P=0.11)$. Body weight change with HCA and PLA was not related to baseline body mass index $(r=0.19$ and $r=0.05$, respectively).

\section{Energy intake}

Daily energy intake and energy intake from carbohydrates is shown in Table 2. Daily energy intake and macronutrient composition were not different between treatments during the entire experiment. Total energy intake during 7-day overfeeding was $121.0 \pm 1.7 \mathrm{MJ}$ with HCA and $120.3 \pm 1.9 \mathrm{MJ}$ with PLA (NS). This means an excess of energy intake of $37.9 \pm 0.6 \mathrm{MJ}$ with HCA and $36.9 \pm 0.7 \mathrm{MJ}$ with PLA compared to predicted energy expenditure based upon the Harris and Benedict (12) formula on day 4 to day 8 and measured energy expenditure on day 9 to day 10. This excess energy intake was higher with HCA compared to PLA $P<$ 0.05). Efficiency, that is the excess of energy intake that is needed for a $1-\mathrm{kg}$ increase in body weight, was $13.6 \pm 1.2 \mathrm{MJ} / \mathrm{kg}$ with $\mathrm{HCA}$ and $13.6 \pm 0.9 \mathrm{MJ} / \mathrm{kg}$ with PLA (NS).

Table 2 Energy and carbohydrate intake (MJ)

\begin{tabular}{|c|c|c|c|c|c|c|}
\hline \multirow[b]{3}{*}{ Day 1} & \multicolumn{3}{|c|}{ PLA } & \multicolumn{3}{|c|}{$\mathrm{HCA}$} \\
\hline & \multicolumn{2}{|c|}{ EI } & \multirow{2}{*}{$\frac{\mathrm{CHO}}{3.5 \pm 0.1}$} & \multicolumn{2}{|c|}{ EI } & \multirow{2}{*}{$\frac{\mathrm{CHO}}{3.4 \pm 0.0}$} \\
\hline & $12.0 \pm 0.2$ & $(100 \%)$ & & $12.0 \pm 0.2$ & $(100 \%)$ & \\
\hline Day 2 & $12.0 \pm 0.2$ & $(100 \%)$ & $2.9 \pm 0.1$ & $12.0 \pm 0.2$ & $(100 \%)$ & $2.9 \pm 0.1$ \\
\hline Day 3 & $11.8 \pm 0.3$ & $(99 \%)$ & $3.5 \pm 0.1$ & $11.8 \pm 0.3$ & $(98 \%)$ & $3.5 \pm 0.1$ \\
\hline Day 4 & $15.3 \pm 0.3$ & $(128 \%)$ & $13.5=0.2$ & $15.5 \pm 0.2$ & $(129 \%)$ & $13.6 \pm 0.2$ \\
\hline Day 5 & $15.5 \pm 0.2$ & $(130 \%)$ & $13.6 \pm 0.2$ & $15.6 \pm 0.2$ & $(130 \%)$ & $13.7 \pm 0.2$ \\
\hline Day 6 & $15.3 \pm 0.2$ & $(128 \%)$ & $13.5 \pm 0.2$ & $15.5 \pm 0.2$ & $(130 \%)$ & $13.7 \pm 0.2$ \\
\hline Day 7 & $17.4 \pm 0.3$ & $(146 \%)$ & $15.2 \pm 0.3$ & $17.6 \pm 0.3$ & $(147 \%)$ & $15.2 \pm 0.3$ \\
\hline Day 8 & $17.5 \pm 0.3$ & $(146 \%)$ & $15.5 \pm 0.3$ & $17.4 \pm 0.3$ & $(145 \%)$ & $15.5 \pm 0.3$ \\
\hline \multirow[t]{2}{*}{ Dey 9} & $19.0 \pm 0.3$ & $(159 \%)$ & $16.7 \pm 0.3$ & $19.0 \pm 0.3$ & $(159 \%)$ & $16.8 \pm 0.3$ \\
\hline & & $(163 \%)^{1}$ & & & $(169 \%)^{\|}$ & \\
\hline \multirow[t]{2}{*}{ Day 10} & $20.3 \pm 0.3$ & $(170 \%)$ & $18.4 \pm 0.3$ & $20.4 \pm 0.3$ & $(170 \%)$ & $18.5 \pm 0.3$ \\
\hline & & $(169 \%)^{t}$ & & & $(170 \%)^{\frac{*}{2}}$ & \\
\hline
\end{tabular}

Values are mean \pm SE. The energy intake as a percentage of predicted energy expenditure based upon the Harris and Benedict formula is given between brackets. 'For day' 9 and day 10 the energy intake is also given as a percentage of measured energy expenditure. $E$ I = energy intake; $\mathrm{CHO}=$ carbohydrate; $\mathrm{PLA}=$ placebo; $\mathrm{HCA}=(-)$-hydroxycitrate. Statistical significance was determined by paired two-tailed t-test. 


\section{Appetite ratings}

The mean for appetite ratings over 2 -day stay in the respiration chamber was not different for HCA and PLA (hunger, $24 \pm 4 \mathrm{~mm}$ and $21 \pm 4 \mathrm{~mm}$ " fullness, $60 \pm 4 \mathrm{~mm}$ and $63 \pm 4 \mathrm{~mm}$; appetite, $22 \pm 3 \mathrm{~mm}$ and $20 \pm 4 \mathrm{~mm}$; satiety, $65 \pm 3 \mathrm{~mm}$ and $67 \pm 4$ $\mathrm{mm}$; thirst, $29 \pm 5 \mathrm{~mm}$ and $31 \pm 4 \mathrm{~mm}$; anticipated food intake, $32 \pm 4 \mathrm{~mm}$ and $30 \pm$ $5 \mathrm{~mm}$; desire to eat, $19 \pm 4 \mathrm{~mm}$ and $19 \pm 4 \mathrm{~mm}$.

\section{Energy expenditure}

On day 9, 24-h EE was significantly lower with HCA compared to PLA (HCA, $11.3 \pm$ $0.2 \mathrm{MJ}$; PLA, 11.6 $\pm 0.2 \mathrm{MJ} ; P<0.05 ;$ Figure 2) and RMR tended to be lower with HCA compared to PLA (HCA, $9.4 \pm 0.2 \mathrm{MJ} ; \mathrm{PLA}, 9.7 \pm 0.2 \mathrm{MJ} ; \mathrm{P}<0.1)$. No significant differences were found in SMR, DIT, or AEE between the two treatments on day 9 . On day 10, 24-h EE was not significantly different between treatments (HCA, 12.0 \pm $0.2 \mathrm{MJ}$; PLA, $12.1 \pm 0.2 \mathrm{MJ}$; Figure 2). However, HCA resulted in lower RMR (HCA, $9.9 \pm 0.2 \mathrm{MJ} ;$ PLA, $10.2 \pm 0.2 \mathrm{MJ} ; P<0.01)$ and higher AEE (HCA, $2.2 \pm 0.1 \mathrm{MJ} ; \mathrm{PLA}$, $1.9 \pm 0.2 \mathrm{MJ} ; P<0.05)$ compared to PLA. No significant differences were found for SMR and DIT between the two treatments on day 10. PAL was not different between treatments on both day 9 (HCA, $1.58 \pm 0.02$; PLA, $1.62 \pm 0.02$ ) and day 10 (HCA, $\left.1.52 \pm 0.02 ; P L A_{i} 1.48 \pm 0.02\right)$. Furthermore, radar output was similar for $H C A$ and PLA, on both day 9 and day 10. SMR, RMR, and 24-h EE were significantly related lo FFM with PLA and HCA on both day 9 and day 10. Change in activity as AEE, physical activity level or radar output from day 9 to day 10 was similar in both treatments. 24-h EE was higher on day 10 compared to day 9 (PLA, $P<0.01$; HCA, $P<0.001$ ). The lower PAL on day 10 compared to day 9 (PLA, $P<0.01$; HCA, $P<$ $0.05)$ was due to a higher SMR (PLA, $P<0.001$; HCA, $P<0.001)$ and RMR (PLA, $P$ $<0.01$; HCA, $P<0.05$ ) on day 10 compared to day 9 (PLA, $P<0.001$; HCA, $P<$ $0.001)$ rather than to increased activity, as AEE was not significantly different on day 10 compared to day 9 in both treatments.

\section{Respiratory quotient and substrate oxidation}

24-h RQ was $>1.00$ in all subjects on both day 9 and day 10 indicating that de novo lipogenesis was occurring. Mean 24-h RQ was similar for HCA and PLA on both days (Figure 3). RQ during the night, measured from 0.00 $\mathrm{h}$ to $7: 00 \mathrm{~h}$, was lower with HCA compared to PLA on day $10(P<0.05$ ), but not on day 9 (Figure 3). No significant difference was found in $\mathrm{RQ}$ during the day, measured from 7:00 $\mathrm{h}$ to $0: 00 \mathrm{~h}$, between the two treatments on both day 9 and day 10 (Figure 3 ). On both days, $R Q$ during the night was higher compared to $R Q$ during the day $(P<0.001)$. 24-h NPRQ was similar for HCA and PLA on day 9 , but tended to be lower with HCA compared to $P L A$ on day 10 (Figure 3). RQ and NPRQ were increased on day 10 compared to day $9(P<0.001)$, indicating that de novo lipogenesis was accurring to a greater extent on day 10 . 


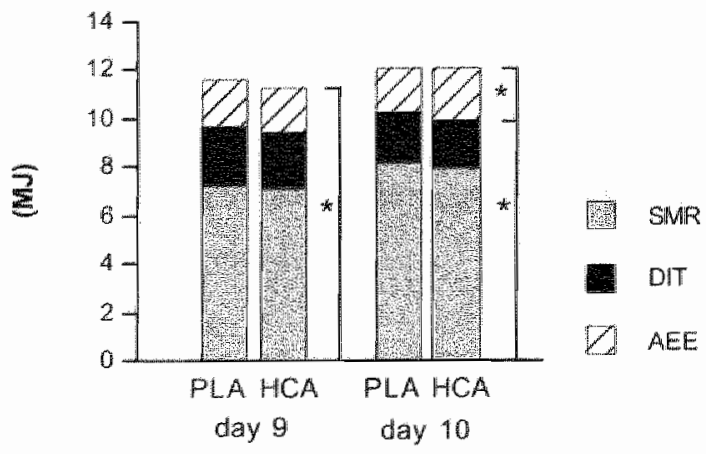

Figure 2 24-h energy expenditure and components of energy expendliture during the stay in the respiration chamber

Values are mean \pm SE. PLA = placebo; HCA = (-) whydroxycitrate; SMR = sleeping metabolic rate; $\mathrm{DIT}=$ diet-induced thermogenesis; $\mathrm{AEE}=$ activity-induced thermogenesis. "Statistical significance was determined by paired one-tailed t-test.

\section{De novo lipogenesis}

Protein oxidation was similar for the treatments on both day 9 ( $\mathrm{HCA}, 46 \pm 3 \mathrm{~g} / \mathrm{d}$; PLA, $48 \pm 2 \mathrm{~g} / \mathrm{d})$ and day 10 ( $\mathrm{HCA}, 40 \pm 3 \mathrm{~g} / \mathrm{d} ;$ PLA, $43 \pm 2 \mathrm{~g} / \mathrm{d})$. Net carbohydrate utilization was $>100 \%$ on both day 9 and day 10 indicating that carbohydrate was utilized for both oxidation and storage as fat (Table 3). On day 10, net carbohydrate utilization was increased compared to day $9(P<0.001)$, indicating that more carbohydrate was utilized for oxidation and storage as fat. Net fat utilization was negative indicating that fat was synthesized rather than oxidized (Table 3). On day 10 , net fat utilization was more negative compared to day 9 , indicating that more fat was synthesized rather than oxidized. There was no difference in net carbohydrate or fat utilization between treatments on day 9. However, there was a tendency for a less positive carbohydrate utilization and a less negative fat utilization with HCA compared to PLA $(P<0.1)$. Carbohydrate balance was more negative on day 10 compared to day 9 ( $P<0.001$; Table 3). Carbohydrate balance "expressed as the weight of carbohydrate oxidized or stored per MJ of non-protein heat production, was similar for both treatments on day 9 but tended to be less negative with HCA compared to PLA on day $10(P<0.1)$. However, carbohydrate balance, expressed as the weight of carbohydrate oxidized or stored during a day, was less negative with HCA compared to PLA on day $9(P<0.05)$, with no difference on day 10. Carbohydrate was utilized for heat production and fat storage (Table 3). There was no difference in the percentage of carbohydrate utilized for heat production or fat storage between PLA and HCA on day 9. However, there was a tendency for carbohydrate to be utilized more for heat production and less for fat storage with HCA compared to PLA on day $10(P<0.1)$. On day 10 , less carbohydrate was utilized for heat production and more for fat storage compared to day $9(P<0.001)$. Fat balance, expressed both as the weight of fat oxidized or synthesized per MJ non-protein heat production and as the weight of fat oxidized or synthesized during 

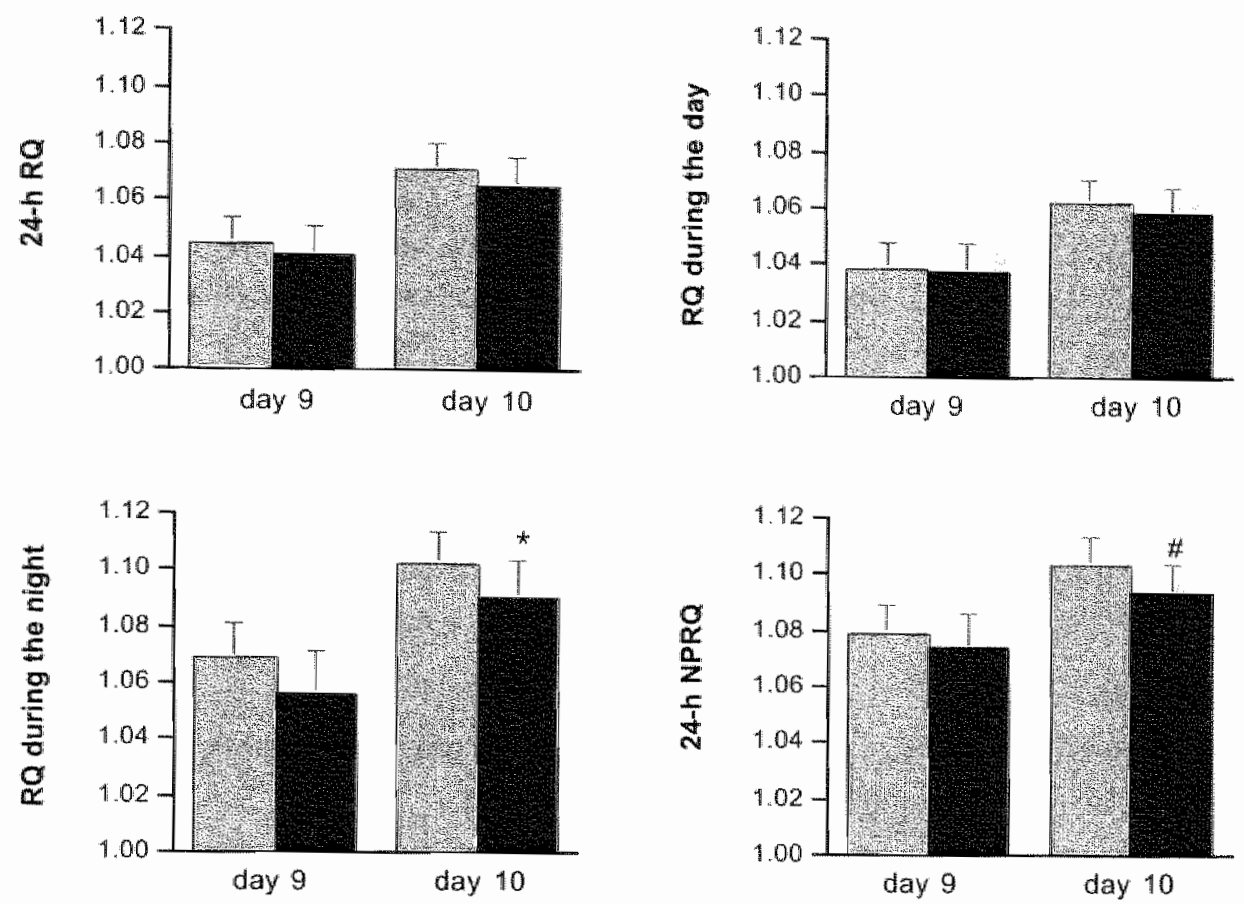

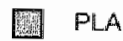

HCA

Figure 3 Respiratory quotient and non-protein respiratory quotient during the stay in the respiration chamber

Values are mean $\pm S E$. PLA = placebo; $H C A=(-)$-hydroxycitrate. $R Q=$ respiratory quitient; $N P R Q=$ non-protein respiratory quotient. Statistical significance was determined by paired one-tailed thest ( ${ }^{*} P<0.05$; $\left.P<0.1\right)$.

a day, was positive (Table 3; Figure 4). Fat balance increased from day 9 to day 10 $(P<0.001)$, indicating that more fat was synthesized. There was no difference in fat balance between both treatments on day 9 , but there was a tendency for a less positive fat balance with HCA compared to PLA on day $10(P<0.1)$. Fat synthesis as de novo lipogenesis was not different between PLA and HCA on day 9 (Figure 4). Fat synthesis as de novo lipogenesis was increased on day 10 compared to day $9(P<0.001)$, and tended to be lower with HCA compared to PLA $(P<0.1)$.

\section{Mood}

In general, subjects scored sufficient on the positive mood aspects (relaxed, fine) and low on the negative mood aspects (gloomy, angry, sad, scared). Mean values from day 0 to 11 for mood ratings were not different between treatments, except for gloominess $(P<0.05)$. 
Table 3 Do nowo lipogenesis

\begin{tabular}{|c|c|c|c|c|c|c|}
\hline & \multicolumn{3}{|c|}{ diay 9} & \multicolumn{3}{|c|}{ day 10} \\
\hline & PLA & HCA & $P$ & PLA & HCA & P \\
\hline CHO ufilization (\%) & $125 \pm 3$ & 12344 & NS & $132 \pm 3$ & $129 \pm 3$ & $<0.1$ \\
\hline Fat utilization $(\%)$ & $-25 \pm 3$ & $-23 \pm 4$ & NS & $-32 \pm 3$ & $-29 \pm 3$ & $<0.1$ \\
\hline CHO balance (g/MJ) & $-79 \pm 2$ & $-78 \pm 2$ & NS & $-84 \pm 2$ & $-82 \pm 2$ & $<0.1$ \\
\hline CHO balance (gid) & $.918 \pm 25$ & $-879 \pm 27$ & $<0.05$ & $-1007 \pm 25$ & $-982 \pm 26$ & NS \\
\hline CHO as heat $(\%)$ & $81 \pm 2$ & $82 \pm 2$ & NS & $77 \pm 2$ & $79 \pm 2$ & $<0.1$ \\
\hline CHO stored as fat (\%) & $19 \pm 2$ & $18 \pm 2$ & NS & $23 \pm 2$ & $21 \pm 2$ & $<0.1$ \\
\hline Fat balance $(\mathrm{g} / \mathrm{M} / \mathrm{l})$ & $6 \pm 1$ & $6 \pm 1$ & NS & $8 \pm 1$ & $7 \pm 1$ & $<0.1$ \\
\hline
\end{tabular}

Values are mean \pm SE. PLA = placebo; $H C A=(-)$-hydroxycitrate. $C H O=$ carbohydrate; $D N L=d e$ novo lipogenesis. Statistical significance was determined by paired one-tailed t-test. NS $=$ no significance.

\section{Tolerance}

Mean values from day 0 to 11 for gastrointestinal and other complaints were low (< 0.9) and not different between treatments.

\section{Blood parameters}

Figure 5 and 6 show the changes in plasma parameters during the entire experiment. There was no time $x$ treatment interaction for these plasma parameters. No differences between treatments were found in the average concentration of these plasma parameters over time, in the plasma concentration at each time, and in the changes during the different periods.
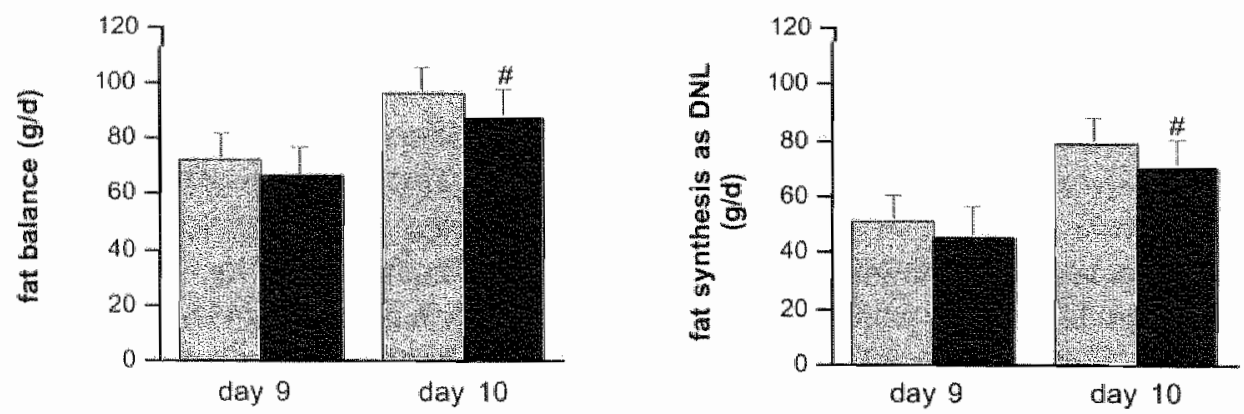

\footnotetext{
Figure 4 Fat ballance and fat synthesis as de nowo lipogenesis during the stay in the respiration chamber

Values are mean $\pm S E$. PLA = placebo: $\mathrm{HCA}=(-)$-hydroxycitrate. $\mathrm{CHO}=$ carbohydrate; $\mathrm{DNL}=$ de novo lipogenesis. Statistical significance was determined by paired one-talled thest ( $P<0.1)$.
} 

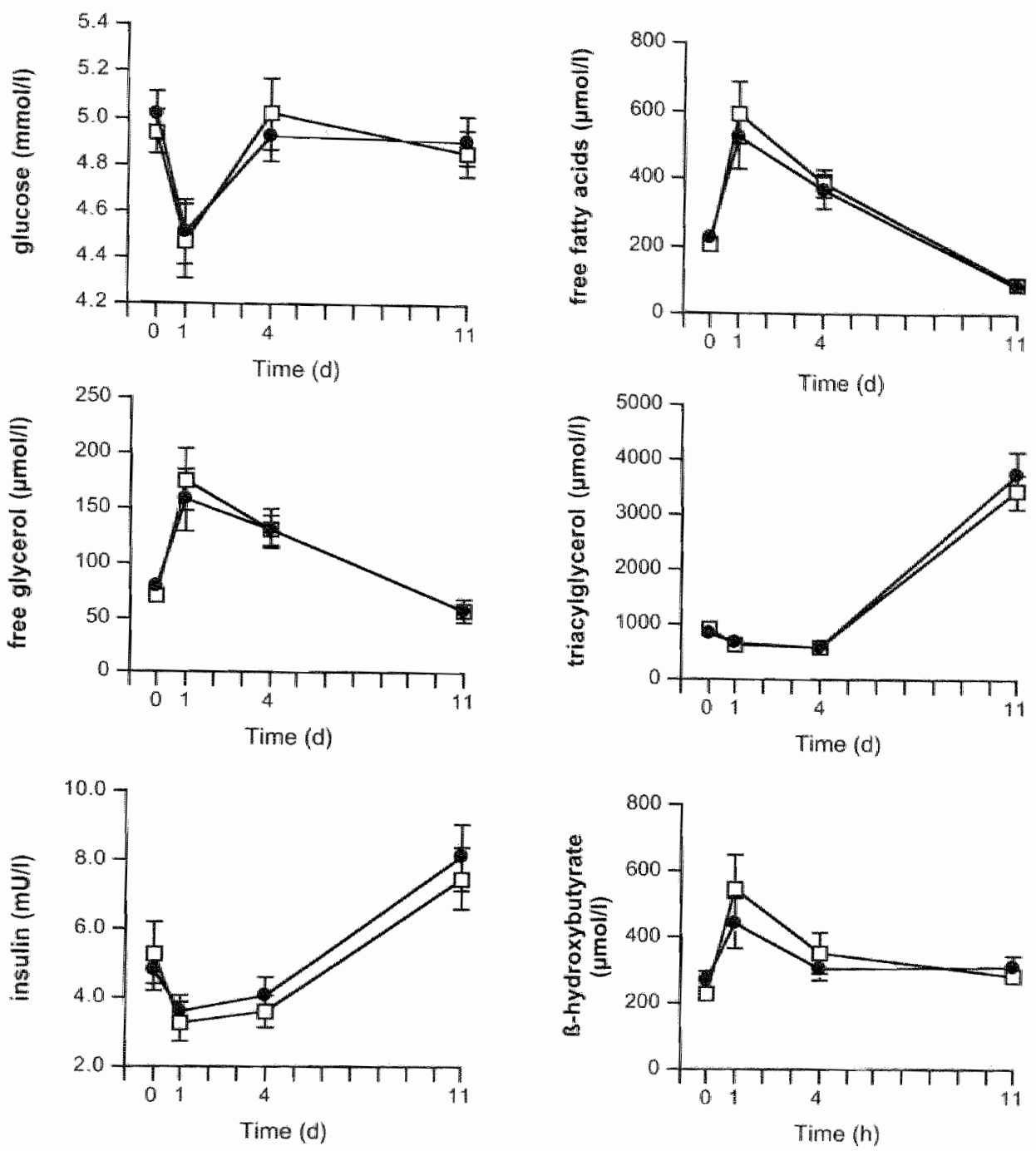

Figure 5 Changes in plasma parameters during the experiment

Values are mean $\pm S E$. PLA $=$ placebo; $H C A=(-)$-hydroxycilrate

Plasma glucose decreased from day 0 to day 1 as a result of the glycogen depletion exercise test $(P<0.001)$, increased from day 1 to day 4 during the depletion period in both treatments $(P<0.001)$ and remained stable from day 4 to day 11 during the overfeeding period. Plasma insulin decreased from day 0 to day 

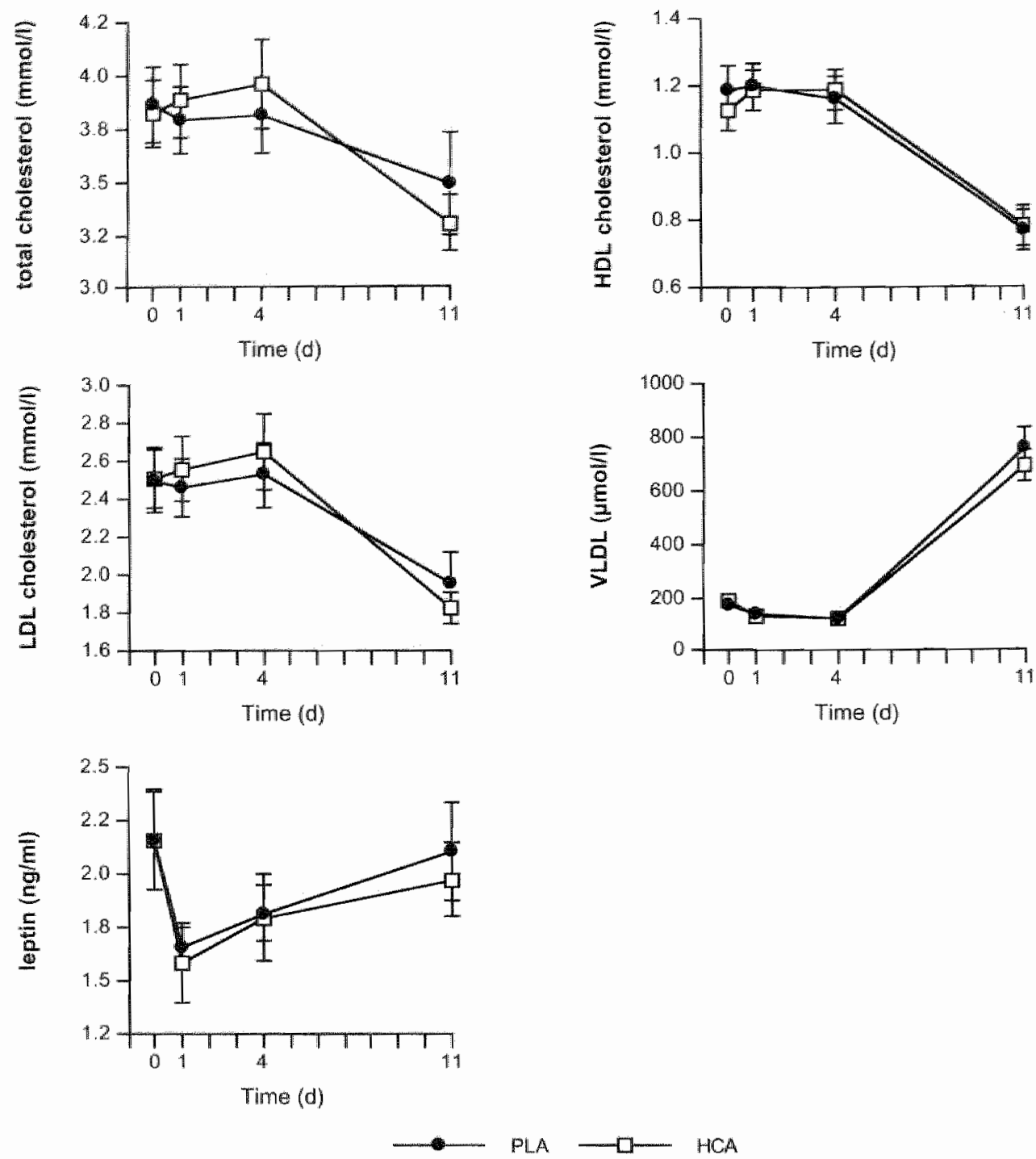

Figure 6 Changes in plasm parameters during the experiment Values are mean $\pm S E$. PLA $=$ placebo; HCA $=(-)$-hydroxycitrate.

1, but only significantly for HCA $(P<0.001)$, remained stable from day 1 to day 4 and increased 2 -fold in both treatments from day 4 to day $11(P<0.001)$. Plasma free fatty acids and free glycerol increased from day 0 to day $1(P<0.001)$, decreased from day 1 to day 4 and further decreased from day 4 to day 11 in both treatments $(P<0.001)$. Plasma triacylglycerol and VLDL cholesterol remained stable from day 0 to day 4 and increased about 6 -fold from day 4 to day 11 in both treatments $(P<0.001)$. Plasma $B$-hydroxybutyrate increased from day 0 to day 1 
and decreased from day 1 to day 11 , but only significantly with $H C A(P<0.01)$. Plasma leptin decreased from day 0 to day 1 in both treatments (HCA, $P<0.001$; PLA, $P<0.05$ ), did not change significantly from day 1 to day 4 and increased, but only significantly with $\mathrm{HCA}(P<0.001)$, from day 4 to day 11 .

\section{Urinary glucose}

24-h urinary glucose excretion (HCA, $0.58 \pm 0.09 \mathrm{mmol} ;$ PLA, $0.82 \pm 0.18 \mathrm{mmol}$; NS) remained within the normal range $(<0.5 \mathrm{~g} / \mathrm{d}$ or $<2.8 \mathrm{mmol} / \mathrm{d})$.

\section{DISCUSSION}

In the present study, respiratory quotient and non-protein respiratory quotient exceeded 1.0 in all subjects during the $6^{\text {th }}$ and the $7^{\text {th }}$ day of carbohydrate overfeeding, indicating that de novo lipogenesis was present. Fat synthesis by de novo lipogenesis was considerable and averaged $49 \mathrm{~g} / \mathrm{d}$ on the $6^{\text {th }}$ and $74 \mathrm{~g} / \mathrm{d}$ on the $7^{\text {th }}$ day of overfeeding. De novo lipogenesis was not only evident from respiratory exchange data, but also from a 6-fold increase in plasma triacylglycerol and VLDL cholesterol concentrations, despite the low amounts of fat provided in the diet. Although, it has been suggested that de novo lipogenesis is a quantitatively minor pathway under normal conditions in humans $(3,13)$, de novo lipogenesis can be observed in humans under artificial conditions of carbohydrate overfeeding $(1,4,22)$. Interestingly, it has been shown that after massive carbohydrate overfeeding, only $2 \%$ of net fat synthesis occurs in the liver and the remaining $98 \%$ takes place in the adipose tissue (1). Glycogen stores need to be saturated before de novo lipogenesis can occur (4). This can be reached if energy intake from carbohydrates is greater than total energy expenditure (minus protein intake) long enough to fill glycogen stores to their maximal capacity (15). In the present study, energy intake from carbohydrates was 13.5 to $18.5 \mathrm{MJ} / \mathrm{d}$ during the overfeeding period and exceeded energy expenditure $(11.2$ to $12.1 \mathrm{MJ} / \mathrm{d})$. Assuming that glycogen is stored with two to four times its weight of water (31) while fat gain by de novo lipogenesis was about $150 \mathrm{~g}\left(49 \mathrm{~g}\right.$ on the $6^{\text {th }}$ day, $74 \mathrm{~g}$ on the $7^{\text {th }}$ day, and small amounts on previous days), glycogen stores would have been 550 to $910 \mathrm{~g}$ during the overfeeding period. Storage of glycogen and water mainly explains the large body weight increase of almost $3 \mathrm{~kg}$ during carbohydrate overfeeding.

The conversion of carbohydrate to fat is energetically a very costly synthesis. The energetic cost of converting giucose to fat amounts to $\sim 0.24 \mathrm{MJ}$ per $\mathrm{MJ}$ of ingested carbohydrate. while the energetic cost of converting glucose to gllycogen is estimated at $\sim 0.05 \mathrm{MJ}$ per $\mathrm{MJ}$ of ingested carbohydrate (9). Recent studies have clearly shown that the mechanisms responsible for increased energy expenditure are activated during carbohydrate overfeeding $(4,7,17)$. In contrast, this is not the case during fat overfeeding $(7,17,22)$. In the present study, we did not observe increased $24-h$ energy expenditure measured in the respiration chamber after 
carbohydrate overfeeding compared to predicted energy expenditure calculated at baseline. Similarly, Lammert et al (22) did not find any change in energy expenditure as a result of carbohydrate overfeeding. However, they only measured energy expenditure at night. They therefore might have overlooked the possibility of increased diet-induced energy expenditure ("luxury consumption") when the subjects were awake $(5,25)$. In the same line, Pasquet et al. (34) did not find increased energy expenditure during carbohydrate overfeeding following the Guru Walla model, which could be explained by a substantial reduction in physical activity level. In our study "the physical activity level measured in the respiration chamber at the end of the experiment was similar to the physical activity level used for calculation of predicted energy expenditure. A possible explanation why no increase in energy expenditure as a result of carbohydrate overfeeding was found, is that a substantial amount of energy could have been lost through feces (22). Unfortunately, we did not collect feces, so we are not able to draw a conclusion on this regard. Energy expenditure was higher during the second day of staying in the respiration chamber (12 MJ) compared to the first day $(11.2$ to $11.6 \mathrm{MJ})$, consisting of increased sleeping metabolic rate. This might indicate a possible increase in energy expenditure during carbohydrate overfeeding over the longer term.

Respiratory quotient during the day was lower compared to the respiratory quotient at night, indicating that storage of carbohydrates as fat mainly occurred at night. Some more mobilization and oxidation of fat likely occurred during the day, as a result of activity. Thus, the usual circadian rhythm with a low respiratory quotient during night-time and a high respiratory quotient during the daytime under conditions of energy ballance (40) switches to a reversed cycle during de novo lipogenesis. This is in contrast to the hypothesis of Hellerstein (15), who proposed a circadian model with a low non-protein respiratory quotient during the overnight post-absorptive phase and a higher non-protein respiratory quotient during the daytime absorptive phase.

The suggestion that de novo lipogenesis is not a quantitatively significant pathway in humans, even during massive carbohydrate overfeeding, because excessive intake of carbohydrates would result in hyperglycemia and hyperinsulinemia and eventually glucose intolerance (6) was not observed in the present study, in that no glucosuria was observed at the end of the experiment, similar to the observation by Acheson ef al. (4). Fasting plasma glucose concentration was normal ( 4.9 mmol/l) but insulin concentration was increased.

Changes in plasma parameters during this de novo lipogenesis experimental design with carbohydrate overfeeding included 6-fold increases in plasma triacylglycerol and VLDL cholesterol, and decreases in plasma free fatty acids, free glycerol, HDL, LDL and total cholesterol. These changes were more pronounced compared to changes that are normally observed during body weight (re)gain with a diet containing large quantities of fat $(32,33)$.

The increase in plasma leptin concentration during overfeeding is in agreement with recent findings, in which changes in leptin with overfeeding were positively 
correlated to changes in body fat $(22,26)$. The decrease in leptin during the glycogen depletion exercise test is only partly in line with other observations during exercise, probably due to differences in intensity and duration $(23,24)$.

We found that treatment with (-)-hydroxycitrate resulted in reduced de novo lipogenesis as indicated by a lower 24 -h energy expenditure, resting metabolic rate, and respiratory quotient during the night and supported by a tendency for a lower non-protein respiratory quotient, a higher percentage of carbohydrates utilized for heat production, a lower percentage of carbohydrates stored as fat a lower fat balance and a lower fat synthesis from de novo lipogenesis, while part of the excess of energy intake was spent on activity. With exception of the effects on 24-h energy expenditure, the effects of $(-)$-hydroxycitrate on other parameters were only seen after 7 days of overfeeding, when de novo lipogenesis was present to a higher degree. As the conversion of carbohydrate to fat is energetically very costly, reduced de novo lipogenesis requires relatively less energy. Accordingly. (-)hydroxycitrate treatment resulted in decreased 24-h energy expenditure after 6 days of overfeeding. No difference was found in 24-h energy expenditure between the wo treatments on the $7^{\text {th }}$ day of overfeeding. However, resting metabolic rate was lower with (-)-hydroxycitrate, again indicating that less energy is needed during rest when de novo lipogenesis is reduced, as indicated by a llower respiratory quotient during the night. The excess of energy intake was eliminated as activity. Because there were no differences in physical activity level and radar output between the two treatments, the excess energy intake must have been expended as non-exercise activity thermogenesis (25).

Because of the significant but yet small effects on fat synthesis between the two treatments, increases in body weight were similar. As expected, no differences were found in appetite-related parameters between the two treatments. Moreover, the values for satiety and fullness were so high, and for hunger, desire to eat, appetite, and anticipated food intake so low "that a possible difference would have not been detected. Finally, the $(-)$-hydroxycitrate treatment was tolerated as well as the placebo treatment.

We conclude that treatment with (-)-hydroxycitiate resulted in a relatively lower (11\%) de novo lipogenesis. Although it remains questionable whether HCA may play a role as an agent in the treatment of obesity, we suggest that (-) -hydroxycitrate reduces fat deposition from de novo lipogenesis during weight gain, thus affecting body composition.

\section{ACKNOWLEDGEMENT}

We gratefully acknowledge Manuela Lejeune, Paul Schoffelen, Joan Senden, Jos Stegen, Annemie Gijsen, Patrick Schrauwen, Klaas Westerterp, Martijn Berger and Kathleen Melanson for their assistance. We thank Apotheek Ten Hoorn, Maastricht. the Netherlands for preparing the capsules. This study was supported by Novartis Consumer Health Ltd, Nyon, Switzerland. 


\section{REFERENCES}

1. Aarsland $A$, Chinkes $D$, Wolfe RR. Hepatic and whole-body fat synthesis in humans during carbohydrate owerfeeding. Am J Clin Nulr 1997; 65: 1774-1782.

2. Abu-Elheiga L, Matzuk MM, Abo-Hashema KAH. Wakil SJ. Continuous fatty acid oxidation and reduced fat storage in mice lacking acetyl-CoA carboxylase 2 . Science 2001; 291: 26132616.

3. Acheson $K J$, Schutz $Y$, Bessard $T$, Ravussin $E$, Jéquier $E$, Flatt JP. Nutritionall influences on lipogenesis and thermogenesis after a carbohydrate meal. Am J Physiof 1984; 246: E62E70.

4. Acheson KJ. Schutz $Y$, Bessard T, Anantharaman K, Flatt J.P. Jéquier $E$. Glycogen storage capacity and de nowo lipogenesis during massive carbohydrate overfeeding in man. $A m J$ Clin Nutr 1988; 48: 240-247.

5. Astrup A, Raben A. Commentary: Sugar as a slimming agent? Br J Nutr 2000; 84: 585-587.

6. Biörntorp $P$, Sjöström L. Carbohydrate storage in man: speculations and some quantitative considerations. Metabolism 1978; 27 (Suppl): 1853-1865.

7. Dirlewanger $M$, di Vetta, Guenat $E$, Battilana $P$, Seematter $G$, Schneiter $P$, Jéquier $E$, Tappy L. Effects of short-term carbohydrate or fat overfeeding on energy expenditure and plasma leptin concentrations in healthy female subjects. Int J Obes 2000; 24: 1413-1418.

8. Ellia $M_{\text {, Livesey }} \mathrm{G}$. Theory and validity of indirect calorimetry during net lipid synthesis. Am $J$ Clin Nutr 1988; $47: 591-607$.

9. Flatt JP. The biachemistry of energy expenditure. In: Bray GA (ed). Recent advances in obesity research. Newman: London, 1978, pp 211-228.

10. Fogelholm M, Kukkonen-Harjula $K$, Oja P. Eating control and physical activity as determinants of short-term weight maintenance after a very-low-calorie diet among obese women. lnt at Obes 1999; 23: 203-210.

11. Friedwald WT, Levy RI, Fredrickson DS. Estimation of the concentration of low-density lipoprotein cholesterol in plasma, without use of the preparative ultracentrifuge. Clin Chem 1972; 18: 499-502.

12. Harris JA, Benedict $F G$. A biometric study of basal metabolism in man. Carnegie institution: Washington, 1919.

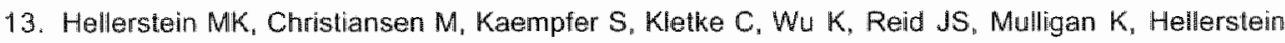
NS, Shackleton CHL. Measurement of de novo hepatic lipogenesis in humans using stable issolopes. I Clin Invest 1991; 87: 1841-1852.

14. Hellerstein MK. Xie $Y$. The indirect pathway of hepatic gllycogen synthesis and reduction of food intake by metabolic inhibitors. Life Sci 1993; 53: 1833-1845.

15. Hellerstein MK. De novo lipogenesis in humans: metabolic and regulatory aspects. Eur $J$ Clin Nutr 1999; 53(Suppl): \$53-565.

16. Herman CP, Poliwy J. Restrained eating. In: Stunkard AJ (ed). Obesity. W.B. Saunders: Philadelphia, 1980, pp 208-225.

17. Horton $\mathrm{TJ}$, Drougas $H$, Brachey A, Reed GW, Peters JC, Hill JO. Fat and carbohydrate overfeeding in humans: different effects on energy storage. Am J Clin Nutr 1995; 62: 19-29.

18. Kovacs EMR, Westerterp-Plantenga MS, Saris WHM. The effects of 2 -week ingestion of $\rightarrow$ hydroxycitrate and (-hydroxycitrate combined with medium-chain triglycerides on satiety, fat oxidation, energy expenditure and body weight. Int I Obes 2001; 25: 1087-1094.

19. Kriketos AD. Thompson $\mathrm{HR}_{n}$ Greene H, Hill JO. (-)-Hydroxycitrate acid does not affect energy expenditure and substrate oxidation in adult males in a post-absorptive state. Int d Obes 1999; 23: 867-873.

20. Kuipers $H_{\text {" Verstappen } F T J}$ Keizer HA, Geurten P, Kramenburg G van. Wariability of aerobic performance in the laboratory and its physiologic correlates. Int J Sports Med 1985; 6: 197 . 2011.

21. Kuipers $H$. Keizer HA, Brouns F, Saris WHM. Carbohydrate feeding and glycogen synthesis during exercise in man. Pflugers Arch 1987; 410:652-656. 
22. Lammert $O$, Grunnet $N$. Faber $P$, Schroll Biarnsbo, Dich J. Olesen Larsen L, Neese RA, Hellerstein MK, Quistorf B. Effects of isoenergetic overfeeding of either carbohydrate or fat in young men. Br $\backsim$ Nutr 2000; 84: 233-245.

23. Landt M, Lawson $G M_{*}$ Helgeson JM, Davila-Roman, VG, Ladlenson JH, Jaffe AS, Hickner RC. Prolonged exercise decreases serum leptin concentrations. Metabolism 1997; 46: 1109 1112.

24. Leal-Cerro A, Garcia-Luna PP, Astorga R, Parejo J, Peino R, Dieguez $C$, Casanueva FF. Serum leptin levels in male marathon athletes before and after the marathon run. I Clin Endocrinol Merab 1998; 83: 2376-2379.

25. Levine JA, Eberhardt NL, Jensen MD. Role of nonexercise activity thermogenesis in resistance to fat gain in lhumans. Science 1999; 283: 212-214.

26. Levine JA, Eberhardt NL, Jensen MD. Leptin responses to overfeeding: relationship with body fat and nonexercise activity thermogenesis. I Clin Endocinol Metab 1999; 84: 2751 . 2754.

27. Loon L van, Rooijen JJM van, Niesen B, Verhagen H, Saris WHM. Wagenmakers AJM. Effects of (-)-hydroxycitrate supplementation on substrate metabolism at rest and during exercise in humans. Am I Ckin Nutr 2000; 72: 1445-1450.

28. Lorr M, McNair DM. Manual. Profile of Mood States. Bi-Polar Form (POMS-Bi). Educational and Industrial Testing Service (EDITS): San Diego, CA. 1984.

29. McGarry JD, Foster DW. In support of the roles of malonyl-CoA and carnitine acyltransferase II in the regulation of hepatic fatty acid oxidation and ketogenesis. I Biol Chem 1979; 254: $8163-8168$.

30. Moore Jل, Marcus M, Sax SM. Kinetic assay of B-hydroxybutyrate in plasma with COBAS-BIO centrifugal analyzer. Clin Chem 1982; 73: 1334-1339.

31. Olsson KE. Saltin $B$. Variations in total body water with muscle glycogen changes in man. Acta Physiol Scand 1970; 80; 11-18.

32. Pasman WJ, Westerterp Plantenga MS, Saris WHM. The effectiweness of long-term supplementation of carbohydrate, chromium, fiber and caffeine on weight maintenance. Int $J$ Obes 1997; 21: 1143-1151.

33. Pasman WJ, Saris WHM, Muls E, Vansant G, Westerterp-Plantenga MS. The effect of exercise training on long-term weight maintenance in weight-reduced men. Metabolism 1999; 48: $15-21$.

34. Pasquet $P$, Brigant L, Froment A, Koppert GA, Bard D, Garine I de, Apfelbaurn M Massive overfeeding and energy balance in men: the Guru Walla model. Am I Clin Nutr 1992; 56 : 483-490.

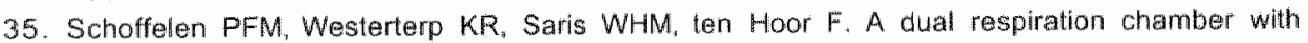
automated calibration. I Appl Physiol 1997; 83: 2064-2072.

36. Seidell JC. Obesity in Europe. Obes Res 1995; 3(Suppl): 249s-259is.

37. Stunkard AJ. Messick $S$. The three-factor eating questionnaire to measure dietary restraint, disinhibition, and hunger. I Psychosom Res 1985; 29: 71-83.

38. Sullwan AC, Hamilton JG, Miller ON, Whealley VR. Inhibition of lipogenesis in rat liver by $(-)$ hydroxycitrate. Arch Biochem Piophys 1972; 150: 183-190.

39. Szutowicz A, Stepien M. Lysiak W. Angieiskil S. Effect of $(-)$-hydroxycitrate on the activities of ATP citrate lyase and the enzymes of acetyl-CoA metabolism in rat brain. Acta Biochim Pol $1976 ; 23: 227-234$.

40. Verboeket-van de Venne WPHG, Westerterp KR. Influence of the feeding frequency on nutrient utilization in man: Consequences for energy metabolism. Eur J Clin Nutr 1991; 45 : $161-169$.

41. Wagenmakers AJM, Beckers EJ, Brouns F, Kuipers H, Soeters P, Vusse GJ vd, Saris WHM. Carbohydrate supplementation, glycogen depletion, and amino acid metabolism during exercise. Am J Physiol 1991; 260: E883-E890.

42. Watson JA. Fang M. Lowenstein JM. Tricaballylate and hydroxycitrate: substrate and inhibitor of ATP: citrate oxaloacetate lyase. Arch Biochem Biophys 1969; 135: 209-217. 
Chapter 8

43. Weir JBDV. New methods for calculating metabolic rate with special references to protein metabolism. I Physiol 1949; 109: 1-9.

44. Westerterp KR, Wilson S.AJ, Rolland $V$. Diet induced thermogenesis measured over $24 \mathrm{~h}$ in a respiration chamber: effect of diet composition. Int J Obes 1999; 23: 287-292.

45. Westerterp-Plantenga MS, Kempen KPG, Saris WHM. Determinants of weight maintenance in women after diel-induced weight reduction. Int J Obes 1998; 22: 1-6.

46. Westerterp-Plantenga MS, Rolland $\mathrm{W}$, Wilson SAJ. Westerterp KR. Satiety related to $24 \mathrm{~h}$ diet-induced thermogenesis during high protein / carbohydrate vs high fat diets measured in a respiration chamber. Eur I Clin Nutr 1999; $53: 1-8$. 


\section{APPENDIX}

The formula are derived from Elia and Livesey (1988).

Carbohydrale utilization:

$C \%=\frac{2112 \times(N P R Q-0.7097)}{21.120 \times(\mathrm{NPRQ}-0.7097)+19.502 \times(1-\mathrm{NPRQ})}$

where $C \%$ is net carbohydrate utilization as a percentage of the non-protein heat production.

$\mathrm{C} \%$ becomes $>100 \%$ when $\mathrm{NPRQ}>1$ because carbohydrate is utilized for both oxidation and storage of energy as fat.

Fat utilization:

$$
F \%=100 \%-C \%=\frac{1950.2 \times(1-N P R Q)}{19.502 \times(1-N P R Q)+21.120 \times(N P R Q-0.7097)}
$$

where $F \%$ is net lat utilization as a percentage of the nom-protein heat production. $F \%$ is negative when NPRQ $>1$, indicating that fat is synthesized rather than oxidized.

Carbohydrate balance, expressed as the weight of carbohydrate oxidized or stored per MJ nonprotein heat production:

Carbohydrate balance $=\frac{10 \times \mathrm{C} \%}{-\Delta \mathrm{Hc}_{\mathrm{e}}}$

where $\mathrm{C} \%$ is net carbohydrate utilization

$\Delta \mathrm{HC}_{\mathrm{c}}$ is heat of combustion of $1 \mathrm{~g}$ carbohydrate $=15.76 \mathrm{k} \cdot \cdot \mathrm{g}^{-1}\left(\Delta \mathrm{Hc}\right.$ for $\mathrm{C}_{66} \mathrm{H}_{12} \mathrm{O}_{61}=$ $2840.3 \mathrm{~kJ} \cdot \mathrm{mol}^{-1}$ )

carbohydrate balance has the unit $\mathrm{g} \cdot \mathrm{M} / \mathrm{J}^{-3}$ of non-protein heat released carbohydrate balance is always negative

Daily carbohydrate balance:

Carbohydrate balance $\left(g \cdot d^{-1}\right)=$ carbohydrate balance $\left(g \cdot M J^{-4}\right) \times 24-h E E\left(M J \cdot d^{-1}\right)$

The percentage of carbohydrate utilized for heat production or stored as fat was determined from Table 3.

Fat balance, expressed as the weight of fat oxidized or synthesized per M.J mon-protein heat production:

Fall balance $=\frac{-10 \times \mathrm{F} \%}{\mathrm{AHC}}$

where $F \%$ is net fat utilization

$\Delta \mathrm{HC}_{\mathrm{c}}$ is theat of combustion of $1 \mathrm{~g} \mathrm{fat}=39.41 \mathrm{~kJ} \cdot \mathrm{g}^{-1}\left(\mathrm{AHC}\right.$ for $\mathrm{C}_{55} \mathrm{H}_{402} \mathrm{O}_{6}=33876 \mathrm{~kJ} \cdot \mathrm{mol}^{-1}$ )

fat balance thas the unit $\mathrm{g} \cdot \mathrm{M} \mathrm{M}^{-1}$ of non-protein heat released

fat balance is positive when $F \%$ is negative (NPRQ $>1$ ), indicating that fat synthesis is occurring

Dailly fat balance:

Fat balance $\left(g \cdot d^{-1}\right)=$ fat balance $\left(g \cdot M^{-1}\right) \times 24-h E E\left(M \cdot d \cdot d^{-4}\right)$ 



\section{The effects of enterostatin intake on food intake and energy expenditure}

Kovacs EMR, Lejeune MPGM, Westerterp-Plantenga MS 


\section{ABSTRACT}

Enterostatin has been found to inhibit food intake and selectively inhibit fat intake in rats. Both peripheral and central mechanisms have been proposed. II also has been suggested that enterostatin may increase thermogenesis. This study investigated the effects of oral enterostatin administration on food intake, energy expenditure and body weight in subjects with a preference for a high-fat diet. In a double-blind, placebo-controlled, randomized and crossover design, nine female and three male healthy subjects (mean $\pm S D$; age, $34 \pm 11 \mathrm{y} ; \mathrm{BM}, 24.5 \pm 2.5 \mathrm{~kg} / \mathrm{m}^{2}$ ) with a preference for a high-fat diet ingested enterostatin (ENT) or placebo (PLA) $3 \times 15 \mathrm{mg} / \mathrm{day}$ while consuming an ad libitum 4-day high-fat diet. Eight subjects ended each intervention with a 36-h stay in the respiration chamber, continuing the diet and treatment. Body weight loss was significant (mean $\pm S E ; E N T, 0.8 \pm 0.3 \mathrm{~kg}_{\text {i }}$ $\left.P<0.05 ; P L A, 1.3 \pm 0.3 \mathrm{~kg}_{*} P<0.001\right)$, but not different between treatments. There was no difference between treatments in total energy intake (ENT, $37.1 \pm 2.6$ M. PLA, $35.9 \pm 3.2 \mathrm{MJ}$ ), macronutrient composition, hunger, satiety and hedonic scores during the 4-day high-fat diet. 24-h energy expenditure (ENT, $9.6 \pm 0.4 \mathrm{MJ}$; PLA, $9.5 \pm 0.4 \mathrm{M}$ l) , sleeping and resting metabolic rate, diet-induced thermogenesis, activity-induced energy expenditure and 24-h respiratory quotient (ENT, $0.77 \pm 0.01 ;$ PLA, $0.77 \pm 0.01$ ) were similar for both treatments. We canclude that oral enllerostatin administration did not affect food intake, energy expenditure or body weight in subjects with a preference for a high-fat diet.

Keywords: energy intake, fat intake, energy expenditure, body weight, fat preference 


\section{INTRODUCTION}

A high fat intake causing a high energy intake together with the possible inability to couple fat oxidation to fat intake for energy balance has been found to be related to obesity in humans $(23,28)$. Selective inhibition of fat intake can be a useful approach to reduce energy intake. Recently, a growing list of peptides has been shown to inhibit energy intake (2). Enterostatin, a pentapeptide produced by trypsin cleavage of pancreatic procolipase in the intestine, is one of those peptides. Enterostatin administration has been found to reduce energy intake and to selectively inhibit fat intake in rats in a dose-dependent manner $(4,9,15,25)$. However, the exact mechanism by which enterostatin causes its effects is unclear. Both peripheral and central sites of action have been proposed. The peripheral response is mediated via the afferent vagus (29). The central response is thought to be mediated through both opioid and serotonergic pathways $(10,18)$. Chronic administration of enterostatin has been found to reduce body weight and body fat in rats $(9,17)$. Besides effects on food intake, metabolic effects, such as reduction of insulin secretion $(12,13,17)$, stimulation of corticosterone secretion (17), and stimulation of brown adipose tissue (14), have also been suggested to contribute to body weight and body fat loss. In humans, it is suggested that enterostatin secretion may be reduced in obesity, in both a fasting and a postingestive state $(1,19)$. However, only a few studies have investigated the effects of enterostatin administration on food intake and appetite in humans $(20,24)$. It has been suggested that only humans who express a particular preference for fat will be responders to enterostatin (20). In rats it has been observed that chronic ingestion of fat is required for the response to enterostatin (10). However, the mechanism through which chronic ingestion of fat increases the susceptibility to enterostatin is not known. A range of endocrine, metabolic, and neurochemical changes due to fat ingestion may be involved.

The aim of the present study was to investigate the effects of oral enterostatin administration on food intake, energy expenditure and body weight in humans. This was studied in subjects with a preference for a high-fat diet. We hypothesized that enterostatin would reduce the rewarding value of fat consumption. We therefore offered the subjects a high-fat diet for four days, expecting that the reduction in rewarding value for fat would decrease food intake beyond a decrease through sensory specific satiely. This would result in a relatively larger decrease in total energy intake, ultimately leading to a larger body weight reduction.

\section{METHODS}

\section{Subjects}

The subjects were recruited by advertisements on boards at the university or in local newspapers, in which we asked for men and women who enjoy eating. Fortyfive subjects were invited for a pre-test in order to make a distinction between 
subjects with a preference for a high-fat diet (fat cravers) and subjects with no preference for a high-fat diet (non-fat cravers). This was done using a macronutrient specific food frequency questionnaire and a macronutrient specific food choice test. Development of the macromutrient specific food frequency questionnaire and the macronutrient specific food choice test and determination of the selection criteria to indicate whether subjects were fat cravers or non-fat cravers were carried out separately in a previous test. Subjects were selected on being healthy (no diabetes, no gastrointestinal and cardiovascular diseases, and no medical treatment) and on having a body mass index between 22 and $30 \mathrm{~kg} / \mathrm{m}^{2}$. Nine female and three male subjects were selected for participation in this study. Baseline characteristics of the subjects are presented in Table 1. The nature and risks of the experimental procedure were explained to the subjects, and all subjects gave their written informed consent. The study was approved by the Ethical Committee of Maastricht University.

\section{Experimental design}

The experiment had a double-blind, placebowcontrolled, randomized, crossover design. The intervention period consisted of two times a 4-day high-fat diet with ad libitum food intake separated by a washout period of at least two weeks (4-day high-fat diet experiment). We chose to offer the subjects a high-fat diet because it has been previously shown in rats that enterostatin reduces food intake only when the fat content of a diet is high $(4,9,16)$.

From the evening of the $4^{\text {th }}$ day until the morning of the $6^{\text {th }}$ day, a subsample of two male and six female subjects stayed in a respiration chamber for $36 \mathrm{~h}$. Measurements of energy expenditure and substrate oxidation were performed on the $5^{\text {th }}$ day (respiration chamber experiment).

The subjects ingested enterostatin (ENT) or placebo (PLA) during 4 or 5 days of intervention, respectively.

\section{Interventions}

\section{Food intake during the 4-day high-fat diet}

The high-fat diet that was provided was composed of $60 \%$ en fat $25 \%$ en carbohydrate, and $15 \%$ en protein. The subjects came to the University Eating Laboratory for breakfast, lunch and dinner, always at the same time of the day.

Breakfast consisted of bites of $1 \mathrm{~g}$ thin crispbread with $5 \mathrm{~g}$ of meat (cervelat sausage) or cheese (gouda), having similar macronutrient composition (18 bites: energy, 1,7.4 MJ; protein, $21 \mathrm{~g}$; carbohydrate, $14 \mathrm{~g}$; fat, $31 \mathrm{~g}$ ). Lunch consisted of bites of $1 \mathrm{~g}$ thin crispbread with $5 \mathrm{~g}$ of meat (cervelat sausage or liver sausage) or cheese (brie or port salut), all having similar macronutrient composition (18 bites; energy, 1,62 MJ; protein, $19 \mathrm{~g}$; carbahydrate, $14 \mathrm{~g}$; fat, $28 \mathrm{~g}$ ). Dinner consisted of different small party snacks (ball-shaped ciroquette, meat ball and cheesecroquette) (18 snacks; energy, $7,35 \mathrm{MJ}$; protein, $68 \mathrm{~g}$; carbohydrate $79 \mathrm{~g}$; fat $132 \mathrm{~g}$ ), served together with a cucumber $(100 \mathrm{~g})$ and tomato (100 g) salad. 
Tabie 1 Subjects characteristics ( $n=12 ; 3$ men, 9 women) at baseline

\begin{tabular}{lcc}
\hline & mean \pm SD & range \\
\hline Age (y) & $34 \pm 11$ & $21-49$ \\
Height (m) & $1.73 \pm 0.12$ & $1.54-1.98$ \\
Weight $(\mathrm{kg})$ & $73.10 \pm 11.48$ & $54.06-96.02$ \\
Body mass index $\left(\mathrm{kg} / \mathrm{m}^{2}\right)$ & $24.5 \pm 2.5$ & $22.1-29.8$ \\
Waist circumference $(\mathrm{cm})$ & $82 \pm 11$ & $70-102$ \\
Hip circumference $(\mathrm{cm})$ & $101 \pm 5$ & $93-106$ \\
Waist-hip ratio & $0.81 \pm 0.08$ & $0.73-0.98$ \\
Body fat (\%) & $28.3 \pm 6.1$ & $16.2-40.9$ \\
F1 (cognitive restraint) & $5 \pm 5$ & $1-14$ \\
F2 (disinhibition) & $4 \pm 4$ & $1-13$ \\
F3 (hunger) & $5 \pm 4$ & $0-11$ \\
Herman-Polivy restraint & $12 \pm 6$ & $5-23$ \\
Food frequency questionnaire & $0.49 \pm 0.01$ & $0.48-0.52$ \\
Food choice test questionnaire & $85 \pm 14$ & $70-100$ \\
\hline
\end{tabular}

F1-F3, factors $1-3$ of the Three-Factor Eating Questionnaire. For Herman-Poliwy restraint (normal < 15) and F1-F3 scores (normal < 9) a higher value indicates more restraint, disinhibition, hunger.

Food intake during breakfast, lunch and dinner was ad libitum with exception of the cucumber and tomato salad. If the amount of food served was not enough, extra bites were offered to the subjects. Snacks consisting of crisps and cashew nuts were consumed ad libitum in the morning and in the afternoon between meals. and in the evening. The subjects had to consume an apple in the afternoon. The subjects were not allowed to eat and drink anything else in addition to the prescribed food items, with exception of water, coffee and tea (without sugar and milk).

\section{Food supplements}

During the high-fat diet, three times daily, the subjects ingested a capsule containing $15 \mathrm{mg}$ enterostatin (PolyPeptide Laboratories, Wolfenbüffel, Germany) and $485 \mathrm{mg}$ placebo (lactose) (ENT treatment) or $500 \mathrm{mg}$ placebo (lactose) (PLA ireatment).

This resulted in a daily intake of $45 \mathrm{mg}$ or $0 \mathrm{mg}$ enterostatin, respectively. The capsules were ingested immediately before breakfast, lunch and dinner along with a glass of water. The timing of capsule ingestion immediately before the meals was chosen because it has been previously shown that hunger suppression is likely to appear early after enterostatin ingestion. (24). 


\section{Measurements}

\section{Macronutrient preference test}

Prior to the actual experiment a macronutrient specific food frequency questionnaire and a macronutrient specific food choice test were developed.

Fifty-two subjects (forty-one females and eleven males) participated in two tesis concerning a macronutrient specific food frequency questionnaire and a macronutrient specific food choice test. Their characteristics were (mean \pm SD): age, $28 \pm 10 \mathrm{y}$; body mass index, $22.3 \pm 2.5 \mathrm{~kg} / \mathrm{m}^{2}$. They were dietary unrestrained, as indicated by the Three Factor Eating Questionnaire $(27,32)$ and the Herman and Polivy questionnaire (32).

\section{Macronutrient specific food frequency questionnaire}

The subjects received a questionnaire that we have designed with questions about the frequency of eating high-fat and high-carbohydrate food items. The number of food items given in the questionnaire was the same $(n=22)$ for high-fat and highcarbohydrate. The answers to the questions were given according to a 1 to 4 point scale $(1=$ never, 2 = at least once a year, $3=$ at least once a month, $4=$ at least once a week). The mean frequency for eating high-fat or high-carbohydrate food items was calculated. The ratio

mean frequency for eating high-fat food items.

mean frequency for eating (high-carbohydrate + high-fat food items)

was calculated. Mean $\pm S D$ ratio was $0.46 \pm 0.03$ (range, $0.38-0.51$ ). The cult-off point for a preference for a high-fat diet was calculated using frequency distribution and was based on the highest tertile. The subjects in the highest tertile had a score $\geq 0.48$ on the macronutrient specific food frequency questionnaire.

Macronutrient specific food choice test

The subjects came to the laboratory at lunchtime, at least $2 \mathrm{~h}$ after the last meal. They received a choice of high-fat and high-carbohydrate food items. The high-fat food items were halves of croissants with cheese or salami, or sausage rolls. The high-carbohydrate items were bread rolls with jam or fresh cheese, or currant bunts. Food intake was ad libitum and the subjects were instructed to eat until they felt comfortable. They were allowed to drink tap water. The percentage of high-fat

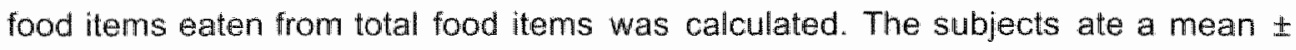
$\mathrm{SD}$ of $62 * 30 \%$ (range, $0-100 \%$ ) high-fat food items. The cut-off point for a preference for a high-fat diet was calculated using frequency distribution and was based on the highest tertile. The subjects in the highest tertile had a score $\geq 70 \%$ on the macronutrient specific food choice test.

\section{Screening}

Body weight and body mass index

Body weight (BW) was measured on a digital balance (Seca, model 707, Hamburg Germany; weighing accuracy of $0.1 \mathrm{~kg}$ ) with subjects in underwear, in the fasted 
state and after voiding their bladder. Height was measured to the nearest $0.1 \mathrm{~cm}$ using a wall-mounted stadiometer (Seca, model 220, Hamburg, Germany). The body mass index was calculated by BW/height ${ }^{2}\left(\mathrm{~kg} / \mathrm{m}^{2}\right)$.

\section{Fat distribution}

The distribution of fat was investigated by measuring the waist and hip circumferences and calculation of the waist-hip ratio. The waist circumference was measured at the site of the smallest circumference between the rib cage and the ileac crest, with the subjects in standing position. The hip circumference was measured at the site of the largest circumference between the waist and the thighs. The waist-hip ratio was calculated by dividing the waist circumference by the hip circumference.

\section{Body composition}

Whole bady composition was determined by underwater weighing with simultaneous assessment of residual lung volume by the helium dilution technique using a spirometer (Volugraph 2000, Mijnhardt, the Netherlands). Measurements were performed in triplicate and the average was used to calculate body density.

\section{Attitude towards eating}

Attitude towards eating was determined using a validated Dutch translation of the Three Factor Eating Questionnaire $(27,32)$. Cognitive restrained and unrestrained eating behavior (Factor 1), emotional eating and disinhibition (Factor 2) and the subjective feeling of hunger (Factor 3) were scored. Body weight concern and chronic dieting behavior were investigated with the Herman Polivy questionnaire (7).

\section{4-day high-fat diet experiment}

\section{Energy intake}

24-h energy intake and macronutrient composition were determined using the Dutch food composition table (26) and the accessory computer program (Becel Nutrition Program 1988).

\section{Hunger and satiety}

Hunger and satiety were scored every day on anchored $100-\mathrm{mm}$ visual analogue scales. Questionnaires were completed at ten fixed time points, respectively immediately before and after breakfast, in the morning between 10:00 and 11:00 $\mathrm{h}$. immediately before and after lunch, in the afternoon at 15:00 $\mathrm{h}$, immediately before and after dinner, in the evening between 21:00 and 22:00 h, and before sleeping.

\section{Hedonics}

Pleasantness of the taste of the food was scored every day on a 1 to 10 -point scale after the first bite of each food item consumed during breakfast, lunch and dinner.

\section{Tolerance}

Adverse events were recorded every day using a questionnaire on the occurrence of gastrointestinal and other complaints and the severity of the outcome was 
specified on a 5 -point scale $\left(0=\right.$ not at all, $1=$ less $_{3} 2=$ sometimes, $3=$ relatively much, $4=$ extremely).

Mood

Parameters of mood (11) were scored every day on anchored $100 \mathrm{mmm}$ wisual analogue scales.

\section{Respiration chamber experiment}

\section{Energy intake}

Foods offered during the stay in the respiration chamber were similar to that of the previous 4 days. To determine the appropriate level of energy intake for attaining energy balance, sleeping metabolic rate was measured during the first night and multiplied by an activity index of 1.65 (22).

\section{Protacol}

In the respiration chamber, subjects followed a protocal consisting of fixed times for breakfast $(8: 30 \mathrm{~h})$, lunch (12:00), dinner (18:00 h), and snacks (10:00 h, 15:00 h, $20: 30 \mathrm{~h})$, sedentary activities and bench stepping exercise. The bench stepping exercise was performed three times a day (10:30 h, 14:30 h, and $20: 30 \mathrm{~h}$ ) for 30 min each time, consisting of intervals of $5 \mathrm{~min}$ exercise alternated with 5 min rest, at a rate of one step per second with a bench height of $25 \mathrm{~cm}$. Apart from the exercise protocols, subjects were not restricted in their activities, except that sleeping and strenuous physical activity were not allowed. Subjects were expected to sleep from $23: 00 \mathrm{~h}$ to $8: 00 \mathrm{~h}$. Subjects further completed questionnaires on hunger and satiety, hedonics, tolerance, and mood, which are described previously.

Indirect calorimetry

Oxygen consumption and carbon dioxide production were measured in a respiration chamber (21). The respiration chamber is a $14-\mathrm{m}^{3}$ room, furnished with a bed, chair, computer, television, radio-cassette player, telephone, intercom, sink and $a$ toilet. The room was ventilated with fresh air at a rate of $70-80 \mathrm{l} / \mathrm{min}$. The ventilation rate was measured with a dry gas meter (Schlumberger, type 4, the Netherlands). The concentrations of oxygen and carbon dioxide were measured using a paramagnetic $\mathrm{O}_{2}$ analyzer (Hartmann \& Braun, type Magnos 6G, Germany; Servomex, type OA184A, England) and an infrared $\mathrm{CO}_{2}$ analyzer, respectively (Hlartmann and Braun. type Uras 3G, Germany). During each 15-min period six samples of outgoing air for each chamber, and one sample of fresh air, zero gas, and calibration gas were measured. The gas samples to be measured were selected by a computer that also stored and processed the data (21).

Energy expenditure and substrate oxidation

24-h energy expenditure consisted of sleeping metabolic rate "diel-induced thermogenesis, and activity-induced energy expenditure. 24-h energy expenditure and 24 -h respiratory quotient were calculated from $7: 00 \mathrm{~h}$ to $7: 00 \mathrm{~h}$, from oxygen consumption and carbon dioxide production according to the formulas of Weir (30). 
Physical activity was monitored using a radar system working on the Doppler principle. Sleeping metabolic rate was defined as the lowest mean energy expenditure measured over three consecutive hours between $0: 00 \mathrm{~h}$ and 7:00 $\mathrm{h}$. Sleeping metabolic rate was measured on both nights and the average of the two nights was used for further calculations. Diet-induced thermogenesis was calculated by plotting energy expenditure against radar output, both averaged over 30-min periods. The intercept of the regression line at the lowest radar output represented the energy expenditure in the inactive state (resting metabolic rate). consisting of sleeping metabolic rate and diet-induced thermogenesis (31). Dietinduced thermogenesis was determined by subtracting sleeping metabolic rate from resting metabolic rate. Activity-induced energy expenditure was determined by subtracting resting metabolic rate from 24-h energy expenditure. Physical activity level was calculated by dividing $24-\mathrm{h}$ energy expenditure by sleeping metabolic rate. Carbohydrate, fat, and protein oxidation were calculated using oxygen consumption and carbon dioxide production and urinary nitrogen excretion, using the formula of Brouwer (3).

Protein oxidation $(\mathrm{g} / \mathrm{d})=6.25^{*} \mathrm{~N}$

Fat oxidation $(\mathrm{g} / \mathrm{d})=1.718 * \mathrm{VO}_{2}-1.718 * \mathrm{VCO}_{2}-0.315 * \mathrm{P}$

Carbohydrate oxidation $(\mathrm{g} / \mathrm{d})=4.17 * \mathrm{VCO}_{2}-2.965 * \mathrm{VO}_{2}-0.390 * \mathrm{P}$

Where: $\quad N$ is total nitrogen excreted in urine $(\mathrm{g} / \mathrm{d})$

$\mathrm{VO}_{2}$ is oxygen consumption (l/d)

$\mathrm{VCO}_{2}$ is carbon dioxide production ( $\left./ / \mathrm{d}\right)$

$P$ is protein oxidation $(\mathrm{g} / \mathrm{d})$

24-h urine was collected from the second voiding on the day of measurement in the respiration chamber until the first voiding of the following day. Samples were collected in containers with $10 \mathrm{ml} \mathrm{H}_{2} \mathrm{SO}_{4}$ to prevent nitrogen loss through eveporation. Volume and nitrogen concentration were measured, the latter using a nitrogen analyzer (Elemental Analyzer, CHN-O-Rapid, Heraeus).

\section{Data analysis}

Data are presented as mean \pm standard error (SE). Differences between the two treatments were determined using paired t-test. Pearson correlation coefficients, $r$, were calculated to determime the relationship between selected variables. The level of significance was set at $P<0.05$. All statistics were executed with STATVIEW ${ }^{\text {TM }}$ SE+ GRAPHICS (1988; Abacus Concepts, Inc., Berkeley, CA, USA).

\section{RESUILTS}

There was a significiant body weight loss during the 4-day high-fat diet (ENT, $0.8 \pm$ $0.3 \mathrm{~kg} ; P<0.05 ;$ PLA, $1.3 \pm 0.3 \mathrm{~kg} ; P<0.0011$, with no significant difference between treatments. 
Table 2 24-h energy intake during the high-fat diet (MS)

\begin{tabular}{lccc}
\hline & PLA & ENT & P \\
\hline Day 1 & $8.7 \pm 0.8$ & $9.0 \pm 0.8$ & NS \\
Day 2 & $9.2 \pm 0.8$ & $9.6 \pm 0.5$ & NS \\
Day 3 & $8.9 \pm 0.9$ & $9.4 \pm 0.7$ & NS \\
Day 4 & $9.1 \pm 1.0$ & $9.0 \pm 0.8$ & NS \\
\hline
\end{tabular}

Values are mean \pm SE. PLA = Placebo; ENT = enterostatin. Statistical significance between treaiments was determined by paired two-tailed t-test. NS = no significance.

24-h energy intake during the 4-day high-fat diet is given in Table 2. There was no difference in total energy intake during the 4-day high-fat diet (ENT, $37.1 \pm 2.6$ MJ; PLA, $35.9 \pm 3.2 \mathrm{MJ}$ ) or during each day separately. The subjects were in negative energy balance, as shown by body weight loss. There was no significant correlation between energy intake, calculated as \% of predicted energy expenditure (6), and factor 1 of the Three-Factor Eating Questionnaire. Macronutrient composilion was $64 \%$ en fat, $20 \%$ en carbohydrate and $16 \%$ en protein, on each day. Also, there were no differences in energy intake and macronutrient composition from the different meals (breakfast, lunch, dinner, and snacks).

Mean hunger and satiety scores on each day or over the 4-day high-fat diet (ENT, $34 \pm 3 \mathrm{~mm}$; PLA, $34 \pm 4 \mathrm{~mm}$ and ENT, $58 \pm 3 \mathrm{~mm}$; PLA, $58 \pm 4 \mathrm{~mm}$; respectively) were not different between treatments.

Hedonics, measured as mean score on each day and over the 4-day high-fat diet (ENT, $7.4 \pm 0.2 ;$ PLA, $7.4 \pm 0.2$ ), were not different between treatments. Hedonic scores did not change over the 4 days (ENT, $0.1 \pm 0.1 ;$ PLA $_{*}-0.2 \pm 0.2$ ).

Occurrence of gastrointestinal and other complaints was low and not different between treatments, with the exception of "headache" and "constipation" that tended to be lower with ENT compared to PLA, as shown by the daily mean score over the 4-day high-fat diet (headache: ENT, $0.3 \pm 0.1 ; P L A, 0.8 \pm 0.2 ; P<0.1$; constipation: ENT, $0.3 \pm 0.2 ;$ PLA, $0.5 \pm 0.3 ; P<0.1$ ).

The subjects felt mone relaxed (ENT, $83 \pm 4 \mathrm{~mm} ;$ PLA. $75 \pm 5 \mathrm{~mm} ; P<0.05$ ) and less gloomy (ENT, $7 \pm 3$ mm; PLA, $16 \pm 4 \mathrm{~mm}$ : $P<0.05$ ) with ENT compared to $P L A$, as shown by the mean total scores measured during the 4-day high-fat diet. This was caused by a higher baseline score for "relaxed" (ENT, $81 \pm 6 \mathrm{~mm}$; PLA, $68 \pm 7 \mathrm{~mm} ; P<0.05$ ) and a lower score for "gloomy" (ENT $5 \pm 2 \mathrm{~mm}$; PLA $20 \pm 8$ mm; $P<0.05$ ) with ENT compared to PLA on day 1. No difference between treatments was found for the other mood parameters.

24-h energy intake on day 5 during the stay in the respiration chamber was similar for both treatments (ENT, $10.3 \pm 0.5 \mathrm{MJ}$; PLA, $10.2 \pm 0.6 \mathrm{MJ}$ ). Macronutrient composition was $66 \%$ en fat, $18 \%$ en carbohydrate and $16 \%$ en protein and food quotient was 0.77 . 
Table 3 Relation between energy expenditure and fat-free mass

\begin{tabular}{lcccccc}
\hline & \multicolumn{3}{c}{ PLA } & & \multicolumn{2}{c}{ ENT } \\
\hline & $r$ & 0.90 & $<$ & & $r$ & $P$ \\
\hline SMR wS FFM & 0.88 & $<0.05$ & & 0.93 & $<0.01$ \\
RMR wS FFM & 0.93 & $<0.05$ & & 0.86 & $<0.05$ \\
24-h EE WS FFM & & & 0.87 & $<0.05$ \\
\hline
\end{tabular}

PLA = placebo; $E N T$ = enterostatin. SMR = sleeping metabolic rate; $R M R$ = resting metabolic rate; $E E=$ energy expenditure: $F F M=$ fat-free mass. Relationships between variables were determined by calculating Pearson correlation coefficients $r$.

24-h energy intake on day 5 was higher compared to day 4 (ENT, $7.6 \pm 0.7 \mathrm{MJ}: \mathrm{P}<$ $0.001 ; P L A, 7.2 \pm 0.8 \mathrm{MJ} ; \mathrm{P}<0.001$ ). Mean hunger score on day 5 (ENT, $20 \pm 4 \mathrm{~mm}$ : PLA, $22 \pm 5 \mathrm{~mm}$ ) was significantly lower compared to day 4 (ENT, $30 \pm 5 \mathrm{~mm} ; P<$ $0.05 ; P L A, 32 \pm 6 \mathrm{~mm} ; P<0.01$ ). Similarly, mean satiety score on day 5 (ENT, $69 \pm$ $4 \mathrm{~mm}$; PLA, $69 \pm 6 \mathrm{~mm}$ ) was significantly higher compared to day 4 (ENT, $60 \pm 6$ $\mathrm{mm} ; P<0.1 ; P L A, 61 \pm 7 \mathrm{~mm} ; P<0.01)$. Mean hedonic scare tended to be lower on day 5 (ENT, $6.9 \pm 0.4 ;$ PLA, $6.7 \pm 0.4$ ) compared to day 4 (ENT, $7.3 \pm 0.2 ; P<0.1$; PLA, $7.1 \pm 0.4 ; P<0.1)$.

24-h energy expenditure was similar for both treatments (ENT, $9.6 \pm 0.4 \mathrm{MJ}$; PLA, $9.5 \pm 0.4 \mathrm{MJ}$ ), indicating that the subjects were in positive energy balance of $0.7 \pm$ $0.3 \mathrm{MJ}$ for both treatments during the stay in the respiration chamber. There were no differences in sleeping metabolic rate, diet-induced thermogenesis, resting metabolic rate, activity-induced energy expenditure (Figure 1) and physical activity level between treatments. There were also no differences in respiratory quotient (ENT, $0.77 \pm 0.01 ;$ PLA, $0.77 \pm 0.01$ ) and non-protein respiratory quotient (ENT, 0.76 $\pm 0.01 ;$ PLA, $0.76 \pm 0.01$ ). Sleeping metabolic rate, resting metabolic rate and 24henergy expenditure were significantly related to fat-free mass in both treatments (Table 3).

\section{DISCUSSION}

In the present study, we did not find an effect of oral enterostatin administration on food intake, appetite, or body weight. This is in contrast to animal studies, where promising results on the effects of enterostatin on food and fat intake have been shown during normal feeding and in experimental paradigms that involve dietary choice $(4,9,15,25)$. However, the exact mechanism by which enterostatin provokes its effects is still unclear. It has been suggested that both peripheral and central sites of action may be involved. The peripheral mechanism involves an afferent vagal signaling pathway to hypothalamic centers (29). The central response is thought to be mediated through pathways including both serotonergic and $\mathrm{k}$ opiodergic components $(8,18)$. These mechanisms might have an important role in the selection and appreciation of macronutrients, in this case fat. 


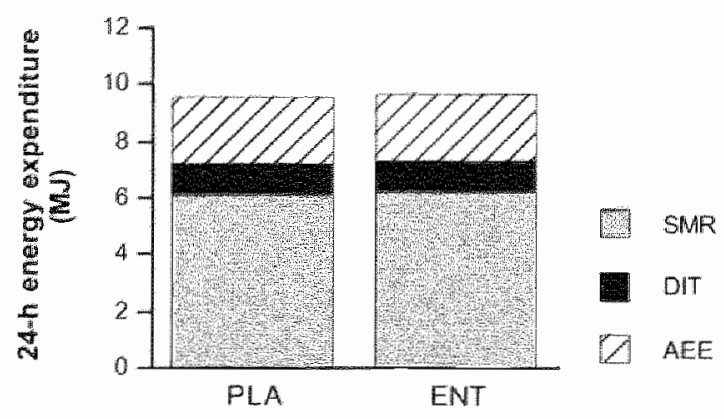

Figure 1 24-h energy expenditure and components of energy expenditure during the stay in the respiration chamber

Values are mean 1 SE. PLA = Placebo; ENT = enterostatin; SMR = sleeping metabolic rate; $\mathrm{DIT}=$ diet-induced thermogenesis; $A E E$ = activity-induced energy expenditure. Statistical significance between treatments was detemined by paired two-tailed t-test.

Until now, only a few studies have investigated the effects of enterostatin administration on food intake and appetite in humans $(20,24)$. Rössner et al. (20) failed to observe an effect of intravenous enterostatin administration ( $4 \mathrm{mg}$ and 16 $\mathrm{mg}$ ) in healthy obese male subjects on subsequent food intake during a test meal. They speculate that the lack of an effect may be due to the inability of intravenous enterostatin to reach the site of action, the time between enterostatin administration and the subsequent meal ( $5 \mathrm{~min}$ ), and the possibility that human responders would be those who have a particular preference for fat.

In this respect, Lin \& York (10) observed in rats that chronic ingestion of dietary fat is a prerequisite for the inhibiting action of enterostatin on feeding. They suggested that chronic ingestion of fat initiates metabolic, endocrine or neurochemical changes that are required for the response to enterostatin. For this reason, subjects with a preference for a high-fat diet were selected in the present study. Furthermore, it has been previously shown in rats that enterostatin reduces food intlake of single- and wo-choice diets when the fat content is high, but not when the fat content is low $(4,9,16)$. Therefore, a high-fat diet was used together with the treatment in the present study. Smeets ef al. (24) failed to find an effect of oral enterostatin administration (4 $\mathrm{mg}$ and $16 \mathrm{mg}$ ) in healthy male subjects ranging from normal weight to obese on subsequent food intake during a test meal presented after 60 min. However, they observed that hunger was significantly reduced 30 min after oral ingestion with both doses of enterostatin but not with placebo. After $60 \mathrm{~min}$, hunger remained significantly reduced only with the $16 \mathrm{mg}$ dose, suggesting that hunger suppression is likely to appear early after enterostatin ingestion. Furthermore, it has been shown in rats that with the exception of intravenous administration, the action of enterostatin is rapid $<30$ min) after administration by other routes, i.e. intraduodenally, intraperitoneally, and 
intracerebroventricularly (5). This explains the rational for the timing of capsule ingestion immediately before the meals in the present study.

Data suggest that obese individuals are probably more likely to be sensitive to enterostatin administration compared to normal weight subjects. Individuals that do not show increased enterostatin secretion following a meal are the most likely to show reduced food intake after enterostatin administration. In this respect, it would be useful to investigate enterostatin secretion in the different individuals in order to identify enterostatin sensitive subjects. Because an assay sensitive enough to determine enterostatin concentrations in serum was lacking until recently, individual enterostatin secretion has been poorly investigated (5). Procolipase activity, measured in the duodenal content after cholecystokinin administration, is reduced in obese compared to normal weight subjects. Enterostatin immunoreactivity can be detected in serum of normal weight but not of obese individuals. Enterostatin concentration in urine is significantly lower in obese compared to normal weight subjects (5). In the present study, the subjects had a body mass index between 22 and $30 \mathrm{~kg} / \mathrm{m}^{2}$. Because these subjects were normal weight to overweight, it might be possible that they were not sensitive enough for a response to enterostatin. Due to the rigid selection criteria, we were not able to include a larger number of subjects in order to look at a relationship between body mass index or body fat and the response to enterostatin. Furthemore, the negative energy balance may have contributed to the lack of a response to enterostatin. Although the diet was high in fat, it might be possible that the absolute amount of fat ingested was too small to induce an effect of enterostatin.

In the present study, we did not find a metabolic effect as a result of enterostatin treatment. 24-h energy expenditure and the components of energy expenditure measured during a $36-\mathrm{h}$ stay in a respiration chamber at the end of a 4 -day high-fat diet were not affected by enterostatin administration. This is in contrast to animal studies, where it has been found that several metabolic effects may be involved in the reduction of body weight and body fat. Enterostatin has been found to decrease insulin secretion $(12,13,17)$ and to stimulate corticosterone secretion (17). This will promote the catabolic effects of glucocorticoids and stimulate adipose tissue lipolysis. In the present study, we did not measure insulin and corticosterone concentrations in blood, so we are not able to draw a conclusion in this regard. In addition to the endocrine effects, enterostatin has been found to activate the sympathetic drive to brown adipose tissue, which would be expected to increase thermogenesis (14). Because brown adipose tissue is limited in adull humans. this might explain why we did not abserve any effect of enterostatin on thermogenesis in our subjects.

During ingestion of the ad libitum 4-day high-fat diet, the subjects were in a negative energy balance. Energy intake was $78 \%$ of predicted energy expenditure. The discrepancy between actual and expected energy intake was not due to restrained eating behavior, as there was no rellationship between energy intake as 
$\%$ of predicted energy expenditure and Factor 1 of the Three-Factor Eating Questionnaire. The negative energy intake during the intervention period was probably due to a specific and imposed food/fat intake pattern that was not familiar to the subjects. On the contrary, the subjects were in positive energy balance on day 5 during the stay in the respiration chamber, when the energy intake was fixed. Energy intake was $107 \%$ of the energy expenditure measured in the respiration chamber. One explanation might be that the subjects: were relatively inactive in the respiration chamber and that therefore the activity index used to calculate energy intake from sleeping metabolic rate was too high.

Some parameters of mood were more positive in the enterostatin compared to the placebo treatment. This may suggest that enterostatin might have an effect on the opioid system and that this would influence mood. However, the differences in mood parameters between the treatments were already present at baseline on day 1 , indicating that the differences were not due to the treatment, but already existed before the intervention started.

During the 4-day high fat diet, we did not observe a decrease in hedonics. This indicates that in this experiment we did not detect a sensory specific satiety effect of fat. However hedonic scores were lower on day 5 during the stay in respiration chamber compared to the previous days in both treatments. This is likely caused by overconsumption on day 5 , which resulted in increased satiety and decreased hunger scores and subsequently in lower hedonic scores.

It is known that oral administration of peptides and proteins is often limited because of their instability in the gastrointestinal environment. Therefore, it might be argued that enterostatin administered orally will lose its effects when passing through the stomach, as a result of deactivation by enzymes. In this respect, it would be suitable to administer enterostatin in capsules that release their content within the lumen of the duodenum. However, an effect of enterostatin on appetite was found also when administered orally (24). Furthermore, enterostatin has been found not only to be formed in the intestine by the cleavage of secreted pancreatic procolipase, but also to be produced in the gastric mucosa and the mucosal epithelia of the small intestine (5).

We conclude that oral administration of enterostatin ( $45 \mathrm{mg} /$ day) together with a high-fat diet did not affect food intake, appetite, energy expenditure, or body weight in subjects with a preference for a high-fat diet.

\section{REFERENCES}

1. Bowyer RC, Rowston WM, Jehanli AMT, Lacey JH, Hermon-Taylor J. The effect of satiating meal on the concentrations of procolipase activation peptide in the serum and urine of normal and morbidity obese individuals. Gut 1993; 34: 1520-1525.

2. Bray GA. Afferent signals regulating food intake. Proc Nutr Soc 2000; 59: 373-384.

3. Brouwer $E$. On simple formulae for calculating the heat expenditure and the quantities of carbohydrate and fat oxidised in metabolism of men and animals, from gaseous exchange 


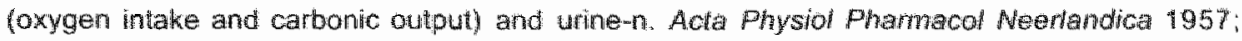
6: $795-802$.

4. Entanson-Abersison C. Mei "Okada S, York D. Bray GA. Pancreatic procoloase propeptide, enterostatin, specifically infibits fat intake. Physiol Betaw 1991; 49: 191-1194.

5. Ertanson-Albertsson C. York D. Enterostatin - A peptide regulaning fat intake. Obes Res 1997: 5: $360-372$.

6. Harris JA. Benedict FG. A Biometric Study of Besal Metabolism in Man. Carnegie Institulion: Washington, 1919.

7. Herman CP. Polivy J. Restraned eating. In: Stunkard AJ (ed). Obesily. W.B. Saunders: Philadelphia, 1980, po 208-225.

8. Lin L. York DA. Metergoline blocks the feeding response to enterostatin (abstrac). Appertie $1994 ; 23: 313$.

9. Lin 1 . Chen J, York DA. Chronic icv enterostanin preferentially reduced fal intake and lowered body weight. Peptides 1997; 18: 657-661.

10. Lin L. York DA. Chronic ingestion of diefary fat is a prerequisite for inhibition of feeding by enterostatin. Am A Physiof 1998; 275: R619-R623.

11. Lor M, McNair DM. Manual. Profile of Mood Siates. Bimpolar Form (POMS-B1). Educational and Industrial Testing Senvice (EDITS). San Diego, Catifornia, 1984.

12. Mei $J$, Cheng $Y$, Erlanson-Abetssion $C$. Enterostatin - Its ability to inhibit insulin secretion and to decrease highmat food intake. Int y Obes 1993:17: 701-704.

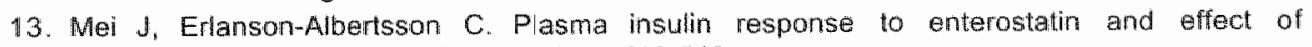
adrenalectomy in rat. Obes Res 1996; 4: 513-519.

14. Nagase H. Bray GA, York DA. Effect of galanin and enterostatín on sympathetic nerve activity to interscapular brown adipose tissue. Brain Ras 1997; 709: 44-50.

15. Okada S, York DA, Bray GA. Erlanson-Albertsson C. Enterostatin (Val-Pro-Asp-Pro-Arg) the activation peptide of procolipase selectively reciuces fat intake. Physio Behaw 1991: 49: $1185-1189$.

16. Okada S, York DA, Bray GA, Mei d, Erlanson-Albertsson C. Differential inhibition of fat intake in two strains of rat by the peptice enterostatin. Am J Clin Nutr 1992; 262: R1111-R1116.

17. Okada S, Lin L. York DA. Bray GA. Chronic effects of intracerebiral ventricular enterostatin in Osborne-Mendel rats fed a high-fat diet. Physiol Behav 1993; 54: $325-330$.

18. Ookuma KC, Barton C, York DA, Bray GA. Effect of enterostatin and kappa-opioids on macronutrien selection and consumption. Peptides 1997; 18: 785-791.

19. Prasad C. Imamura M. Debata C. Svec F. Sumar N, Hermon-Taylor J. Hyperenterostatimemia "lin premenopausal obese women. J Clin Endoctinol Metab 1999: 84: 937.941.

20. Rössner S, Barkeling B. Erlanson-Albertsson C. Larsson P. Wahin-Boll E. Intravanous enterostatin does not affect single meal food intake in man. Appetite 1995; $24: 37-42$.

21. Schoffelen PFM, Westerterp KR, Saris WHM, ten Hoor F. A dual respifation chamber with automatted calibration. I Appl Physiol 1997; 83: 2064-2072.

22. Schrauwen P. Marken Lichtenbelt WD van, Saris WHM, Westerterp KR. Changes in nutrint oxidation in response to a high-fat diet. Am I Clin Nutr 1997: 66: 276-282.

23. Schutz $Y$. Macronutrients and energy balance in obesily. Motabolism 1995; 44 (Suppi): 7-11.

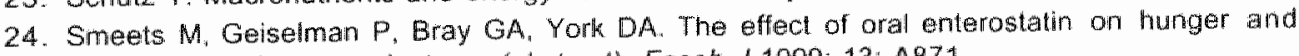
lood intake in human volunteers (abstract). Faseb J 1999; 13: A871.

25. Söhedie M, Mei J. Enlansomalbertsson C. Enterostatin - a gut-brain peptide - regulating fat intake in rait. Physiol Paris 1993; $87: 273-275$.

26. Stichting Nederlands Voedingsstofenbestand. Newo Tabel. Voorlichtingsbureau voor de voeding: Den Haag, 1996.

27. Stunkard AJ, Messick S. The three-factor eating questionnaire to measure dietary restraint. disintuibition, and hunger. I Psychosom Res 1985; 29:71-83.

28. Swinbum BA, Ravusssin E. Energy balance or fat balance? Am I Clin Nutr 1993; 57 (Suppl): $7665-7705$

29. Tian $Q$. Nagase $H$, York DA Bray $G A$. Vagal-central nervous system interactions modulate the feeding response to peripherall enterostatio. Obes Res 1994; $2: 527-534$. 
30. Weir JBOV. New methods for calculating metabolic rate with special references to protein metabolism. J Physiol 1949; 109: 1-9.

31. Westerterp KR, Wilson SAJ Rolland $W$. Diet induced thermogenesis measured over 24 in in a respiration chamber: effect of diet composition. Int $J$ Obes 1998; 22: 1-6.

32. Westerterp-Plantenga MS, Rolland $V$. Wison SAJ Westerterp KR. Satiety related to 24 h diet-induced thermogenesis during high protein/carbohydrate vs high fat diets measured in a respiration chamber. Eur J Clin Nutr 1999; 53: 1-8. 

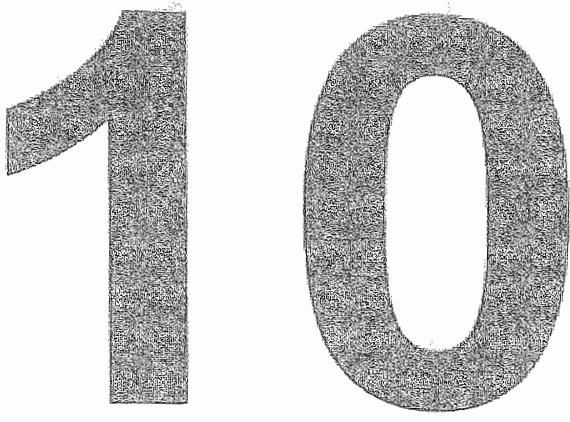

\section{General Discussion}




\section{THE ENERGY BALANCE EQUATION}

The research of this thesis focussed on concept development for treatment of obesity by acting on energy intake, energy expenditure and/or energy storage. The purpose was to identify ingredients or combinations of ingredients that might decrease energy intake, particularly by stimulating satiety, increase energy expenditure, and/or reduce fat storage in the body. The studies presented in this thesis were performed during a relatively short period of time $(<2$ weeks). Subsequently, the most promising ingredients or combinations of ingredients should be proposed for investigation of their effectiveness to improve body weight loss and to prevent body weight (re)gain during a longer period of time $p 3$ months). If effective, these ingredients could be used as food supplements or incorporated in functional foods and consumed within a normal diet or as a support during an energy-restricted diet.

There is a strong relationship between the components of the energy balance equation (Figure 1). Satiety influences energy intake. Energy intake in tum influences satiety. Food intake itself induces satiation and satiety, and administration of a satiety-stimulating ingredient may have an additional effect. Energy expenditure may influence satiety through increased diet-induced thermogenesis (141). Promotion of hepatic fatty acid oxidation and glycogen storage also may enhance satiety $(49,73)$. An imbalance between energy intake and energy expenditure results in energy storage when energy intake exceeds energy expenditure and in energy mobilisation when energy expenditure exceeds energy intake. Energy (fat) storage via increased lipogenesis (excess of fat) or de novo lipogenesis (excess of carbohydrates) results on the long-term in increased body fat and body weight. Energy (fat) mobilisation via increased lipolysis and fatty acid oxidation reduces on the long-term body fat and body weight.

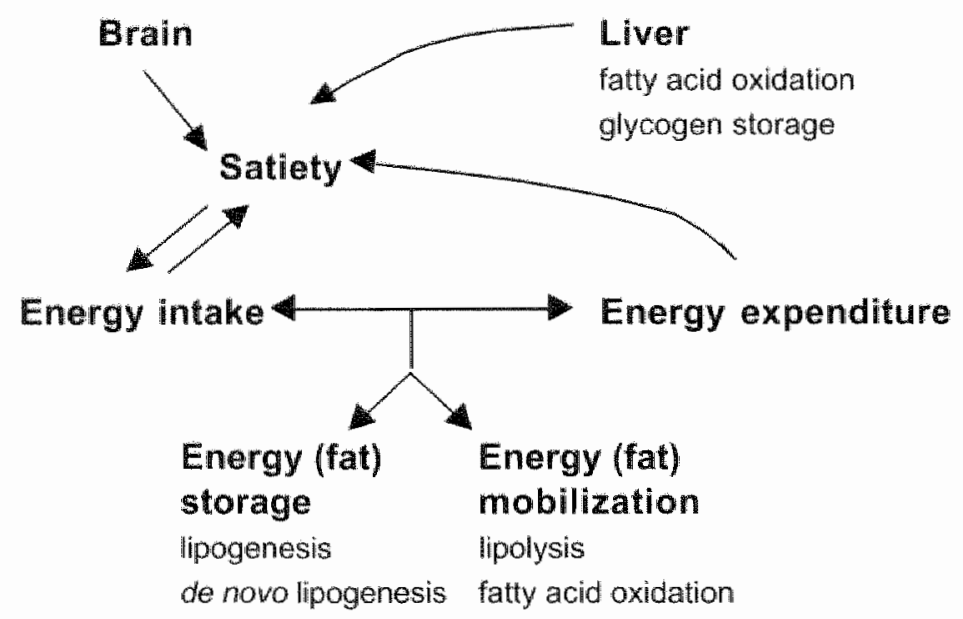

Figure 1: Relationship between the components of the energy balance equation 


\section{BIOMARKERS}

The use of valid markers as outcome parameters is necessary to determine whether the experimental ingredients are effective on food intake and appetite, energy expenditure, and energy storage, and therefore suitable for the treatment of obesity. In addition, bioactivity and bioavalailability of ingredients should be identified, especially when no significant effects appear. For example, the absence of an effect with $(-)$-hydroxycitrate $(61,62)$ was not due to a lack in bioactivity $(80)$ or bioavailability $(83)$.

\section{Food intake}

Food intake on the long term is often determined using dietary assessment methods (weighed/estimated dietary record, food frequency questionnaire, 24-h dietary recall, dietary history, double portion technique). Food intake recording using these methods however is not accurate, because of underestimation of food intake, especially of fat intake (42). Therefore we executed assessment of food intake in a laboratory setting. In this type of setting, subjects are often offered an ad libitum test meal, for example after a preload, Meal size, energy content and macronutrient composition can easily be determined. However, this method does noll account for possible compensation later. Measurement of 24-h food intake should therefore be included in such a laboratory setting. The results with (-)hydroxycitrate (HCA) underline the importance of assessing 24-h food intake (62). If we would have assessed energy intake during the lunch, then our conclusion would have been that (-)-hydroxycitrate increases energy intake. However, this was not the case over $24 \mathrm{~h}$. When determination of long-term energy intake is needed, the water-balance method can be used as an indicator for the reliability of food intake recording $(41,60)$.

\section{Appetite}

A widely used method to investigate the appetite profile is the visual analogue scale for hunger and satiety. This is the required subjective measurement of a human sensation, translated into a score. However, the weak relationship between appetite and food intake meams that only limited conclusions can be drawn from appetite profile scores $(60,87,145)$. Another approach is allowing time-blinded subjects to request a meal whenever they are hungry $(64,91,92,93)$. Meal interval, meal frequency and ad libitum intake can be determined. Rellating these outcomes of eating behaviour to an objective and physiological method for the measurement of appetite would give more insight into the physilology and behaviour of food intake regulation at the same time. Evidence indicates that patterns of blood glucose. particularly transient and dynamic declines, play a role in determining meal iniliation, intermeal interval and satiety $(26,91,92,93,108)$. Changes reflected by declines in blood glucose may therefore contribute to the determination of the appetite profile of an individual. However, this method is not applicable in all situations $(63,92)$. Another way to assess appetite may be the application of realtime functional magnetic resonance imaging (72), which may allow the 
investigation of responses to food stimuli, e.g. administration of an ingredient, in different regions of the central nervous system. The validily of this method has still to be assessed. Both these methods are however more invasive, time-consuming and expensive than a visual analogue scale and not suitable for repeated measurements in a large number of free-living subjects.

\section{Energy expenditure}

Energy expenditure and the components of energy expenditure can be measured by indirect calorimetry in a respiration chamber or using the ventilated hood system (138). The limitation of this technique is that it does not allow determination of energy expenditure under free-living conditions. To measure average daily energy expenditure in free-living subjects for periods of several days to weeks, the doublylabeled water method (138) and the combination of basal metabolic rate (measured or estimated) and physical activity assessed with a tri-axial accelerometer (43) can be used. However, the latter methods only distinguish between the components of energy expenditure to a certain extent.

\section{Energy storage}

The most widely used technique for assessing whole body de novo lipogenesis in vivo is indirect calorimetry (50). The major problem of this technique is that it measures net de novo lipogenesis (respiratory quotient $>1.0$ ) and that it does not distinguish fat synthesis from fat oxidation. Lipogenesis can also be measured using intravenous infusion of ${ }^{13} \mathrm{C}$-acetate and application of the MIDA technique (77) or incorporation of deuterium from deuterated water into triglycerides fatty acid (78). Fat (substrate) oxidation can be determined by assessing oxygen consumption and carbon dioxide production by indirect calorimetry and urinary nitrogen excretion (139). Furthermore, plasma B-hydroxybutyrate concentration can be used as marker for hepatic fatty acid oxidation (58). Plasma free fatty acids and glycerol concentration can be used as markers for lipolysis (74).

\section{Obesity}

Markers for obesity are body weight, body mass index, and body composition (body fat, visceral fat). Body composition can be determined using different techniques (densitometry, dilution techniques, DEXA, CT, MRI, anthropometry, electrical conductance), but the 4-compartment model may be regarded as the reference method (86).

To determine whether an ingredient may be useful for obesity treatment it is not sufficient to find an effect on markers of one or more components of the energy balance equation. The final aim is to identify relevant effects on obesily markers. Increased saliely does not necessarily result in decreased energy intake. Decreased energy intake, increased energy expenditure, inhibition of energy storage or stimulation of energy mobilisation are not a guarantee for a reduction in body weight or body fat, thus for obesity treatment. One of the reasons for this lack 
of efficacy when aiming at body weight loss by affecting one or more components of the energy balance equation is the redundancy of the system (123). Another reason is that energy balance is regulated both physiologically and cognitively. Energy intake and expenditure are not only dependent on signals related to energy balance, but also on signals related to reward, e.g. the opioid reward system. In this respect, behavior, such as eating and activity, related to the context, e.g. social, cuitural or political, is relevant.

\section{INGREDIENTS}

In the last few decades, a growing list of ingredients that might be useful in the treatment of obesity has appeared. These ingredients have been proposed to act by different mechanisms, e.g. by decreasing energy intake, increasing energy expenditure or reducing energy storage. However, clinical trials are often lacking or results are controversial. An overview of the effectiveness of most ingredients in the treatment of obesity is given below.

\section{Decrease in energy intake}

\section{Macronutrient replacement}

Macronutrient substitutes are ingredients that are added to foods to replace macronutrients. Carbohydrate replacers (e.g. polyols, dietary fibers) are aimed to reduce energy content without loss of taste quality (40). Fat replacers are aimed to replace all or part of the fat that is normally in food without influencing the organoleptic quality. (40) Fat replacers can be divided in three categories. Fat mimics (e.g. starch, cellulose, pectin, gums, protein polydextrose) are carbohydrate- or protein-based ingredients that provide a textural replacement of fat and a reduction in energy content (95). Fat substitutes (e.g. Olestra) are physically similar to fats and olls, but are too big to be split by lipases and are therefore indigestible (76). Low-energy fats are true triacylglycerols with a reduced energy content (39) as a result of an impaired absorption.

\section{Impairment of fat absorption}

Dietary fat may be sequestered by binding to an appropriate non-absorbed material (e.g. chitosan). For fat-binding compounds there is a plausible theoretical basis similar to the body weight reducing effect of Orlistat due to impaired fat absorption $(30,114,119)$. However, there is little supporting proof of effects of chitosan on body weight in humans (70) and most studies found no effects $(54,106)$.

\section{Stimulation of satiety}

Sensory-specific satiety

Sensory-specific satiety refers to the dynamic aspect of hedonic response to the sensory properties of a particular food when it is eaten (110). Sensory-specific 
satiety has been shown to be greater for high-protein compared to low-protein foods (136) and not to be related to carbohydrate, fat or energy content $(94,112)$. lt has also been suggested that saturation of fatty acids may play a role in the development of sensory-specific satiety. However, the hypothesis that an oil, containing polyunsaturated fatty acids, i.e. linoleic acid, would stimulate sensoryspecific satiety was not supported (59).

\section{Postingestive satiety}

Certain ingredients may influence postingestive processes including gastric distension, the rate of gastric emptying, small bowel transit and colonic transit, the release of gastrointestinal hormones and the stimulation of specific nutrient receptors along the gastrointestinal tract.

It has been proposed that the satiating effect of soluble viscous fibers (e.g. guar gum) is related to increased viscosity that might delay gastric emptying $(47,148)$, but this has not been confirmed in recent studies $(75,90,98)$. Soluble viscous fibers can inhibit mixing and diffusion in the intestinal tract, leading to a lower intestinal uptake rate of nutrients (79) and prolonging the exposure of intestinal chemoreceptors to nutrients. Ephedrine has also been shown to delay gastric emptying in obese patients (56). However, an effect on satiety has not been investigated yet Different gastrointestinal hormones (e.g. cholecystokinin, corticotropin-releasing factor, insulin, bombesin, serotonin, somatostatin, glucagon, GLP-1, enterostatin) have gained attention as satiety factors. From these, oral administration has only been investigated with enterostatin, but results are not very promising $(65,113$, 121). Therefore, ingredients that may interfere in the release of gastrointestinal hormones may stimulate satiety. In this respect, different types of dietary fibers have been shown to increase cholecystokinin secretion $(17,18,48,90)$ and this mechanism could be involved in their satiating effect. Consumption of yoghurt containing a novel fat emulsion (Olibra ${ }^{\mathrm{TM}}$ ) was found to increase satiety and to reduce subsequently energy and macronutrient intake up to $8 \mathrm{~h}$ without energy intake compensation ower the following $24 \mathrm{~h}(23,24)$. It was speculated that the effect is a result of the "ileal brake" mechanism (122) and of an increased and prolonged release of satiety peptides.

\section{Postabsorptive satiety}

Certain ingredients may affect the metabolism of absorbed nutrients by interfering in the profile of metabolites through a thermogenic effect or by stimulating hepatic fatly acid oxidation and hepatic glycogen concentration.

Profile of metabolites: In addition to their postingestive effect, soluble viscous fibers have been reported to increase satiety and decrease energy intake $(60,101)$ by affecting postprandial glucose and insulin response to a meal (14,61). Two other sources of dietary fiber have been suggested to improve the control of glucose metabolism in subjects with diabetes: soybean and fenugreek (85). However, there is no evidence that dietary fiber from soybean and fenugreek would be effective on satiety through modulation of blood glucose in healthy humans. Soybean and fenugreek supplements might be rather effective in the treatment of diabetes. 
Chromium (e.g. chromium picolinate) has been reported to beneficially affect the glucoselinsulin system and to increase insulin sensitivity in subjects with hypoglycemia, hyperglycemia "diabetes and hyperlipemia $(3,107)$. However, there is mo evidence for a beneficial effect of chromium on satiety or energy intake.

Thermogenic effect it has been suggested that the hierarchy in the satiating efficacies of the macronutrients has a metabolic component (125). The priority with respect to the satiating efficacies shows that protein is more satiating that carbohydrate which is more satiating than fat $(44,126,142,144)$. The priority with respect to the magnitude at which these macronutrients are metabolised shows a higher diet-induced thermogenesis with protein and carbohydrate compared to fat $(55,109,140)$. A relationship between satiety and diet-induced thermogenesis has been reported with meals that differed in macronutrient compositions $(143,144)$. There is some evidence that ingredients that stimulate thermogenesis also induce satiety. Caffeine has been shown to exert an inhibitory effect on energy intake in men, but failed to produce the same effect in women (133). Capsaicin has been shown to decrease appetite and subsequent energy intake (153). Medium-chain triacylglycerols (MCT) have been shown to have satiating properties and to decrease food intake compared to long-chain triacylglycerols $(111,127,150)$, also when supplemented during a very low calorie diet (69).

Stimulation of hepatic fatty acid oxidation and hepatic glycogen concentration: Administration of HCA was found to clearly suppress food intake in rats $(45,80,128)$, while increasing hepatic glycogen content (49). However, the results on the effects of HCA on appetite and energy intake in humans are controversial. Thom and Andrews (131) observed reduced appetite with HCA. WesterterpPlantenga and Kovacs (146) found decreased 24-h energy intake with HCA but no effect on appetite. No significant effect of $\mathrm{HCA}$ on appetite or energy intake was found in other studies that showed a reduction in body weight (88) or not $(61,62)$. Carnitine acyltransferase 1, the limiting enzyme for hepatic fat oxidation, is activated by exogenous carnitine. Carnitine may therefore theoretically promote hepatic fat oxidation and satiety (89). However, carnitine supplementation was not found to affect substrate utilisation, energy expenditure, body weight or body fat $(31,137)$. Sesamin, a sesame lignan, has been shown to increase the activity of enzymes. involved in hepatic fatty acid oxidation in rats (5). However, the effects of sesamin have not been investigated in humans yet.

\section{Increase in energy expenditure}

Obesity has often been associated with a decreased and/or deficient sympathetic nervous system activity (33). It is known that the sympathetic nervous system plays an important role in stimulating energy expenditure and fat oxidation $(1,134)$. Moreover, increased sympathetic nervous system activity has been shown to be related to decreased energy intake $(20,108)$. The inclusion of ingredients that interact with the sympathetic nervous system may offer a rational approach for obesity treatment. 
Methylxanthines, such as caffeine from coffee and tea, have been found to increase metabolic rate, lipolysis and fat oxidation $(4,6,19)$. Ephedrine from ephedra has also been shown to have thermogenic effect $(82,418)$. Several studies have suggested a thermogenic and body-weight reducing synergism of caffeine and ephedrine $(7,8,9,10)$. However, this treatment has not been approved by regulating agencies (21) because of its adverse cardiovascular effects $(7,22,29,103,132)$. The Ma Huang/Guarana mixture, the herbal counterpart of the combination of caffeine and ephedrine, was shown to piromote short-term body weight and fat loss, but also caused side effects (16). The green tea extract, rich in caffeine and catechin polyphenols, was shown to have thermogenic properties and to promote fat oxidation to an extent greater than can be attributed to its caffeine content (35), without causing side effects. Oolong lea, also rich in caffeine and catechin polyphenols, has also been shown to stimulate energy expenditure and fat oxidation in men (115). The pungent principles in hot red pepper, capsaicim, and in mustard, allyl isothiocyanate, were shown to have thermogenic effects $(52,151,152)$. The combination of red pepper and caffeine was also shown to stimulate daily energy expenditure and to reduce energy intake (154). The pungent principles of ginger, the gingerols and shogoals, were shown to be thermogenic in the perfused rat hindlimb (36). However, their effects in humans have not been investigated yet. MCT from coconut oil were shown to have thermogenic properties compared to long-chain triacylglycerols $(12,34,53,117,147)$. However, the maximal amount of MCT that the gastrointestinal tract can tolerate is relatively small (57). Beta-hydroxy-beta-methylbutyrate was reported to reduce muscle catabolism and promote fat-free mass gain in subjects initiating resistance training (99), but not in trained athletes (67). The suggestion that HCA may increase energy expenditure and fat oxidation was not confirmed in humans $(61,68,83)$. Pyruvate consumption was shown to reduce weight gain in rats, partly by increasing resting metabolic rate and fatty acid oxidation (27), however in humans this has not been investigated yet.

\section{Reduction in energy storage}

Because of its insulinogenic characteristic, chromium has been suggested to increase lean body mass and decrease body fat (37). However, most studies did not confirm this $(25,46,102,135)$, probably because chromium has no effect on glucose and insulin metabolism in healthy subjects $(2,3,149)$. Yohimbine, an alpha 2 -adrenoceptor antagonist, was found to reduce food intake and induce fat mobilisation in animals $(13,28)$. Yohimbine was found to increase weight loss in humans on a low-energy diet (71). However, this could not be explained by increased energy expenditure, sympathetic system activity, lipolysis (71) or gastric emptying (56). Another study showed no effect of yohimbine on body weight, body fat, or fat distribution (116). HCA was shown to inhibüt de novo lipogenesis in rats (84). Because de novo lipogenesis is not of quantitative importance in humans under normal feeding circumstances. HCA might inhibit energy storage as fat only in extreme situations of carbohydrate intake excess, e.g. during the Guru Walla, a traditional fattening session in a Cameroonian ethnic group (104). Reduction of de 
novo lipogenesis with HCA was indeed shown during carbohydrate overfeeding in lean male subjects (66). When a condition of de novo lipogenesis is not present, the effect of HCA would be small or disappear. Conjugated linoleic acid (CLA) was shown to reduce body fat while increasing lean body mass in animals $(32,100)$. This effect has been linked to increased lipolysis and fatty acid oxidation and reduced fatty acids deposition in adipose tissue (100). Although research on CLA in humans is limited and results are not in complete agreement $(11,15,120,155)$, evidence suggests the possibility that CLA supplementation might gemerate favourable changes in body composition in some individuals $(15,120)$. It has also been suggested that different CLA isomers might have varying effects on body compasition. Diacylglycerol, an intermediate in the process of triacylglycerol digestion in the digestive tract, was shown to decrease body weight and fat deposition compared to triacylglycerol (97). This was probably caused by different metabolic features in the smalf intestine due to the different structure of the lipids (96), rather than to different digestibility (130). In addition to its positive effect on appetite and thermogenesis, MCT supplementation during a very low calorie diet was shown to decrease fat mass and to preserve fat-free mass (72). It has been suggested that calcium can reduce lipid storage by suppressing calcitrophic hormones and adipocyte intracellular calcium (156). In this respect, dietary calcium was found to be related to changes in body weight and body composition $(81,129)$.

In general, controlled clinical trials investigating the effectiveness of ingredients in the treatment of obesity are lacking or the results are controversial. Therefore, further research is needed not only to investigate the effectiveness of most of these ingredients in the treatment of obesity, but also to study the mechanisms by which these ingredients are acting in humans. Also detailled and long-term human research on tolerance and side effects is needed.

\section{METHODOLOGICAL CONSIDERATIONS AND RECOMMENDATIONS FOR FUTURE RESEARCH}

\section{Animal vs. human model}

The results of our experiments and those presented in the literature on the effects of ingredients for obesity treatment make evident that the animal model is different from the human model. Ingredients often show potential in animals, but in humans the effects are generally small or disappear. It is therefore evident that it is not always possible to extrapolate positive results found in animals to humans. An example of this phenomenon is HCA. Although HCA was found to be very promising in rats, the anti-obesity potential of HCA in humans could not be clearly demonstrated. The discrepancy between animal and human results may have various reasons: route of administration (orally, intragastrically, intraduodenally, intravenous, etc.). duration of administration, bioavailability, etc. Moreover, 
physiologic functions in animals and humans may vary substantially. Indeed, all organisms have the enzymes of de novo lipogenesis: bees make wax from honey and pigs fatten on a grain diet (51). However, in contrast to most animals that use de novo lipogenesis to store carbohydrates as fat in daily life, de novo lipogenesis in humans is not of quantitative significance under normal feeding conditions. HCA would therefore only be effective in reducing fat synthesis in humans in a nonphysiological situation of excessive carbohydrate intake. At least regarding converting carbohydrates to fats, humans are neither bees or pigs (51). Besides physiologic factors, also behavior (e.g. restrained eating and habituation, etc.) may strongly influence results in humans, especially those related to appetite and food intake.

It is clear that the animal model is not always an ideal model when the final aim is to study effects in humans. Although animal studies are necessary to gain information on ingredients that might be effective in the treatment of human obesity, alternative models such as in vitro studies, organ cell studies, studies with stoma patients as the compromised human, etc. should also be considered.

\section{From animal to human studies}

Studies on the effects of ingredients in animals generally precede those in humans. Not only the effectiveness of an ingredient should be investigated, but also the mechanism by which the ingredient works. The tendency is then to investigate the same ingredient in humans, hypothesizing that it would be effective through the same mechanism as in animals. Because the main aim is generally to find a compound for the treatment of obesity that can reach the market within short time, a number of research steps are often omitted. The first step should be determination of certain aspects, e.g. optimal dosage, route of administration, time of administration, duration of supplementation, product type (purity, composition, solubility, etc.) in order to reach optimal effects. In general, very little is known about the bioavailability of ingredients. This has been scarcely assessed, often due to absence of sensitive detection methods. However, it is essential to know whether the ingredient administered is absorbed in the body and reaches the tissue or organ where it is supposed to be active. The next step should be to investigate whether the ingredient is effective in the human through the same mechanism as in the animal. For this purpose, a short-term study with the ingredient in the purified form and in the optimal dosage, time and duration of administration should be performed to identify the working mechanism. Only when an effect is detected and the working mechanism is known, the ingredient should be investigated on the long-term on obesity outcomes. If the ingredient is intended to be incorporated in a product, the final product should also be tested. In general, in this type of experiments, the tendency is often to start with investigating the effects of an ingredient or a product on obesity outcomes, without first having assessed the mechanism by which it is likely to be effective. 


\section{Realistic aims for the treatment of obesity}

It is not realistic to expect that (one of) these ingredients will eliminate the obesity epidemic. Effects are generally small. Therefore it is unlikely that these ingredients can be used to treat obesity by reducing body weight loss and body lat. It is rather to expect that these ingredients will contribute to obesity treatment by sustaining weight loss or preventing weight (re)gain. An example of this is guar gum. In our experiments, guar gum did not directly increase body weight loss or decrease foad intake. However, guar gum prevented an increase in appetite during enengy restriction and this may increase compliance and facilitate a low-energy regimen. On the long term this would eventually increase body weight loss. The intermittent treatment with the low energy diet with guar gum and a normal diet may be advantageous for weight reduction or weight maintenance. Prevention of both mental (boredom, decreased alertness) and physiological (down-regulation of receptors) habituation, as it has been frequently shown in pharmacological treatment (10), may also increase compliance to a diet.

\section{Weight maintenance}

Because short-term weight loss is no longer a major problem, more attention should be drawn to prevent weight (re)gain, thus weight maintenance. A widely used model to investigate weight maintenance is using a very low energy diet for few weeks to obtain a situation in which subjects are vulnerable to weight gain and subsequently test the ingredients on the long-term (102). Without prior weight loss, weight gain would take much more time and the intervention period would be much longer. Subjects after smoking cessation (38) or after top sport cessation are also vulnerable for weight gain and may therefore be tested for the same purpose. Overfeeding studies are an alternative to imitate the dynamics of overweight. This rapid and excessive form of weight gain may contribute to obtain information on the very short-term on the effects of ingredients for weight gain prevention. A low/high protein diet given together with the testing ingredient may contribute in magnifying and identifying acquired or genetic differences in the capacity for diet-induced thermogenesis and, hence, the propensity to obesity (124).

\section{The genome map}

Another problem that arises in this type of experiments is the large interindividual variation in the response to an ingredient. In addition to physiologic and behavioral factors the genetic background may also play a major role. Knowing the genetic background of an individual would possibly help in identification of humans at risk for health disorders and in the selection of subjects that are more inclined to respond to certain stimuli, e.g. increase thermogenesis after ingestion of a thermogenic component, compared to others. Application of genome maps (105), in particular the single nucleotide polymorphisms (SNPS) map related to obesity, will contribute in the near future to identify more specific dietary treatments according to the individual genetic background. The avallable techniques for 
determination of multiple SNPS in an individual to determine a genetic profile are so far limited and prevent high throughput screening of a large number of subjects.

\section{Conclusions}

From the results presented in this thesis and results from the literature, it is concluded that a treatment with ingredients that affect energy intake, expenditure or storage is unlikely to provide a 'magic bullet' for obesity treatment. Diet and lifestyle changes are likely to remain the cornerstone of obesity treatment for the foreseeable future. Howewer, supplementation of ingrediemts that affect appetite, energy intake, energy expenditure or energy storage may be useful in sustaining body weight loss and preventing body weight (re)gain.

\section{REFERENCES}

1. Acheson KJ, Ravussin $E$, Schoeller $D A$, Christin, Bourquin $L$, Baertschi $P$, Danforth $E$. Jéquier $E$. Twoweek stimulation or blockade of the sympathetic nerwous system in man: influence on body weight, body composition, and twenty four-hour energy expendifure. Melabolism 1988; 37: 91-98.

2. Amato P, Morales AJ, Yen SS. Effects of chromium picolinate supplementation on insulin sensitivity, serum lipids, and body composition in healthy, nonobese, older men and women. $J$ Gerontol A Biol Sci Med Sol 2000; 55: M260-M263.

3. Anderson RA. Nutritional factors influencing the glucose/insulin system: chromium. $J$ Am Coll Nutr 1997; 16:404-410.

4. Arciero PJ, Gardner AW, Calles-Escandon J, Benowitz NL, Peohlman ET. Effects of caffeine ingestion on NE kinetics, fat oxidation, and energy expenditure in younger and older men. Am I Physiol 1995; 268: E1192-E1198.

5. Ashakumary L, Rouyer I, Takahashi Y, Ide T, Fukuda N, Aoyama T. Hashimoto T, Mizugaki $M$. Sugano $M$. Sesamin, a sesame lignan, is a potent inducer of hepatic fatty acid oxidation in the rat. Metabolism 1999; 48: 1303-1313.

6. Astrup A, Toubro S, Cannon S, Hein P. Ereum L, Madsen J. Caffeine: a double-blind. placebo-controlled study of its thermogenic, metabolic, and cardiovascular effects in healthy volunteers. Am J Clin Nutr 1990; 51: 759-767.

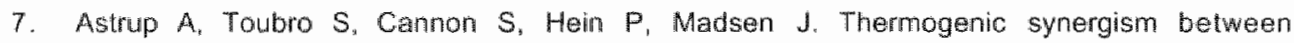
ephedrine and caffeine in healthy volunteers: a double-blind, placebo-controlled study. Metabolism 1991; 40: 323-329.

8. Astrup $A$. Breum L. Toubro S, Hein P, Quaade $F$. The effect and safety of an ephedrinelcaffeine compound compared to ephedrine, caffeime and placebo in obese subjects om an energy resitricted diet. A double bind trial. Int J Obes 1992: 16: 269-277.

9. Astrup A, Buemann B, Christensen NJ, Toubro $S$, Thorbek $G$, Victor OJ, Quaade F. The effect of ephedrine/caffeine mixture on energy expenditure and body composition in obese women. Metabolism 1992; 41: 686-688.

10. Astrup $A$, Breum $L$, Toubro $S$. Pharmacological and clinical studies of ephedrine and other thermogenic agonists. Obes Res 1995; 3 (Suppl): 537S-540S.

11. Atkinson RL. Conjugated linoleic acid for altering body composition and treating obesity. In: Yurawecz MP. Mossoba MM. Kramer JKG, Pariza MW. Nelson GJ (eds). Advances in Conjugared Linoleic Acid Research. AOCS Press: Champaign,lli: 1999, pp 328-353.

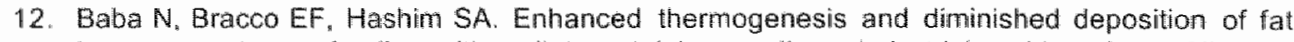
in response to overfeeding with a diet containing madium chain triglycerides. Am $J$ Clin Nutr 1982: $35: 678-682$

13. Berlan M, Galitzky J, Tran MA, Montastruc P. Anorectic effect of alpha 2-antagonists in dog: effect of acute and chronic treatment. Pharmacol Biochem Behav 1991: 39: 313-320. 
14. Blackburn NA, Redfern JS, Jarjis H. Holgate AM. Hanning I. Scarpello LHB, Johnson IT, Read NW. The mechanism of action of guar gum in improving glucose tolerance in man. Clin Sci $1984 ; 66: 329-336$.

15. Blankson $H$, Stakkestad JA, Fagertun $H$. Thom E, Wadstein J. Gudmundsen O. Conjugated linoleic acid reduces body fat mass in overweight and obese humans. \& Nutr 2000; 130: 2943-2948.

16. Boozer CN, Nasser JA, Heymsfield SB. Wang V, Chen G, Solomon JL. An herbal supplement containing Ma Huang-Guarana for weight loss: a randomized, double-blind trial. Int a Obes 2001: 25: 316-324.

17. Bourdon I, Yokoyama W, Davis P, Hudson C. Backus R, Richter D, Knuckles B, Schneman $\mathrm{BO}$. Postprandial lipid, glucose, insuluin, and cholecystokinin responses in meir fed barley pasta enriched with betamglucan. Am J Clin Nutr 1999; 69: 55-63.

18. Bourdon 1. Olson B, Backus R, Richter BD, Dawis PA, Schneeman BO. Beans, as a source of dietary fiber, increase cholecystokinin and apolipoprotein b48 response to test meals in men. J Nutr 2001; 131: 1485-1490.

19. Bracco D, Ferrara JM, Arnaud MJ. Jequier E, Schutz Y. Effect of caffeine on energy metabolism, heart rate, and methyllxanthine metabolism in lean and obese women. Am $J$ Physiol 1995; 269: E671-E678.

20. Bray GA. Food inlake, sympathetic activity, and adrenal steroids. Brain Res Bull 1993; 32 : $537-541$

21. Bray GA. Drug treatment of obesity. Baillieres Best Pract Res Clin Endocrinol Metab 1999; 13: $131-148$.

22. Breum L, Pedersen $\mathrm{JK}_{\mathrm{K}}$ Ahistrom $\mathrm{F}$. Frimodt-Moller J. Comparison of an ephedrine/calfeine combination and dexfenfluramine in the treatment of obesity. A double-blind multi-centre trial in general practice. Int J Obes 1994; 18: 99-103.

23. Burns $A A_{\text {s }}$ Livingstone MBE, Welch RW, Dumne $A_{4}$ Robson PJ, Lindmark $L$, Reid CA, Mullaney U, Rowland IR. Short-term effects of yoghurt containing a novel fat emulsion on energy and macronutrient intakes in non-obese subjects. Int J Obes 2000; 24: 1419-1425.

24. Bums AA, Liwingstone $\mathbb{M B E}$, Welch RW, Dunne $A$, Reid CA, Rowland $\mathbb{R}$. The effects of yoghurt containing a novel fat emulsion on energy and macronutrient intakes in nonoverweight, overweight and obese subjects. Int $J$ Obes 2001; 25: 1487-1496.

25. Camplbell WW, Joseph LJ, Davey SL, Cyr-Campbell D. Anderson RA, Evans WJ. Effects of resistance training and chromium picolinate on body composition and skeletal muscle in older men. I Appl Physiol 1999; 86: 29-39.

26. Campfieid LA, Smith FJ, Rosenbaum M. Hirsch J. Humam eating: evidence for a physiological basis using a modified paradigm. Newrosai Biobehav Rev 1996; 20: 133-137.

27. Cortez MY, Torgan CE, Brozinick JT Jr. Miller RH. Ivy JL. Effects of pyruvate and dihydroxyacetone consumption on the growth and metabolic slate of obese Zucker rats. Am $J$ Clin Nutr 1991; 53: 847-853.

28. Currie $\mathrm{PJ}$, Wilson LM. Yohimbine attenuates clonidine-induced feeding and macronulrient selection in genetically obese (ob/ob) mice. Pharmacol Biochem Behav 1992; 43: 10391046.

29. Dally PA, Krieger DR, Dulloo AG, Young JB, Landsberg L. Ephedrine, caffeine and aspirin: safety and efficacy for treatment of human obesity. Int of Obes 1993; 17 (Suppl): S73-S78.

30. Davidson MH. Hauptman J Di Girolamo M. Foreyt .P. Halsted CH. Heber D. Heimburger DC. Lucas CP, Robbins DC, Chung J. Heymsfield SB. Weight control and risk factior reduction in obese subjects treated for 2 years with orlisitat: a randomized controlled trial. JAMA 1999; 281: $235-242$.

31. Decombaz J, Deriaz O, Acheson K, Gmuender B, Jequier E. Effect of L-carnitine on submaximal exercise metabolism after depletion of muscle glycogen. Med Sci Sports Exerc 1993; 25: 733-740.

32. Delany JP, Blohm F, Truett AA, Scimeca JA, West DB. Conjugated linoleic acid rapidly reduces body fat content in mice without affecting energy intake. Am J Physiol 1999,276 : R1172-R1179. 
33. Doucet $E$, Tremblay A. Food intake, energy balance and body weight control. Eur $J$ Chin Nutr 1997: 51: 846-855.

34. Dulloo $\mathrm{AG}_{\mathrm{x}}$ Fathi $M$, Mensi $\mathbb{N}$, Girardier L. Twenty-four-hour energy expenditure and urinary catecholamines of humans consuming low-to-moderate amounts of medium-chain triglycerides: a dose-response study in a human respiratory chamber. Eur J Clin Nutr 1996. 50: $152-158$

35. Dulloo $A G$. Duret $C$. Rohrer $D$, Girardiers $L$, Mensi $N$, Fathi $M$, Chantre $P$, Vendermander J. Efficacy of green tea wextract rich in catechin polyphenols and caffeine in increasing $24-\mathrm{h}$ energy expenditure and fat oxidation. Am J Clin Nutr 1999; 70: 1040-1045.

36. Eldershaw TP, Colquhoun EQ. Dora KA, Peng ZC, Clark MG. Pungent principles of ginger (Zingiber officinale) are thermogenic in the perfused rat hindlimb. Inf $\downarrow$ Obes 1992; 16: 755763.

37. Evans GW. The effect of chromium picolinate on insulin controlled parameters in humans. Int $J$ Biosoc Med Res 1989; 11: 163-180.

38. Ferrara CM, Kumar M, Nicklas $B$, McCrone $S$, Goldberg AP. Weight gain and adipose tissue metaboilsm after smoking cessation in women. Int $J$ Obes 2001; 25: 1322-1326.

39. Finley JW, Levelle, Smith ER. Overview on salatrim, a family of low-calorie fats. J Agric Food Cham 1994; $42: 432-434$.

40. Finley JW, Leveille GA. Macronutrient substitutes. In: Ziegler EE, Filer LJ (eds). Present Knowledge in Nutrition. ILSI Press: Washington, DC: 1996, pp 581-595.

41. Goris $A H C$. KR Westerterp. Underreporting of habitual food intake is explained by undereating in highly motivated leain women. J Nulr 1999; 129: 878-882.

42. Goris AHC, Westerterp-Plantenga MS. Westerterp KR. Undereating and underrecording of habitual food intake in obese men: selective undermreporting of fal intake. Am $J$ Clin Nutr 2000; 71: 130-134.

43. Goris AH, Meijer EP, Kester A, Westerterp KR. Use of a triaxial accelerometer to validate reporled food intakes. Am J Cin Nutr 2001; 73: 549-553.

44. Graaf $\mathrm{C}$ de, Hulshof $T$, Westrate JA, Jas P. Short-term effects of different amounts of protein, fats and carbohydrates on satiety. Am J Clim Nutr 1992; 55: 33-38.

45. Greenwood MR, Cleary MP, Gruen R, Blase D, Stern US, Triscari J, Sullivan AC. Effect of ( $)$ hydroxycitrate on development of obesity in the Zucker obese rat. Am J Physiol 1981; 240: E72-E78.

46. Hallmark MA, Reynolds TH, DeSouza CA, Dotson CO, Anderson RA, Rogers MA. Effects of chromium and resistive training on muscle strength and body composition. Med Sci Sports Exerc 1996: 28: 139-144.

47. Harju $E$. Increases in meal viscosity caused by addition of guar gum decrease postprandial activity and rate of emplying of gastric contents in healthy subjects. Panminerva Med 1985: 27: $125-128$.

48. Heini AF, LaramCastro C. Schneider H, Kirk KA, Considine RV, Weinsier RL. Effect of hydrolyzed guar fiber on fasting and postprandial satiety and satiety hormones: a doubleblind, placebo-controlled trial during controlled weight loss. Int $J$ Obes 1998; 22: 906-909.

49. Hellerstein MK, Xie $Y$. The indirect pathway of hepatic glycogen synthesis and reduction of food intake by metabolic inhibitors. Life Sci 1993; 53 : 1833-1845.

50. Hellerstein MK. De novo lipogenesis in humans: metabolic and regulatory aspects. Eur $J$ Chin Nutr 1999: 53 (Suppl): S53-S65.

51. Hellerstein MK. No common energy currency: de novo lipogenesis as the road less travelled. Am J Clin Nutr 2001; 74: 707-708

52. Henry CJk, Emery B. Effects of spiced food on metabolic rate. Hum Nutr: Clin Nutr 1986; 40C: $165-168$.

53. Hill JO, Peters JC, Yang D. Sharp T, Kaler M, Abumrad NN, Greene HL. Thermogenesis in humans during overfeeding with medium-chain triglycerides. Metabolism 1989; 38: 641-648.

54. Ho SC. Tai ES, Eng PH, Tan CE, Fok AC. In the absence of dietary survellance, chitosan does not reduce plasma lipids or obesity in hypercholesterolemic obese Asian subjects. Singapore Med $J$ 2001; 42: 6-10. 
55. Johnston CS, Day CS, Swan PD. Postprandial thermogenesis is increased $100 \%$ on a highprotein, low-fat diet versus a high-carbohydrate, low-fat diet in healthy, young women. I Am Coll Nutr 2002; 21 : 55-61.

56. Jonderko $K$, Kucio $C$. Effect of anti-obesily drugs promoting energy expenditure, yohimbine and ephedrine, on gastric emptying in obese patients. Aliment Pharmacol Ther 1991: 5: 413418.

57. IVy JL; Costill DL; Fink WJ; Maglischo E. Contribution of medium and long chain intake to energy metabolism during prolonged exercise. Int J'Sports Med 1980; 1: 15-20.

58. Kahler $A$, Zimmermann $M$, Langhans $W$. Suppression of hepatic fatty acid oxidation and food intake in men. Nutrition 1999; 15: 819-828.

59. Kamphuis MMUN, WesterterpwPlantenga MS Saris WHM. Fat-specific satiety in humans for fall high in linoleic acid vs fat high in oleic acid. Eur J Chn Nutr 2001; 55: 499-508.

60. Kovacs EMR, Westerterp-Plantenga MS, Saris WHM, Goossens 1, Geurten, P, Brouns F. The effect of addition of modified guar gum to a low-energy sermisolid meal on appetite and body weight loss. Int J Obes 2001; 25: 307-315.

61. Kovacs EMR. Westerterp-Plantenga MS, Saris WHM. The effects of 2 -weak ingestion of ( $)$ hydroxycitrate and ( $)$-hydroxycitrate combined with medium-chain triglycerides on satiety, fat oxidation, energy expenditure and body weight. Int J Obes 2001; 25: 1087-1094.

62. Kovacs EMR, Westerterp-Plantenga MS, de Vries Mi, Brouns F, Saris WHM. Effects of 2-week ingestion of (-)-hydroxycitrate and $(-)$-hydroxycitrate combined with medium-chain triglycerides on satiely and food intake. Phys Behav 2001: 74: 543-549.

63. Kovacs EMR, Westerterp-Plantenga MS. Saris WHM, Melanson KJ, Goossens 1. Geurten P. Brouns $F$. Associations between spontaneous meal initiations and blood glucose dynamics in overweight men in negative energy balance. Br J Nutr 2002; 87: 39-45.

64. Kovacs EMR, Westerterp-Plantenga MS, Saris WHM, Melanson KJ, Goossens I, Geurten $P$, Brouns $F$. The effect of guar gum addition to a semisolid meal on appetite related to blood glucose, in dieting men. Eur J Clin Nutr 2002; 56: 771-778.

65. Kovacs EMR, Lejeune MPGM, Westerterp-Plantenga MS. The effects of enterostatin intake on food intake and energy expenditure. Submitted 2002.

66. Kovacs EMR, Westerterp-Plantenga MS. Does (-)-hydroxycitrate reduce de novo lipogenesis in humans? Submitted 2002.

67. Kreider RB, Ferreira M, Willson M, Almada AL. Effects of calcium beta-hydroxy-beta methylbutyrate (HMB) supplementation during resistance-training on makers of catabolism, body composition and strength. Int I Sports Med 1999; 20: 503-509.

68. Kriketos $A D$, Thompson $H R$, Greene $H$, Hill JO. (-)-Hydroxycitric acid does not affect energy expenditure and substrate oxidation in adult males in a post-absorptive slate. Int J Obos $1999 ; 23: 867-873$

69. Krotkiewski M. Value of VLCD supplementation with medium chain triglycerides. Int I Obes 2001: 25: 1393-1400.

70. Krotkiewski $M$, Zahorska-Markiewicz B. Olszanecka-Glinianowicz M. Zurakowsiki A. Chitosan as an adjunct to dietary treatment of obesity (abstract). Int $J$ Obes 2001: 25 (Suppl): $\$ 105$.

71. Kucio $C$. Janderko $K$. Piskorka $D$. Does yohimbine act as a slimming drug? Isr J Med Sci $1991 ; 27: 550-556$.

72. LaBar $\mathrm{KS}$, Gitelman DR, Parrish TB, Kim YH, Nobre AC. Mesulam MM. Hunger selectively modulates corticolimbic activation to food stimuli in humans. Behav Neurosci 2001; 115: 493500 .

73. Langhans W. Metabolic control of food intake. Role of the liver. In: Westerterp-Plantenga MS, Steffen AB, Tremblay A. (eds). Regulation of food intake and energy expenditure. EDRA: Milano, 1999, 185-199.

74. Large V. Arner P. Regulation of lipolysis in humans. Pathophysiological modulation in obesity, diabetes, and hyperlipidaemia. Diabetes Metab 1998; 24: 409-418.

75. Lavin JH. Read NW. The effect on hunger and satiety of slowing the absorption of glucose: relationship with gastric emptying and postprandial blood glucose and insullin responses. Appetite $1995 ; 25: 89-96$. 
76. Lawson KD. Middleton SJ, Hassal CD. Olestra a nonabsorbed, noncaloric replacement for detary fat: a rewew. Drug Metab Rew 1997; 29: 651-703.

77. Lee WN. Stable isotopes and mass isotopomer siudy of fatty acid and cholesterol synthesis. A review of the MIDA approach. Adv Exp Med Biol 1996: 399: 95-114.

78. Leitch CA, Jones P. Measurement of human lipogenesis using deuterium incorporation. I Lipid Res 1993: 34: 157-163.

79. Lembcke B, Ehert R, Ptok M, Caspary WF, Creutzfeld W, Schicha H. Emrich D. Role of gastrointestinal transit in the delay of absorption by viscous fibre (guar). Hepatogastroenterology 1984; 31: 183-186.

80. Leonhardt $M$. Hrupka $B$, Langhans $W$. Effect of hydroxycitrate on food intake and body woight regain after a period of restrictive feeding in male rats. Physiol Behav 2001; 74: 191196.

81. Lin YL, Lyle RM, McCabe LD, McCabe GP. Weaver CM, Teegarden D. Dairy callium is related to changes in body composition during a fwo-year exercise intervention in young women. I Am Coll Nuts 2000; 19;754-760.

82. Liu $\mathrm{YL}$. Toubro $S$. Astrup A. Stock Mঊ. Contribution of beta 3-adrenoceptor activation to ephedrine-induced thermogenesis in humans. Int $J$ Obes 1995; 19:678-685.

83. Loon L van, Rooijen JJM, Niesen B, Varhagen H, Saris WHM, Wagenmakers AJM. Effects of $(-)$-hydroxycitrate supplementation on substrate melabolism at rest and during exercise in humans. Am J Clin Nutr 2000; 72: 1445-1450.

84. Lowenstein JM. Effect of (-)-hydroxycitrate on fatty acid synthesis by rat liver in wivo. J Biol Chem $1971 ; 246: 629-632$.

85. Madar Z. New sources of dietary fibre. Int $J$ Obes 1987: 11 (Suppl): 57-65.

86. Marken Lichtenbelt $W$ van, Fogelholm M. Bady composition. In: Westerterp-Plantenga MS, Steffens $\mathrm{AB}$, Tremblay $\mathrm{A}$ (eds). Regulation of Food intake and Energy Expenditure. EDRA: Milano, 1999, pp 383-404.

87. Maltes RD. Hunger ratings are not a walid proxy measure of reported food intake in humans. Appetite 1990; 15: 103-113.

88. Mattes RD, Bormann L. Effects of (-)-hydroxycitric acid on appelitive variables. Physiol Behav $2000 ; 71: 87-94$

89. McCarty MF. Promotion of hepatic lipid oxidation and gluconeogenesis as a strategy for appetite control. Med Hypotheses 1994; 42: 215-225.

90. Meier R, Beglinger $C$. Schneider $H$, Rowedder A, Gyr KK. Effect of a liquid diet with and without soluble fiber supplementation on intestinal transit and cholecystokinin release in volunteers. J Parent Enteral Nutr 1993: 17: 231-235.

91. Melanson KJ, Westerterp-Plantenga MS, Smith FJ, Campfield LA. Saris WHM. Blood glucose palterns and appetite in time-blinded humans: carbohydrate versus fat. Am a Physiof 1999; 277: R337-R345

92. Melanson KJ. Westerterp-Plantenga MS, Campfield LA, Saris WHM. Appetite and blood glucose profiles in humans following glycogen-depleting exercise. A Appl Physiol 1999; 87; 947.954 .

93. Melanson KJ, Westerterp-Plantenga MS, Campfield LA, Saris WHM. Blood glucose and meall patterns in time-blinded males, after aspartame, carbohydrate, and fat consumption, in relation to sweetness perception. $\mathrm{Br}$ J Nutr 1999; 82: 437 446.

94. Miller DL, Bell EA, Pelkman CL, Peters JC, Rolls BJ. Effects of dietary fat, nutrition labels, and repeated consumption on sensory-specific satiety. Physiol Behav 2000; 71: 153-158.

95. Miraglio AM. Nutrient substitutes and their energy values in fat substitutes and replacers. Am 1 Clin Nutr 1995; 62: 1175S-1179S.

96. Murata $M$, Hara $K$. lide T. Alteration by diacylglycerals of the transport and falty acid composition of lymph chylomicrons in rats. Biosci Biotech Biochem 1994; $58: 1416-1419$.

97. Nagao $T$, Watanabe $H$, Goto $N$, Onizawa $K$, Taguchi $H$, Matsuo $N$, Yasukawa $T$. Tsushima $\mathbb{R}$, Shimasaki $H$, Itakura $H$. Dietary diacylglycerol suppresses accumulation of body fat compared to triacylglycerol in men in double-blind controlled trial. J Nutr 2000; 130: 792-797. 
98. Nieuwerhoven MA van, Kovacs EMR, Brummer R-JM, Westerterp-Plantenga MS, Brouns F The effect of different dosages of guar gum on gastric emplying and small intestinal transit of a consumed semisolid meal. I Am Coll Nutr 2001; 20:87-91.

99. Nissen S, Sharp R, Ray M. Rathmacher JA, Rice D. Fuller JC Jr, Connelly AS, Abumrad Effect of leucine matabolite beta-hydroxy-beta-methylbutyrate on muscle metabolism during resistance-exercise training. I Appl Physiol 1996; 81: 2095-2104.

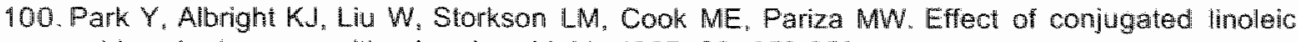
acid on body composition in mice. Lipids 1997; $32: 853-858$.

101. Pasman WJ, Wauters W. Westerterp-Plantenga MS, Saris WHM. Effect of one week of tibre supplementation on hunger and satiely or energy intake. Appetite 1997: 29:77-87.

102 Pasman WJ. Westerterp-Plantenga MS, Saris WHM. The effectiveness of long-lem supplementation of carbohydrate, chromium, flbre and caffeine on weight maintenance. Int $J$ Obes 1997; $21: 1143-1151$.

103. Pasquall R. Casimirri F. Clinical aspects of ephedrine in the treatment of obesity. Int I Obes 1993: 17: S65-S68.

104. Pasquet P. Brigant L., Fromen: A, Koppert GA, Bard D. Garine I de, Aplelbaum M. Massive overfeeding and energy balance in men: the Guru Walla model. Am I Clin Nutr 1992: 56 : $483-490$.

105. Perusse L. Chagnon YC, Weisnagel Si, Rankinen T, Snyder E. Sands J, Bouchard C. The Human abesity gene map: the 2000 update. Obes Res 2001; 9: $135-169$.

106. Pittler MH. Abbat NC. Harkness EF, Emst E. Randomized, double-blind trial of chitosian for body weight regulation. Eur J Clin Nutr 1999; 53: 379-381.

107. Patter JF, Lewin P. Anderson RA, Freiberg JM. Andres R, Elahi D. Glucose metabolism in glucosemintolerant older people during chromium supplementation. Metabolism 1985; 34: 199-204.

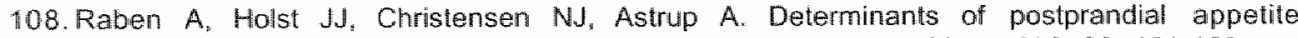
sensations: macironutrient intake and glucose metabolism. Int J Obes 1996: 20: 161-169.

109. Robinson $S M$, Jaccard $C$, Persaud $C$, Jackson $A A_{\text {, Jequier }} E$, Schutz $Y$. Protein turnover and thermogenesis in response to high-protein and high-carbohydrate feeding in men. Am I Clin Nutr $1990 ; 52: 72-80$.

110. Rolls Bu. Sensoric-Specific satiefy. Nuir Rev 1986; 44: 93-101..

111. Rolls BJ., Gnizak N. Summerfeld $A_{n}$ Laster LJ. Food intake in dieters and nondleters aflerr a liquid meal containing medium-chain triglycerides. Am \& Clin Nutr 1988; 48:66-71.

112. Rolls BJ, Laster LJ. Summerfelt A. Hunger and food intake following consumption of lowcalorie foods. Appetite 1989; 13:115-1127.

113. Rössner S. Barkeling B. Erlanson-Albertsson $C$, Larsson $P$. Wahlin-Boll E. Intrawenous enterostatin does nol affect single meal food intake in man. Appetite 1995: $24,37-42$.

114. Rössner S, Sjöström L. Noack R, Meinders AE, Noseda G. Weigh loss, weigh mantenance. and improved cardiovascular risk tactors after 2 years treatment with orlistat for obesily. European Orlistat Obesity Study Group. Obes Res 2000; 8: 49-61.

115. Rumpler $W$, Seare J Clevidence B. Judd J, Wiley E, Yamamolo $S$, Komatsu $T$, Sawak $T$. Ishikura $r$, Hosoda $K$. Oolong tea increases metabolic rate and fat oxidation in men. J Nutr $2001 ; 131: 2848-2852$

116 . Sax L. Yohimbine does not affect fal distribution in men. Int J Obes 1991; 15:561m565.

117 . Scalfi L. Coltorti A, Contaldo F. Postprandial thermogenesis in lean and obese subjects after meals supplemented with medium-chailn and long thain triglycerides. Am I Clin Nuitr 1991; 53: $1130-1133$.

118. Shamnon JR, Goltesdiener $K$, Jordan $J_{*}$ Chen $K$, Flattery $S$, Larson PJ, Candelone MR, Gentz B. Robertson D, Sun M. Acute effect of ephedrine on 24-h energy balance. Clin $5 \mathrm{ct} 1999$; 96: $483-491$.

19. Sjöstrom L. Rissanen A, Andersen T. Boldrin M, Golay A, Koppeschaar HP. Krempf M. Randonized placebo-controlled trial of orlistat for weight loss and prevention of weight regan in obese patients. European Mulicentre Orlistat study group. Lancet 1998: 352; 167-172 
120. Smedman A, Vessby B. Coniugated finoleic acid supplementation hn humans - melabolic wects. Lipids 2001; 36: 773-781.

121. Smeets M. Geiselman P. Eray GA, York DA. The effect of oral enterostatin on hunger and food intake in human volunteers (abstract). Faseb $1999 ; 13$ : A871.

122. Spiller RC, Trotman IF, Higgins BE Ghatei MA, Grimble GK, Lee YC, Bloom SR, Misiewicz MJ. Silk DE. The ilea brake - inhibition of jejunal motily after ileal fat perfusion in man. Gul $1984 ; 25: 365-374$

123. Steffens $A B$, Dijk $G$ van. Central narvous control of food intake, metabolism, and body weight, In: Westerterp-Plantenga MS, Steffens AB, Tremblay A (eds). Regulation of Food Intake and Eniergy Expenditure. EDRA: Milano, 1999, pp 121-134.

124. Stock MJ. Gluttony and thermogenesis revisited. Int J Obes 1999; 23: 1105-1117

125. Stubbs RJ. Macromutrient effects on appetite. Int $J$ Obes 1995: 19 (Suppl): S11-S19.

126. Stubbs RJ, wan Wyk MC, Johnstone AM. Harbron CG. Breakiasts high in protein, fat or carbohydrate: effect on within-day appelite and energy balance. Eur I Chin Nutr 1996; 50: $409-417$.

127. Stubbs Ru, Harbron CG. Covert manipulation of the ratio of medium- lo long-chain triglycerides in isoenergetically densie diets: effect on food intake in ad libitum feeding men. Int J Obes 1996; 20: 435-444.

128. Sullivan AC. Triscari $J$. Hamilton JG, Miler ON. Effect of $(-)$-hydroxycitrate upon the accumulation of lipid in the rat. II. Appatite. Lipids $1974 ; 9: 129-134$.

129. Summerbell CD. Watts C. Higgins JPT, Garrow JS. Randomized controlled trial of movel. simple, and well supervised weight reducing diets in outpatients. Er Med J 1998: 317 : 1487 . 1489

130. Taguchi $H$, Nagao $T$, Watanabe H, Onizawa K, Matsuo N, Tokimitsu I, Itakura H. Energy value and digestibility of dietary of containing mainly 1,3 -diacylglycerol are sinmilar to those of triacylglycerol. Lipids 2001; 36: $379-382$

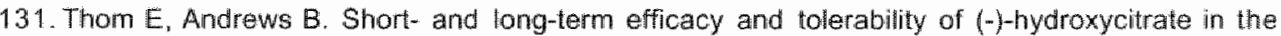
treatment of obesity (absiract). Int I Obes 1997;21: 553 .

132. Toubro S. Astrup A. Breum L, Quaade F. Safety and efficacy of long-term ureatment with ephedrine, caffeine, and ephedrinelcaffeine mixture. Int Jobes 1993; 17: $569-572$

133. Tremblay A, Masson $E$. Leduc $S$, Houde $A$. Després JP. Caffene reduces spontaneous energy intake in men: but not in women. Nutr Res 1988; 8: 553-558

134. Tremblay A. Coveney JP: Despres JP. Nadeau A, Prudhomme D. Increased resting metabolic rate and lipid oxidation in exercise-irained individuals: evidence for a role of beta adrenergic stimulation. Can I Physiol Phamacol 1992; 70: 1342-1347.

135. Trent LK. Thieding-Cancel D. Effects of chromium picolinate an body composition. J Sports Med Phys Filness 1995; 35: 273-80.

136. VandeWater $K$, Vickers 2 . Higher-protein foods produce greater sensory-specific satiely. Physiol Bohav 1996; 59:579-583

137. Vilami RG, Gannon J, Self M, Rich PA. L-Camitine supplementation combined with aerobic tiraining does not promote weight loss in moderately obese women. Int I Sport Nutr Exerc Metab 2000; 10: 199-207.

138. Westerlerp KR. Energy expenditure. In: Westerterp Plantenga MS, Fredrix EWHM, Steffens AB (eds). Food intake and Energy Expenditure. CRC Press: Boca Raton, 1994, pp 235-257.

139. Westerterp KR. Nutrient utilization and energy balance. In: Westerterp-Plantenga MS, Fredrix EWHM. Steftens AB (eds). Food intake and Energy Expenditure. CRC Press: Boca Raton. 1994: pp 31\%-319.

140. Mesterterp KR. Mison SA. Rolland $V$. Diet induced thermogenesis measured over $24 h$ in a respiration chamber: effect of diet composition. Int J Obes 1999; 23: 287-292.

141. Westerterp.plantenga MS. Wouters $L$. Hoor ten F. Deceleration in cumulative food intake curves, changes in body temperature and diet-induced thermogenesis. Physiof Behav 1990; 48: $831-836$. 
142. Westerterp-Plantenga MS, ljedema MJW, Wijckmans-Duijsens NEG. The role of macronutrient selection in determining patterns of food intake in obese and non-obese women. Eur $J$ Clin Nutr 1996; $50: 580-591$.

143. Westerterp-Plantenga MS, Wijckmans-Duijsens NEG, Verboeket-van de Venne WPHG, Graaf de $\mathrm{C}$. Westrate JA, Hof van het $\mathrm{KH}$. Diet-induced thermogenesis and satiety in humans, after full fat and reduced fat meals. Physiol Bohav 1997; 61: 343-349.

144. Westerterp-Plantenga MS. Rolland V. Wilson SAJ, Westerterp KR. Satiety related to 24 in diet-induced thermogenesis during high protein/carbohydrate vs high fat diets measured in a respiration chamber. Eur J Clin Nutr 1999; 53: 495-502.

145. Westerterp-Plantenga MS, Saris WHM, Hukshorn CJ, Campfield LA. Effects of weekly administration of pegylated recombinant human $O B$ protein on appetite profile and energy metabolism in obese men. Am J Clin Nutr 2001; 74: 426-434.

146. Westerterp-Plantenga MS, Kovacs EMR. The effect of $(-)$-hydroxycitrate on energy intake and satiety in overweight humans. Int $J$ Obes 2002; 26: 870-872.

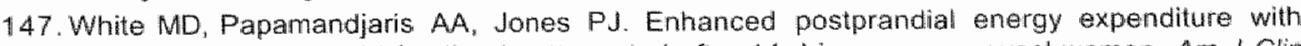
medium-chain fatty acid feeding is attenuated after $14 \mathrm{~d}$ in premenopausal women. Am of Clin Nutr 1999; 69: 883-889.

148. Wilmshurst $\mathrm{P}$, Crawley $\mathrm{JCW}$. The measurement of gastric transit time in obese subjects ${ }^{24} \mathrm{Na}$ and the effects of energy content and guar gum on gastric emplying and satiety. Br J Nutr $1980 ; 44: 1-6$.

149. Wilson BE, Gondy A. Effects of chromium supplementation on fasting insulin levels and lipid parameters in healthy, non-obese young subjects. Diabetes Res Clin Pract 1995; 28: 179 184.

150. Wymelbeke $V$ van, Himaya $A$, Louis-Sylvestre J, Fantino $M$. Infiuence of medium-chain and long-chain triacylglycerols on the control of food intake in men. Am J Chin Nutr 1998; $68: 226-$ 234.

151. Yoshioka M, Lim K, Kikuzato $S$, Kiyonaga $A$. Tanaka $H$, Shindo M. Suzuki $M$. Effects of redpepper diet on the energy metabolism in men. J Nutr Sci Witaminol 1995; 41: 647-656

152. Yoshioka M, St-Pierre S, Suzuki M, Tremblay A. Effects of red pepper added to thigh-fat and high-carbohydrate meals on energy metabolism and substrate utilizalion in Japanese women. Br I Nutr 1998; 80: 503-510.

153. Yoshioka M. St-Pierre $S$, Drapeau V. Dionne I, Doucet E, Suzuki M, Tremblay A. Effects off red pepper on appetite and energy intake. Br J Nutr 1999; 82: 115-123.

154. Yoshioka M, Doucet $E$, Drapeau $V$, Dionne I. Tremblay A. Combined effects of red pepper and caffeine consumption on $24 \mathrm{~h}$ energy balance in subjects given free access to foods. $\mathrm{Br}$ J Nutr 2001; 85: 203-211.

155. Zampbell KL, Keim NL, Van Laan MD, Gale B. Benito P. Kelley DS, Nelson GJ. Conjugated linoleic acid supplementation in humans: efects on body composition and energy expenditure. Lipids 2000; 35: 777-782.

156. Zemel MB, Shi H, Greer B, Dirienzo D. Zemel PC, Regulation of adiposity by dietary calcium. FASEB J 2000; $14: 1132-1138$. 


\section{Summary}




\section{SUMMARY}

During the past few decades, the prevalence of obesity has dramatically increased morldwide. Factors suggested to be related to the development of obesity are increased energy intake and decreased energy expenditure. Because obesity is known to be associated with increased health risks, strategies to induce body weight loss or to prevent weight (re)gain should be identified. Although short-term body weight reduction is no longer a major problem, poor results have been found on the long term. Habituation, decreased compliance and increased appetite during an energy-restricted diet are major factors related to unsuccessful hong-term body weight loss. Furthermore, body weight loss is often not maintained during a prolonged period of time.

The research described in this thesis focussed on development of strategies for the treatment of abesity by acting on energy intake, energy expenditure andlor energy storage. The aim was to identify ingredients or combinations of ingredients that might decrease energy intake, particularly by stimulating satiety in the postingestive and postabsorptive phase, increase energy expenditure, and/or reduce fat storage in the body.

Dietary fiber has been suggested to be an effective food ingredient to induce satiety and reduce energy intake. However, controversial findings have been shown on the effects of addition of dietary fiber to an energy-restricted diet. We therefore performed an experiment with 2-week supplementation of a particular soluble viscous fiber (madified guar gum) to a ready-to-eat low-energy semisolid meal in overweight subjects. Guar gum addition to the semisolid meal was found to prevent an increase in appetite, hunger and desire to eat, which increase was present with the unsupplemented semisolid meal and with a similar but solid meal. Although all three treatments were similarly effective with respect to body weight loss during 2 -week treatment, sustained satiety with guar gum supplementation might improve compliance on the long term. The satiating effect of soluble viscous fiber has been proposed to be related to delayed gastric emptying and/or to delayed glucose absorption. Addition of guar gum to the semisolid meal was not found to affect the rate of gastric emptying or intestinal transit, but resulted in more moderate blood glucose changes, as determined by continuous on line glucose monitoring. Therefore, postabsorptive rather than postingestive mechanisms were likely to be involved in the satiating effect of guar gun. Because changes in blood glucose have been proposed to play a role in short-term food intake regulation, we investigated whether an association between meal initiations and blood glucose dynamics was present in dieting overweight subjects. The usual association between transient declines and spontaneous meal initiations was absent in these subjects. However, we could not distinguish whether this was due to the energy balance state (negative energy balance) or to subject's characteristics (overweight).

(-)-Hydroxycitrate has been proposed to be effective in body weight regulation by increasing hepatic fatty acid oxidation, by increasing the rate of hepatic glycogen 
synthesis or by limiting the capacity for de novo lipogenesis. Medium-chain triglycerides have been proposed to increase satiety and decrease food intake by involving both pre-and postabsorptive mechanisms. We performed an experiment with 2-week supplementation of (-)-hydroxycitrate and (-)-hydroxycitrate combined with medium-chain triglycerides in overweight subjects. 2-week supplementation of (-)-hydroxycitrate and (-)-hydroxycitrate with medium-chain triglycerides did not result in increased satiety, decreased energy intake, increased ffat oxidation, increased 24-h energy expenditure or increased body weight loss. We further investigated whether (-)-hydroxycitrate had the potential to reduce de novo lipogenesis during carbohydrate overfeeding in normal weight subjects. We found that (-)-hydroxycitiate reduced de novo lipogenesis, as indicated by a lower 24-h energy expenditure, resting metabolic rate and respiratory quotient during the night and a tendency for a lower non-protein respiratory quotient and fat synthesis from de novo lipogenesis while part of the excess of energy ingested was spent on activity.

Several peptides have been shown to inhibit food intake. One of these peptides. enterostatin, has been found to inthibit food intake and selectively inhibit fat intake in rats. Enterostatin has also been suggested to increase thermogenesis. We investigated the effects of oral administration of enterostatin during a high-fat diet on food and fat intake and energy expenditure in subjects with a preference for a high-fat diet. Oral enterostatin administration did not affect food or fat intake, energy expenditure, or body weight.

In summary, guar gum addition to an energy-restricted diet was found to suppress hunger by affecting the blood glucose response. This might stimulate compliance to an energy-restricted diet and therefore be promising for obesity treatment. (-)Hydroxycitrate and medium-chain triglycerides were not found to contribute to body weight loss. However, (-)-hydroxycitrate might prevent fat deposition from de novo lipogenesis during weight gain. Administration of enterostatin was not promising for obesity treatment.

We conclude that a treatment with ingredients that affect energy intake, expenditure and/or storage is unlikely to provide a "magic bullet" for obesity treatment. Diet and lifestyle changes are likely to remain the cornerstone of obesity treatment for the foreseeable future. However, supplementation of ingredients that affect appetite, energy intake, energy expenditure or energy storage may be useful in sustaining body weight loss and/or preventing body weight (re)gain. 



\section{Samenvatting}




\section{SAMENVATTING}

In de laatste decennia is de prevalentie van overgewicht in de hele wereld drastisch gestegen. Factoren die een invloed hebben op de ontwikkeling van overgewicht zijn een verhoogde energie-inname en een verminderd energiegebruik. Overgewicht is gerelateerd aan een verhoogde kans op gezondheidsrisico's. Daarom is het van belang om strategieën te ontwikkelen die tot gewichtsreductie of tot het voorkómen van gewichtstoename leiden. Gewichtsreductie op de korte termijn is niet langer een groot probleem. Op de lange termijn zijn de resultaten echter niet bevredigend. Gewenning, verminderde compliantie en verhoogde eetlust tijdens een vermageringsdieet zijn belangrijke factoren die gewichtsreductie op de lange termijn tegenwerken. Men is vaak niet in staat om de behaalde gewichtsreductie gedurende een langere periode te handhaven.

Het onderzoek beschreven in dit proefschrift richt zich vooral op de ontwikkeling van strategieën voor de behandeling van overgewicht door beïnvloeding van de energie-inname, het energiegebruik en/of de energie-opslag. Het doel van het onderzoek was het vinden van ingrediënten of een combinatie van ingrediënten die de energie-inname verminderen, vooral door stimulering van postprandiale en postabsorptive verzadiging, thet energiegebruik verhogen en/of de vet-opslag reduceren.

Van voedingsvezels wordt verondersteld dat ze de verzadiging stimuleren en de energie-inname verminderen. Onderzoeksresultaten waarbij voedingsvezels werden toegevoegd aan een laag energetisch dieet zijn echter tegenstrijdig. In het kader van het onderwerp van dit proefschrift, "verzadiging en gewichtregulatie" hebben we een onderzoek uitgevoerd waarbij een bepaalde voedingsvezel (gemodificeerd guar gum) toegevoegd werd aan een kant-en-klare laag energetische halfvloeibare maaltijd die gedurende twee weken door mensen met overgewicht genuttigd werd. Toevoeging van guar gum aan de halfvloeibare maaltijd resulteerde in het voorkómen van een toename in eetlust, honger en wens om te eten. Deze toename werd wel gevonden wanneer de halfvloeibare maaltijd zonder guar gum of een vaste maaltijd met dezelfde samenstelling gebruikt werden. Het effect van de drie behandelingen op lichaamsgewicht was niet verschillend. De toevoeging van guar gum resulteerde echter in een verhoogd verzadigingsgevoel hetgeen ook op termijn tot een verbeterde compliantie kan leiden. Er wordt verondersteld dat guar gum de verzadiging stimuleent door de maaglediging en/of de bloedglucoseopname te vertragen. Toevoeging van guar gum aan de halfvloeibare maaltijd bleek echter geen effect op de maaglediging en de passage in de darm te hebben, maar resulteerde in gematigde veranderingen in het bloedglucosegehalte, dat door middel van 'on-line glucose monitoring' continu gemeten werd. Bij het verzadigend effect van guar gum bleken eerder postabsoptive dan postingestive mechanismen betrokken te zijn. Omdat verondersteld wordt dat veranderingen in het bloedglucosegehalte een rol spelen bij de regulatie van voedselinname op de korte termijn, hebben we de relatie 
tussen het moment waarop een maaltijd spontaan begint en veranderingen in het bloedglucosegehalte bij mensen met overgewicht die een vermageringsdieet volgden, onderzocht. De normale relatie tussen "transient declines" en het moment waarop een maaltijd spontaan begint bleek niet aanwezig te zijn. Of dit het gevolg was van de negatieve energie-balans of van overgewicht kan op basis van deze resultaten niet worden vastgesteld.

Van (-)-hydroxycitraat wordt verondersteld dat het een positief effect heeft op lichaamsgewichtsregulatie door vetoxidatie in de lever te stimuleren, glycogeensynthese in de lever te bevarderen of de novo lipogenese te onderdrukken. Van middellangeketen triglyceriden wordt verondersteld dat ze, door zowel postprandiale als postabsorptive mechanismen, de verzadiging stimuleren en de voedselinname onderdrukken. We hebben een onderzoek uitgevoerd bij mensen met overgewicht waarbij (-)-hydroxycitraat en (-)-hydroxycitraat gecombineerd met middellangeketen triglyceriden gedurende twee weken gebruikt werden. Twee weken gebruik van (-)-hydroxycitraat en (-)-hydroxycitraat gecombineerd met middellangeketen triglyceriden resulteerde niet in verhoogde verzadiging, verminderde energie-inname, verhoogde vetoxidatie, verhoogd 24-uur energiegebruik of verhoogde gewichtsreductie. Voorts hebben we nagegaan of (-) hydroxycitraat de novo lipogenese zou kunnen onderdiukken. We hebben dit onderzocht bij mannen met een normaal lichaamsgewicht op een overvoedingsdieet rijk aan koolhydraten. (-)-Hydraxycitraat was effectief in de onderdrukking van de novo lipogenese. Dit bleek uit een verminderd 24-uurs energiegebruik, rustmetabolisme en respiratoir quotiënt gedurende de nacht en ook uit een tendens voor een verlaagd non-protein respiratoir quotiënt en verminderde vetsynthese uit de novo lipogenese. Een deel van de overmaat aan energie-inname bleek gebruikt te worden voor lichamelijke activiteit.

Van sommige peptiden is er evidentie dat ze de voedselinname verlagen. Van een van deze peptiden, enterostatine, is gevonden bij ratten en muizen dat het de voedselinname en selectief de vetinname onderdrukt. Van enterostatine wordt tevens verondersteld dat het de thermogenese stimuleert. We hebben onderzoek gedaan naar het effect van orale inname van enterostatine gedurende een hoogvet dieet op voedsel- en vetinname en energiegebruik bij mensen met een voorkeur voor een hoog-vet dieet. Orale inname van enterostatine had geen invloed op voedsel- en vetinname, energiegebruik of gewichtsreductie.

Samengevat, toevoeging van guar gum aan een laag energetisch dieet resulteerde in een verhoogd verzadigingsgevoel door beínvioeding van de bloedglucose respons. Dit effect van guar gum zou compliantie gedurende een laag energetisch dieet kunnen verhogen en daardoor kunnen bijdragen aan de behandeling van overgewicht. (-)-Hydroxycitraat en middellangeketen triglyceriden hadden geen effect op gewichtsreductie. (-)-Hydroxycitraat bleek echter vetopslag uit de novo lipogenese tijdens gewichtstoename te kunnen beperken. Gebruik van enterostatine bleek niet veelbelovend te zijn voor de behandeling van overgewicht. 
We concluderen dat een behandeling met ingrediënten die energie-inname, energlegebruik en/of energie-opslag beinvloeden momenteel niet de magische oplossing voor de behandeling van overgewicht betekent. Verandering in voeding en in levensstijl zal ook in de nabije toekomst het fundament van de behandeling van overgewicht blijwen. Echter kan het gebruik van ingrediënten die eellust, energie-inname, energiegebruik of energieopslag beïnvloeden van belang zijn om gewichtsreductie te ondersteunen en/of gewichtstoename te voorkómen. 


\section{RIASSUNTO}

Negli ultimi decenn: la prevalenza dellabesità è cresciuta in maniera drammatica a livello mondiale. Laumento del consumo di energia e la diminuzione dellutilizzazione di energia sono tra i fatton che possono determinare lo sviluppo dellobesita. E noto che la salute delle persone obese è soggetta a maggiori rischi. Per questo motivo, e necessario individuare strategie in grado di ridurre il peso corporeo o almeno di prevenime l'aumento. Se non è più un grosso problema ottenere una riduzione di peso a corto termine, i risultati a lungo termine non sono invece promettenti. L'abituazione, la ridotta aderenza alla diela e l'aumento del senso dí appetito durante una dieta pocalorica sono il principali fattori che determinano gli insuccessi a lungo termine dei tentativi di riduzione di peso. Inoltre, spesso non si riesce a mantenere a lungo termine la riduzione di peso ottenuta.

La ricerca descritta in questa tesi si è concentrata sullo sviluppo di strategie per il trattamento del problema dell'obesita, tentando di influenzare il cansumo, lutilizzazione e l'immagazzinamento di energia. Lo scopo della ricerca era quello di individuare gli ingredienti o le combinazioni di ingredienti in grado di ridurre if consumo di energia, in particolare stimolando il senso di sazietà nella fase postingestiva e postassorbitiva, di aumentare l'utilizzazione di energia elo di diminuire l'immagazzinamento di grassi nel corpo.

E stato postulato che le fibre alimentari sono efficaci nello stimolare il senso di sazietà e nel ridurre ill consumo di energia. Tuttavia, i risultati degli studi sull'effetto delle fibre alimentari in una dieta ipocalorica sono comtroversi. Per questo motivo, abbiamo eseguito il seguente esperimento con individui sovrappeso. Durante due settimane abbiamo aggiunto una particolare fibra alimentare solubile (gomma guar modificata) ad un pasto semisolido, pronto per il consumo e con un basso tasso energetico. L'aggiunta di gomma guar ad un pasto semisolido ha permesso di prevenire l'aumento del senso di appetito, del senso di fame e del desiderio di mangiare; laumento dei citati effetti è invece stato riscontrato sia senza l'aggiunta di gomma guar sia con un pasto solido di composizione simile. Nonostante i tre trattamenti siano stati di uguale efficacia nel ridurre il peso durante il traftamento di due settimane, il senso di sazietà ottenuto con l"aggiunta di gomma guar può migliorare a lungo termine l'aderenza a una dieta dimagrante. É stato postulato che la capacità delle fibre alimentari solubili di influenzare il senso dil sazietà è dovuta ad un rallentamento dello svuotamento nello stomaco elo ad un rallentamento dell'assorbimento di glucosio. Non abbiamo tuttavia riscontrato alcun effetto della gomma guar sul rallentamento dello svuotamento nello stomaco o nell'intestino. L'aggiunta di gomma guar ha però comportato variazioni più moderate del glucosio nel sangue. Sembra perciò che I meccanismi postassorbitivi siano più efficaci dei meccanismi postingestivi nello stimolare il senso di sazietà in caso d"aggiunta di gomma guar. E stato suggerito che le variazioni del glucosio nel sangue abbiano un ruolo nella regolazione a corto termine del consumo alimentare. Per questa ragione, abbiamo cercato di scoprire 
se esisteva un legame tra l'inizio spontaneo di un pasto e la variazione di glucosio nel sangue in individui sovrappeso che seguivano una dieta dimagrante. In questi soggetti mancava l'abituale legame esistente tra "transient declines" e gli inizi spontanei di un pasto. Tuttavia, non ci è stato possibile individuare se ciò era dovuto al bilancio energetico (negativo) o alle caratteristiche individuali (persone con sovrappeso).

E stato postulato che l'idrossicitrato é efficace nella regolazione del peso corporeo attraverso diversi meccanismi: aumento dell'ossidazione di acidi grassi nel fegato, aumento della sintesi di glicogeno nel fegato, soppressione o limitazione della capacità di trasformare carboidrati in grassi (de novo lipogenesi). E stato pure postulato che catene medie di trigliceridi sono in grado di aumentare il senso di sazietà e di diminuire ill consumo di alimenti attraverso meccanismi preassorbitivi e postassorbitivi. Abbiamo eseguito un esperimento nel quale individui sovrappeso hanno consumato per due settimane idrossicitrato o idrossicitrato in combinazione con catene medie di trigliceridi. Entrambi i trattamenti non sono stati efficaci nell'aumentare il senso di sazietà, nel ridurre il consumo di energia, nell'aumentare l'ossidazione di grassi o l"utilizzazione di energia durante 24 ore o nell'accrescere la riduzione di peso. Abbiamo inoltre studiato in individui di peso normale se l'idrossicitrato è in grado di ridurre la de novo lipogenesi durante una sovralimentazione ricca in carboidrati. Abbiamo constatato che l'idrossicitrato ha diminuito la de novo lipogenesi. Abbiamo riscontrato segnatamente una riduzione dell'utilizzazione di energia durante 24 ore, del metabolismo a riposo e del quoziente respiratorio durante la notte nonché una tendenza a un ridotto quoziente respiratorio (corretto per l'ossidazione di proteine) durante 24 ore cosi come una riduzione della sintesi di grassi per la de novo lipogenesi. Una parte dell eccesso di energia consumata è andala persa in forma di attivita fisica.

E stato postulato che certi peptidi riducono il consumo di alimenti. É stato osservato nei ratti che uno di questi peptidi, l'enterostatina, è in grado di inibire il consumo alimentare e più specificamente il consumo di grassi. E stato inoltre suggerito che l'enterostatina $\dot{e}$ in grado di stimolare la temogenesi. In un esperimento abbiamo studiato l'effetto della somministrazione orale di enterostatina, durante una dieta ricca in grassi, sul consumo di energia e di grassi nonché sull'utilizzazione d'energia im individui con una preferenza per un"alimentazione ricca in grassi. Abbiamo appurato che la somministrazione orale di enterostatina non ha avuto alcun effetto sul consumo di energia e di grassi. sull"utilizzazione di energia e sul peso corporeo.

Riassumendo, abbiamo constatato che l'aggiunta di gomma guar a una dieta ipocalorica è in grado di aumentare il senso di sazietà, influenzando le variazioni del glucosio nel sangue. Questo effetto della gomma guar puó aumentare l'aderenza a una dieta dimagrante e perciò il suo uso può essere promettente nel trattamento del problema dell"obesita. L'idrossicitrato e le medie catene di trigliceridi non hanno avuto alcun effetto nel ridurre il peso corporeo. Tuttavia, l'idrossicitrato puó prevenire l'immagazzinamento di grassi dovuto alla de novo 
lipogenesi durante un aumento di peso. La somministrazione di enterostatina non è molto promeltente per il trattamento del problema dell'obesità.

In conciusione possiamo quindi affermare che un trattamento con ingredienti che possono influenzare il consumo di energia, lutilizzazione di energia e/o l'immagazzinamento di energia non può essere considerato una soluzione magica per il trattamento del problema dellobesita. Un cambiamento nella maniera di alimentarsi e nello stile di vita rimarra anche nel prossimo futuro la base per il trattamento del problema dell'obesita. Tuttavia, laggiunta di ingredienti in grado di influenzare il senso di sazietả, il consumo di energia, lutilizzazione di energía o l"mmagazzinamento di energia può essere efficace nel sostenere una riduzione di peso o nel prevenime l"aumento. 


\section{Dankwoord}




\section{DANKWOORD}

Men zegt dat triatleten gek ziin vanwege de zware inspanningen die ze leveren. Maar niet iedereen realiseert zich dat promoveren veel meer zweet en energie vergt. Ik spreek uit ervaring. Toch zijn er een aantal overeenkomsten tussen het beoefenen van de triatlonsport en het promoveren. Doorzettingsvermogen, hard werken, motivatie en mentale kracht zijn de factoren die tellen en niet zo zeer het talent. En van beide wordt je niet rijk. Triatleten zijn individualisten, net als promovendi. Toch is het niet mogelijk om te promoveren zonder de hulp van anderen. Daarom, wil ik alle mensen bedanken die me op welke wijze dan ook in de afgelopen acht jaar gesteund hebben. Zonder jullie vertrouwen, stimulans en medewerking was dit proefschrift nooit tot stand gekomen.

Fred, jij bent degene die me de kans heeft gegeven om naar Maastricht te komen en om in Maastricht te blijven. Jij bent ook degene die me gestimuleerd heeft om aan dit promotieavontuur te beginnen. Alhoewel ik in het begin erg heb getwijfeld, nu ben ik je zeer zeker heel dankbaar. Helaas gingen op een gegeven moment onze wegen uit elkaar (een dieptepunt!), maar ik hoop dat we elkaar in de toekomst, hoe dan ook, heel vaak zullen tegenkomen.

Margriet, bedankt voor je begeleiding tijdens mijn promotieonderzoek en voor het vertrouwen in me en in mijn werk. Je hebt steeds tijd vrij gemaakt als ik iets nodig had en dat heb ik zeer gewaardeerd. Door onze discussies ben ik veel kritischer geworden, iets dat het manuscript, maar ook mijn huidige baan, zeker ten goede is gekomen.

Wim, bedankt voor het in mij gestelde vertrouwen en voor het kritisch doorwerken van mijn manuscripten. Jij was er als aanspreekpunt als ik iets had en jouw adviezen hebben me telkens wijzer gemaakt.

I am thankful to Prof. Dr. P. v. d. Brandt, Prof. Dr. W. Langhans, Prof. Dr. A. Steffens, Prof. Dr. R. Mensink, and Dr. R.-J. Brummer for their time and effort to critically evaluate this thesis.

Joan, ik wil je bedanken voor de prettige samenwerking in de eerste jaren. Van jou heb ik geleerd het accuraat uitvoeren van experimenten, het analyseren van bloeden urinemonsters (wat ik inmiddels weer vergeten ben), het omgaan met (lastige) proefpersonen en van alles nog wat. Maar ik wil je vooral bedanken dat je me de Nederlandse taal hebt bijgebracht (inclusief het Limburgs accent...).

Asker en Antoinette, ik kon altijd op jullie rekenen. Dankzij jullie geborgenheid heb ik me in Maastricht thuis kunnen voelen. Ik beloof het, ik kom jullie ooit bezoeken. Maar we kunnen elkaar ook gezellig in Embrun treffen.

Jos, jij hoeft je niet meer te verstoppen als je me ziet, want ik heb allang geen klusjes meer die ik je will laten uitvoeren (jammerl). Ik heb onze samenwerking heel plezierig gevonden, ook was ik het niet eens met je visie over de bekwaamheid en het intellect van de (blonde) vrouw.

Michiel, onze samenwerking een vriendschap is wat stroef begonnen, maar in de $100 p$ van de jaren zijn we elkaar steeds meer gaan respecteren en appreciëren. Als 
kamergenoten hebben we de voorkamer van het lab gedeeld, een echte kamer, de 'meterkast' en uiteindelijk heb je me vertaten (weer een dieptepunt). We hebben ook aan een aantal proeven samengewerkt, waarvan éen in dit proeffschrift beschreven is. Ik hoop dat we in de toekomst nog vaak leuke conversaltes zullen hebben bij een kopje koffie, een glaasje wijn of een lekker hapje.

Marleen, een ding is zeker: je hebt de sfeer in onze kamer levendig gehouden. Ik heb wel eens overwogen om 's nachts te gaan werken, maar dan had ik wel je gezelligheid en je warmte gemist.

Manuela, naast het feit dat je me ontzettend veel hebt geholpen in het uitvoeren wan verschillende onderzoeken, wil ik je vooral bedanken voor de gezelligheid tijdens de lunch-en koffiepauzes.

Marleen en Manuela, ik vind het fijn dat jullie als paranimfen achter me willen staan (letterlijk en figuurlijk) tijdens de verdediging van mijn proefschrift.

Ik wil alle medewerkers van de Unit bedanken voor de prettige samenwerking en de prettige steer. Martina (jouw creativiteit heeft geresulteerd in een prachtige omslag), Martine (ik mis onze gezamenlijke koffiepauzes), Nicky, Rien, Bert (jouw suggesties en ideeën waren altijd heel inspireerend). Camiel, Christianne, Dean (thank you for your friendliness), Elke (good to be colleagues again), Eric, Gerard en Peter (met jou heb ik de langste en diepste discussies gehad, wat hadden we ze nodig!).

Mensen uit alle landen hebben me geholpen bij het uitvoeren van de experimenten en ik wil ze bedanken voor het harde werk en hun inzet: Regina uit Duitsland, Prof. Rabindar uit Malaysia (I really enjoyed your collaboration and vriendschip), Ellen, Anne-Marie en Ine uit België, en Miranda uit Nederland.

Joan, Jos en Annemie, ik wil jullie bedanken voor de bepalingen van bergen bloed-, urine- en zweetmonsters.

Paul en Loek, bedankt voor de snelle handeling bij problemen met de respiratie kamers, de ventilated hoods en de on-line glucose monitoring. Ook bedankt voor het oplossen van alle computercalamiteiten. Ik heb altid een schuldgevoel naar jullie toe gehad, want ik kwam jullie opzoeken alleen als er weer een probleem was. Loek. ji ook bedankt voor het bereiden van honderden deuterium flesjes en voor het meten van de vele urinemonsters.

Kathleen, thank you for explaining me the on-line glucose monitoring system. I also appreciated your corrections and comments on my manuscripts.

Een hartelijke dank ook voor de mensen van het secretariaat (Claudia, Marion, Ilona, Desiree, Truus, Marco) zonder wie niets zou draaien. Met name Truus will ik bedanken voor de gezelligheid op en buiten het werk.

Mijn dank gaat ook uiteraard uit naar alle andere collega's en ex-collega's van Humane Biologie en Bewegingswetenschappen voor de prettige werksfeer en de leuke momenten: Annelies, Annemarie, Annemiek Arjen, Chris, Danielle, Daphne, Dorien, Edgar, Ellen, Elke, Erwin, de andere Erwin, Freddy, Gerrit, Guy. Ilse, Jochgum, Joost, Klaas, Luc, Ludo, Marieke, Marco, Marja, Marleen, Neeltje, 
Freddy, Patrick, Petra, Renate, Sandra, Tanja, Ton, Wouter, de andere Tanja, Wilhelmine, Wilrike, Fred, Gerard, Lars, Matthijs, en alle anderen.

Ik will ook alle proefpersonen die aan de onderzoeken die in dit proefschrift zijn beschreven bedanken. Jullie hebben soms heel zware metingen en dieetprotocollen (afvaldieet of overvoedingdieet) ondergaan. Zonder jullie inzet was dit proefschrift niet tot stand gekomen. Ook wil ik alle fietsers en triatleten bedanken die in de eerste jaren aan de inspanningsproeven hebben meegedaan, vooral de vaste kern: Aart, Bas, Edwin, Frank, Freddy, Mark, Nico, Peter, Richard, Reinout, Roger, Rojen Tim.

Mijn famillie wil ik bedanken omdat ze me alle deze jaren hebben moeten missen maar nooit geklaagd hebben.

Een grote dank ook aan alle collega's van de Triathlon Club Maastricht. Dankzij jullie, jullie gezelligheid en het afzuen tijdens de trainingen kon ik de dagelijkse stress en het hard werken vergeten en nieuwe energie bijtanken. Dat had ik ook vaak nodig.

Leo, dit hoofdstuk wil ik beëindigen door jou te bedanken. Jij weet als geen andere hoeveel tijd en energie dit allemaal heeft gekost. Helaas, heb jij ook alles door moeten maken: vermoeidheid, de stress, weekeinden op het werk, geen tijd voor niets. Maar jij hebt nooil geklaagd. Leo, bedankt dat je er was en dat je er bent.

\section{Grazie di cuore}


Publications 


\section{PUBLICATIONS}

\section{Full papers}

Kovacs E, Brouns F. Nutritional and physiological aspects of exercise-induced dehydration and rehydration. Medicina Sportiva 1997; 1:27-36.

Brouns F, Kovacs E. Functional drinks for athletes. Trends in Food Science \& Technology $1997 ; 8: 414-421$.

Kovacs EMR, Stegen JHCH, Brouns $F$. The effect of caffeinated carbohydrate-electrolyte solutions on substrate metabolism, caffeine excretion and time trial cycling performance. $\checkmark$ Appl Physiol 1998; 85: 709-715.

Brouns F, Kovacs EMR, Senden JMG. The effect of different rehydration drinks on postexercise electrolyte excretion in trained athletes. Int J Sponts Med 1998; 19: 56-60.

Kovacs EMR, Senden JMG, Brouns $F$. Urine color, osmolality and specific elecirical conductance are not accurate measures of hydration status during post-exercise rehydration. J Sports Med Phys Fitness 1999; 39; 47-53.

Colombani P. Kovacs E, Frey-Rindova P. Frey W. Langhans W. Arnold M. Wenk C. Metabolic effects of a protein-supplemented carbohydrate drink in marathon runners. Int $\mathfrak{I}$ Sport Nutr 1999; 9: 190-209.

Hogervorst E, Riedel Wd, Kovacs $E$, Brouns $F$, Jolles J. Caffeine improves cognitive performance after strenuous physical exercise. Int I Sports Med 1999; 20: 354-361.

Kovacs EMR, Westerterp-Plantenga MS, Saris WHM, Goossens I, Geurten P, Brouns F. The effect of addition of modified guar gum to a low-energy semisolid meal on appetite and body weight loss. Int J Obes 2001; 25: 307-315.

Kovacs EMR. Westerterp-Plantenga MS, Saris WHM. The effects of 2 -week ingestion of (-) hydroxycitrate and (-)-hydroxycitrate combined with medium-chain triglycerides on satety, fat oxidation, energy expenditure and body weight. Int J Obes 2001: 25: 10871094.

Kovacs EMR, de Vries M, Westerterp-Plantenga MS, Brouns F, Saris WHM. Effects of 2-week ingestion of $(-)$-hydroxycitrate and $(-)$-hydroxycitrate combined with medium-chain triglycerides on satiety and food intake. Phys Behav 2001: 74: 543-549.

Nieuwenhowen MA van, Kowacs EMR, Martin A-M, Brummer R-JM, Westerterp-Plantenga MS, Brouns $F$. The effect of different dosages of guar gum on gastric emptying and small intestinal transit of a consumed semisolid meal. I Am Coll Nutr 2001; 20:87-91.

Kovacs EMR, Westerterp.Plantenga MS, Saris WHM, Melanson KJ, Goossens I. Geurien P. Brouns F. Associations between spontaneous meal initiations and blood glucose dynamics in overweight men in negative energy balance. Br I Nutr 2002; 87: 39-45.

Kovacs EMR, Westerterp-Plantenga MS, Saris WHM, Melanson KJ, Goossens I, Geurten $P$, Brouns $F$. The effect of guar gum addition to a semisolid meal an appetite and blood parameters, in dieting men. Eur J Chin Nutr 2002; 56: 771-778. 
Kovacs EMR, Schmahl RM, Senden JMG, Brouns F. Effect of high and low rates of fluid intake on post-exercise rehydration. Int J Sport Nutr Exarc Metab 2002; 12: 14-23.

Kovacs EMR, Martin A-M, Brouns $F$. The effect of ad libitum ingestion of a caffeinated carbohydrate-electrolyte solution on urinary caffeine concentration after 4 hours of endurance exercise. Int I Sports Med 2002; $23: 237 \cdot 241$.

Westerterp-Plantenga MS, Kovacs EMR, Melanson KJ. Habitual meal frequency and energy intake regulation in partially temporally isolated men. Int $J$ Obes 2002; 26: 102-110.

Westerterp-Plantenga MS, Kovacs EMR. The effect of (-)-hydroxycitrate on energy intake and satiety in overweight humans. Int J Obes $2002 ; 26: 870-872$.

Kowacs EMR, Westerterp-Plantenga MS Does (-)-hydroxycitrate reduce de novo lipogenesis in humans? Submitted 2002.

Kovacs EMR, Lejeune MPGM, Westerterp-Plantenga MS. The effects of enterostatin on food intake and emergy expenditure. Submitted 2002.

Kovacs EMR, Senden JMG, Brouns F. A high drink sodium content improves post-exercise rehydration in trained cyclists. Submitted 2002.

Nieliwenhowen MA van, Brouns $F$, Kovacs EMR. The effect of sports drinks on performance and incidence of gastrointestinal complaints during running: A randomized controlled field study. Submitted 2002

\section{Published abstracts}

Kovacs $E$, Senden J, Brouns F. Urinary variables are unreliable as a measure of postexercise hydration status. I Sports Sci 1996; 14: 354.

Kovacs EMR, Westerterp-Plantenga MS, Saris WHM. The effect of ingestion of low energy meals on appetite in relation to blood glucose. Int J Obes 2000; 24 (Suppl 1): S111.

Kovacs EMR, Nieuwenhowen MA van, Brummer R-JM, Westerterp-Plantenga MS, Brouns $F$. The effect of different dosages of guar gum on the rate of gastric emptying and intestinal transit of a consumed semisolid meal. int ul Obes 2000; 24 (Suppl 1): $\mathbf{S 1 6 9 .}$

Kovacs EMR, Westerterp-Plantenga MS, Saris WHM. The effect of ( $\%$ )-hydroxycitrate and medium-chain triglycerides supplementation on satiety and energy expenditure in humans. Int I Obes 2000; 24 (Suppl 1): S189.

Kovacs EMR, Westerterp-Plantenga MS, Saris WHM. The effect of (-) -hydroxycitrate and medium-chain triglycerides supplementation on satiety and energy expenditure in humans. Appetite 2000; 35: 295.

Kovacs EMR, Westerterp-Plantenga MS, de Vries M, Brouns F, Saris WHM. The effect of (-)mydroxycitrate and medium-chain triglycerides supplementation on satiefy in humans. Appetite 2000:35: 295 .

Kovacs EMR. Westerterp-Plantenga MS. Does (-)-hydroxycitrate reduce de novo lipogenesis? Int $J$ Obes 2001; 25 (Suppl 2): $\$ 127$. 
Kovacs EMR, Westerterp-Plantenga MS. The effects of HCA on body weight regulation. Ann Nutr Metab 2001; 45 (Suppil 1): 234.

Kovacs EMR, Melanson KJ. Westenterp-Plantenga MS. A habitual but not introduced nibbling eating pattem contributes to energy intake regulation in time-blinded young lean men. Ann Nutr Metab 2001; 45 (Suppl 1): 584.

Kovacs EMR, Westerterp-Plantenga MS. Does (*)-hydroxycitrate reduce de novo lipogenesis? Appetite 2001: $37: 147$.

Wassmer P, Kơvacs E, Colombani P, Werling D, Frey $W$, Frey-Rindova P. Arnold $M$, Langhans W. Wenk $C$. Marathon running caused elevation in circulating $I L-1$ receptor antagonist levels: high correlation with circulating IL-6 levels. Int J Sports Med 1996; 17: S36.

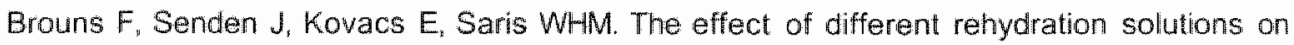
post-exercise fluid balance in trained cyclists. I Sports Sci 1996; 14:353.

Brouns F, Kovacs E, Senden J, Saris WHM. The effect of ad libitum consumption of different drinks on post-exercise rehydration. J Sponts Sci 1996; 14: 352-353.

Senden J., F. Brouns, E. Kovacs, W.H.M. Saris. The effect of different rehydration drinks on post-exercise electrolyle balance in trained cyclists. I Sports Sci 1996; 14: 353-354.

Schmahl R, Brouns F, Kovacs E, Senden J, Saris WHM. Effect of a high and a low rate of fluid intake on post-exercise rehydration. J Sponts Sci 1996; 14: 352.

Frey-Rindova $P$, Colombani $P$, Kovacs $E$, Boutellier $U$, Villiger $B$, Frey $W$. Effect of an ultramarathon on moderate altitude on the pulmonary function. Med Sci Sports Exerc 1996; 28 (Suppl): S204.

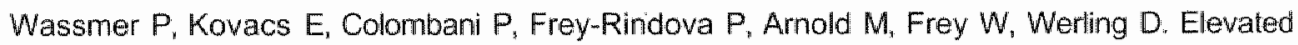
serum levels of IL-1 receptor antagonist (UL-1RA) in marathon runners. Int I Sports Med $1997 ; 18: 5117$.

Wassmer P. Kovacs E, Colombani P, Frey-Rindova P. Arnold M, Frey W, Werling D. Elevated IL-6 and TNF serum levels in marathon runners. Int J Sports Med 1997; 18: S117.

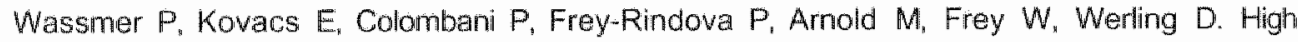
correlation between bload level of $\| \mathrm{L}-6$ and $\mathbb{L}-1$ recieptor antagonist (IL-1RA) in marathon runners. Int I Sports Med 1997; 18: $\$ 117$.

Nieuwenhowen MA van, Kovacs EMR, Martin A-M, Brummer R-JM, Brouns F. Comparison of ${ }^{13} \mathrm{C}$-acatate and ${ }^{13} \mathrm{C}$-octanoate for determination of gastric-emptying of semi-solids using the ${ }^{13} \mathrm{C}$-breath test. Digestion 1998; 59 (Suppl 3): 246.

Westerterp-Plantenga MS, Kovacs EMR. The paradoxical effect of (-)-hydroxycitrate on energy intake regulation in humans. Int J Obes 2000; 24 (Suppl 1): $\$ 189$.

Westerterp-Plantenga MS, Kovacs EMR. The paradoxical effect of (-)-hydroxycitrate on energy intake regulation in humans. Appetite 2000; 35: 317.

Westerterp-Plantenga MS, Kovacs EMR, Melanson KJ. Energy intake regulation and habilual meal frequency in time-blinded men. Int J Obes 2001; 25 (Suppl 2): S58. 
Nieuwenhoven MA van, Brouns F, Kovacs EMR. The effect of different dhinks on the occurrence of gastrointestinal symptoms during running: A randomised controlled field study. Gut 2001; 49 (Suppl 3): A1862.

Westerterp-Plantenga MS, Kovacs EMR, Melanson KJ. Energy intake regulation and habitual meal frequency in time-blinded men. Appetite 2001; 37: 170-171.

Nieuwenhoven MA van. Brouns F, Kovacs. The effect of different drinks on the occurrence of gastrointestinal complaints during running: A randomized controlled field study. J Gastroenterol Hepatol 2002; 17 (Suppl): A755.

\section{Popular scientific publications}

Brouns F, Kovacs E. Sportgetränke in Europa: Rehydrationsgetränke - Beurteilen Ste selbst Ihr bevorzugtes Getränk. Leistungssport 1995 4: 49-54.

Brouns F. Kovacs E. Durstiöscher auf dem Prüfstand. Läufer 1995; 6: 51-57.

Brouns F, Kovacs E. Sportgetränke im Test. Runner's World 1995; Juli: $30-42$.

Brouns F. Kovacs E. Optimale Zusammensetzung eines Sportgetränkes. TW Spont + Medizin 1996; 8: $163-166$.

Brouns F, Kovacs E. Rehydrationsgetränke für Sportler. TW Sport + Medizin 1996; 8: $167-$ 174.

Brouns F. Kovacs E. Boissons sportives européennes sous la loupe (1). Raisons explicatives. Macolin 1996; 10: 6-7.

Kovacs EMR. Voedingsvezels onderdrukken honger mogelijk via glucosestofwisseling. Voeding Nu 2000; 4: 20-21.

Kovacs EMR. internationaal congres over functional foods in Parijs. Voeding Nu 2001; 12: 23 25. 
Curriculum vitae 
${ }_{190} \mid$ 


\section{CURRICULUM VITAE}

Eva Margit Rita Kovacs was born on 24 January 1969 in Locarno, Switzerland. She completed secondary school in Locarno in 1988. In the same year, she started her academic education at the Swiss Federal Institute of Technology (Eidgenössische Technische Hochschule) in Zurich, Switzerland, where she studied Food Science and Technology. As part of the training she worked in different food industries in Switzerland and in the Netherlands. She graduated in 1994.

During 1994-1998 she worked as Research Scientist at the Department of Human Biology, Maastricht University in collaboration with Novartis Nutrition Research Unit. During this period she mainly did research in the area of nutrition and exercise. She particularly studied the effects of sports drinks on rehydration and performance and the effects of caffeine intake on performance, metabolism and caffeine excretion.

In 1998 she started her Ph.D. research "Satiety and body weight regulation" at the Department of Human Biology, Maastricht University. Her research was mainly focussed on the effects of food ingredients on satiety, food intake, energy expenditure, substrate oxidation, and changes in body weight and body composition. The research performed during this period is described in this thesis. From April 2002 she is working as Energy Metabolism Scientist at the Unilever Health Institute, Unilever R\&D, in Vlaardingen. 